\title{
Family-member migration and the psychosocial health outcomes of children in Moldova and Georgia
}

Citation for published version (APA):

Vanore, M. T. (2015). Family-member migration and the psychosocial health outcomes of children in Moldova and Georgia. [Doctoral Thesis, Maastricht University]. Boekenplan. https://doi.org/10.26481/dis.20150617mv

Document status and date:

Published: 01/01/2015

DOI:

10.26481/dis.20150617mv

Document Version:

Publisher's PDF, also known as Version of record

\section{Please check the document version of this publication:}

- A submitted manuscript is the version of the article upon submission and before peer-review. There can be important differences between the submitted version and the official published version of record.

People interested in the research are advised to contact the author for the final version of the publication, or visit the DOI to the publisher's website.

- The final author version and the galley proof are versions of the publication after peer review.

- The final published version features the final layout of the paper including the volume, issue and page numbers.

Link to publication

\footnotetext{
General rights rights.

- You may freely distribute the URL identifying the publication in the public portal. please follow below link for the End User Agreement:

www.umlib.nl/taverne-license

Take down policy

If you believe that this document breaches copyright please contact us at:

repository@maastrichtuniversity.nl

providing details and we will investigate your claim.
}

Copyright and moral rights for the publications made accessible in the public portal are retained by the authors and/or other copyright owners and it is a condition of accessing publications that users recognise and abide by the legal requirements associated with these

- Users may download and print one copy of any publication from the public portal for the purpose of private study or research.

- You may not further distribute the material or use it for any profit-making activity or commercial gain

If the publication is distributed under the terms of Article $25 \mathrm{fa}$ of the Dutch Copyright Act, indicated by the "Taverne" license above, 
Family-Member Migration and the Psychosocial Health Outcomes of Children in Moldova and Georgia

\author{
Michaella Vanore
}




\title{
Colophon
}

\author{
Cover illustration: Vasile Botnaru \\ Printing: $\quad$ Boekenplan, Maastricht. www.boekenplan.nl
}

ISBN: 9789086663668

(c) Michaella Vanore, 2015.

All rights reserved. No part of this thesis may be reproduced or transmitted in any form or by any means without prior written permission from the author. 


\section{Family-Member Migration and the Psychosocial Health Outcomes of Children in Moldova and Georgia}

\section{DISSERTATION}

to obtain the degree of Doctor at Maastricht University, on the authority of the Rector Magnificus, Prof. Dr. L.L.G. Soete in accordance with the decision of the Board of Deans, to be defended in public on Wednesday, 17 June 2015 at 12:00 hrs

by

Michaella Theresa Vanore 


\section{Supervisor:}

Prof. Dr. Valentina Mazzucato

\section{Co-supervisor:}

Dr. Melissa Siegel

\section{Assessment Committee:}

Prof. Dr. R. Skeldon (Chair), Maastricht University/ University of Sussex

Prof. Dr. J. Carling, the Peace Research Institute Oslo (PRIO)

Dr. F. Gassmann

Dr. L. Jordan, University of Washington

Financial support for this dissertation was received from the European Commission through grant number DCI-MIGR/2010/229-604. 


\section{TABLE OF CONTENTS}

ACKNOWLEDGEMENTS

CHAPTER ONE: INTRODUCTION

CHAPTER TWO: LITERATURE REVIEW \& THEORETICAL FRAMEWORK

2.1 Transnational Family Life \& Parent-Child Relations

2.2 Migration \& Child Psychosocial Health

2.3 Who Leaves? Migration Decision Making \& Child Psychosocial Health 32

2.4 The Role of Family in Psychosocial Health: Child Attachment \& Loss 37

2.5 Family-Member Migration \& Child Psychosocial Health: Expectations for Moldova \& Georgia

CHAPTER THREE: DATA \& METHODOLOGY

3.1 Household Survey Data

3.2 Interviews

3.3 Data Limitations

3.4 Analytical Strategy

CHAPTER FOUR: MOLDOVA \& GEORGIA COUNTRY CONTEXTS

4.1 The Post-Soviet Transition \& Legacy Challenges

4.1.1 Economic \& Political/Civic Transition

61

4.1.2 Contemporary Economic Situation

62 
4.2.2 Links between Migration and Children Remaining in the Origin Country 70

4.3 Social Norms, Gender, \& the Family 72

$\begin{array}{ll}\text { 4.3.1 Moldova } & 73\end{array}$

$\begin{array}{ll}\text { 4.3.2 Georgia } & 79\end{array}$

4.4 Discussion: Moldova, Georgia, \& the Value of Comparison 84

4.4.1 Geopolitical Ties $\quad 85$

$\begin{array}{ll}\text { 4.4.2 Migration Patterns } & 88\end{array}$

$\begin{array}{lr}\text { 4.4.3 Family Arrangements } & 88\end{array}$

CHAPTER FIVE: SIMILAR BUT NOT THE SAME - THE FEMINISATION OF MIGRATION FROM MOLDOVA \& GEORGIA $\quad 90$

$\begin{array}{lr}5.1 \text { Introduction } & 90\end{array}$

5.2 Literature \& Theory $\quad 92$

\begin{tabular}{l}
5.3 Background Context \\
\hline
\end{tabular}

$\begin{array}{lr}5.4 \text { Methodology } & 97\end{array}$

$\begin{array}{ll}\text { 5.4.1 Data } & 97\end{array}$

5.4.2 Methodology \& Variable Definition 99

$\begin{array}{ll}5.5 \text { Results } & 102\end{array}$

$\begin{array}{ll}\text { 5.6 Discussion \& Conclusions } & 113\end{array}$

CHAPTER SIX: 'LEFT BEHIND' BUT NOT LEFT ALONE -

PARENTAL MIGRATION \& THE PSYCHOSOCIAL HEALTH OF CHILDREN IN MOLDOVA 118

$\begin{array}{ll}6.1 \text { Introduction } & 118\end{array}$

$\begin{array}{ll}\text { 6.2 Background } & 119\end{array}$

$\begin{array}{ll}\text { 6.3 Method } & 123\end{array}$

$\begin{array}{ll}\text { 6.3.1 Data } & 123\end{array}$ 


\section{CHAPTER SEVEN: ALL IN THE FAMILY - FAMILY MEMBER MIGRATION AND THE PSYCHOSOCIAL HEALTH OF CHILDREN IN GEORGIA}

7.1 Introduction

7.2 Background

7.2.1 Evidence on the Psychosocial Health of Children with Migrant Kin

7.2.2 Study Context

7.2.3 Hypotheses

7.3 Methods

7.3.1 Data \& Sample

7.3.2 Variable Identification \& Measurement

7.3.3 Analytical Method

7.4 Results

8.2.4 Conclusions: The Relationship between Migration \& Child Psychosocial

Health 
$\begin{array}{ll}\text { 8.4 Study Limitations } & 186\end{array}$

$\begin{array}{ll}\text { 8.5 Future Research Directions } & 191\end{array}$

REFERENCES 194

$\begin{array}{ll}\text { APPENDICES } & 213\end{array}$

A. Expert Interview Overview 213

$\begin{array}{lr}\text { B. Sample Interview Guide } & 215\end{array}$

C. In-Depth Interview Sample Characteristics 219

D. Methodological Note on Creation of the Wealth Index 220

E. Full Models of Analyses Presented in Chapter Five 223

KNOWLEDGE VALORISATION 227

$\begin{array}{ll}\text { ABOUT THE AUTHOR } & 231\end{array}$ 


\section{LIST OF TABLES \& FIGURES}

\section{Figures}

4.1 Moldova at a Glance 64

4.2 Georgia at a Glance 65

5.1 Migrants' Year of First Migration, by Gender \& Origin Country 103

5.2 Destination Region of Georgian \& Moldovan Migrants 104

5.3 Predicted Migration Probabilities by Age \& Child Presence 111

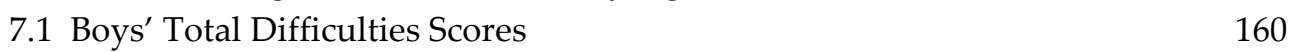

7.2 Girls' Total Difficulties Scores 161

\section{Tables}

4.1 Key Similarities \& Differences between Moldova \& Georgia 86

5.1 Survey Sample by Country 98

5.2 Weighted Means/Percentages of Variables 101

5.3 Demographic Traits of Current- and Non-Migrants 105

5.4 Odds Ratios of Being a Current Migrant 107

5.5 Relative Risk Ratios of Current Migrants per Destination 112

$\begin{array}{ll}\text { 6.1 Means/Percentages of Variables } & 128\end{array}$

6.2 SDQ Scores by Child Gender and Parental Migration Status 130

6.3 Probit Regression Results, Parental Migration Status \& Outcomes 132

6.4 Probit Regression Results, Type of Parental Migration \& Outcomes 133

6.5 Probit Regression, Parental Migration/Caregiver Type \& Outcomes 134

7.1 Means/Percentages of Variables 154

7.2 Total Difficulties Scores by Child Gender \& Family Migration Status 156

7.3 Type of Family-Member Migration \& Boys' Total Difficulties Scores 158

7.4 Type of Family-Member Migration \& Girls' Total Difficulties Scores 159

A.1 Organisation \& Functions of Experts Interviewed 213

C.1 In-Depth Interview Sample Characteristics 219

E.1 Full model: Odds Ratios of Being a Current Migrant 223

E.2 Full model: Relative Risk Ratios of Current Migrants by Destination 225 


\section{ACKNOWLEDGEMENTS}

Of the experiences I've anticipated most in my recent professional life, writing these acknowledgements is the one I've approached with the greatest excitement. I've never had the feeling that pursuing a PhD is a lonely experience; along this road I've never been without good traveling companions, and I'm happy for the opportunity to thank them all for their endless good humour and patience.

To my promotor, to Valentina, thank you very much for the guidance over the past years. I appreciate your patience in trying to cultivate in me a capacity for brevity and concision, and I am so grateful that you have set a standard that takes genuine effort to achieve. To my co-supervisor, to Melissa... it is thanks to you that I have followed this very specific path. Thank you for giving me the freedom to learn what I enjoy (and do not) and what my competencies are (and are not). Thank you for taking a chance on me.

To the members of my reading committee-Prof. Dr. Ronald Skeldon, Dr. Lucy Jordan, Prof. Dr. Jørgen Carling, and Dr. Franziska Gassmann-thank you very much for your critical comments and ideas. I very much so appreciate your thorough reading of my work and your suggestions for how it can be better honed and refined.

To the staff at MGSoG and UNU-MERIT, I owe a great deal of gratitude for your help and patience. Susan, despite my best attempts to drive you out of your mind with questions, you always found the time to answer me, for which I am grateful. The same goes for Eric, Janneke, Marc, Mieke, Mindel, Ralph, Robin, and Tatiana. Thank you for your assistance over the years. Sueli, thank you for educating me in the nuances of my own language. Eveline, it's a shame that it's only in the last few weeks that I've had the chance to know you better-your help has been indispensable and your humour a beautiful bonus!

Appreciation is also due to the European Commission, the funder of the project "The Effects of Migration on Children and the Elderly Left Behind in Moldova and Georgia". I would also like to thank our project partners: at the Kiel Institute for the World Economy, thank you very much Matthias, Marcus, and Toby for your assistance and knowledge. Thank you Marcus and Toby for being the remote support team for implementation of the survey in Georgia, and Toby, thank you for teaching me so much about how to work with our data. From the International Centre for Social Research and Policy Analysis, thank you very much George and Elene for providing me the context to understand Georgian politics and society. You gave me a first taste of Georgian hospitality that I will always treasure. I am also grateful for the work of CIVIS and IPM, the survey 
implementers in Moldova and Georgia whose professionalism and endurance resulted in some beautiful data. To Hendrik, Mira, and Jenny, thank you so much for your assistance in this project-I learned an incredible amount through each of you. Jenny in particular, thank you for your hard work, dedication, and continued efforts to produce something meaningful with our results. Franziska, it's been a pleasure to work with you and to learn when your scoffing and head-shaking actually mean something is dire (instead of just a little annoying). It has been a privilege to learn from you, and I hope that when I grow up I can lend as much joy to the people who I teach as you do.

I owe the greatest debt of gratitude to the participants in this study. It's often uncomfortable to invite friends into your home to discuss such personal matters as family relationships, feelings about absent kin, and expectations for the future; doing so with strangers requires a special kind of patience. I thank my respondents so much for giving me the opportunity to learn and understand migration and its place in their lives through their own accounts, experiences, and foods. To wherever in this world you're scattered, thank you for letting me in.

I owe enormous thanks to Jana and Elene, my interpreters and coconspirators during my fieldwork. Jana, through you and your family I came to better understand some of the beautiful peculiarities of Moldova; your hospitality (both intellectually and in the traditional sense) made it possible to do such intensive and emotionally-challenging fieldwork. There is no one else with whom I would rather carry 15 kilos of sugar uphill in 30 degree heat;). Thank you for your patience and humanity. To Elene, thank you for your insight and humour. Georgia can be a daunting place to understand, and through you I came to value that challenge. Thank you so much for your assistance and friendship over the years. There is no one else with whom I would rather share a commiseration vodka after facing the threat of legal action;). Thank you for the years of patience, and I hope I can continue to test it in the future.

Over the years I've had some of the most patient, intelligent, and dedicated colleagues and friends anyone could want. To the members of the "migration team", whether short- or long-term-Aleksandra, Ayla, Biljana, Craig, Elaine, Georgina, Jenny, Katie, Katrin, Marieke, Nora, Özge, Sarah, Silja, Skerlida, Sonja, Victor, Vivianne-thank you for sharing these last years with me. Thank you for sharing your knowledge and humour so freely. Katie, Özge, and Sonja, I appreciate the many times you've patiently explained super complex ideas to me-seriously Sonja, your unfortunate assignment as my desk mate taught me more about econometrics than any class could. I am also very grateful to the members of the TMG for the opportunity to learn more about the larger field in which we workthank you Bilisuma, Karlijn, Kim, Marieke, Miranda, and Natalia. I am also grateful to the larger intellectual community at MGSoG/UNU-MERIT, through 
which I am always learning. Martin, it's been a pleasure to learn from you; your enthusiasm seems boundless, and I'm looking forward to some surely rewarding future collaborations. Sonila, you are easily the most patient person I will ever meet. It was a great joy to work with you, and I hope another opportunity will arise in the future. Ortrun, it hasn't happened yet, but I hope we can work together in the future, even if all that entails is more marvelling at the glorious strangeness of Georgia over coffee. During my time at MGSoG, I've also made some irreplaceable (and unlikely) friends. Irina, you are one of the most crazy-making people I have ever met-which is a compliment because that craziness draws people in. Thank you for being a genuine friend. Katrin... goodness, you must have infinite patience to have worked with me for so long. Thank you for your tenacity, your adaptability, your capacity to turn the other cheek - and the endless chocolate supply. Elaine, thank you for keeping me laughing-you have unrivalled story-telling skills. I appreciate our conversations about all things deep and superficial, and I am so grateful to have found such a patient friend.

To my family... without you, nothing I have done would have been possible. To my Dutch family, to Nora, Tjeu, and Paula, thank you for making sure I had another family that would support me in the absence of my own, and for letting me steal your son. To my siblings-Jeannine, Chrissy, and A-I miss you every day. You taught me the most fundamental lessons about how to be a human being; you've taught me how important family is to living a fulfilling life, about how to laugh at the frustrating and ludicrous moments, and about why one should not pick columbines in Colorado, among many other things. I never laugh so hard as I do when we're together. Thank you for laughing with me (and at me) and for busting my chops when I need it. Seamie, you are by far my biggest champion, and I cannot thank you enough for being the perfect partner in crime through every stage of my life. To my parents-yikes! Thank you so much for your endless, endless patience and love. Thank you for trusting me to make my own choices and decisions, even the bad ones. Dad, thank you for passing on to me a love of details and process, fanaticism for nature, and the knowledge of how to prepare a balanced meal-these skills have pushed me through these last few years. Art, thank you for always supporting me in my education and giving me the resources to continue learning, no matter how expensive that process is. Mum, thank you for teaching me how not to panic about everything. You once told me that when you want to eat an elephant, you just have to take it one bite at a time. That advice has gotten me through many, many overwhelming moments, and I thank my lucky stars every day that you will help me face any challenge. To Ludo... you know, without you I never would have gotten into this mess. I am so grateful for meeting you when I did. For these last ten years, thank you for your patience, tolerance, and co-suffering. I look forward to sharing whatever adventures these next uncertain years bring. 


\section{CHAPTER ONE: INTRODUCTION}

"Migration is not an experience that belongs solely to those who leave their countries. The protagonists in the migration saga include those who leave, those who stay, and those who come and go for generations to come." Falicov (2000; pp 400)

Over the last decades, increased focus on the manifold links and exchanges migrants and their families maintain over national borders has brought an entirely different cast of characters into the "migration saga". Among these new protagonists are children living in transnational families, those families in which members maintain close ties and continue to engage in family practices over geographical distances (Bryceson \& Vuorela, 2002). Children perceived to be 'left behind' in the home country have attracted a great deal of attention from academics and policy makers alike, particularly in countries like Moldova and Georgia where large outward migration flows-and growing numbers of women among those flows-have inspired discussions on the potential consequences of migration for the children who remain. One such consequence that has generated increasing concern is the potential erosion of child psychosocial health as a result of separation from close family members, chiefly parents.

Child psychosocial health is particularly pertinent to investigate given the intimate ties between psychosocial health and other domains of child health. Poor psychosocial health can manifest itself in physical health complaints, in a child's inability to focus in school, or a child's inability to engage with his or her peers, among other possibilities. Psychosocial health is an essential element that enables a child to lead a productive life. If we conceptualise child psychosocial health very simply - as "the presence of positive psychosocial traits, such as best friendship, or the absence of negative traits, such as aggression or anxious symptoms" (Clarke, 2006; 13) - then it could be expected that the migration of close kin, particularly those who provide a child with care, could have negative repercussions for that child. Migration, and the many potential changes it can generate in a child's life, may be considered a negative life event or risk that generates stress and potentially impairs a child's functioning (Arrington \& Wilson, 2000). Many different mechanisms can be proposed through which migration can generate stress: a child may be left without adequate parental guidance and may face a level of 
independence for which he or she is unprepared; a child may become responsible for more household chores and may need to learn how to differently balance time commitments; or, quite simply, a child may miss the presence of a beloved person. These stressors need not translate into psychosocial dysfunction, however; different children living in different family and migration contexts can cope and adapt to these changes. Understanding this adaptation process requires more nuanced understanding of how migration and child psychosocial health are linked, if at all. It is precisely this idea with which this book is concerned.

This research investigates how different forms of family member migrationthat of a parent, a grandparent, a sibling, or other members of the extended family-influence the psychosocial health of children in the Republic of Moldova (hereafter: Moldova) and Georgia. Central to this research is a desire to better understand if family member migration and child psychosocial health have any connection and, if so, why and how. This research has thus been driven by the central question: What is the relationship between the migration of a parent or other member of the co-resident extended family and child psychosocial health? Answering this question requires the exploration of the following sub-questions: 1) how has the feminisation of migration from Moldova and Georgia occurred, and how do these gendered migration trends reflect underlying factors that shape the migration propensities of men and women?; 2) what is the relationship between different forms of family-member migration, such as that of a mother, father, grandparent, or other kin, and child psychosocial health?, and; 3) what is the magnitude of the relationship between migration and child psychosocial health relative to other factors in a child's life that influence wellbeing outcomes?

Moldova and Georgia are relevant case studies through which to explore the linkages among migration, child psychosocial health, and family life given the increasing prevalence of transnational families within these countries. Transnational family arrangements arise when family affairs are conducted across national spaces in response to the dispersal of members beyond the confines of the state (Glick Schiller, Basch, \& Szanton-Blanc, 1995; Bryceson \& Vuorela, 2002). These arrangements result from mobility among certain members of the family and immobility among others, a situation that may reflect an active choice of the migrant and family to split membership across countries or may instead result from structural constraints, such as restrictive migration regimes in destination 
countries, that limit possibilities for family migration or reunification (Mazzucato \& Schans, 2011).

Since gaining independence from the United Soviet Socialist Republic (USSR; shorthanded as "Soviet Union") in 1991, both Moldova and Georgia have experienced unprecedented emigration flows that have given rise to diverse forms of transnational families. Initial emigration waves from both Moldova and Georgia were driven by ethnic minorities "returning" to their (ancestral) homelands; the migration of whole families fleeing conflict, political unrest, and corruption; and the migration of individuals and families seeking reprieve from poverty and persistent unemployment (Makaryan, 2012). Large-scale emigration began at the end of the 1990s, when migration from both countries was driven predominantly by labourers seeking employment or better working conditions abroad (Panţîru et al., 2007; Gugushvili, 2013). Beginning in the mid-2000s, another shift in the composition of migration flows occurred: women, who comprised a relatively small proportion of migrants in the past, began entering migration in much larger numbers (Cantarji \& Mincu, 2013; Labadze \& Tukhasvili, 2013). These different migration movements led to the formation of different kinds of transnational families, with the dislocation of both nuclear and extended families across national borders becoming more common with the rise of individual labour migration in the 1990s. The result is a diverse group of families in which children remain in the home country following the migration of one or both parents, grandparent(s), sibling(s), or other kin.

Despite the prevalence of transnational families, their increasing recognition in public policies, and their inclusion in active public discourses that presume a deleterious effect of migration on child well-being, little academic research has been conducted on the psychosocial health of children living in transnational families in Moldova and Georgia. Few studies have been conducted in general in the Eastern European and Caucasus region; the growing body of evidence on the links between migration and child psychosocial health has been generated from studies conducted largely in Latin America or Asia. Most studies that address the potential consequences of migration for the psychosocial well-being of children who remain in the country of origin following the migration of kin have been conducted in countries with significant emigration movements and relatively high rates of female migration. Much of the pioneering work on the topic has been conducted in South-East Asia in countries such as the Philippines, Indonesia, 
Thailand, and Vietnam (e.g., Battistella \& Conaco, 1998; Asis, 2006; Parreñas, 2005; Graham \& Jordan, 2011; Jordan \& Graham, 2012; Hoang \& Yeoh, 2012). The Philippines has attracted particular attention given its long history of large-scale migration as well as the strong role of policy in encouraging and facilitating the migration of both men and women for work in particular sectors abroad. Recent academic work investigating the relationship between parental migration and the emotional well-being of non-migrant children has also appeared in China, where the internal migration of young workers has resulted in increasing incidence of geographically-dispersed families (e.g., Biao, 2007; Jia \& Tian, 2010).

Countries in Latin America and the Caribbean have also increasingly fallen under the scope of transnational migration and family researchers, given the scale of migration movements from the region and the predominance of circular and serial migration among young labourers. In Mexico a number of studies have explored how parental migration affects caregiving regimes and the quality of parent-child relations (e.g., Hondagneu-Sotelo \& Avila, 1997; Dreby, 2007; Heymann et al., 2009). Other studies conducted in the Caribbean have explored how child emotional well-being is cultivated in contexts of serial parental separation and reunification, a relatively common phenomenon in several countries where retained ties to former colonies such as the United Kingdom facilitate circular mobility of individuals yet entail limited possibilities for family reunification (e.g., Smith, Lalonde, \& Johnson, 2004).

Very few studies that explicitly address the emotional functioning of children in transnational families have been conducted in other regions of the world. Despite a significant body of research in Africa on parent-child separation and the practice of child fostering, the psychosocial health of children living in transnational families has only recently been studied in the region (Mazzucato \& Schans, 2011). Mazzucato et al. (2015) is one of the few studies to address differences in the psychological health of children living in different forms of transnational families in Africa, with a particular focus on Angola, Ghana, and Nigeria. Studies on Eastern Europe and the Caucasus are also notably lacking. The few studies available that address the experiences of children with migrant parents often do so indirectly, by exploring how migrants negotiate expectations and commitments in transnational parenting (see, for instance, Tolstokorova, 2010 on transnational mothering in the Ukraine). The majority of studies that directly address the experiences of children do so from an interventionist perspective, 
particularly in Moldova where international organisations such as UNICEF, Save the Children, and HelpAge International have undertaken studies on the 'left behind' with the explicit aim of finding vulnerabilities and suggesting methods to mitigate them (see, for instance, UNICEF/CIDDC, 2006; HAI, 2008; UNICEF/CRIC, 2008). The strong emphasis on producing policy- or programme-relevant studies has stymied efforts to understand both the true scale of the phenomenon and the implications of family separation for child well-being.

The limited number of studies conducted in countries beyond Latin America or Asia are accompanied by a lack of studies with comparative research designs, of which there are only two academic studies, to the author's knowledge. Much of the comparative research conducted in the South-East Asian region has been conducted within the framework of the CHAMPSEA (Child Health and Migrant Parents in South-East Asia) project, which was implemented in Indonesia, the Philippines, Thailand, and Vietnam. The project aimed to uncover the potential impacts of parental absence on the well-being of children who remained in the origin countries, and the multi-country research design was chosen to generate insights into larger regional trends ${ }^{1}$. The second comparative study is the Transnational Child-Raising Arrangements between Africa and Europe (TCRAf$\mathrm{Eu}$ ) project, which used a multi-sited research design to study the effects of transnational family arrangements for all actors within those families (children, parents and caregivers). The project focused on Angola, Ghana, and Nigeria and followed the migration of one or both parents from these countries to Ireland, the Netherlands, Portugal, or South Africa ${ }^{2}$. The present research adds to this small body of comparative research by focusing on two countries in the former Soviet Union region, which not only enables discussion of country-specific experiences but also allows for discussion on trends within the wider post-Soviet region.

\section{DISSERTATION STRUCTURE}

This research was carried out within the project "The Effects of Migration on Children and the Elderly Left Behind in Moldova and Georgia," which was

\footnotetext{
${ }^{1}$ Additional information on the CHAMPSEA project can be found on the project website at: http://www.populationasia.org/CHAMPSEA.htm.

${ }^{2}$ Additional information on the TCRA-AfEu project and its individual research programmes can be found on the project website at http://www.tcra.nl.
} 
conducted by the Maastricht University Graduate School of Governance in cooperation with the Kiel Institute for the World Economy and the International Centre for Social Research and Policy Analysis. The project aimed to understand how the well-being of dependent individuals residing in households with one or more members living abroad was influenced by migration. Within this project, several different domains of well-being were investigated: physical health, psychosocial health, material well-being and housing quality, education, and social well-being.

This dissertation hones in on one domain: psychosocial health. This domain was chosen for study given the strong influence this aspect of health could potentially have on others such as physical health or school performance. The choice was also made to study this domain given the strong emphasis prior studies had placed on the negative emotional consequences of migration for children remaining in the origin country, despite the often limited data or methods used to assess the relationship. By studying psychosocial health outcomes of children with migrant kin in the Eastern European and Caucasus region, this research could also provide additional geographical points of comparison to the body of academic studies on this topic, most of which has been conducted in South-East Asia or Latin America.

This dissertation explores the relationship between migration and child psychosocial health using quantitative analytical methods. Household survey data is used in the core analytical chapters, but understanding child psychosocial health and its relationship to the migration of normally co-resident kin requires understanding the larger contexts in which children live and develop. Those larger contexts involve factors such as family systems, gender norms, experiences of conflict, and discourses around migration. This dissertation is therefore organised in the following way.

Following Chapter One (this introduction), Chapter Two provides a review of literature from transnational family, family sociology, and child development studies that address how child psychosocial health can be influenced by the migration of kin. This review reveals that children living within different country, migration, and family contexts are influenced by the migration of kin in differing ways: characteristics of the child, such as age and sex; characteristics of the migrant, including sex and role as caregiver to a child; and characteristics of the migration episode, such as duration and contact with the household, are all factors 
found to influence child well-being outcomes. This chapter concludes with a reflection of how prior research suggests a theoretical framework to guide the present analysis.

In Chapter Three, the data and methods used in this study are described. This study relied on household survey data collected in both Moldova and Georgia, which is referred to as CELB-MD/GE (Children and Elderly Left Behind in Moldova and Georgia). This data and the methods by which they were collected are described in this chapter. This chapter also describes the collection of qualitative data from in-depth interviews with experts and with the families of migrants in Moldova and Georgia, which were used to better understand the trends uncovered in survey data.

Chapter Four provides profiles of Moldova and Georgia and describes their value as case studies for investigating the links between family-member migration and child psychosocial health. This chapter describes how both countries have experienced significant outward migration movements since independence from the Soviet Union in 1991, with both experiencing the loss of more than 20 percent of their populations over the past two-and-a-half decades. In recent years, an increasing number of women have become international migrants from both countries, a phenomenon that has led to increasing concerns about the potential consequences of migration for family solidarity and child well-being. Trends and values relating to family organisation and childcare are also described in this chapter, revealing that while both countries share broadly similar expectations about how childcare responsibilities should be distributed, family organisation differs in important ways. Moldovan households are more often organised around the nuclear family whereas Georgian households more often include multiple generations and members of the extended family, with such arrangements implying different childcare environments. This chapter concludes with a comparison of country contexts, which suggests that nuanced differences between Moldova and Georgia in terms of migration trends and family arrangements make them appropriate to compare and contrast.

These descriptive chapters are followed by three empirical chapters that explore how migration, family life, and child psychosocial health are linked in the two study countries. As who leaves a household is an important part of understanding how migration can influence the psychosocial health of children separated from their migrant kin, Chapter Five explores how the feminisation of 
migration from Moldova and Georgia has occurred. This chapter takes a cue from contemporary discourses on migration from Moldova and Georgia by testing the odds of women migrating compared to men. It further explores the factors that influence men's and women's entrance into international migration and into particular destination regions. The results suggest that Moldovan women have much lower odds of being international migrants than men, but this difference cannot be explained by child co-residency, as the presence of children in the household did not correspond to different migration odds among women. Georgian women, in contrast, did not have significantly different migration odds from men but had much lower odds of migrating given the presence of dependents (children or elderly individuals) in the household. This chapter importantly demonstrates that the "selection" of individuals into international migration" - the process by which different individuals become migrants-is distinctly gendered and non-random, with particular characteristics differentially increasing the odds of men and women being international migrants.

Chapter Six compares the psychosocial health outcomes of Moldovan children with a mother, father, or both parents living abroad to children residing with both parents in Moldova. The results of this second analytical chapter reveal relatively minor differences between children with and without migrant parents in terms of emotional symptoms and conduct problems, two indicators of psychosocial health that were measured using the Strengths and Difficulties Questionnaire (SDQ). Male children with both parents living abroad were found to have a higher probability of achieving abnormal emotional symptoms scores, and those with a father living abroad who were cared for by a mother had a higher probability of achieving abnormal conduct problem scores. No form of parental migration corresponded to significant differences in the scores of female children, however. These results highlight that the relationship between migration and child psychosocial health differs by the gender of the child and of the migrant.

Chapter Seven compares the psychosocial health outcomes of Georgian children who had experienced different forms of family-member migration (that of a parent, grandparent, or other kin) to those of children residing with both parents in Georgia. The total difficulties score, an aggregate measure of psychosocial health derived from the SDQ, is used as the indicator of psychosocial health. The results of this chapter suggest that migration bears a relatively benign influence on the psychosocial health of both male and female children. Female children with a 
father living abroad were found to have slightly better total difficulties scores than children residing with both parents in Georgia, but migration bore an otherwise insignificant influence on child psychosocial health outcomes.

The final chapter, Chapter Eight, reflects on the three analytical chapters and two review chapters to answer the research questions posed above. The conclusion suggests that the relationship between different forms of family member migration and child psychosocial health cannot be characterised as exclusively positive or negative: the relationship depends on the specific psychosocial health outcome being measured, the gender of the child, and the gender and role of the absent migrant. It also suggests that other factors of a child's life beyond migration may be more meaningful in shaping psychosocial health outcomes across contexts: being called names such as "stupid" or "lazy" by a caregiver, for instance, was one such factor that consistently contributed to less favourable outcomes for children of both genders in both countries. The more limited role of migration in shaping child psychosocial health outcomes in Georgia than in Moldova is a likely reflection of different family environments, with children in Moldova more likely to experience significant changes to daily routines given the migration of a parent because of the limited role of the extended family in child care. This chapter also reflects on the possible policy implications of this research, discusses the limitations this research faced, and outlines potential avenues that future research could take to advance knowledge of the links between migration and the psychosocial health of children who remain on the country of origin following the migration of close kin.

Chapters Five, Six, and Seven were prepared as stand-alone articles; there is therefore some repetition across chapters in terms of background information and literature review. As the theory and literature review presented in Chapter Two provides a complete guide to relevant literature for each of the analytical chapters, the reader may choose to skip sections 5.2 and 5.3 in Chapter Five, section 6.2 in Chapter Six, and section 7.2 in Chapter Seven, which review literature only for that particular chapter. Chapters Five, Six, and Seven in this book differ in minor ways from the versions submitted for publication, as references have been moved from the end of each chapter to one centralised reference list following Chapter Eight, and section numbering has been changed to be consistent with the rest of the chapters. Where the chapters have been published 
or submitted for publication elsewhere, the authorship, location, and date of publication are indicated in the footnotes of the chapter.

\section{NOTES ON TERMINOLOGY}

Some discussion of terminology is necessary before moving to the next chapters. In the study of spatially-separated families, different naming conventions have been adopted to describe and identify the phenomenon as well as the individuals directly involved in it. Throughout this dissertation, the term transnational families is used to describe families in which members are geographically separated-in this case, across country borders-but who maintain collective commitments and a sense of unity across these distances (Bryceson \& Vuorela, 2002). Within these transnational families, two broad types of members can be distinguished: movers and stayers. 'Movers' - those members who leave the origin country - are consistently identified in the literature as migrants. 'Stayers', as the name suggests, are the individuals who remain in the origin country following the migration of a family member, and their identification in the literature is less consistent. Different phrases have been used to identify members of this group, including: 'left behind', 'stay behind', 'home-based', 'home-land kin', and 'nonmigrant', among others (Baldassar, 2007). Several of these identifiers carry normative connotations - 'left behind', for instance, implies unwilling immobility and suggests a lack of agency on behalf of the stayer, whereas both 'home-based' and 'home-land kin' imply that the country of origin is a definitive home, denying the possibility for transnationalism. 'Non-migrant', as a term used to describe all individuals who have not moved, is not specific to individuals within transnational families and is therefore more encompassing than is useful. The term 'left behind' has been used most consistently in the literature specifically on children who remain in the country of origin following the migration of kin (generally a parent), and as such it is used in this dissertation when discussing the academic and policy literature that itself adopts this terminology. It is also used, however, to highlight or challenge the implicit assumptions the term contains. In the empirical chapters, children with migrant parents are generally not identified with a categorical name such as 'stay behind' or 'home-based' children but are instead described as 'children who remain in the country of origin' or 'children with migrant kin'. 


\section{CHAPTER TWO: LITERATURE REVIEW \& THEORETICAL FRAMEWORK}

Understanding the relationship between migration and child psychosocial health necessarily starts by addressing its basic premise - that the physical absence of a family member through migration does, indeed, have any bearing on child well-being. The family is theorised to impact child well-being through many different mechanisms. Attachment theory proposes that a child's caregiver, often a mother, is generally the first figure with whom a child forms intimate bonds of attachment, and the consistent availability and accessibility of that person promotes healthy child emotional development (Bowlby, 1977; Ainsworth, 1969). Family sociologists suggest that the presence of two parents in the home provides better socio-economic conditions for children given the availability of two potential income sources and two adults who can share household burdens (Thomson et al., 1994; Rege et al., 2011). Conversely, childhood stress may result from children in one-parent homes assuming significant household responsibilities, including physical chores as well as emotional support of the remaining parent (Carlson \& Corcoran, 2001). These mechanisms suggest that for children to benefit from family interaction and exchange, the physical presence of parents or other key family members is necessary, an assumption that transnational family scholars have challenged (Mazzucato \& Schans, 2011).

A fundamental question that arises in the study of transnational familiesthose families in which members maintain close ties and continue to engage in family practices despite geographical distance (Bryceson \& Vuorela, 2002) - is if the physical separation of children from their parents or other kin undermines child well-being. Since the early 2000s, a growing body of scholarship has addressed the potential impacts of transnational family life on different domains of child health and well-being (Mazzucato \& Schans, 2011; Mazzucato, 2014b). Research from different disciplines and based on both qualitative and quantitative methods has addressed aspects such as quality of child-parent relationships (see Parreñas, 2005; Dreby, 2007; Moran-Taylor, 2008; Haagsman \& Mazzucato, 2014), child physical health (see, for example, Salah, 2008 and Cortés, 2007), child educational performance (see de la Garza, 2010; Yang, 2008; Mansuri, 2006), and child emotional health (see, for instance, Graham \& Jordan, 2011; Jordan \& 
Graham, 2012; Mazzucato et al., 2014). These studies have highlighted that child well-being outcomes vary widely by the contexts in which children live and experience migration (Mazzucato, 2014a), and there is no clear offset between the potential benefits of migration, through financial or social remittances, for instance, and its potential downsides, such as lack of caregiver supervision or weakened emotional ties between children and their parents (Kandel \& Kao, 2001).

This dissertation focuses on the psychosocial health of children living in transnational families, which incites two questions: why focus on children, and why focus on the role of the family? Children have been chosen as the unit of analysis because they are often regarded as a vulnerable population group, particularly within discourses about migration. In countries like Moldova and Georgia, however, very little research has actually addressed if migration does correspond to worse well-being outcomes. At the same time, children are a unique population group; the components of child well-being differ from those of adults, as children face different needs and vulnerabilities given their specific positions within the life cycle (White, Leavy, \& Masters, 2003). Children, particularly of very young ages, are often regarded as being particularly vulnerable because they have limited control over the resources and processes that affect well-being and must therefore rely on other individuals, such as family members, to meet their basic needs. The role of the family in ensuring that children receive the resources necessary for their healthy development justifies the focus on the family as the key vector through which migration can influence child psychosocial health. This focus does, however, require further examination. Why, and in what ways, would the migration of a family member be expected to influence child psychosocial health?

This chapter addresses this question by reviewing literature from different disciplines that explores how child psychosocial health can be influenced by the absence of a family member. The first section reviews literature from the field of transnational family studies. Based primarily on qualitative accounts collected among geographically-dispersed families, this literature highlights how family relationships persist across distances but often not without consequences for the relationships between children and their migrant kin. The second section explores research conducted by family sociologists and migration scholars, whose quantitative assessments of the well-being outcomes of children living in transnational families have demonstrated how contextual factors relating to the family and the migration episode influence children's psychosocial health. The 
research reviewed in these first sections suggests that transnational families are fundamentally unlike families that are not dispersed across geographical spaces, in part because of who migrates and what that change in family membership implies for those who remain. The third section therefore reviews literature from migration scholars on the factors that influence the migration of particular individuals, which suggests that who migrates is not a random process but is one intimately tied to expectations about the roles and responsibilities different members of the family have. The fourth section addresses why the physical separation between a child and a family member, particularly a parent, would be expected to affect child psychosocial health from a child psychology and development perspective. The fifth and final section of this chapter addresses how these different strands of literature can be brought together into one analytical framework that addresses the potential consequences of family-member migration for the psychosocial health of children who remain in the country of origin following family-member migration.

\subsection{TRANSNATIONAL FAMILY LIFE \& PARENT-CHILD RELATIONS}

Over the past three decades, migration scholarship has increasingly recognised that migrants do not conduct their lives exclusively within their countries of origin or residence but can simultaneously participate in activities and processes that take place within and across geographical spaces (Glick Schiller, Basch, \& SzantonBlanc, 1995). Within studies of migrant transnationalism more generally, studies of transnational families began emerging in the early 2000s, when transnational family scholars began challenging the assumption that maintaining family relationships across geographical distances is unfeasible (Mazzucato \& Schans, 2011; Mazzucato, 2014b). Transnational family scholars proposed that migrants can and do continue to engage in family practices and processes despite physical distances (Bryceson \& Vuorela, 2002). Focus on the retained ties between migrants and their families remaining in the home country drew attention to the experiences of children living in geographically-dispersed families.

Much of the transnational family literature has explored how parent-children relations evolve in transnational family settings, with many early studies suggesting that children separated from their parents suffered emotionally from the migration because of perceived abandonment by parents and feelings of 
loneliness throughout the separation (Dreby, 2007; Moran-Taylor, 2008; Parreñas, 2005; Schmalzbauer, 2004). The relationships between children and their parents were found in many cases to deteriorate as a result, with factors such as the child's age at separation and the duration of the separation found to erode child-parent intimacy. In her explorations of transnational mothering in the Ukraine, Tolstokorova (2010) found that the inability of particularly young children to understand the necessity of their mother's migration led to feelings of abandonment and betrayal, resulting in children withdrawing from contact with their mothers. Several studies found that children separated from their parents at a young age regarded their absent parents as being strangers, and many did not recognise their biological parents as being their true parents, with some children of migrant mothers referring to their mother by name (Schmalzbauer, 2004) and referring to their (temporary) caregivers as 'mother' despite the non-biological bond (Dreby, 2007; Schmalzbauer, 2004). As part of the CHAMPSEA (Child Health and Migrant Parents in South-East Asia) project, the research of Hoang and Yeoh (2012) in Vietnam found that children who had been separated from their parents from a young age and had only limited, telephone/Skype-based contact with their migrant parents were apathetic about their absent parents or, in some cases, even fearful of them during return visits, with fathers particularly regarded with anxiety. These studies all suggest that parent-child separation is particularly challenging when children are separated from their parents at a young age and for long periods of time.

Other studies found that the deterioration of child-parent ties coupled with growing bonds between children and their temporary caregivers challenged family solidarity following a migrant's return, with sometimes negative consequences for child behaviour. Smith, Lalonde, and Johnson (2004) found that children from the Caribbean who had been separated from their migrant parents for significant durations of time before reunification more closely identified with their caregivers than with their parents, with many children regarding their caregivers as more legitimate authority figures than their parents. Hondagneu-Sotelo and Avila (1997) noted that children in Mexico with migrant mothers may be less responsive to their mother's authority when they are reunited, resulting in loss of parental control of children's behaviours. Parental migration and caregivers' difficulties in controlling children's behaviours have been linked to greater delinquency among 'left-behind' children in several countries. In Guatemala, Moran-Taylor (2008) noted that parental migration has been anecdotally linked to increased rates of boys' 
substance abuse, participation in petty criminal activities, and membership in gangs, whereas among girls migration has been linked to promiscuity and teenage pregnancy. In Moldova, children with parents living abroad were perceived by teachers, medical personnel, and other community members as being more likely to use alcohol and drugs, to drop out of school, to spend more time and money on leisure activities, and to engage in sexual relationships (UNICEF, 2006). Several authors proposed that the expression of these risk behaviours reflects not only the absence of authority or oversight but also a child's emotional state, with acting out as a way for children to gain attention and to express their emotional discomfort (Smith, Lalonde, \& Johnson, 2004; UNICEF, 2006; Moran-Taylor, 2008).

Transnational parenthood is not always associated with deteriorating parentchild relationships and worsening child well-being, however, particularly when parents remain engaged in family affairs from afar. In examining how the children of international migrants in the Caribbean regarded their childhoods in transnational families, Fog-Olwig (1999) observed that parents who cultivated a strong presence in the family home despite their physical absence had children who reported strong bonds with their parents and a better sense of security and belonging in their families. Smith et al. (2004) similarly found that children who were separated from their parents for significant lengths of time were less likely to feel estranged from their parents after reunification if their parents communicated with them regularly during their time apart. Åkesson, Carling, and Drotblohm (2012) further noted that in Cape Verde, the separation of children from their mothers is perceived of as "normal" given not only its prevalence but its degree of societal acceptance. The normalisation of separation as well as the intense participation of female kin in childrearing and caregiving activities prior to a mother's migration were noted as unique elements of the Cape Verdean experience that could promote less turbulent mother-child separation. In contrast to many transnational family studies that suggest that a parent's absence will correspond to decreased intimacy between parents and children and worsening child behaviour as a result, these studies suggest that consistent communication and continued emotional proximity to absent parents can promote child well-being despite physical separation from their parents. 


\subsection{MIGRATION \& CHILD PSYCHOSOCIAL HEALTH}

The findings from qualitative studies on transnational families are complemented by quantitative studies that assess specific well-being outcomes of children living in transnational families, often through comparison to a control group of children who had not experienced the migration of kin. A growing body of quantitative family sociology and child psychology studies have investigated how children living in transnational families fare in terms of narrowly-defined emotional, behavioural, and health outcomes (Mazzucato, 2014a). These studies suggest that migration does not correspond to universally positive or negative child well-being outcomes but that factors relating to the absent migrant, the postmigration caregiving arrangements, characteristics of the child, and the environment in which children live all influence child psychosocial health in migration contexts.

Several studies conducted in different country contexts have found that the relationship between migration and child psychosocial health varies by the sex and role of the migrant in relation to the child. In a cross-country comparative study conducted within the CHAMPSEA project, Graham and Jordan (2011) found that the emotional symptoms and conduct problems scores of children living in transnational families in Indonesia, the Philippines, Thailand, and Vietnam differed significantly from those of children living with both parents in the home country, but only under some circumstances. In Indonesia and Vietnam, children with a father abroad were slightly more likely to have problematic emotional symptoms scores than were children without a migrant parent, and in Thailand, children with a father abroad were slightly more likely to have conduct problems. In the Philippines, children with either a mother or father abroad were actually less likely to have a conduct problem than their peers residing with both parents. A later study (Jordan \& Graham, 2012) utilising the same data from Indonesia, the Philippines, and Vietnam on self-reported and caregiver-reported happiness found that children living in a transnational family - particularly one in which the mother was away-were less likely to be considered happy compared to their peers with both parents at home. Interestingly, the duration of maternal absence was correlated to higher odds of a child being considered happy, suggesting that over time the severity of a child's emotional response to a separation event may 
diminish. Both studies suggest that whether and how child psychosocial health is affected by migration depends on who specifically has migrated.

Further nuances were suggested by Mazzucato et al. (2014) in their study of the psychological health of children in Angola, Ghana, and Nigeria. Comparisons between children living with both parents in the home country and children living in different forms of transnational households revealed that parental migration corresponded to worse child psychological health in some situations. In Angola, children with a mother, father, or both parents abroad achieved much worse scores on a standardised measure of child psychological health than did their peers residing with both parents, a result that contrasted markedly to those found in Ghana and Nigeria. In Ghana, children living in transnational families, regardless of the specific arrangement, did not have significantly different health outcomes from children living with both parents. In Nigeria, children with a mother living abroad had significantly worse psychological health scores than children living with both parents but only when they were cared for by a father. The authors suggest that the negative associations between specific types of migration and child psychological health outcomes may reflect post-migration caregiving arrangements. In all three countries, children who had experienced unstable caregiving arrangements - the changing of a caregiver one or more times-had significantly worse emotional well-being outcomes. The results of the study suggest that the context in which migration occurs is important, with caregiver instability or the provision of care by a father found to correlate to worse outcomes.

Other aspects of the post-migration caregiving situation, such as who specifically provides care, may also have bearing on child psychosocial health. As alluded to by the study of Mazzucato and colleagues (2014), changes to the caregiving arrangement were linked to poor child well-being outcomes in other studies conducted in Mexico (Lahaie, Hayes, Markham Piper, and Heymann, 2009) and China (Jia \& Tian, 2010). In Mexico, a study among children in transnational families found that children who had experienced the migration of a caregiver were more than three times as likely as children who had experienced the migration of a non-caregiver to have a reported emotional problem. The odds of a household having a child with a reported emotional problem also increased when a respondent found it difficult to request time off from a job for an emergency, suggesting that the availability of a parent or caregiver played a role in child 
emotional health (Lahaie et al., 2009). In their cross-sectional analysis of children left behind by internal migrant parents in one rural area of China, Jia and Tian (2010) found that children of migrant parents had higher odds of reporting being lonely than did children with both parents at home, particularly if they were cared for by a grandparent. The participation of non-parents in caregiving may facilitate child resilience in other contexts, however. In a comparison of elementary-school children with and without migrant parents in the Philippines, Battistella and Conaco (1998) found few differences between children with and without migrant parents in reported anxiety and loneliness symptoms. A 2003 follow-up to the 1998 study, which engaged a larger group of school children, found that children with migrant parents had slightly better outcomes on a standardised anxiety measure than did members of their cohort with both parents in the Philippines, and the two groups of children had scores on a measure of loneliness that were nearly identical (SMC, 2004). The researchers proposed that the benign and even positive relationship between parental migration and child well-being outcomes could reflect the active participation of members of the extended family in child care, which ensured that the migration of a parent does not result in caregiving gaps.

The competence of the caregiver to navigate child care may also buffer children from the potential negative consequences of migration. The role of caregiving strategies in encouraging child psychological health was documented in Moldova (Robila, 2012), where the complex ties among migration, economic pressures, parental monitoring, parental support, and child psychological functioning were explored using structural equation modelling. This study found that parents were able to insulate their children's psychological functioning from the impacts of migration and economic pressure by using age-appropriate monitoring and parenting practices, suggesting that it is not migration as such that may contribute to worse child psychological outcomes but rather migration coupled with lack of appropriate caregiving practices.

Much literature has addressed how the role of the migrant in relation to the child (e.g., a parent or caregiver) can influence child well-being, but some studies have also suggested that characteristics of the migration episode itself can play a role in influencing the development of child psychosocial health. Despite targeting a slightly different population group, studies conducted among children who were separated from their parents prior to reunification in a destination country suggest that specific aspects of the separation episode correlate to child well-being 
outcomes. In a study of newly-arrived adolescent migrants to the United States from China, Central America, the Dominican Republic, Haiti, and Mexico, SuárezOrozco, Ban, and Kim (2011) found that children who emigrated to the US after a period of separation from one or both parents were more likely to report symptoms of anxiety or depression than children who emigrated as a family unit. Children who had been separated from a mother for a period of four years or more reported the highest level of distress, whereas children who had been separated for two years or fewer from a father or both parents expressed the lowest. The participants in the study were then observed five years after their arrival in the US, at which point the anxiety and depression levels between cohorts of children who had and had not experienced parental separation did not statistically differ. These findings suggest that characteristics of the migration episode such as duration of separation coupled with who has migrated influence child psychosocial health outcomes, but the outcomes also depend on the time at which a child is observed.

The well-being outcomes of children in migration contexts can also be influenced by child-specific characteristics, including their sex and age at separation. In child psychology literature, child sex has long been regarded as an important factor in explaining differential risks of developing unfavourable internalising behaviours such as anxiety or depression and externalising behaviours such as delinquency or aggression (Eisenberg et al., 2001). In their studies of children in transnational families in South-East Asia, Graham and Jordan (2011) found that with the exception of children in the Philippines, girls had a lower likelihood than boys of expressing conduct problems but had a higher likelihood of having emotional problems. A child's age at separation from a parent has also been found to be an important predictor of the development of unfavourable psychosocial outcomes. In a study among children who had experienced the internal migration of one or both parents in China, Liu, Li, and Ge (2009) found that children who experienced parental separation before the age of three reported the highest scores on measures of depressive symptoms and trait anxiety, and children who were between the ages of three and six at their parents' first migration reported the highest scores on a state anxiety measure. The findings of Graham and Jordan (2011) and Liu, Li, and Ge (2009) both suggest that while child-specific traits such as sex and age are important predictors of the development of unfavourable psychosocial health outcomes, significant differences can be seen by the specific element of psychosocial health being measured. 
A final set of characteristics found to influence the psychosocial health outcomes of children in transnational families relates to the larger circumstances in which children live and develop. In China, Jia and Tian (2010) found that the odds of child experiencing moderate or severe loneliness given the migration of a parent were higher among children who lived in economically poor households. Biao (2007), in a review of studies that compared the psychological well-being of children with and without internal migrant parents in China, noted that parental migration does not pose as large a risk for the development of poor psychological health as economic underdevelopment does. Biao proposed that differences between children with and without migrant parents may in fact reflect the difference between urban and rural contexts, as children in rural areas (from which many migrants hail) live in areas of social and economic deprivation that contribute to worse psychosocial health (Biao, 2007). In their study of children in transnational families in Angola, Ghana, and Nigeria, Mazzucato et al. (2014) note that the worse well-being outcomes observed among children living in transnational families in Angola compared to Ghana and Nigeria likely reflect the effect of conflict in undermining child resilience. Such studies suggest that worse psychosocial health outcomes observed among children in migration settings may be attributable to other aspects of a child's environment that challenge a child's ability to cope with change, such as a parent's migration, rather than to the change itself.

\subsection{WHO LEAVES? MIGRATION DECISION MAKING \& CHILD PSYCHOSOCIAL HEALTH}

Much of the literature on the relationship between child psychosocial health and migration addresses who specifically leaves, which recognises that the migration of individuals with different biological (e.g., mother, father) and social (e.g., caregiver) relationships to a child can affect child well-being in different ways. As was highlighted by both qualitative and quantitative accounts of children in transnational families, who migrates has the potential to affect many different

elements of a child's life, both directly-through changes to interpersonal relationships, for instance-and indirectly, through changes to the caregiving environment. 
Who becomes a migrant is not a random process, nor is who takes on specific social roles in relation to a child. Both are shaped in important ways by gender, which is a particularly relevant aspect of the relationship between migration and child psychosocial health to consider given that: 1) gender constrains who within a household or family migrates, and; 2) there is a strong link between childcare and gender, based on normative, gendered expectations of social reproduction, which; 3) implies that depending on the gender and household role of the absent migrant, the resources available within the household that directly affect child well-being may change. Each of these linkages merits examination.

Gender patterns the opportunities and constraints an individual faces throughout life, including migration. Gender is not a static characteristic of an individual but is also a social institution and a process. As a social institution, gender ascribes membership of individuals into distinct categories on the basis of which rights and responsibilities are assigned. Expectations about gender pattern the distribution of resources, the division of labour, and the transmission of values (Lorber, 1994). As a process, gender is "constructed and reconstructed interactionally" (Laslett \& Brenner, 1989; pp 382), through social interactions in which individuals learn what actions and reactions are expected and appropriate for a given gender (Lorber, 1994). These expectations are further institutionalised in structures such as family, schools, the labour market and work places, and larger culture and ideology (Laslett \& Brenner, 1989). As both an institution and a process, gender is part of larger social stratification system that establishes ranking of individuals (Lorber, 1994).

This stratification is apparent in the "selection" of individuals into migration, which is the process by which different individuals become migrants. Much migration theory has addressed the migration decision-making process, but economic theories of migration selection have generally failed to address stratification within decision-making units. The new economics of labour migration (NELM) theory (Stark \& Bloom, 1985) provides an example of this. The theory proposes that the decision for an individual to emigrate is based on household-level decision making aimed at diversifying sources of income, and thereby risk, by promoting the relocation of an income earner into a sector that is isolated from localised economic shocks (Stark \& Bloom, 1985; Massey et al, 1993; Taylor, 1999). Household or family members decide who in the household should leave based on a comparison of the projected benefits of the move, namely 
remittances, against the cost of the move, including not only the cost of the physical relocation but also the cost of lost wages in the local economy and the cost of lost household labour (Taylor, 1999; Pfeiffer, Richter, Fletcher, \& Taylor, 2008). This sort of cost-benefit analysis relies on appropriate quantification of loss, a difficult calculation to make when the contributions an individual adds to the household have no market value, as with childcare, which is disproportionately provided by women (Pfeiffer et al., 2008). The theory assumes that migration is a calculated strategy developed cooperatively by household members, which ignores potential power differentials that may limit or exclude particular individuals from the decision-making process (Cerutti \& Massey, 2001).

Feminist scholarship has been particularly sceptical of migration-decision making theories that assume consensus and reciprocity within a household or family, as hierarchies of power based on gender and generation are likely to influence household decisions (Pessar, 1999). Grieco and Boyd (2003) observe that the family plays an essential role in influencing who migrates by defining and assigning the gender roles that determine who has the motivation and incentives to migrate, and the family also decides on the allocation of the resources that can enable migration. Gender roles defined with a family also influence what kinds of resources female migrants are expected to produce, such as remittances, access to social networks, or family reunification in the host country, as well as expectations about the duration of migration and frequency of return (Pedrazza, 1991). Studies conducted in different country contexts have illustrated the gendered nature of migration decision making within families.

In Mexico, for instance, women were found to be discouraged from migrating internationally because of their greater perceived vulnerability; women who planned international moves were found to need more resources than their male counterparts to either convince their families that they could migrate or to facilitate their migration without familial support (Curran \& Rivero-Fuentes, 2003). In the Ukraine, older women displaced from the local labour market were found to be preferable international, circular migrants because they could provide economic support for their children and grandchildren while simultaneously allowing young women to remain at home to care for children (Solari, 2010). In the Philippines, male household heads were found to support the migration of their young daughters to urban areas to work because their daughters were perceived as being more likely to find non-seasonal work, to share larger portions of their incomes 
through remittances, and to more reliably support the household even in absentia than sons were (Lauby \& Stark, 1988). These studies suggest that different elements of the migration decision-its funding, its spatial limits (internal or international), its temporal dimensions (circular or non-circular), and its benefits-are moderated by gendered ideologies within the family.

The gendered selection of individuals into migration interacts with family life in ways that can affect children who remain in the country of origin, particularly in terms of the responsibilities and roles different members of a family perform. The distribution of labour both within and outside of a household is strongly gendered. Activities and attitudes relating to the maintenance of daily life, including tasks such as food preparation, the care and socialisation of children, or the upkeep of the home (referred to as social reproduction) are organised by different stratification levels such as gender and generation (Laslett \& Brenner, 1989). Men and women often perform different social reproduction tasks, with women assuming the most intensive childcare tasks within many cultures. Changes to household composition, or changes in the availability of a particular individual within the household, are likely to require changes in the distribution of household tasks.

Evidence from across the globe has suggested that the redistribution of household labour differs markedly in different country and migration contexts. Pessar and Mahler (2001), in their review of the intersection between gender and transnational migration, note that several studies have found that women and girls remaining in the home country following the emigration of male kin took on traditionally "male" tasks such as agricultural work, managing expensive purchases, and physical discipline of children (Pessar \& Mahler, 2001).

Men have also been found to assume more "female" household tasks when faced with the migration of female kin. In Vietnam, Hoang and Yeoh (2011) found that fathers often assumed responsibility for child care following the migration of their wives because they felt that participation in child care was an essential part of fathering. Fathers were found to be willing to take on caregiving roles even when other potential caregivers such as grandparents were available and even when providing such care required adjustment to paid employment. A different study conducted among transnational families in Indonesia, the Philippines, and Vietnam found that the migration of a mother often encouraged members of the extended family, such as grandmothers and aunts, to provide care to children 
within the family. Fathers were found to become the primary caregiver generally only when other alternatives were not available, but among those who did take on intensive caregiving roles, most did so despite their anxieties about taking on roles and responsibilities that they had not performed before their wives' migration (Yeoh \& Lam, 2013).

Other studies have demonstrated that the reconfiguration of gendered work is done reluctantly if at all by those who remain behind. In Sri Lanka, men whose wives worked as domestic staff abroad performed some of the household tasks their wives had performed before but were reluctant to admit it in public for fear of its emasculating implications (Gamburd, 2000). In her study of transnational Filipino families, Parreñas (2005) found that in most households where a mother had migrated, fathers generally maintained the gendered division of labour within the household by performing only those tasks traditionally assigned to men. When they did take on activities previously performed by their wives, such as cleaning or cooking, they tended to justify them as extension of their professional capacities, and they carefully avoided performing those activities (such as emotionally supporting their children) that were considered the mother's key domain. Those activities that were perceived as intensely "female" were generally taken up by other female kin such as oldest daughters, grandmothers, or aunts. Schmalzbauer (2004), in her study of transnational families in Honduras, similarly found that "other-mothers" enabled the migration of women by providing care for children who remained behind. Women who migrated sought out other female caregivers for their children such as their own mothers or mothers-in-law or, when unavailable, an aunt, sister, or older daughter. Hondagneu-Sotelo and Avila (1997) found that Latina transnational migrants from countries such as Mexico, El Salvador, and Guatemala actively preferred for their own mothers to assume the care of their children in their absence, both due to the practical advantages of doing so, such as availability and low cost, as well as due to the cultural value placed on care given from a woman's own mother.

Such studies highlight that the post-migration caregiving environment is shaped both by who migrates and by who assumes the responsibilities the migrant used to perform, which may imply changes to the resources within a household and the accessibility of those resources for children who remain behind. The literature on gender and transnational migration studies suggests that women and men are not only subject to different rationales that justify or deny their migration 
possibilities but that households adjust differently to the migration of men and women. Many studies have focused on the shift in caregiving roles following the migration of a child's mother or father, with many (such as Gamburd, 2000; Parreñas, 2005; Yeoh \& Lam, 2013) suggesting that the migration of a mother may require significant shifts in caregiving responsibilities to a father that he may be unprepared to handle alone. Better understanding of the gendered nature of migration and social reproduction allows for greater contextualisation of the findings from studies of the psychosocial health of children in transnational families. Many of the studies surveyed in Sections 2.1 and 2.2 above suggested strong correlations between the migration of a mother or father and child psychosocial health outcomes; understanding these results requires understanding how migrant gender and social reproduction intersect, as the caregiving situation a child lives in is a very likely contributor to psychosocial health.

\subsection{THE ROLE OF FAMILY IN PSYCHOSOCIAL HEALTH: CHILD ATTACHMENT \& LOSS}

The discussion of the potential consequences of migration for child psychosocial health has so far focused on child-family separation without much exploration of why the family is presumed to be so important to child health. Child and development psychology literature provides several compelling reasons why child-family separation through migration could potentially be problematic. Prior literature investigating the psychosocial consequences of child-parent separation has relied largely on clinical data and on situations of separation resulting from parental death, divorce, or desertion (Mazzucato, 2014a). Such forms of separation, while fundamentally unlike the separation experienced during migration, have helped pattern expectations about how child well-being evolves following parental loss. Three types of theories from the child and family psychology literatureobject relations, attachment, and (ambiguous) loss-provide insight into the underlying mechanisms through which separation can affect child psychosocial health, with some clear implications for the unique separation experienced with migration. 
Object relations theories suggest that the development of a child's psyche is strongly influenced by the interactions between children and key 'others' during infancy and very early childhood. Based on these interactions, children are thought to form internal objects in the subconscious that are internalised images of important others, such as a mother, father, or other caregiver. These objects are derived from the patterns children detect in repeated experiences with others, and as they are based on a child's subjective experiences, they may not necessarily reflect external realities of these interactions. These objects are carried into adulthood and help the developing person predict behaviours of others, patterning an individual's expectations and relationships throughout life (Ainsworth, 1969; Priel \&Besser, 2010).

The concept of attachment, which modified the basic concept of object relations, has been used by child psychologists to explain the specific, discriminating, and enduring ties children form to specific others throughout life (Bowlby, 1977; Ainsworth, 1969). The first type of attachment a child forms is generally to its mother or other habitual caregiver, with a child gradually forming more affective bonds with other individuals over time (Ainsworth, 1969). The initial attachment a child forms to a caregiver is thought to be based on the child's unconscious identification of the caregiver as a source of help and trust (Bowlby, 1982); early attachment relationships thus tend to be characterised by dependency, yet these early attachment are made at a time when the child also develops the competencies that will enable independence later in life (Ainsworth, 1969). Within the theory, attachments are expected to endure over time and space, but their manifestation in the behaviour of the individual changes with maturity. An individual will behave in ways to maintain proximity to the trusted other, particularly during times of vulnerability. Ainsworth (1969) proposed that a child will act in ways to ensure physical proximity to its caregiver through activities such as crying and clinging; at later ages, the intensity and frequency of proximitypromoting behaviours by individuals can be directed to maintaining symbolic proximity via less direct communication, such as through telephone calls (Armsden \& Greenberg, 1987).

The predictability of attachment relationships throughout life are thought to contribute to psychosocial health because "...human beings at any age are most well-adjusted when they have confidence in the accessibility and responsiveness of a trusted other" (Armsen \& Greenberg, 1987; pp 428). The actual or threatened 
disruption of attachments can lead to emotional and psychological disturbances such as depression, anxiety, sadness, or anger, all of which result from an inability to maintain set proximity limits. The development of unresponsive or unpredictable attachment relationships can disrupt the sense of security an individual derives from attachments (Armsden \& Greenberg, 1987), the consequence of which is likely to be more disruptive to the psychosocial health of very young children for whom physical proximity is key. The expectations individuals form about early attachment figures are furthermore thought to influence how individuals relate to others later in life (Bowlby, 1982) in a similar way that early object relations pattern expectations. The disruption of an attachment relationship between a child and a caregiver through migration may therefore be expected to disturb the psychological development of a child, which could contribute not only to the development of problematic conditions such as anxiety, depression, or emotional detachment but also to the inability of a child to form trust relationships later in life (Bowlby, 1977).

A child's experiences of separation can also be understood through the lens of loss. The transition of an individual from a social unit such as a familywhether permanent (as in the case of death), or uncertain (as in the case of migration, divorce, or incarceration) - can be understood as a form of loss (Boss, 2004). Two levels of loss can be discerned: primary loss, which refers to the loss of the individual who has "exited", and secondary loss, which refers to the loss of security and routines associated with the particular individual who has gone. Both levels of loss imply that the child and other members of the family must adapt; in this process of adaptation, a child can develop emotional, physical, and behavioural responses that are more or less healthy (Suárez-Orozco, Louie, \& Todorova, 2002).

Loss itself does not necessarily imply worse child psychosocial outcomes; rather, the persistence of loss and the inability of the family to adapt to it are more important factors that increase a child's risk of developing poor outcomes. The primary loss - the acute loss experienced with the "exit" of an individual-may be a less significant contributor to the development of psychiatric disorder among children than the chronic effects of that loss, particularly in terms of the associated secondary losses of routines and roles (Boss, 1980). For instance, a child's experience of parental separation may be painful, but it is the experience of persistent family discord or impaired parenting as the result of that loss that is 
most strongly correlated to the development of child psychiatric disorder (Rutter \& Sandberg, 1992).

The prolongation of loss may be particularly concerning in situations of ambiguous loss. The theory of ambiguous loss builds off of the concept of family boundary ambiguity, which occurs when a family member is psychologically present but physically absent (i.e., when an individual is physically apart from the family but is still perceived as psychologically available, as in the case of divorce) or when an individual is physically present but psychologically absent (i.e., when an individual has remained physically with the family but is emotionally or psychologically unavailable, as can occur when an individual has a disorder such as PTSD or Alzheimer's disease) (Boss \& Greenberg, 1984; Boss, 2004). Ambiguous loss occurs when the event that created the boundary ambiguity is unclear or when the family refuses to acknowledge the facts of the event, resulting in uncertainty about the severity and finiteness of the loss (Boss, 2004). The inconclusiveness of a loss can result in grief that remains unresolved because the normal cues and rituals that accompany other forms of loss, such as death, are absent, and an individual may not feel as if they have 'permission' to grieve (Suárez-Orozco, Louie, \& Todorova, 2002). This is especially true in situations where other family members or members of the community do not acknowledge or react to the loss. When feelings of grief are not validated by members of the wider community, an individual processing a loss may internalise the stress, developing negative psychological symptoms such as depression or anxiety (Johnson \& Easterling, 2012).

The delayed or unresolved grief associated with an ambiguous loss can hinder the process of recovery and adaptation, particularly if roles and tasks within a family are not reassigned. This dynamic is best understood by envisioning the family as a system, with rules and routines that determine who belongs in a family, what that belonging implies for the individual's actions and behaviours, and when someone should participate in family life (Carroll, Olson, \& Buckmiller, 2007). Within this view of a family as a system, an individual cannot be viewed as an isolated segment but rather as an embedded part of that system, with each individual's activities and choices influencing and influenced by other members of that system. In situations of family boundary ambiguity, members of that system may be uncertain about who is still a member of the family and what tasks and roles individuals should play in the family system (Boss, 1980). Uncertainty about 
the duration of a loss and what the (temporary) absence of an individual means for the activities that occur within a family can hinder the development of coping mechanisms and result in key family activities not being reassigned at all (Boss, 2004; Carroll, Olson, \& Buckmiller, 2007).

There are compelling ways in which migration can be considered a sort of ambiguous loss, and doing so can provide a helpful lens to understand the links between migration and child psychosocial health. Falicov (2002; 2007) has argued that migration bears many similarities to ambiguous loss for its inconclusiveness and for the relational stress it brings into families given that inconclusiveness. Migration could be ambiguous in the sense that its duration is not certain; a migrant could plan to return only after meeting an investment goal or could plan to reunify with a family in the destination country, with the "resolution" of the absence depending on conditions beyond the migrant's immediate control. The ambiguity can be heightened by lack of information exchange between migrants and their family members, with the family's inability to directly observe conditions in the host country heightening the uncertainty about the conditions of migration and return. The situation may be especially problematic when a migrant resides irregularly in a territory, which not only enhances the risks of separation but is likely to limit a migrant's ability to communicate with the family and to return on a temporary basis. At the same time, a migrant's ability to remain psychologically present while physically absent may enhance ambiguity in its own way. As documented by Parreñas (2005), for instance, some men with migrant wives may feel as if they cannot or should not provide for the emotional needs of their children, a perception that may be enhanced by the accessibility of a mother via telephone. The perception that the mother is still capable of performing emotional care from abroad may limit the extent to which a father or other family members takes on those activities, potentially leading to tasks and roles relating to childcare not being completely addressed.

Theories from child and family psychology suggest underlying mechanisms by which family-member migration can affect child psychosocial health, but they are somewhat limited in their application to non-Euro-American contexts and to the specificities of migration as a unique form of separation or loss. Transnational migration scholars have noted that the attachment theory, for instance, reflects normative, Western family structures; the focus on parent-child attachment at the exclusion of other potential caregivers ignores the many 
enduring attachments a child could form with others, which is likely to occur in settings where the extended family participates in childcare (Suárez-Orozco, Todorova, \& Louie, 2002; Graham \& Jordon, 2011; Mazzucato \& Schans, 2011). Falicov (2007) notes that the promotion of the biological mother-child relationship above other forms of attachment ignores the extent to which children are embedded in larger social and family systems in which care can be coordinated and provided by multiple people. Understanding a child's experiences of loss and disruption involves understanding the multiple attachments a child forms and the affective hierarchies in which attachments are placed, which necessarily involves widening the scope from beyond just a child and a mother.

The extent to which migration can be considered analogous (or not) to other forms of loss, such as divorce or incarceration, also limits the extent to which the reviewed theories can usefully predict the relationship between family-member migration and child psychosocial health. Migration and other forms of separation such as parental divorce seem similar: both may imply continued emotional engagement despite physical distance, negotiation of the shift of authority within the household, adaptation of family roles, and coping with the emotional sense of abandonment. There are important differences between the two forms of separation, however, that are likely to correspond to different child well-being outcomes. As noted by Nobles (2011), for instance, in her study of the children of divorced and migrant fathers in Mexico, the underlying motivations of the two types of separation are likely to fundamentally differ. Some fathers emigrated for the explicit purpose of earning money to pay for a child's educational expenses, for instance, whereas investment motives did not inform divorce. Nobles noted that patterns of investment also differed: whereas divorced fathers tended to selectively allocate resources to particular children, migrant fathers invested more equally among their children. Migrant fathers were also found to communicate more consistently with their children than were divorced fathers, suggesting that the patterns of retained child-parent ties can strikingly differ depending on the type of absence and its motivation. A similar conclusion was suggested by Carling and Tønnessen (2013) following their comparison of the well-being outcomes of children in Malawi who had experienced different forms of paternal separation. Based on child well-being indicators such as use of mosquito netting around a bed, being underweight, and possessing a pair of shoes (among others), Carling and Tønnessen found that the well-being outcomes of children with migrant fathers were quite similar to those of children living with both parents, whereas children 
whose fathers were divorced or deceased had significantly worse outcomes than their peers living with both parents on most well-being indicators. The dissimilarities observed between children with migrant fathers and children with fathers absent for other reasons suggests that only limited parallels can be drawn between distinct forms of loss. Different types of separation are likely to occur from different motivations, to correspond to different levels of retained ties, and to require different strategies for adaptation within families. Migration cannot be expected to be completely analogous to other forms of loss in its implications for child psychosocial health.

\subsection{FAMILY-MEMBER MIGRATION \& CHILD PSYCHOSOCIAL HEALTH: EXPECTATIONS FOR MOLDOVA \& GEORGIA}

The different strands of literature surveyed in this chapter suggest that the line of influence between migration and child psychosocial health is not a direct one; the absence of a migrant as such is not expected to impact child psychosocial health, but it is rather what that absence implies for family membership and the reassignment of roles and responsibilities that matters. The shift in responsibilities normally performed by an absent household member may require household adaptations that can be complicated by gendered expectations and uncertainty over how physical absence affects the ability of an individual to perform particular

roles and tasks. Child psychosocial health is likely to reflect the strains and stresses of these adaptation processes, but different characteristics of the migrant, the child, and the larger environment in which children live influence how child psychosocial health develops.

Studies on children separated from their migrant kin from different disciplines and using different methodological tactics have revealed markedly different relationships between migration and child well-being, each highlighting the importance of the context in which children experience migration. Several studies found that child well-being varied by who had a migrated, with a number of qualitative (Dreby, 2007; Parreñas, 2005; Schmalzbauer, 2004) and quantitative (Jordan \& Graham, 2012; Mazzucato et al., 2014) studies suggesting that a mother's migration can be particularly challenging for specific aspects of child psychosocial 
health. Among the quantitative, comparative country studies, the relationship between different forms of parental migration and child health outcomes varied by the specific country under study, however, suggesting that in different countries, families adapt to migration in different ways. Some of these differences can be explained by caregiver choice, with some studies (Mazzucato et al., 2014; Lahaie et al., 2009; Jia \& Tian, 2010) suggesting that changing caregivers and the provision of care by specific individuals, such as fathers or grandparents, linked to worse child well-being.

Many studies suggest that different strategic adaptations to absence within a family can aid child psychosocial health and bolster a child's resilience to change. Such adaptations include the participation of the extended family in childcare, which was found to promote child well-being by reducing caregiving gaps in a number of geographically-dispersed studies (including Hondagneu-Sotelo \& Avila, 1997; Battistella \& Conaco, 1998; Schmalzbauer, 2004; Parreñas, 2005; Robila, 2012). Consistent communication between the absent individual and a child, as well as the continued participation of the migrant in decisions and activities within the family, were also found to contribute to better child adaptation to absence by a number of studies of both internal and international migration (Fog-Olwig, 1999; Jia \& Tian, 2010; Smith et al., 2004). Acknowledgement of absence and the wider "normalisation" of separation on community level were further linked to greater adaptation to migration processes (Graham and Jordan, 2011; Åkesson, Carling, \& Drotblohm, 2012; UNICEF, 2006), suggesting that validation of a child's feelings play a role in supporting resilience. Some factors beyond the immediate control of a child or his/her family, such as living in poor socio-economic conditions (Jia \& Tian, 2010; Biao, 2007) and being exposed to conflict (Mazzucato et al., 2014), however, may enhance the vulnerability of children to developing unfavourable psychosocial health outcomes given the migration of kin.

These findings can help frame expectations about the relationship between the migration of normally co-resident kin and the psychosocial health among children in Moldova and Georgia. Based on prior studies, the following hypotheses are posed:

1. The migration of any family member will correspond to worse child psychosocial health outcomes, but; 
2. The migration of a mother will correspond to particularly negative outcomes, and;

3. Child psychosocial health will also differ by type of caregiver, with children cared for by a non-parent given the migration of a parent at particularly high risk of experiencing poor psychosocial health;

4. The migration of a family member is just one of the potential risk factors for the development of poor psychosocial health, with environmental factors such as poverty or exposure to conflict correlated to worse psychosocial health outcomes.

The first three hypotheses propose that the specific type of migration that is experienced and the post-migration caregiving arrangements implied by different types of migration are important nuances in predicting the relationship between migration and psychosocial health. In line with the findings of past studies that maternal migration can be the most challenging for children to adapt to given her role as primary caregiver and attachment figure, these hypotheses predict that a mother's absence will correspond to markedly negative outcomes. Who migrates and who remains to give care are not the only factors that could influence child psychosocial health, however, and the final hypothesis therefore proposes that other factors such as a child's exposure to poverty and conflict will correspond to worse well-being outcomes.

These hypotheses are formulated without reference to the specific contexts of migration and family life in Moldova and Georgia, yet many prior studies noted the importance of country context in understanding the relationship between migration and child psychosocial health. Drawing together literature on the migration decision-making process, social reproduction, and transnational families, several hypotheses are thus proposed based on the particularities of these country contexts:

1. In both Moldova and Georgia, female migration-by extension, maternal migration - is expected to be less common than male migration, as; 
2. Gendered norms regarding social reproduction will discourage female migration, particularly among women with children or other household dependents, however;

3. When female migration does occur, it will correspond to considerably worse outcomes among children, particularly in Moldova where children are less likely to reside with members of the extended family who can provide care.

4. In Georgia, higher rates of co-residency with the extended family are expected to reduce potential negative consequences of parental migration, yet the migration of members of the extended family will correspond to negative psychosocial health outcomes given the ability of a child to form multiple attachment relationships.

These country-specific hypotheses draw from studies conducted in very different country contexts, as very little research has been conducted on children in transnational families in Moldova, Georgia, or indeed the wider post-Soviet space. Given the absence of academic studies on the links between migration and the psychosocial health of children in the Eastern European and Caucasus regions, this dissertation faces the challenge of understanding how country- and specificmigration trends interact with family systems and other elements of a child's everyday life to influence the development of psychosocial health. Chapter Four therefore surveys literature on Moldova and Georgia, with specific attention paid to how each country's experience of post-Soviet transition contributed to significant flows of emigration that have the potential to undermine the psychosocial health of the children who remain behind. 


\section{CHAPTER THREE: DATA \& METHODOLOGY}

This dissertation was completed within the framework of the two-and-ahalf-year research project "the Effects of Migration on Children and the Elderly Left Behind in Moldova and Georgia" (CELB-MD/GE). The project, which was funded by the European Commission ${ }^{3}$, was completed by a consortium led by Maastricht University, Maastricht Graduate School of Governance (MGSoG) in the Netherlands in cooperation with the Kiel Institute for the World Economy (IfW) in Germany and the International Centre for Social Research and Policy Analysis (ICSRPA) in Georgia. The project ran from December 2010 to June 2013.

The research project was designed in mid-2009, at a time when academic research on the potential consequences of migration for the well-being of dependent household members was relatively limited. When the study was designed, several geographical and methodological gaps were apparent in the literature: no academic studies had addressed the Eastern European and Caucasus region, very few comparative country case studies had been conducted, and few studies had made use of quantitative methods to collect information on the prevalence and potential consequences of migration for populations thought to be adversely affected by the migration of kin. At the same time, government and policy interest in addressing 'left behind' populations was becoming more clearly articulated, particularly in Moldova where migration was increasingly discussed as a cause of family dissolution or abandonment.

Within the research project, Moldova was chosen as a research site given the increasing visibility of transnational families on the policy agenda and within public discourses. Combined with the large scale of emigration the country had experienced in the past decade and the fact that it was in an understudied region, Moldova appeared to be an ideal country for the study of family members separated from their migrant kin. Georgia was chosen as a comparative case because it shared many characteristics with Moldova-both are former Soviet Union states that had experienced the emigration of significant shares of their populations-but differed in terms of the policy response to and public discourse about migration and its implications for the family. Within these two countries, the

\footnotetext{
${ }^{3}$ Grant number DCI-MIGR/2010/229-604.
} 
choice was made to study two specific subpopulations - children and the elderlyon the basis that both populations may be especially dependent on household-level resources to achieve minimum standards of well-being and may thus be more sensitive to the changes in household composition and resources brought about by migration.

When the research was designed, very little data was available in either country about children and elderly individuals in transnational families; as is described in more detail in Chapter Four, only few research studies about the topic had been conducted prior to 2009, most of which had been prompted by the desire to build intervention strategies for vulnerable parts of these populations. Despite the lack of information available, the Moldovan state and some international organisations such as UNICEF promoted the perception that a large proportion of children were being abandoned by their migrant parents, but no data on the size of this trend had been collected. This suggested an important starting point for our study: to document the actual scale of migration and the number of children or elderly persons 'left behind' by their migrant kin. As one of the goals of this study was to assess the prevalence of the trend, a quantitative data collection method that would enable sampling of a representative population was considered most appropriate. The project had an equally important second goal, however, which was to understand if dependent household members (children or the elderly) with migrant kin had significantly worse well-being outcomes than other members of their cohort who did not have migrant family members. The decision was made to assess well-being through survey measures rather than narrative accounts so that it would be possible to understand how different factors or characteristics (e.g., kin migration, individual age, household income, housing quality) shaped well-being outcomes and to understand the relative impact of different factors on specific aspects of well-being. A survey was furthermore considered to be the most appropriate methodological tool because information would be collected on different types of populations in both countries, which would require a significant volume of data to capture important variations within each population. Any survey would need to be appropriately grounded in the implementation context and to contain key questions to capture the desired information, however, thus a qualitative component of the project was designed to collect data on local conditions, perceptions, and knowledge. Project staff (myself included) therefore employed a mixed-methods approach to collecting different types of data through different tools, including semi-structured interviews with key experts, community 
surveys implemented among community leaders, household surveys, and in-depth interviews with the families of migrants in the home country.

The chapters in this dissertation rely on the primary data collected in the household survey. Unlike use of secondary data, which has been collected, cleaned, and often validated by other sources, the use of primary data involves participation in the entire data collection process. The process of primary data collection through both household surveys and in-depth interviews is outlined here, as these are the stages in which I participated most intensively and that form the basis of this dissertation; information about other data collection methods employed by the project at large can be found on the project website 4 .

\subsection{HOUSEHOLD SURVEY DATA}

The household survey implemented in Moldova and Georgia collected information on the daily lives and circumstances of individuals living in households both with and without migrant household members. The survey was designed around the following modules: 1) a household roster, which collected basic demographic information about every individual living in the household; 2) a section on household characteristics, which collected information on incomes and assets of household members as well as information on housing conditions; 3) a migration section, which collected information on the migration histories of every household member, with detailed information collected on every move occurring in or after 1999; 4) a section for the caregiver of each child in the household, which collected information on the health, education, and future aspirations of each child in the household as well as on the caregiver's own child-raising behaviours; 5) a section for children over the age of 10, which collected similar information as in the caregiving section but from children themselves, and 6) a section on the elderly, which collected information from individuals over the age of 60 on their health, social relationships, and activities. Staff from the Kiel Institute for the World Economy took the lead in developing the survey instrument, with staff from MGSoG aiding in its construction.

The household survey was designed with both household- and individuallevel units of analysis in mind. Information was collected on household-level

\footnotetext{
${ }^{4}$ Available here: http://mgsog.merit.unu.edu/research/moldova_georgia.php .
} 
features that were shared among all household members such as the material of the dwelling floors, monthly household expenditures, and number of televisions in the home. More information was collected on individual-level experiences, however, to enable exploration of characteristics or features of individuals' lives that differed even among those individuals living in the same household. As the aim of the survey was to capture snapshots of the multidimensional well-being of individuals in different stages of the life cycle, the survey was designed to collect information on sub-population specific features of well-being. Its construction was informed by a range of other data collection measures that were specific to these population subgroups.

Sources for questions on child and adolescent well-being included the Young Lives Survey conducted by the University of Oxford ${ }^{5}$ implemented in Ethiopia, India, Peru, and Vietnam; the Maryland Adolescent Development in Context Study conducted by the University of Colorado and the University of Michigan ${ }^{6}$ implemented in Maryland in the United States; the National Survey of Families and Households conducted by the University of Wisconsin-Madison ${ }^{7}$ implemented in the United States; the Gansu Survey of Children and Families coordinated by the University of Pennsylvania ${ }^{8}$ and implemented in China; the National Mental Health Services Survey of the United States Department of Health and Human Services ${ }^{9}$ implemented across the United States, and; the Transnational Child-Raising Arrangements projects coordinated by Maastricht University Faculty of Arts and Social Sciences ${ }^{10}$ implemented in Ghana, Angola, and Nigeria. The survey also collected information on the migration histories of household members. Questions in this section were informed by country-specific versions of the Labour Force Survey (LFS) designed by the International Labour Organisation ${ }^{11}$, the Living Standards Measurement Survey (LSMS) designed by the

\footnotetext{
${ }^{5}$ More information available at: http://www.younglives.org.uk/

${ }^{6}$ More information available at: http://www.rcgd.isr.umich.edu/pgc/home.htm

${ }^{7}$ More information available at: http://www.ssc.wisc.edu/nsfh/home.htm

8 More information available at: https://china.pop.upenn.edu/gansu-survey-children-andfamilies-gscf

${ }^{9}$ More information available at: http://info.nmhss.org/

${ }^{10}$ More information available at: http://www.tcra.nl

${ }^{11}$ More information available at: http://www.ilo.org/dyn/lfsurvey/lfsurvey.home
} 
World Bank ${ }^{12}$, and the Demographic and Health Survey (DHS) of the DHS Program ${ }^{13}$.

The survey was tested, translated into local languages (Romanian, Russian, and Georgian) and adjusted before being piloted in each of the implementation countries. The survey is available on the project website in all implementation languages ${ }^{14}$. In both Moldova and Georgia, survey companies were subcontracted to help refine the sampling frames for the community and household surveys, to suggest revisions to the translated survey items, to pilot the survey and suggest necessary adjustments, to implement the survey, and to provide supporting information such as sampling weights upon completion of the survey. The household surveys in both Moldova and Georgia were implemented using computer-assisted personal interviewing (CAPI) methods. The open-source Census and Survey Processing System (CSPro) survey software designed by the United States Census Bureau and ICF International was used as the platform for electronic data collection. In conjunction with two of the IfW project staff, I helped programme the electronic survey into CSPro. Data collection in Moldova was overseen by staff from IfW, and I oversaw the data collection in Georgia. This entailed training subcontracted survey companies on the use of CSPro as well as on issues such as data storage and confidentiality, data export, and data management. I also attended pilot interviews in Georgia and accompanied staff into the field in the first three weeks of survey implementation, after which I remotely managed all incoming data and advised implementation staff at the survey company about necessary adjustments to survey behaviour.

The household survey was implemented in Moldova between September 2011 and March 2012 and in Georgia from March to December 2012. The survey was implemented in all regions of both countries except for the semi-autonomous region of Transnistria in Moldova and the de facto independent regions of Abkhazia and South Ossetia in Georgia. Both surveys were drawn from a random stratified sample, with oversampling of target population groups (children, elderly, and

\footnotetext{
12 More information available at: http://econ.worldbank.org/WBSITE/EXTERNAL/EXTDEC/EXTRESEARCH/EXTLSMS/0,,co ntentMDK:21478196 menuPK:3359066 pagePK:64168445 piPK:64168309 theSitePK:3358997 ,00.html

${ }^{13}$ More information available at: https:/www.dhsprogram.com/

14 The project website can be found at: http://mgsog.merit.unu.edu/research/moldova_georgia.php.
} 
migrants). Only households with a child under the age of 18, an elderly individual over the age of 60 , or both types of population were sampled.

In Moldova the sampling frame was provided by the Moldovan National Bureau of Statistics from the quarterly Moldovan LFS. The LFS sampling frame is based on the population census augmented by the list of electricity consumers and is updated every two years. Within this sampling frame, the sample is stratified according to geographic region and population size of the locality ${ }^{15}$. After all household surveys were collected for the CELB-MD/GE project, sampling weights were calculated by a representative of the Moldovan National Bureau of Statistics, which allows for extrapolation of results onto national level and adjusted to the true distribution of sample characteristics across the entire population. The final survey sample included 3,548 households containing 12,262 individuals.

In Georgia an appropriate sampling frame had to be created for this project, as the last national census was conducted in 2002, and no other appropriate and contemporaneous sampling frames were suggested by the state statistical office (GeoStat) during bilateral meetings. A sampling frame was elaborated on the basis of electoral districts. The country was first divided into ten regions, which were then split into six strata each on the basis of settlement size and type. The strata were then divided into primary sampling units (PSUs) based on electoral districts - the most recently-updated administrative subdivision. Data collection occurred in two stages: in the first stage, surveyors conducted a listing exercise whereby information on the composition and features of all contacted households were collected, regardless of eligibility for the survey. This data was then used to calculate the proportion of households with particular characteristics (e.g., a current migrant, a child, an elderly person). Interviews were conducted with eligible households following the random walk method. In the second stage of data collection, quotas were set for certain types of households, such as those with a migrant. Identification of households still occurred at random, but surveyors interviewed households with only those characteristics determined by the quota. Following data collection, probability weights were calculated based on the distribution of population characteristics derived from the first data collection phase. In Georgia the final survey sample included 4,010 households containing 16,212 individuals.

15 Methodological documentation on the LFS and its sampling can be found at: www.statistica.md/public/files/Metadate/alte/Metodology_AFM.pdf. 
The detailed data generated by the household surveys provided an excellent snap-shot of the lives of respondents, and the method advantageously provided concrete, comparable indicators of key concepts (like child psychosocial health) that had been largely absent from previous studies conducted in the region. The data and its implied analytical methods have limits, however: complex phenomena-like the development of child psychosocial health within family ecosystems - can be difficult to understand from decontextualized survey data.

\subsection{INTERVIEWS}

To better understand what types of questions to include in the survey or econometric models, and to better under the results of such models, I also conducted interviews with experts and the families of migrants in Moldova and Georgia. I carried out expert interviews with representatives from international organisations (e.g., UNICEF, Save the Children), local NGOs active in child protection and advocacy, orphanages, government ministries, university departments that had conducted studies on children in migrant families, and family counselling and child psychiatry clinics. Some of these interviews were conducted while the household survey was being designed to ensure that relevant questions were included in the survey, and others occurred during and after survey implementation about topics such as family roles and responsibilities, local perspectives on child health, and support mechanisms available at local level that were used by the children of migrants. An overview of expert interviews is available in Table A.1 in Appendix A.

I also conducted semi-structured interviews with the families of migrants in Moldova and Georgia to better understand the household survey data; these interviews were particularly helpful for me to understand issues such as family composition and household roles given the limited amount of English-language literature on these topics. I conducted interviews in 35 households in Moldova in May and June 2012 and in 34 households in Georgia in October and November 2012. Interviews were generally conducted in the homes of respondents with the primary caregivers of children living in the household about topics such as the roles and responsibilities of different family members within the household and perceptions of the child(ren)'s experience of separation though migration. Sample interview guides can be found in Appendix B; key characteristics of the in-depth 
interviews can be seen in Table C.1 in Appendix C. All interviews were conducted with the assistance of a local interpreter. Almost all interviews were recorded with respondents' permission, transcribed in the original language, and then translated to English.

The data collected through interviews were not formally analysed and used in any of the analytical chapters but were instead used as reference material to guide analytical decisions or to help place survey results in proper context. The interviews were helpful for me to understand the results that emerged from the quantitative analyses, particularly when those results deviated from those of past studies. For example, the analyses revealed several factors that strongly predicted results, including the gender of the subject (i.e., the migrant in Chapter Five or children in Chapters Six and Seven), household composition, and the relationship between the migrant and children in the household. All of these factors related to country-specific family settings, which could not be inferred or understood from survey data alone.

\subsection{DATA LIMITATIONS}

The process of collecting data encountered some problems that affected the quality of resulting data and its subsequent analysis. The collection of household survey data was particularly challenging given three types of problems: sampling, implementation methods, and content of the data collection tool.

In both Moldova in Georgia, households were eligible to participate in the survey if they contained household members under the age of 18 or over the age of 60. Households without any members of these ages were excluded from the survey, which could introduce a potential source of bias when assessing trends such as migration, as a key demographic group (individuals of prime working age) with potentially higher migration propensities are only included in the sample if they resided with children or the elderly. The survey also could not capture households in which all members had relocated abroad, leaving no respondents in the origin county to sample. The absence of these two groups could potentially affect the representativeness of the data, but their omission may not significantly affect the representativeness of the analysis, because in both countries only relatively small shares of the population live in households without children or elderly individuals, and a relatively small proportion of migrants from both 
countries relocate as whole family or household units, with the majority of migrants emigrating as single workers.

Two further challenges were encountered during implementation of the survey, which contributed to high rates of missing data in specific survey modules. The survey was multilevel, with some information asked for the household as a whole, some for each individual within the household, and other information only for specific household members. The survey was divided into six modules according to topic and unit of analysis, and different modules could be answered by different respondents, based on who the most-knowledgeable person in the household was for that module. The most-knowledgeable respondent was generally the household head or his/her spouse, but this individual was not always able to recall information accurately, particularly information related to absent household members. Inaccurate recall was especially problematic in the migration histories module, which collected information on the migration experiences of every household member, including specific details such as how the first migration episode was financed, why the individual decided to migrate for the first time, and if a current migrant has legal residency status. Limited knowledge about the details of other household members' migration histories, particularly of individuals who resided abroad at the time of the survey and could therefore not confirm information, resulted in some missing information in the migration module, which limited the number of observations that could be included in the analysis in Chapter Five.

The multilevel survey design was also technically challenging. The survey was implemented using CSPro, an electronic survey implementation tool designed for implementation of population censuses, which are typically less complex than the CELB-MD/GE survey. Within CSPro, one unified survey featuring all modules could not be programmed, as some modules required a sub-roster or had unique skip logic. Each module was essentially a separate electronic "file" that had to be unified with all other modules collected from the same household after implementation. To correctly unify the survey modules into a single household survey, each module had to contain a common set of identification codes comprised of district, PSU, and household identification codes. If any of these codes were inaccurately entered by an enumerator, modules may not be correctly matched as belonging to the same household. Where a household was found to be missing a module, the data manager (myself for data collected in Georgia and a colleague from IfW for data collected in Moldova) attempted to identify potential 
matches manually. Not all modules could be matched, however, due to other enumerator errors such as incorrect names or ages of household members, which were common variables used to confirm the match of individual-level records. Mismatched household identification codes were most problematic in Georgia for the modules on children. During the analysis in Chapter Seven, it became clear that some data about children was missing, likely because the module for caregivers either had never been implemented or could not be matched because of incorrect household identifiers. Missing data reduced the final analytical sample significantly; as is discussed in Chapter Seven, that data did not seem to be missing systematically, but it did reduce possible forms of analysis because there were not enough observations with specific characteristics.

The content of the survey itself also introduced some limitations to the following analyses, particularly in terms of the measurement of child psychosocial health. The Strength and Difficulties Questionnaire (SDQ), which is described in greater depth in Chapters Six and Seven, was used to collect information on child psychosocial health. Caregivers of children between the ages of four and 17 completed the SDQ for each child under their care, and children aged 11 to 17 also completed the SDQ themselves. Collection of SDQ data from both caregivers and children could enable valuable comparison, but it is most useful when accompanied by a teacher-completed assessment, which enables triangulation of data. In both Moldova and Georgia, caregiver- and child-SDQ assessments seldom fully agreed, but there is no method to judge which is more accurate or representative. The caregiver-rated SDQ data have been used in the analyses that follow, and this data may either over- or under-estimate problematic outcomes given respondent-specific biases. Jensen et al. (1999) note that children and caregivers seldom report the same information in assessments of child mental health, and some characteristics - the child's age, child and caregiver gender, and caregiver depression-can result in systematic differences between reports. These characteristics are all controlled for in the quantitative analyses in Chapters Six and Seven, but possible systematic differences in reporting may still remain between different respondents such as male and female caregivers.

Another SDQ-specific limitation relates to its application in Georgia. The original SDQ tool is available in English; other language versions must be developed by individual research teams with the approval and participation of staff from Youth in Mind (the developers and copyright holders of the SDQ). In Moldova, the SDQ was implemented using the Romanian and Russian translations 
that were approved by Youth in Mind and posted for public use on their website. In Georgia, no Georgian translation had yet been made when the project started, and project staff in Georgia translated the tool from English to Georgian without guidance from Youth in Mind. It was only after the survey had been implemented that this oversight was recognised, after which Youth in Mind was contacted to discuss the translation. A revised Georgian instrument ${ }^{16}$ was drafted in cooperation with Youth in Mind, which modified the Georgian version of the SDQ implemented in the CELB-GE survey. After this revision, Youth in Mind gave permission to use the data generated from the previously-unapproved Georgian SDQ translation. As the wording of some questions was changed for the approved Georgia version, however, Youth in Mind requested that any analyses of the Georgia data avoid indicating score ranges and score bandings, as this could signal normative score thresholds. For this reason, different forms of analyses had to be conducted in Georgia and Moldova, which disallows one-to-one comparisons of SDQ outcomes between the two countries.

The use of SDQ data also differed in Moldova and Georgia because of the distribution of SDQ scores across the countries. As is discussed in more depth in Chapter Six, the SDQ is comprised of five subscales: emotional symptoms, conduct problems, peer problems, hyperactivity and inattention, and prosocial behaviours. Within each of these subscales, the lowest 80 percent of scores would indicate low risk, the next ten percent borderline or middle risk, and the highest ten percent, high risk (Goodman, 1997). In some of the subscales in Moldova, however, a greater proportion of scores than would be expected fell into the high- and middlerisk score ranges, which could suggest that the particular subscale items needed to be better calibrated to reflect local norms. For this reason, analyses in Chapter Six used the emotional symptoms and conduct problems scores, two subscales in which the answer distribution approximated the distribution patterns seen in other country samples. In Georgia, scores in each of the subscales were distributed according to the anticipated pattern, thus the total difficulties score-an aggregate measure of psychosocial health based on four of the five subscales-could be used in analyses. Given differences in the main independent variable (emotional symptoms and conduct problems scores or total difficulties scores) across the countries as well as the expression of these outcomes (as binary or continuous values), the same forms of analyses could not be used in Moldova and Georgia.

16 The approved Georgian translation of the SDQ is now available on the SDQ website at http://www.sdqinfo.org/py/sdqinfo/b0.py. 
The data resulting from interviews also have some weaknesses relating to the respondent selection and interview implementation process. The interviews I conducted with the families of migrants in Moldova and Georgia aimed to help me understand the environments in which children grow up; I wanted to know how care for children was organised within families, what expectations respondents held about appropriate ways for children to act, and respondents' perceptions about how migration can change how children grow up, among other trends. Opinions such as these may be influenced by migration, thus the understanding I gained about "typical" families may not be typical at all and may instead be specific to families that have first-hand experience with migration. Similarly, in both countries the majority of the respondents I interviewed were women; only six of 37 respondents in Moldova and two respondents of 35 in Georgia were male. Men and women are likely to have different perspectives related to their differing roles in households and families, and my limited inclusion of male respondents may have limited my understanding of how families accommodate the migration of one of their members.

\subsection{ANALYTICAL STRATEGY}

The core analytical chapters of this dissertation rely on quantitative analysis of the household survey data. Econometric methods appropriate for use with cross-sectional survey data are used for the analyses presented in Chapters Five, Six, and Seven. In Chapter Five, the odds of men and women being international migrants, first in general and then to specific destination regions, are predicted using ordered and multinomial logistic regression. In Chapter Six, the psychosocial health outcomes of children with a mother, father, or both parents living abroad are compared to those of children residing with both parents in Moldova using the probit regression method. The results of the probit models are transformed into marginal effects, which indicate the probability a child has of attaining abnormal psychosocial health outcomes given a particular set of covariates. In Chapter Seven, the psychosocial health scores of children with a mother, father, grandparent, or other family member living abroad are compared to those of children residing with both parents in Georgia using the sequential quantile regression method. This method makes use of the entire conditional score distribution by estimating how different covariates, such as family-member 
migration, correspond to changes in the psychosocial health scores of children with low scores (those in the lowest $20^{\text {th }}$ percentile), median scores (those in the $40^{\text {th }}$ and $60^{\text {th }}$ percentile), or high scores (those in the $80^{\text {th }}$ percentile). Additional details of the specific data and methods used in each chapter are described in sections 5.4 (for Chapter Five), 6.3 (for Chapter Six), and 7.3 (for Chapter Seven). 
Emigration from both Georgia and Moldova-and the potential changes it can introduce to the families who remain in the country of origin-strongly reflects the economic, political, and social contexts of each country. Given the strong connections among migration, its drivers, and its implications, understanding the larger context in which emigration has occurred is essential. This chapter profiles Moldova and Georgia to achieve two ends: 1) to contextualise the migration process itself, providing better insight into why emigration has occurred in such large numbers, and 2) to provide insight into how migration fits within existing family systems and childcare environments.

The first section in this chapter examines the economic and political context from which large-scale emigration arose in the immediate post-Soviet years before describing the current economic situation in each country. The second section provides an overview of how emigration patterns have evolved in the postSoviet years. The third section describes family structures, childcare environments, and how migration interacts with traditional notions of gendered work. The fourth and final section considers the commonalities and differences between the two case study countries, illustrating the value of engaging two countries that have undergone similar mobility transitions within markedly dissimilar family cultures.

\subsection{THE POST-SOVIET TRANSITION \& LEGACY CHALLENGES}

Following the collapse of Soviet Union in 1991, both Moldova and Georgia along with the other former Soviet republics experienced a "triple transition", the simultaneous processes of market reform, nation building, and state consolidation (Offe, 1991). Coupled with the dissolution of barriers to personal mobility, each of these transitions contributed to large-scale migration that began in the worst years of the post-Soviet transitional crisis and has continued relatively unabated since. 


\subsubsection{Economic \& Political/Civic Transition}

In both Moldova and Georgia, the decade following the collapse of the Soviet Union was characterised by severe economic contraction and high rates of poverty. The Moldovan economy steadily declined until 2000, when GDP was 32.2 percent of the 1989 level (Fidrmuc, 2003; Panţîru, Black, \& Sabates-Wheeler, 2007). The Georgian economy began recovering earlier, in 1995, but the magnitude of decline was greater: in 1994 Georgia's GDP was just over one-quarter of the 1989 level (Fidrmuc, 2003). Limited economic production was coupled with problems such as currency instability and hyperinflation, which in Georgia averaged 60-70 percent per month between 1993 and August 1994 (Papava, 2013). In both countries, this situation contributed to pervasive poverty: 71 percent of the Moldovan population (IMF, 2006) and 60 percent of the Georgian population (IMF, 2003) lived below the poverty line in 1999.

The protracted recessions experienced by both countries occurred simultaneously with state/nation-forming processes that were tumultuous and often violent (Offe, 1991; Kuzio, 2001). In Moldova, the territories of Transnistria and Gagauzia both declared independence from the forming Moldovan state in 1990 (Roper, 2001). A power devolution agreement was agreed with the leadership of Gagauzia in 1995, which resulted in the territory receiving autonomous status, but reconciliation with Transnistria has yet to occur. Open civil war between Moldova and Transnistria began in March 1992, and while a ceasefire was concluded in July 1992, the status of the territory has remained unresolved. Transnistria now essentially functions as an independent state with limited prospects for reunification with Moldova (Popescu, 2005).

Consolidation of the Georgian state was similarly undermined by several interrelated conflicts that are collectively called the "Georgian civil war": the civil unrest and subsequent coup that overthrew the government of Zviad Gamsakhurdia in 1991/2 and the conflicts over the breakaway territories of Adjara, South Ossetia, and Abkhazia (Fawn, 2012; Tuathail, 2009). Following the violent coup d'état that saw Gamsakhurdia, Georgia's first democratically-elected

president, removed from power, fighting between members of opposed political forces broke out in Tbilisi, and a period of rampant corruption, power struggles, energy outages, and lawlessness ensued (Wheatley, 2005; Kabachnik, 2012). 
Conflicts over three semi-independent regions-Adjara, South Ossetia, and Abkhazia-occurred at the same time. Adjara retained the status of an autonomous republic within Georgia following the dissolution of the Soviet Union in a relatively peaceful process, but the territories of South Ossetia and Abkhazia have yet to be reconciled with the rest of the Georgian state. South Ossetia declared independence in September 1990, which led to a bloody civil war that resulted in the ethnic cleansing of both ethnic Georgians and ethnic Ossetians, the internal displacement of around 23,000 Georgians within Georgia, and the displacement of approximately 100,000 ethnic Ossetians who sought refuge in Russia (Wheatley, 2005; HRW, 1996). A ceasefire was agreed in 1992, but open conflict broke out in both 2004 and 2008, with the latter escalating into war between Georgia and Russia (called the "August War"). In August of 1992, the parliament of Abkhazia essentially declared Abkhazia as an independent, sovereign state; Georgian troops tried to regain military control over the territory, and by September 1993, more than 10,000 people had been killed in the conflict (Popescu, 2010). Up to half of the population of Abkhazia had been displaced, including ethnic Abkhazians, Georgians, Greeks, and Armenians (Coppieters, 2004). By the end of 1993, Georgian forces had been expelled from Abkhazia, and the territory has remained beyond Georgian control since, despite periodic attempts to reintegrate some parts of Abkhazia into Georgian territory (Blakkisrud \& Kolstø, 2012). The August War also brought renewed conflict over Abkhazia, leading to new internal displacement and further complicating the return of IDPs displaced from earlier conflicts (Kabachnik et al., 2012).

\subsubsection{Contemporary Economic Situation}

In both Moldova and Georgia, the economic and political difficulties experienced in the immediate post-Soviet years have in many ways remained unresolved. Both countries have faced persistent economic difficulties and ongoing political strife that have played a role in encouraging and sustaining significant outward population movements. Key information on contemporary aspects of Moldova and Georgia can be seen in Figures 4.1 and 4.2. 
Since independence, Moldova has remained the poorest country in Europe in terms of gross domestic product (GDP) per capita, and poverty has remained high, with 16.6 percent of the population living below the national poverty line ${ }^{17}$ in 2012 (NBS, 2014). Low GDP per capita reflects the ongoing struggle to modernise the Moldovan economy, which is still largely agrarian due both to the availability of arable land and the lack of population in urban centres to support the development of large-scale manufacturing (World Bank, 2011).The lack of reconciliation with the breakaway region of Transnistria has further challenged economic growth, as the region is home to most of the heavy industry and energy production infrastructure in Moldova (Hensel \& Gudim, 2004). Economic opportunities outside of the agricultural sector are relatively scarce, and nearly 30 percent of total employment is considered vulnerable, involving work in low-wage functions with minimal security (UNDP, 2014). This is reflected in the structures of incomes: as of the first quarter of 2014, the National Bureau of Statistics of Moldova estimated that the average per capita monthly income was 1,650 lei (approximately US\$124.66), of which just over 42 percent was contributed by wages from employment. Over ten percent of average individual monthly income was estimated to come from self-employment in agriculture, 20 percent from social protection payments such as pensions and child allowance, and an additional 17 percent from remittances (NBS, 2014).

The economic situation in Georgia is similar to that of Moldova. Despite significant economic growth over the last decade and economic liberalisation policies that attracted large flows of foreign direct investment, material poverty still affects a large share of the population. In 2013, 26.9 percent of the population lived below US $\$ 2$ per day, and 17.9 percent lived below US $\$ 1.25$ per day (UNDP, 2014). The scale of poverty amid economic growth reflects significant income inequality ${ }^{18}$, particularly between rural and urban areas, which can be partially attributable to lack of secure employment opportunities.

17 The absolute poverty line is based on value of food expenses equivalent to 2282 $\mathrm{kcal} /$ person/day, and the actual lei value of the poverty line is not provided by the NBS.

18 The income Gini coefficient for Georgia is .421 (UNDP, 2014). 


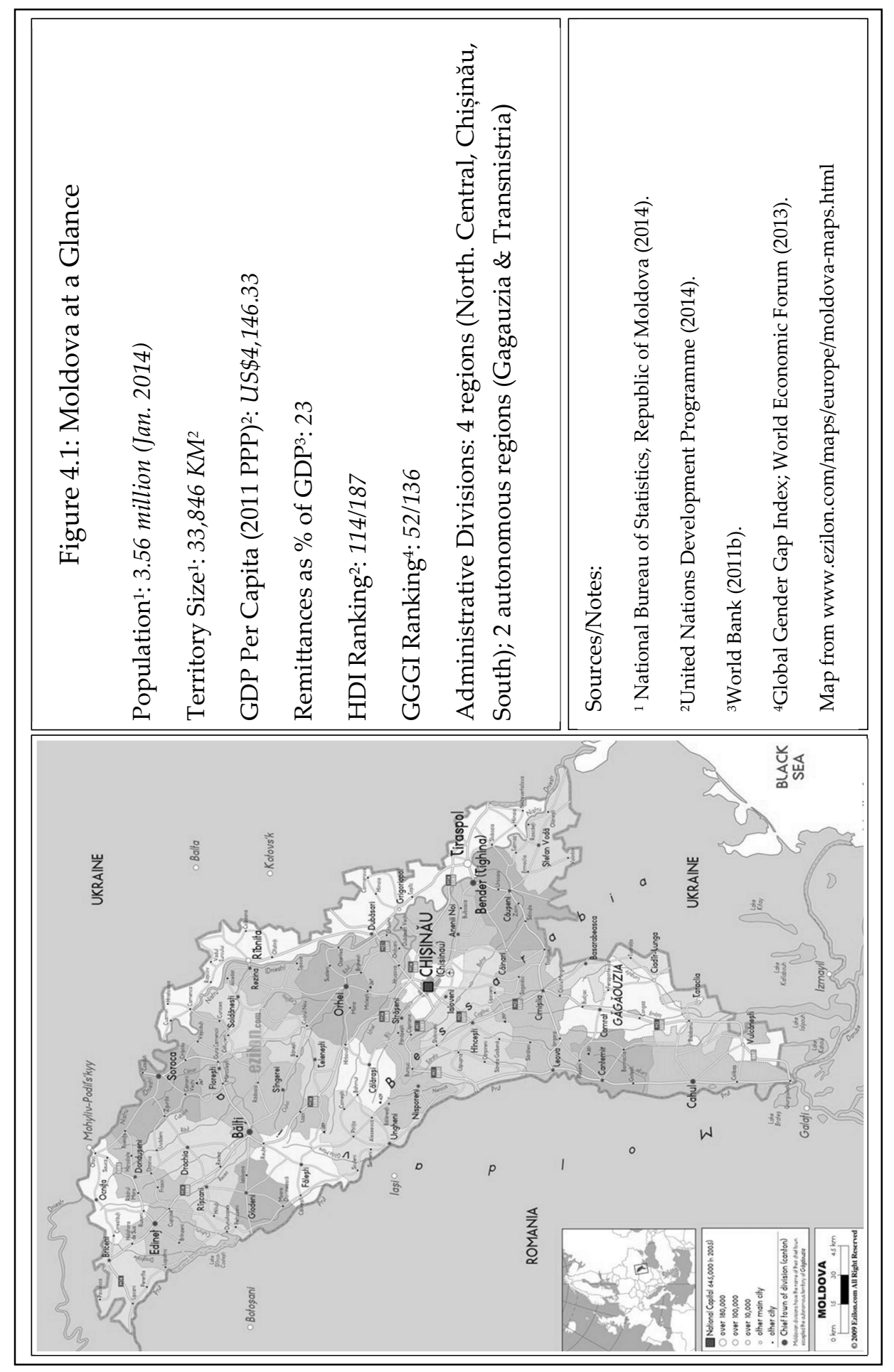




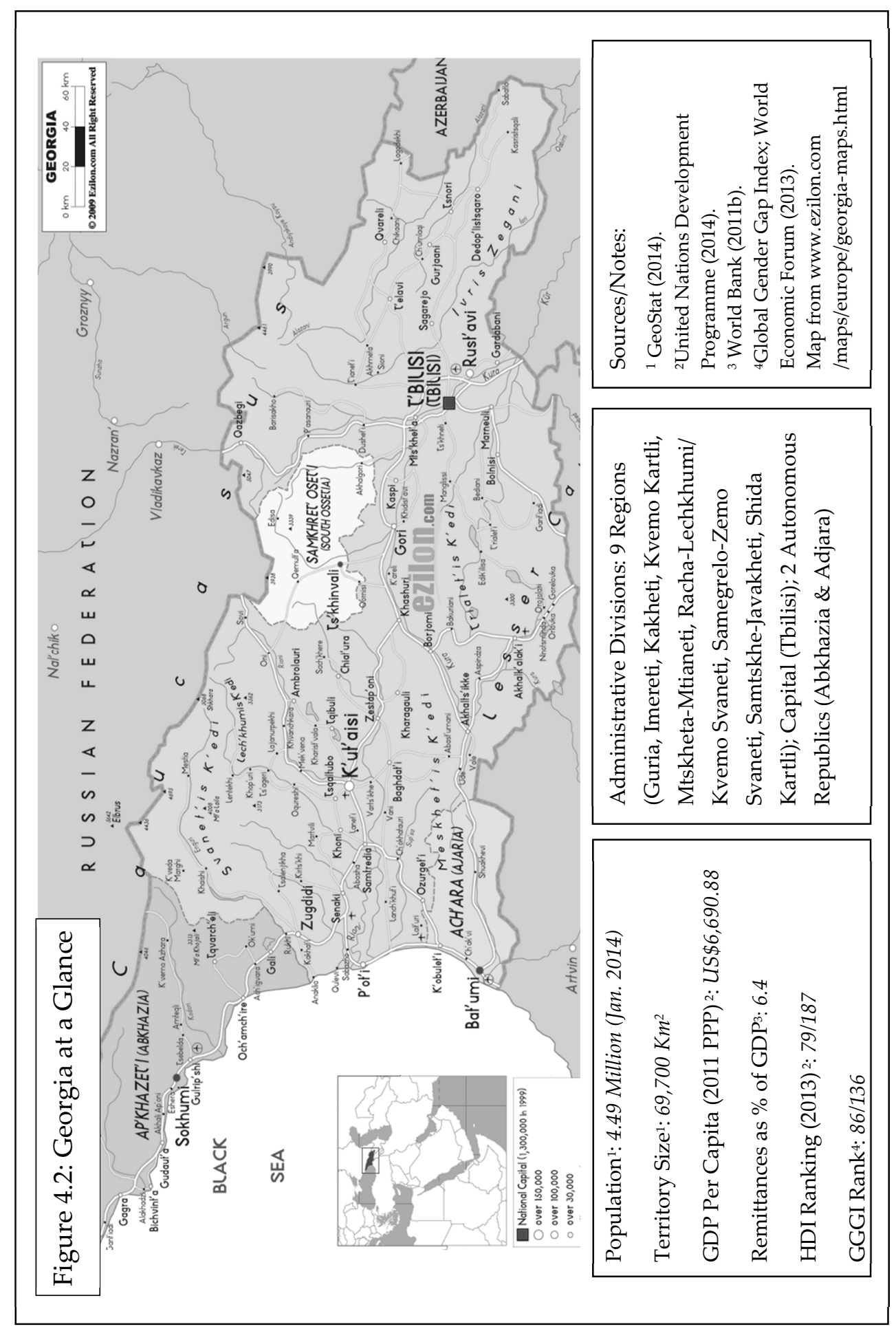


Unemployment appears relatively low at 15 percent among the adult population aged 15 and older in 2013 (UNDP, 2014); such statistics disguise the tenuous economic opportunities the population faces by including the selfemployed, such as individuals working in subsistence agriculture, who constituted 64 percent of all employed persons in 2011 (Gassmann, Berulava, \& Tokmazishvili, 2013). Most employment is considered vulnerable, with 60.6 percent of all employment characterised by low wages and minimal job security (UNDP, 2014). The poor quality of employment is reflected in the reliance of most households on insecure and volatile income sources. In 2013, the Georgian state statistical services (GeoStat) estimated that on average, only 37 percent of monthly per capita incomes were derived from wages from employment. Around 16 percent were derived from social assistance and other benefits, and 13 percent were from "gifts" - likely transfers sent within families or internal remittances ${ }^{19}$. An additional 13 percent was derived from borrowing or withdrawal from savings (GeoStat, 2014). The economic situation is also impacted by ongoing territorial conflicts. Georgia is now divided into nine regions (Guria, Imereti, Kakheti, Kvemo-Kartli, MtskhetaMtianeti, Racha-Leckhumi and Kvemo Svaneti, Samegrelo and Zemo Svaneti, Samtskhe-Javaketi, and Shida Kartli), the capital (Tbilisi), and two autonomous republics (Adjara and Abkhazia). The central Georgian government has no control over the Autonomous Republic of Abkhazia, the territory of the former South Ossetian Autonomous Oblast, and only limited administrative control over the Autonomous Republic of Adjara.

Throughout the post-Soviet years, the combination of conflict, economic decline, and poverty encouraged the emigration of large portions of the population from both countries. Over the last two-and-a-half decades, both Moldova and Georgia have lost more than 20 percent of their populations to migration, a trend with clear implications for the children and families who remain.

${ }^{19}$ International remittances constituted a negligible share of income, at less than one percent of monthly per capita income on average. 


\subsection{POST-SOVIET MOBILITY TRENDS}

\subsubsection{Eras of Emigration in the Post-Soviet Period}

Since 1990 both Moldova and Georgia have experienced three distinct "eras" of emigration characterised by different kinds of population outflows. The first era, which spanned from 1990 to around 1995, was notable for high rates of ethnic repatriation, conflict-induced displacement, and the relocation of whole families. Significant shares of emigrants in the first five years after independence were thought to be ethnic minorities returning to their (ancestral) homelands after having been moved as part of population resettlement programmes in the Soviet era (Cantarji \& Mincu, 2013; CRRC, 2007). Some of this movement was voluntary, but some former Soviet Union states (FSUs) forcibly repatriated ethnic minority populations as a way to restore a perceived historical norm of national or ethnic homogeneity. The forced return of ethnic Russians to the Russian Federation often occurred first, but ethno-nationalist policies in particular FSUs often targeted other groups whose presence within the territory was perceived as being a relic of colonisation (Tishkov, Zayinchkovskaya, \& Vitkovskaya, 2005). In Georgia, nationalistic rhetoric encouraged many members of the Azeri and Armenian communities to emigrate, and the conflicts over South Ossetia and Abkhazia displaced large proportions of the population both internally and internationally (Gugushvili, 2013; HRW, 1996). Much of the emigration in this era involved the permanent resettlement of whole families abroad, with only limited return occurring. Estimates of the size of emigration during this era are limited and informal. In Moldova, 33,000 people were thought to have emigrated just between 1992 and 1993 (Cantarji \& Mincu, 2013), and in Georgia up to 650,000 people were estimated to have emigrated by 1995, many of whom were ethnic Russians, Greeks, and Jews destined for an ancestral homeland (CRRC, 2007).

The second era of emigration, which began in the mid-1990s and ended around 2004, was characterised by the increasing emigration of individuals seeking temporary work abroad (Panțîru et al., 2007; Gugushvili, 2013). Emigration rates peaked and dipped irregularly during this time in response to both economic and political developments. In Moldova, for instance, significant spikes in emigration occurred in 1999 and 2000 in response to the Russian economic crisis. By the early- 
2000s it was estimated that approximately one-third of all households had experienced the emigration of a family member (Panţîru et al., 2007), and by August 2004, 600,000 migrants were thought to work abroad-over 37 percent of the entire economically-active population (Penger, 2009). The pace of emigration from Georgia was more consistent in response to ongoing political crises and conflicts, and by 2002 it was thought that approximately one million people had emigrated from Georgia (Labadze \& Tukhasvili, 2013). Gendered (and classed) emigration flows from both countries began emerging during this era. Among Moldovan emigrants, it was primarily men from larger families in the rural and poorer areas of the country who emigrated to the CIS region, mostly toward Russia where they worked in the construction sector. Migrants from better-off and bettereducated urban households tended to migrate more toward south-western Europe, namely to Italy and Spain where women in particular could work in the care or tourism sectors (Penger, 2009). A similar trend appeared in Georgia: male migrants predominantly from rural areas were destined for the CIS, and an equal mix of male and female migrants from urban areas were destined for European countries such as Greece and Germany (Labadze \& Tukhasvili, 2013; CRRC, 2007). Some emigration was also motivated by education, however, with urban, elite families sending their children to study abroad in countries such as the United Kingdom, Germany, and the United States during this period (CRRC, 2007).

The final era of mobility, which began in the mid-2000s and is still ongoing, has been characterised by relatively stable rates of (circular) emigration, some permanent return, and the expansion of migration flows beyond the CIS (Cantarji \& Mincu, 2013; Gugushvili, 2013). In Moldova this era has seen increased emigration of slightly older women to EU countries and the continued emigration of men primarily to Russia. A significant share of migrants of both genders are considered either seasonal or circular workers, with seasonal work more common among men working in the construction sector in Russia (Görlich \& Trebesch, 2008). In Georgia, net migration rates were strongly negative until 2004, after Mikheil Saakashvili's transition to power with the 2003 Rose Revolution. The governance transition signalled both political and market reforms that reinstated some confidence in the Georgian economy and political system, incentivising some Georgian migrants to return (CRRC, 2007; Gugushvili, 2013; Labadze \& Tukhasvili, 2013). The net migration rate was positive in some years since 2004, but emigration is still thought to be sizable (Gugushvili, 2013). 
Both past patterns of emigration and more contemporary shifts in conditions in both origin and destination countries have contributed to large and diverse populations of emigrants from Moldova and Georgia. By 2010, 21.5 percent of Moldova's population was estimated to reside abroad, with the largest communities in the Russian Federation, the Ukraine, Italy, and Romania (World Bank, 2010). The majority of migrants are thought to be male, with men representing 58 percent of the migrant stock in 2008 (Salah, 2008) and over 63 percent of outgoing migrants flows in 2010 (IOM, 2012). Women, however, accounted for the largest share of migrants in particular destinations, as in Italy, where they constituted more than 68 percent of all Moldovan migrants (IOM, 2012). Differences in the proportion of men and women among international migrants can also be seen by age cohort, with women constituting 60 percent of all migrants aged 65 or older and 55 percent of migrants in the 20-64 age cohort in 2010 (ICPD, 2012).

A similar trend can be seen among Georgia migrants. In 2010 over onequarter of Georgia's population was thought to reside abroad, the largest number of which resided in the Russian Federation, Armenia, the Ukraine, Greece, and Israel (World Bank, 2010). Men represented a greater share of migrants who left in the early post-Soviet period, but with progressively worsening political ties between Georgia and Russia-including the abolition of visa-free travel between Georgia and Russia in December 2000 and the periodic cessation of visa issuance to Georgians, as occurred following the 2008 conflict-men have encountered fewer legal opportunities for work and stay in their primary destination country (Hofmann \& Buckley, 2013). At the same time women have experienced greater opportunities to emigrate to countries with growing home- and eldercare markets, including Greece and Italy in the EU and countries such Turkey and Israel beyond the EU (IOM, 2009; Labadze \& Tukhashvili, 2013). The majority of labour migrants (i.e., those who emigrated for work purposes and not for reasons such as study or family reunification) of both genders are thought to reside and work irregularly in their destination countries; up to three-quarters of all labour migrants working in a country other than Turkey, where residence permits are not needed as long as migrants periodically return, have been estimated to reside without proper legal documentation (Labadze \& Tukhashvili, 2013).

Based on recent emigration patterns and changing geopolitical relations, emigration from both Moldova and Georgia could be directed more towards the 
EU and beyond. Increasing economic and political integration of both countries with the EU may encourage greater emigration to Europe. Both Moldova and Georgia are Eastern Partnership countries and have agreed on action plans with the EU in the framework of the European Neighbourhood Policy, which includes provisions for visa facilitation and mobility partnerships (Cantarji \& Mincu, 2013; Labadze \& Tukhashvili, 2013). Moldova has moved closer to this goal: as of April 2014, Moldovan citizens with biometric passports no longer need visas to enter the Schengen area. In June 2014, both Moldova and Georgia signed Association Agreements with the EU, which provide frameworks for bilateral relations (including deep and comprehensive free-trade agreements) that could potentially prepare both countries for future EU candidacy (Rieker, 2014). Increasing cooperation with the EU has contributed to souring relationships with Russia, and the current conflict between Russia and the Ukraine may serve to further distance Moldova from Russia (Transnistria could potentially follow a similar path as Crimea). Migration to the CIS region may thus be expected to slow or taper off in the coming years, a prospect that would be made more likely given greater mobility to the EU.

\subsubsection{Links between Migration and Children Remaining in the Origin Country}

Given the origins and characteristics of contemporary migration flows and their potential future changes, three clear links between migration trends and the health of the children who remain in the origin country can be identified. First, the nature and scale of emigration has undergone several transitions over the postSoviet period, with each 'era' of migration bearing unique consequences for the family. In the years immediately following independence, a greater share of emigrants were likely to be whole families resettling abroad, either as part of forced or voluntarily ethnic repatriation movements or in response to conflict and insecurity. The dislocation of nuclear families through migration may be relatively less common among migrants who left in the earliest post-independence years. The second era of migration, from the mid-1990s to the early 2000s, is characterised by different forms of mobility. During these years, more single individuals began emigrating with the purpose of finding employment in countries such as Russia 
and the Ukraine, with men overrepresented among the emigrants who left during this period. Temporary return and serial migration may be more common among members of this cohort of migrants, resulting in a large number of families experiencing many short-term spells of physical separation. The third era of migration, which began in the mid-2000s and is still ongoing, has been characterised by limited permanent return of migrants from earlier cohorts as well as the continued emigration of short-term, seasonal, and circular migrants. The destination countries and characteristics of migrants have shifted in this era, however, with increasing numbers of women migrating to the EU for relatively long periods of time. As a result, a significant share of families will have experienced extended periods of absence, with some children experiencing the simultaneous absence of both a mother and a father (or the absence of multiple types of family members, including grandparents or siblings).

The second link between migration and children with migrant family members is connected to the peculiarities of specific migration corridors: high rates of temporary or serial migration for work in season-specific sectors such as construction and agriculture in neighbouring countries (namely Russia and Turkey) and high rates of irregular residence or work in countries of the EU (like Italy and Greece) imply limited opportunities for family reunification in destination countries. Among Moldovan migrants to countries of the CIS and Georgian migrants to Turkey, entry visas, residency permits, and work permits are not required for individuals staying for less than 90 days. Migrants are thus incentivised to return to their home countries on a regular basis. As many do not plan to permanently reside in the country of work and can visit their families at least four times a year, many have limited incentive to apply for family reunification (and no legal right to do so). Migrants in the EU who do not have the right to reside or work in specific destination countries face a similar yet more complex dilemma. Irregular migrants may face limited possibilities to travel between the country of origin and destination given high initial costs of migration (e.g., payment of a smuggler, purchase of a short-term tourism visa, travel agency fees) coupled with the fear that if they leave they will not be able to return. Irregular migrants often have neither the possibility to return for short-term visits nor to apply for family reunification in the destination country. Among migrants who reside legally in a country yet work illegally, family reunification is unlikely to occur if a migrant needs to meet a minimum income threshold, provide proof of income, or provide an employment guarantee. Despite some evidence that family 
reunification may be increasing among particular groups of migrants (such as Moldovan women in Italy and Spain who had their legal status regularised during amnesty campaigns, who hold Romanian citizenship, or who are otherwise entitled to stay), rates of family reunification are generally low and limited by both legal status and migrant desire for permanent settlement (Marchetti, Piazzalunga, \& Venturini, 2013).

A third and final link between the characteristics of contemporary migration flows and the family remaining in the origin country relates to the changing profiles of migrants. Over the past decade, the share of women among international migrants from Moldova and Georgia has risen, and with them the average age of emigrants has risen as well. This change reflects not only differences in the employment possibilities of women abroad (with many older female migrants, particularly in the EU, increasingly employed by individual households) but also increased possibilities for migration given the expansion of female-specific social networks into preferred destination countries. Whereas female migrants from Moldova are relatively young and more likely to be mothers, women from Georgia are often significantly older and more likely to be grandmothers (Marchetti, 2013). The gradual feminisation of migration implies that a growing number of families may experience the migration of female kin, whose absence may imply more difficult family-level adaptations given the specific, gendered nature of social reproduction.

\subsection{SOCIAL NORMS, GENDER, \& THE FAMILY}

This section provides information on how family life is arranged in both Moldova and Georgia, which necessarily implies a certain degree of generalisation. Even within relatively homogenous national cultures, families differ; presenting a set of values or traditions as "normal" or "average" across families can be a doubtful prospect. With that said, what is understood as "traditional" or "normal" has important implications for how a culture and a state perceives and addresses issues such as family organisation or female mobility. While recognising that there is variety in the norms and practices of individual families, this section describes the broad contours of family organisation within each country. 


\subsubsection{Moldova}

As in many European countries, the structure and form of families in Moldova has changed over the past few decades. Moldovan families have become smaller since the Soviet period: compared to a total fertility rate of 2.4 in 1990, the fertility rate between 2000 and 2012 remained below the population replacement rate at 1.3 children per woman (ICPD, 2012). Shrinking family sizes have been linked to three interrelated phenomena: 1) increased rural-to-urban internal migration, 2) increasing costs of child raising, and 3) international migration of women in prime child-bearing and rearing ages. Families tend to be larger in rural areas, where economic activities such as farming benefit from additional family labour. The cost of living is also cheaper in rural areas, with the cost of child care and education considerably higher (and the availability of paid employment lower) in urban areas. International migration has also been regarded as a reason for lower fertility rates. In 2013, around 40 percent of all emigrants from Moldova were estimated to be between the ages of 25 and 34, precisely the ages in which many families are started. Some authors propose that migration delays the age of first child birth, potentially corresponding to lower net fertility over time (Lupusor, Cenușă, \& Romaniuc, 2013).

The composition and size of families reflect not only fertility but also intergenerational residency norms. As of 2005, approximately 20 percent of Moldovan households were one-person households, and an additional 78 percent were nuclear-family households ${ }^{20}$ (ICPD, 2012). The limited proportion of complex households-those in which multiple generations live together or in which members of the extended family co-reside-reflects both Soviet and post-Soviet policies that (inadvertently) encouraged the dislocation of kinship networks. During the Soviet era, an encompassing and comprehensive pension scheme was established, which not only guaranteed minimum monthly income above the subsistence level but also entitled pensioners to free or subsidised services. One of the tenets of this scheme was that the burden of care should be shifted from individual families to the larger society, ensuring that elderly persons did not have to rely on informal social support mechanisms. Whereas eldercare had

${ }^{20}$ Defined as households in which parents and children reside as a family unit but not exclusive to two-parent households. A household with a mother and child, or an adult and one or both of his/her elderly parents, would also be considered nuclear family households. 
traditionally existed within a culture of "relatedness" with high levels of intergenerational dependency, the Soviet emphasis on cultivating a culture of "separateness" implied that the state became responsible for meeting the material needs of elderly persons, distancing elderly individuals from their children in the process. Compelled or centrally-planned movements of workers between rural and urban areas, and across Soviet states, also contributed to the dislocation of kinship networks (Grant, Falkingham, \& Evandrou, 2009). Contemporary residency patterns reflect this well, with only a relatively small proportion of households containing extended families.

Residency patterns belie the role of the extended family in family life, however. Since the collapse of the Soviet Union and subsequent changes to social protection benefits, informal support mobilised within kinship networks has become an essential short-term coping strategy for many families, particularly economically (OECD, 2008). Women have become increasingly reliant on members of the extended family to fill childcare gaps experienced with re-entry into the labour force, as childcare benefits and subsidies for childcare provision are generally too low for families to afford placing their children in paid childcare. Grandparents play a particularly strong role in supporting their adult children by supervising their grandchildren when needed (Robila, 2012). The reliance of young families on older kin for support in childcare is also signalled by the apparent preference for grandmothers to care for children following the emigration of both parents.

Within families, the delegation of some responsibilities follows "traditional", gendered patterns. Despite its usage in existing literature, however, it is surprisingly difficult to know what living in a "traditional family" actually entails $^{21}$. A publication on violence against women produced by the National Bureau of Statistics of Moldova in cooperation with UNDP, UNWomen, and UNFPA, for instance, asserts that "traditional gender roles and social norms" and "traditional family structures" all play a part in encouraging the marginalisation of

${ }^{21}$ Lack of English-language literature on the topic was particularly problematic. In much English-language literature, Moldovan culture is equated with Romanian culture, which assumes a level of cultural similarity that may not exist given different population mixes in each country. Given the lack of specific (academic) literature on Moldovan family structures, roles, and responsibilities, publications produced by international organisations on related topics (e.g., gender equality, domestic violence, and post-migration family life) provide some of the only accessible guidance. 
women, but what those "traditional" notions entail is never made explicit (NBS, 2011). What little information there is that specifies what "traditional" actually means often comes from studies on migration and its implications for the family. For instance, a 2008 UNICEF-sponsored study of 3,940 Moldovan families with and without migrant members outlined "traditional" gender roles quite well. The authors note that women with children are generally responsible for food preparation, maintenance of the home, helping children with homework, arranging children's medical visits, and supervising children during their free time-all activities within the domestic domain. The delegation of responsibilities along gender lines did not imply that child care falls exclusively to women, however, with over 54 percent of the (non-migrant) sample population reporting that both a mother and father acted as caregivers for their children. In contrast to "women's work", "men's work" is generally perceived to include activities performed outside of the home, with men responsible for agricultural work and earning money (Vladicescu, Cantarji, \& Jigău, 2008; Peleah, 2007). Peleah (2007) noted that the perception of men as "primary breadwinners" has remained relatively stable over time despite changes to other gender norms. Men in Moldova are considered responsible for ensuring the material well-being of the household, even if that responsibility entails emigrating for work abroad in the absence of viable opportunities in the local labour market (Peleah, 2007). Their presumed role as the primary breadwinner generally makes a man the de facto household head, who has "the vital role in the decision-making process."(UNICEF/CRIC, 2008; pp 56). Children also have specific roles or responsibilities that are allocated to them, which mainly involve studying, helping their parents with minor household chores, and helping in the care of younger siblings (UNICEF/CRIC, 2008).

Several studies have documented changes in the roles of different household members following migration. Vladicescu, Cantarji, and Jigău (2008), for instance, noted marked differences in the division of household tasks between households with and without migrants. Whereas only one percent of men coresiding with their wives reportedly cooked for the family on a regular basis, over 41 percent of men with a migrant wife assumed this duty. Care for children also shifted following migration, with childcare regimes appearing to differ the most for children with mothers abroad. Less than two percent of children without a parent living abroad were cared for exclusively by a father; in contrast, 46 percent of children with a mother abroad were cared for by a father. Fathers did not always take up childcare responsibilities, however, with 14 percent of children with a 
migrant mother reportedly left without a caregiver (compared to one percent of children without migrant parents and three percent of children with a migrant father) (Vladicescu, Cantarji, \& Jigău, 2008). The caregiving situation among children with both parents abroad was unfortunately not noted in this particular study, but other studies, such as that of UNICEF/CRIC (2008) noted that children are often placed with grandmothers or aunts if both parents emigrate. Female kin were also noted to assist fathers in childcare given the emigration of a mother. The roles and responsibilities of children were also reported to change following migration. A study among 75 children aged 10 to 18 who had experienced the migration of a parent found that children's tasks often radically shifted after migration. Whereas before children reported having to only periodically assist with household chores, some children took on larger tasks like daily cooking, food shopping, cleaning, and tending the fields. In some cases children had taken over the primary caregiving role for their younger siblings and occasionally for their ailing grandparents. The change in tasks appeared to be greatest for children living in rural areas with both parents abroad, as many became responsible for agricultural activities (including hoeing, planting seeds, weeding garden plots, harvesting, etc.). Interviews with staff of international organisations and NGOs revealed that tasks children took on were often not that challenging, but children were generally not prepared to perform them because family traditions discourage children from making independent decisions and taking on responsibilities beyond school (UNICEF/CIDDC, 2006).

The limited studies on the way household roles and responsibilities have changed following migration have been produced within a very particular public discourse that frames international migration as a fundamentally negative event for families. As noted by Panţîru, Black, and Sabates-Wheeler (2007; pp 20): “... a very common discourse in Moldova at present is that migration has led to a breakdown of family life, especially in the form of young children being left to fend for themselves as their parents migrate abroad." In Moldova, public perceptions of the effects of migration on children 'left behind' by migrant parents have been informed by strongly normative assessments, some of which arose from the international community working in Moldova. International organisations such as UNICEF and IOM were among the first to identify such children and to suggest that they be explicitly identified and targeted in policy and programme interventions. Much of the research on the 'left behind' promoted by these organisations has been externally commissioned and based on small-scale studies 
(see, for instance, UNICEF/CIDDC, 2006; UNICEF/CRIC, 2008) or have sampled children living in extraordinary situations of vulnerability (HAI/UNICEF/2008). The results of such studies are often thus not representative of wider groups of children who have experienced parental migration, but the negative consequences of parental migration that they have found have been widely disseminated and incorporated into larger public perceptions. Many such studies are also inherently normative. For example, a 2011 publication supported by IOM (among others) declared:

"The mother's presence at the events the children participate in is important for their personal and social affirmation. They [the children] feel the absence of their mother, because they do not look as tidy, appreciated, valued or encouraged as children whose mothers are at home... [they] take part in activities that are important for them without experiencing any positive emotion: they have no one to share their happiness, they feel deprived compared to children whose mothers are at home...." Cheianu-Andrei et al. (2011; pp 98)

The generalisation about what children feel (and why) heavily implies that a mother's role in validating the experiences of her children cannot be replaced and that, by extension, absent mothers actively deprive their children of essential forms of care. A growing "genre" of international (pseudo-)journalism that sensationalises migratory trends and practices has also played a strong role in generating negative discourses about migration and the family. An article published by German broadcaster Deutsche Welle titled "The Plight of Europe's 'Euro Orphans'”, as just one example, declares that migration from Moldova is a crisis for the families that experience it:

"...in the south of Europe's poorest country, an entire generation has grown up traumatized. If you speak with experts about the impact of this family dynamic, they're quick to call it a social disaster... Euro orphans learn that parental love is paid at regular intervals through a bank account, or by post with packages full of brand-name clothes and toys. But they lack a close relationship with their parents. Tinny voices and blurry Skype images are a poor substitute for hugs." Martin Nejezchleba, Deutsche Welle² 2 .

${ }^{22}$ The full article, posted in 4 December, 2013, can be viewed at: http://www.dw.de/theplight-of-europes-euro-orphans/a-17268091. 
This description of the children 'left behind'-as traumatised orphans representing a social disaster, completely lacking affection and care-is by no means an exception. Italian photographer and journalist Carmine Flamminio provides a similar commentary in his photography project "Left Behind":

"The first victims of migration are children. In Eastern Europe half of those who emigrate are women who, in most cases, leave their children at home, entrusting them, at best, to grandparents, or to elderly neighbors, or at worst, and too often, just abandoning them to fend for themselves. A prime example is Moldova..."

Carmine Flamminio, photojournalist ${ }^{23}$. Emphasis original.

This quote represents a common tendency within discourse to present children as victims and to narrowly focus on female migration, particularly that of mothers. Fathers are omitted from this description altogether-both as migrants and as potential caregivers of children. A striking feature of this quote and the project to which it is connected is that it was so readily picked up by various agencies-the BBC $^{24}$, UNICEF Moldova ${ }^{25}$, and Children on the Edge ${ }^{26}$, among others-without any critical analysis of the content. The promotion of highly-normative statements supported by selective research has cultivated a discourse that regards migration as disastrous for child well-being, a trend that has occurred in Moldova but not in Georgia.

Based on this (admittedly limited) literature, how can Moldovan families be characterised? Moldovan families are generally small and organised around the nuclear family, particularly in urban areas. The extended family is an important resource for young families by offering childcare, yet it is uncommon for members of the extended family to live in the same household. Within families, there are clear norms about what specific individuals should do: mothers moderate and maintain the activities of daily life, fathers make decisions about household matters and interact with the outside world, and children concentrate on education. The migration of one or both parents can disrupt both expectations and activities. Residency patterns may shift with migration, particularly if both parents

23 The "Left Behind" photo series is available on Carmine Flamminio's website: http://www.flamminiophotography.it/leftbehind

${ }^{24}$ http://www.bbc.co.uk/news/in-pictures-14488086

${ }^{25}$ https://www.facebook.com/UNICEFMoldova/posts/149677055118241

${ }^{26} \mathrm{http}: / / \mathrm{www}$.childrenontheedge.org/moldova-child-and-community-centre.html 
migrate and the children they leave behind are young and need to be intensively cared for by a member of the extended family. Responsibilities and roles within this household may change: if one parent leaves, the remaining spouse may take on some of the tasks the migrant had done before, in some cases challenging gendered expectations. Children may also assume greater levels of responsibility for household activities, in some cases taking on activities (including making decisions) that they never performed before because their parents always did them. Based on this characterisation, there are many ways in which migration could be expected to change life for children separated from migrant family members, but how those changes are related to psychosocial health is left to speculation.

\subsubsection{Georgia}

Much of Georgian life is centred around the family, and expansive kinship networks play an important role in many domains of life. Georgian families and households tend to be large: a nationally-representative survey conducted in 2011 found that the "average" household contained 3.6 members, yet over 30 percent of surveyed households contained six or more members and a very small portion (14.7 percent) contained one or two persons. Around 43 percent of households had at least one member over the age of 64 , with households containing more than one elderly person relatively uncommon. Over 60 percent of households contained at least one child, the largest share of which had only one (Gassmann, Berulava, \& Tokmazishvili, 2013).

This "average" household structure reflects current fertility trends well. As in many FSUs, the total fertility rate in Georgia has declined since the Soviet period, from 2.1 children per woman in 1989 to 1.7 in 2012 (GeoStat, 2014). This rate has somewhat fluctuated over the years, with a total fertility rate of 1.6 in 2000 and 1.8 in 2010 (UNDP, 2014). The adolescent marriage and fertility rate is relatively high, with 14 percent of women under the age of 19 married and the fertility rate among the 15-to-19-year age cohort at 41 births per 1000 women (WEF, 2013). According to the 2005 round of the Georgian Reproductive Health Survey (GERHS), which surveyed over 6,300 women between the ages of 15-44, a woman's 
average age at marriage was 21.6, and the median age at first birth was 23. Most women stated wanting no more than two children, with target fertility reached very early in their married lives (the highest fertility rate was recorded among women aged 20 to 24). The desire for relatively small families coupled with early marriage, high early fertility, and limited use of modern contraceptive methods has contributed to extremely high total abortion rates-the highest in the world between 2003 and 2005 at 3.1 abortions per woman (Westoff \& Serbanescu, 2008). Such fertility trends signal an underlying conflict between women's own desires, which are often based on economic reasoning, and traditional attitudes toward fertility and child-bearing which are reinforced by the Georgian Orthodox Church and promoted by state policies that encourage family growth ${ }^{27}$.

Fertility trends are closely connected to residency trends and patterns. Complex households containing members of the extended family are common, which reflects both marriage and family formation norms as well as norms relating to eldercare. Households containing three generations are common in both urban and rural areas; while in urban areas more households contain only the nuclear family, most households are still comprised of children, parents, and grandparents (Sumbadze \& Tarkhan-Mouravi, 2003; UNICEF, 2010). It is relatively uncommon for a woman to live alone, as she will often reside in the parental home until marriage, after which she will generally move into her husband's family home. In Georgian families the youngest son is expected to care for his parents into old age and thus remain in the parental home. Elderly individuals who are not cared for by a son often move in with a daughter and her family later in life (Badurashvili et al., 2008). These "traditional" living arrangements, while changing, also reflect cultural norms about childcare. Children are described as the "focal point of any family"

27 Periodically-increasing fertility rates are attributed mainly to the initiatives of the Georgian Orthodox Church to promote family expansion. In 2008 the Patriarch of the Georgian Orthodox Church promised to become the godfather of every third child born to a Georgian family, and by May 2013 the Patriarch had become the godfather of 11,000 children (Chumburidze, 2013). In June 2014, the Prime Minister of Georgia announced that families residing in regions with low birth rates and high mortality rates would receive additional monthly stipends for two years for every third and subsequent child born to the family. The initiative is part of a larger state strategy to improve the demographic situation in Georgia by stimulating family growth (Government of Georgia, 2014). 
(Sumbadze \& Tarkhan-Mouravi, 2003; pp 2), and grandparents often share childcare duties with a child's parents.

Within Georgian families, traditional gender roles are relatively well defined and documented, in part because of the strong association between femininity and national symbols ${ }^{28}$. Motherhood is highly revered in Georgian culture, and women as mothers play strongly into nationalist narratives based on the protection of "Mother Georgia" (Nogaideli, 2012). Idealised versions of women as mothers, whose role is to sacrifice her own personal life for the future of her children, entail that women are highly respected as long as they remain within the domestic domain and look first and foremost toward the promotion of the family (Javakhadze, 2006). The emphasis on women as mothers also places them firmly under the supervision of the family and emphasises their dependency and need to be protected (Hofmann \& Buckley, 2011) - an attitude that seems somewhat at odds with the expectation that women are capable of doing anything for the family, including acting as both mother and father in the case that the latter is absent (Javakhadze, 2006; Nogaideli, 2012).

Women-mothers and grandmothers-are seen as responsible for the household and its functioning, with most domestic tasks such as cleaning and cooking, childcare, and budgeting performed by women. Major purchasing decisions and other large decisions that affect the family are considered to be a man's task (USAID, 2003), and the eldest man in a house is considered the household head and the person with the greatest authority (Sumbadze \& TarkhanMouravi, 2003). Men are also seen as responsible for participating in public life, in community decision making, and in economic affairs. Traditional attitudes toward men as primary breadwinners have gradually changed with the worsening of economic conditions, however. Women have become increasingly responsible for ensuring household economic survival, in part because of their greater perceived ability to adapt to changes in the labour market, their perceived duty to support the family, and their willingness to take on demeaning jobs below their education

${ }^{28}$ Visitors to Tbilisi will be familiar with Kartlis Deda (Mother of Kartli), the 20-metre-high aluminum statue of a woman in traditional Georgian dress who stands over the city. Holding a wine cup in one hand and a sword in the other, the statue is an interesting symbol of the duality both of the "traditional" Georgian character and the role of womenat once welcoming to strangers who come as friends and fiercely protective of a home challenged by enemies. 
or skill levels (Badurashivili \& Nadareishvili, 2012; Zurabishvili \& Zurabishvili, 2010). The economic participation of women has not corresponded to changes to their domestic responsibilities, however. Women are still expected to perform most household-related labour, which often limits their chances for professional development due to very low levels of public support for childcare (Asatoorian et al, 2011; USAID, 2003). The limited participation of fathers in childcare also limits the economic success of women. Based on the 2007 Generations and Gender Survey, Badurashvili and colleagues (2008) found that fathers' participation in childcare activities was generally limited. In 35 percent of families, fathers reported playing with their children as much as or more than mothers did, and in around 15 percent of families, fathers reported helping their children with homework as much as mothers did. In only 15 percent of families did fathers report sharing responsibilities with the children's mothers for dressing children, putting children to bed, or staying home with children when they are ill (Badurashvili et al., 2008).

Despite the significant scale of emigration and the centrality of the family in Georgian culture, there are very few studies that address if and how migration affects family life. Children who remain in Georgia following the migration of parents or other kin are generally not addressed, with what literature there is on migration and its link to family life focusing almost exclusively on female migration and its reconciliation with traditional gender norms (Badurashvili \& Nadareishvili, 2012; Lundkvist-Houndoumadi, 2010; Zurabishvili \& Zurabishvili, 2010; Hofmann \& Buckley, 2011, 2013). In her study of immigrant women in Greece and their families remaining behind in Georgia, Lundkvist-Houndoumadi (2010), for instance, explored how female migrants framed their emigration experiences as sacrifices made to ensure the survival of the family. Respondents emphasised that migration was a way of fulfilling a moral obligation to care for the family, a strategic construction of the migration narrative that legitimised a woman's physical separation from the household and family by reframing her personal agency within traditional gender norms. Hofmann and Buckley (2011, 2013), in their studies of the motivations of female migration and cultural responses to female mobility, similarly found that women (and their husbands) expressed the migration decision as one made out of necessity and under duress. Respondents explained female migration as less about choice and more about compulsion, as the only possible action that could be taken to help the family given lack of employment opportunities for men both at home and abroad. Zurabishvili and Zurabishvili (2010), in their study of female migrants from the village of 
Tianeti, also found that women expressed their identities as women as something inextricably bound to their capacity for sacrifice and suffering. As one respondent explained: "I was happy only when I was getting a salary and was sending it to them [the family]... we women are born to suffer. And men are born to enjoy life..." (in Zurabishvili \& Zurabishvili, 2010; pp 81).

Public discourses around (female) migration and family life are notably less hostile in Georgia than they are in Moldova, perhaps because of the way gender norms have been reconfigured to accommodate the perceived necessity of female labour. In the early post-Soviet period, strongly negative discourses on female migration stigmatised women who emigrated, due largely to the assumption that women who emigrated to countries such as Turkey were workers in the commercial sex trade. The shame associated with female migration strongly reflected underlying expectations about women as protectors of the domestic sphere and the family (Javakhadze, 2006). As the destinations of female migration expanded, and as the overall scale of migration increased, public perceptions gradually shifted, with migration-even that of women-regarded as an unfortunate but necessary sacrifice to ensure household survival amid economic hardship. Despite increasing acceptance of migration (of both women and men), migration has still been connected to the gradual breakdown of family systems. Badurashvili and Nadareishvili (2012), in an assessment of the social implications of emigration in Georgia, note that migration (as well as other economic and social factors) can "alter the sustainability of the family structure... the parental influence of families on children and young people has weakened in Georgia, which is manifested in the growth of juvenile delinquency and problems associated with homelessness and begging." (pp 21). These sentiments have not contributed to public perceptions about migration as an inherently dangerous trend for families, however.

The central role of gendered expectations in the maintenance of the family has clear potential implications for children with migrant kin. The strong responsibility felt by women for the care of the family and the limited level of men's engagement in domestic activities may suggest that if a woman emigrates, her domestic duties will often be discharged to other female family members such as grandmothers, aunts, or even an eldest daughter. Hofmann and Buckley (2011), in their interviews with return migrant women, found that the majority of those who had minor children at the time of their migration relied on their own mothers 
to provide care for the children during their absence. The availability of a grandmother to take on childcare was viewed as not only convenient but also as preferable, with several women expressing the view that their mothers would provide better childcare than they themselves could provide. Despite the reliance on female kin to aid in childcare during a mother's absence, many of a mother's responsibilities may still be performed from abroad, such as by providing intense emotional care to children or sending remittances to meet household financial needs. Past literature, with its almost exclusive focus on the experiences of female migrants, provides very little guidance on how a father or other male family member's migration may correspond to changes in the household or family. The limited domestic roles of men and the diminishing economic participation of men could lead to the expectation that children with a migrant father or other male family member can only benefit, as traditional "male" responsibilities such as a leading household decision making or acting as the primary breadwinner can be performed just as well or better from abroad-particularly if a man's employment possibilities are better in the foreign labour market than in the domestic one. The prevalence of complex households and tightly-bound kinship networks also suggest that regardless of who migrates from a family, children would be unlikely to suffer neglect.

\subsection{DISCUSSION: MOLDOVA, GEORGIA, \& THE VALUE OF COMPARISON}

In assessments of the post-Soviet states, Moldova and Georgia are often mentioned in one breath: both prospered in certain ways during the Soviet period, both faced economic collapse and prolonged economic restructuring as the result of independence, and both are gradually gravitating to the European Union's sphere of influence. The countries share other notable similarities-such as ongoing territorial disputes that threaten the consolidation of the state and, perhaps most compellingly, large and ever-diversifying emigration flows that have the potential to affect large numbers of families. These similarities belie complex and subtle differences between the two countries that make their comparison so worthwhile, however, particularly in terms of understanding how migration and family life intersect. Each country has experienced particular kinds of emigration 
flows in response to different domestic conditions and different geopolitical orientations. Differences in the organisation of family life also imply that absent migrants fulfil different roles, leading to divergent expectations about how their absence can potentially affect the psychosocial health of children remaining in the country of origin. Some of these key similarities and differences are provided in Table 4.1.

\subsubsection{Geopolitical Ties}

Despite their shared Soviet past, Moldova and Georgia have maintained different relationships with other FSUs and with Russia that have resulted in different migration possibilities and trends. Moldova has remained a member of the CIS, and Moldovan migrants therefore have mostly unencumbered access to the Russian labour market. The relationship between Russia and Georgia, in contrast, has become increasingly antagonistic. The visa-free travel regime between and among CIS states excluded Georgians in 2000, and the 2008 Georgia-Russian War and Georgia's subsequent withdrawal from the CIS limited the possibilities for Georgians to legally migrate and work in Russia or other CIS states. Moldova and Georgia also have differing relationships with the EU given modern political relationships and historical ethnic ties. Both states are Eastern Partnership countries with Association Agreements with the EU, but Moldovans are entitled to visa-free travel within the Schengen area. Those with access to Romanian passports can also reside and work legally in the EU.

Georgians, in contrast, have fewer opportunities for legal entry and stay in the EU. Georgia is home to a dwindling population of ethnic Greeks, many of whom are descendants of settlers of the ancient Ionian Greek colonies along the Pontic coast of the Black Sea. Most are not dual nationals: among those individuals with ethnic ties to Greece, most have only Georgian nationality until they choose to repatriate to Greece, when they are granted Greek citizenship as part of the right to return (Diamanti-Karanou, 2010). Among Georgian migrants to Greece, few are ethnic Greeks with the right to legal stay. The majority of Georgian migrants to the EU are thought to reside and work irregularly. 


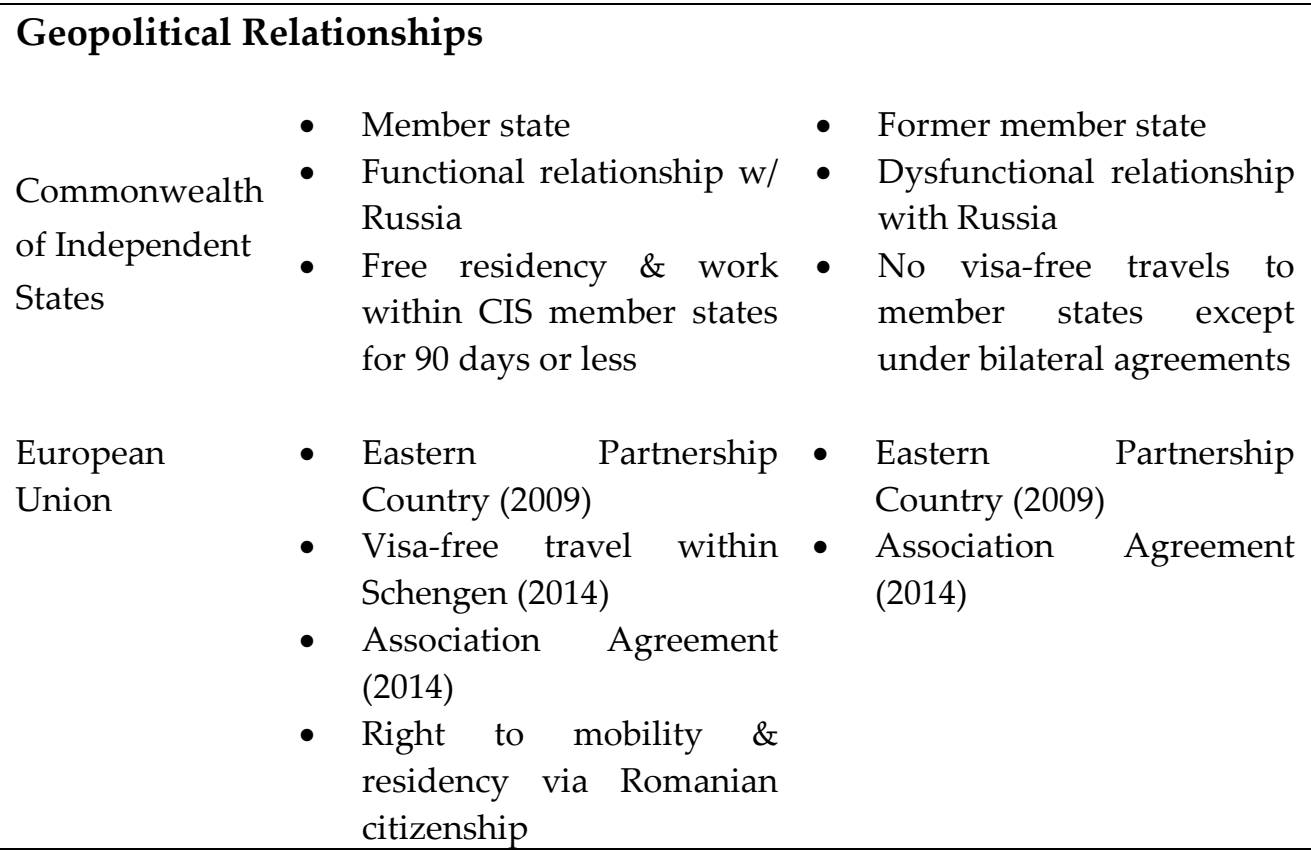

\section{Migration Patterns}

Percent of

Population

Living Abroad

- 21.5

- $\quad 25.1$

$(2010)^{*}$

Gendered

- Slow entry of women into

- Moderate entry of women

Division international migration

- Men higher proportion of migrant stocks \& flows into international migration

- Men higher proportion of migrant stocks, women higher proportion of migrant flows

Destination

- Top 3: Russia, Ukraine, •

Countries Italy Ukraine

- Men concentrated in CIS

- Women concentrated in Italy

- Men concentrated in CIS \& Turkey

- Women concentrated in Greece \& Turkey 
Average

Migrant Age**
- Men: 34.2

- Women: 36.5
- $\quad$ Men: 40.1

- Women: 42.7

Family Arrangements

\begin{tabular}{|c|c|c|}
\hline $\begin{array}{l}\text { Residency } \\
\text { Norms }\end{array}$ & $\begin{array}{l}\text { Predominantly nuclear } \\
\text { families }\end{array}$ & $\begin{array}{l}\text { - Predominantly extended } \\
\text { families }\end{array}$ \\
\hline Family Roles & $\begin{array}{l}\text { Mother: Household } \\
\text { maintenance \& childcare } \\
\text { Father: Decision making, } \\
\text { income earning } \\
\text { - Grandparents: Moderate } \\
\text { support of adult children } \\
\text { and childcare; seldom } \\
\text { reside in same household } \\
\text { as adult children }\end{array}$ & $\begin{array}{l}\text { - Mother: Household } \\
\text { maintenance \& childcare } \\
\text { - Father: Decision making, } \\
\text { income earning } \\
\text { - Grandparents: } \\
\text { participation in childcare; } \\
\text { often reside in same } \\
\text { household as adult } \\
\text { children }\end{array}$ \\
\hline Discourse & & \\
\hline $\begin{array}{l}\text { Female } \\
\text { Migration }\end{array}$ & - Negative & - Neutral \\
\hline
\end{tabular}

Sources: *World Bank (2011); **CELB/MD-GE(2011/12)

These different political relationships imply different possibilities for migration and return. Moldovan migrants living and working in Russia and other CIS countries such as the Ukraine are obligated to periodically return to Moldova to retain their rights of residence. The same policy holds for Georgians in Turkey, but the proportion of migrants affected is smaller, as Georgian emigrants are not yet as concentrated in Turkey as Moldovan migrants are in the CIS. For those emigrants residing in the EU, possibilities for (temporary) return and circularity are dependent on legal status, work contracts, and the availability of low-cost travel options. The lack of reliable statistics on the legal statuses of Moldovan and Georgian nationals in the EU makes it difficult to compare the scope of irregularity, but there is some evidence to suggest that circular migration is more accessible to Moldovans than to Georgians, owing to their greater ease of access to the EU (Marchetti, 2013). 


\subsubsection{Migration Patterns}

The composition of migrant flows from Moldova and Georgia also differs in ways that bear important implications for the family. As Chapter Five discusses at some length, men still dominate both stocks and flows of Moldovan migrants. Among Georgian migrants, in contrast, women have outnumbered men in flows of outgoing migrants for several years, and they comprise the majority of migrant stocks in most destinations outside of the CIS region. Migrants from Moldova and Georgia also differ demographically: Georgian migrants are considerably older than Moldovan migrants. These ages imply that the "average" migrant from Moldova may be in a different stage of the family life cycle than is the "average" Georgian migrant. This is supported by small-scale studies that have found that Moldovan women in Italy tend to be younger than the average migrant woman and to have children, whereas Georgian women are more similar to Ukrainian women, who are significantly older and tend to have adult children and grandchildren (Marchetti \& Venturini, 2013).

\subsubsection{Family Arrangements}

The role of migrants in the families they have left are also likely to differ between Moldova and Georgia, not only due to differences in demographic traits but also due to differences in family structures and residency norms. Moldovan households most often contain only the nuclear family whereas Georgian households generally contain members of the extended family. Grandparents and other members of the extended family provide child care less frequently in Moldova than in Georgia, where co-resident grandparents often care for children in much the same capacity as parents do. The lower prevalence of complex households in Moldova than in Georgia may suggest that when a member of a family migrates, there are fewer people already residing in the household to take on the responsibilities of the absent member. It may also imply that residency patterns change, particularly if responsibilities for childcare shift to someone like a

grandmother who does not already reside in the household. It is relatively more common for a child in Moldova than in Georgia to experience the migration of 
both parents-as can be seen from Chapter Six (on the psychosocial health of children with migrant parents in Moldova) and Chapter Seven (on the psychosocial health of children with migrant kin in Georgia). More changes in residency and caregiving patterns would be expected given the migration of both parents, thus children in Moldova may be more likely to experience more drastic changes given parental migration.

The similarities between Moldova and Georgia as post-Soviet, transitional countries coupled with the marked differences between them in terms of mobility trends and family organisation norms make the two countries fruitful to study side-by-side. Their comparison allows for greater identification of the underlying mechanisms that contribute to or undermine child psychosocial health given the experience of family migration. Against similar histories of Soviet domination, post-Soviet transition, and rapid changes to personal mobility possibilities, would children in both countries experience family-member migration in the same way? If not, why not? What would drive the differing results, and what would this imply for the region at large?

The results of such a comparison are not only revealing for Moldova and Georgia singularly but also for the wider post-Soviet space, which is one of the frontiers of the feminisation of migration. Some authors (including Marchetti, 2013 and Marchetti \& Venturini, 2013) have suggested that Moldova and Georgia belong to particular country 'blocs' within the Eastern European region that share common migration trends and characteristics: Moldova belongs to the group that includes Romania and Bulgaria, and Georgia belong to the group that includes Belarus and the Ukraine. Given similarities in migration trajectories and histories, results derived from studies of Moldova and Georgia offer insights into the wider regions to which they belong. This offers a distinct advantage given the concentration of prior literature on children in transnational families in regions with high rates of female mobility - namely South-East Asia and Mexico. Given the specific nature of historical migration patterns from these regions and the development of state emigration policies (as in, for instance, the Philippines, where female workers are actively recruited, trained, and exported), the extent to which the results gathered from these regions apply beyond them is unclear. The comparison of Moldova and Georgia thus provides an important opportunity to expand the geographic scope of knowledge on children in transnational families who remain in the country of origin. 


\section{CHAPTER FIVE: SIMILAR BUT NOT THE SAME - THE FEMINISATION OF MIGRATION FROM MOLDOVA \& GEORGIA $^{29}$}

\subsection{INTRODUCTION}

The progressive "feminisation of migration" in particular migration corridors has drawn attention to key differences in the mobility choices and experiences of men and women. Despite the growing body of research on gendered differences in migration choices, the topic has remained understudied in many regions-including the former Soviet Union, where many of the nowindependent republics have faced large-scale, sustained emigration in the postSoviet transitional period. Georgia and Moldova are two particularly interesting countries in this regard: both have lost more than 20 percent of their populations to migration (World Bank, 2010), and women outnumber men among migrants to several key destination countries (IOM, 2009; IOM 2012). These trends have been accompanied by active public discourses on the potential implications of (female) migration for families 'left behind'. In Moldova, female migration is often equated with family abandonment and victimisation of homeland kin (Panţîru, Black, \& Sabates-Wheeler, 2007), whereas in Georgia, discourses often emphasise the essential role of female migration in ensuring household economic survival (Hofmann \& Buckley, 2011). Both discourses place female mobility firmly within the realm of the family, yet explorations of female mobility patterns and their connection to the household and family context are notably scarce.

To better nuance the understanding of mobility patterns of women from an understudied region, this paper uses data from Moldova and Georgia to explore three aspects of the feminisation of migration: 1) how the odds of entering international migration are shaped by gender; 2 ) what characteristics differentially influence the migration odds of men and women, and 3) how gender plays into destination choice. Regression analyses are conducted on data collected from two

29 This chapter is based on an article currently under review for journal publication that is entitled "Similar but not the same: The feminization of migration from Moldova and Georgia" and co-authored with M. Siegel and V. Mazzucato. 
household surveys implemented in 2011/12 over a sample of 8,208 adults in Moldova and 11,833 adults in Georgia. The results suggest that women from Moldova have lower odds than their male counterparts of migrating internationally, whereas in Georgia, the migration odds of men and women do not significantly differ. When women from both countries do become international migrants, they have higher odds of migrating to countries in the European Union or to countries such as Turkey, Israel, or the United States than men. Family characteristics such as marital status and residence with dependents such as children or elderly individuals differentially influence the migration propensities of men and women, in sometimes differing ways between the countries. Such nuances suggest that mobility is distinctly shaped by gender but also that those gendered processes differ by country context-lending more points of comparison by which the "feminisation of migration" can be understood.

In this chapter, the term "feminisation" of migration is used to indicate increased participation of women in international moves over time. This usage reflects not only a larger proportion of women among the stock of migrants but also increased numbers of women in flows of migrants, both of which signal underlying changes to the character of female migration in terms of motivation and type (e.g., family reunification versus labour migration) (Piper, 2007).

The following section (5.2) outlines prior literature on the feminisation of migration and the way gender influences the migration decision-making process. Background information on Moldova and Georgia, and the patterns of migration from both countries in the post-Soviet period, are then provided in section 5.3, which helps demonstrate the value of using these particular countries to explore the feminisation of migration. These review sections are followed by a description of the data and analytical methods used in this chapter (section 5.4). Three types of results are then described in section 5.5: descriptive statistics of the sample, the results of binary logit models of the odds of men and women being international migrants, and the results of multinomial logit models that predict the relative risk ratios of men and women being migrants to specific destination regions. The final section of this chapter (5.6) discusses these results, their limitations, and the overall conclusions that can be drawn from them. 


\subsection{LITERATURE \& THEORY}

Social scientists have recognised that migration is an inherently gendered phenomenon in which social norms, motivations, and risks differentially affect the mobility options of men and women (Curran \& Saguy, 2001; Curran \& RiveroFuentes, 2003; Donato et al., 2006). As women have become more visible international migrants, theoretical and empirical focus has shifted to better incorporate gender into understandings of the economic and social processes that shape mobility.

A notable shift in the treatment of gender in migration studies can be seen in the greater engagement of gender in economic theories of migrant selection. Neo-classical economic theories that sought individual-level explanations for migrant selection, such as wage differentials between home- and destination country (Harris \& Todaro, 1970) or differentials in human capital productivity between home- and destination-country (Sjaastad, 1962; Mincer, 1978), ignored gender. These theories largely assumed that if women migrated, it was not as "pioneers" but as "tied" migrants who followed male kin (Hill, 2004). The new economics of labour migration (NELM) theory, despite conceptualising the migration decision as a family-level process, also did not explicitly incorporate gender. The theory suggests that migration is a family- or household-level strategy

to diversify sources of household income, insuring households against local shocks (Stark \& Bloom, 1985) while increasing access to capital to overcome missing or imperfect local credit and insurance markets (Taylor, 1999). Within this theory, migration should occur when a household's net gains exceed the losses represented by the migration of a particular member-an assessment that is difficult to perform when there is no market for household activities such as childcare, which women disproportionately perform (Pfeiffer et al., 2007).

More recent structuralist approaches to migrant selection explicitly incorporate gender into predictive frameworks by observing the intersection between gender and global divisions of labour. These approaches propose that the segmentation of labour markets by skill level and gender creates different economic niches for men and women in both home- and destination-country labour markets, incentivising women to migrate to particular destinations. For instance, the demand for low-skilled, low-wage labour in select female-dominated professions, such as domestic and care work, may create more economic 
opportunities for female than male migrants in specific labour markets (Pfeiffer et al, 2008). This trend is especially clear in economies facing demographic transitions, where there is both a shortage of young people who can take on lowpaid, entry-level jobs (Massey et al., 1993) as well as a shortage of (generally female) caregivers who can meet the long-term care needs of a growing elderly population. As more women have entered the labour market, migrant women have become an increasingly valuable addition to traditional, kin-based eldercare systems by providing affordable care for families lacking informal caregivers (Bettio, Simonazzi, \& Villa, 2006). As noted by Pedraza (1991), structuralist approaches-while a welcome theoretical evolution-ignore the agency of individuals, whose opportunities and constraints exist within larger, gendered cultural contexts.

Qualitative studies on migration have emphasised that migration is a sociocultural practice, not just an economic one, in which an individual's migration strategy is closely tied to gendered expectations within households and families (see Mahler \& Pessar, 2006, for a review of ethnographic literature on the topic). Particularly in patriarchal and male-dominated societies, female (dis)approval of migration intentions may be disregarded (Boyd, 1989) or women may be excluded from the migration decision-making process altogether (Hondagneu-Sotelo, 1992). Hierarchies of power and normative expectations of kinship and gender roles also influence who in a family can migrate, what resources can be invested in that migration, and what expectations there are of that migrant in terms of remittances and return (Pedraza, 1991).

These theoretical perspectives need not be at odds with one another; indeed a growing body of research has suggested that economic motives for migration interact with gendered expectations within households and families to shape an individual's opportunities for and modalities of migration. Studies conducted in the Philippines by Trager (1984) and Lauby and Stark (1988), for instance, found that daughters were preferred rural-urban labour migrants because they were perceived as being more obedient to the family and thus to be more reliable and generous remitters than were sons. Curran and Rivero-Fuentes (2003) found that in Mexico, gender ideologies that emphasised the "domesticity" of women and their greater physical vulnerability contributed to greater control over women's migration and encouragement of internal over international migration. 
Such studies suggest that spatial constraints of mobility are strongly shaped by gendered expectations within households and families.

Other studies have found strong links between household composition and the mobility of men and women. In Albania, Stecklov, Carletto, Azzarri, and Davis (2010) found that female mobility was tightly bound to household-level structures and shocks. Women were more likely to be international migrants if they belonged to households lacking sons, and shocks like property or savings losses incentivised women but not men to migrate. Household structure was also found to influence female mobility in Georgia, where larger household size was found to correspond to higher odds of women being international migrants (Hofmann \& Buckley, 2013).

Migration opportunities and choices have also been found to be strongly shaped by the obligations and roles that men and women are expected to fulfil within marriage and parenthood. In Mexico, the odds of women migrating for the first time was found to decrease with each additional child in the household (Kanaiaupuni, 1995, as cited in Cerrutti \& Massey, 2001), whereas for men, a greater number of children corresponded to higher odds of engaging in serial migration (Massey \& Espinosa, 1997). Kanaiaupuni (2000) suggested that such findings reflect expectations of how men and women should properly "do gender". For men, international migration for the purpose of supporting the family economically was considered part of being a "good father", whereas for women, international mobility contradicted what it meant to be a "good wife", leading to lower rates of mobility among married women (and higher mobility among divorced and separated women). Similar conclusions were reached by Curran, Garip, Chung, and Tangchonlatip (2005) in Thailand, who found that married women had significantly lower odds of living away from the origin village than unmarried women, whereas married men expressed only marginally lower odds of living outside of the origin village compared to their unmarried counterparts.

Such research suggests that normative gender expectations within households and families shape perceptions not only about who should go but to where and for what purpose. Expectations of the roles and responsibilities of various members of the family can lead to promotion of certain types of migration behaviours (e.g., serial migration among fathers) and discouragement of others (e.g., the migration of wives). These findings underscore the particularities of place and culture, and in doing so, they reveal how limited knowledge is about 
gendered migration selection in many other high-migration contexts. Mexico stands alone as one of the few countries where multiple studies have been conducted (such as Kanaiaupuni, 2000; Massey \& Espinosa, 1997; Cerutti \& Massey, 2001), presenting a rare opportunity for comparison and complementarity. The same opportunity is missing in other countries and regions, as so few studies have been conducted in similar enough contexts (and with similar enough research designs) to facilitate meaningful intra- and inter-regional comparisons. The present paper provides an opportunity to examine the predictors of men's and women's migration in a comparative perspective by analysing data derived from household surveys conducted in Moldova and Georgia, two post-Soviet countries that have both experienced marked transitions in mobility patterns over the past two decades.

\subsection{BACKGROUND CONTEXT}

Unprecedented migration in the post-Soviet period makes Moldova and Georgia valuable case studies through which the feminisation of migration can be explored. Following independence from the Soviet Union in 1991, both states experienced sharp economic declines. By 1999, 71 percent of the Moldovan population (IMF, 2006) and 60 percent of the Georgian population (IMF, 2003) lived below the poverty line. The economic recessions occurred simultaneously with civil conflicts, namely the 1992 civil war over Transnistria in Moldova (Kolstø \& Malgin, 1998) and the 1991-1993 conflicts over the territories of Abkhazia and South Ossetia in Georgia. These territories are still contested and have fuelled tensions with Russia, particularly in Georgia where renewed conflict in South Ossetia escalated into the 2008 Georgia-Russian War (Fawn, 2012).

Large-scale emigration picked up in the midst of these transitional crises and has continued relatively unabated since. By 2010 around 21.5 percent of the total Moldovan population lived abroad, with the largest numbers living in the Russian Federation, Ukraine, Italy, and Romania (World Bank, 2010). Over 63 percent of outgoing migrants were male in 2010, but women outnumbered men in particular migration corridors, such as Italy, where 68 percent of migrants were women. Whereas men have been found to migrate more to the Commonwealth of Independent States (CIS) region to work primarily in the construction sector, 
women have increasingly migrated to the EU to perform primarily unskilled household labour (IOM, 2012).

A similar evolution of migration trends occurred in Georgia: by 2010 over a quarter of the population was thought to reside abroad, with the largest populations in the Russian Federation, Armenia, Ukraine, Greece, and Israel (World Bank, 2010). In the early post-Soviet period, the majority of migrants were men destined for the CIS region, but women now account for more than 40 percent of all outgoing migrants and are over-represented among migrants destined for EU countries (Hofmann \& Buckley, 2013; IOM, 2009). Russia's periodic suspension of visas for Georgian migrants and the withdrawal of Georgia from the CIS in 2008 severely limited migrants' access to the Russian labour market (Hofmann \& Buckley, 2013); declining opportunities for male migration coincided with increased demand for home-, child-, and eldercare workers in and even beyond the EU, which increased opportunities for women to migrate to countries such as Greece, Italy, and Turkey (IOM, 2009).

Moldova and Georgia are fruitful to compare for both their similarities and differences. Both experienced similar prompts for emigration during the postSoviet transition, and both have experienced relatively recent diversification of emigrant flows in terms of destinations and gender. These similarities are accompanied by subtle differences in the discourses surrounding migration, however, which suggest differing socio-cultural processes by which male and female mobility options are cultivated. The study of gendered migration propensities from these specific countries also has implications for understanding migration patterns within the region and beyond it. As noted by Marchetti (2013), certain countries in the former Soviet Union can be grouped together based on common migration trends and characteristics. Moldova, Romania, and Bulgaria are often discussed as one 'bloc', as all feature the migration of relatively young women to either other EU countries or to destinations such as the Russian Federation or the Ukraine, where migrants often perform short-term, seasonal labour. Georgia, Belarus, and the Ukraine are considered another bloc, as all have limited access to female-specific destinations in the EU, and female migrants are more diverse in terms of demographic profile. The comparison of Moldova and Georgia can thus further understanding of larger regional migration dynamics while providing the basis for comparison to better-studied contexts such as Mexico. 


\subsection{METHODOLOGY}

\subsubsection{Data}

Data used in this paper were derived from household surveys collected in the project "The Effects of Migration on Children and the Elderly Left Behind in Moldova and Georgia" (CELB-MD/GE) ${ }^{30}$. The surveys were implemented from September 2011 to March 2012 in Moldova and from March to December 2012 in Georgia. The surveys were conducted in all regions of both countries with the exception of Transnistria in Moldova and South Ossetia and Abkhazia in Georgia. Both surveys were drawn from random stratified samples with oversampling of target population groups (children, elderly, and migrants). In Moldova the sampling frame was provided by the Moldovan National Bureau of Statistics on the basis of the Labour Force Survey (LFS) conducted in the second quarter of 2011. The LFS sampling universe included the entire population of Moldova, excluding individuals residing in Transnistria or in institutions. In Georgia the sampling frame was elaborated on the basis of electoral districts given the absence of a recently-updated, nationally-representative sampling frame.

Only households containing one or more children (under the age of 18) or elderly individuals (aged 60 or older) were eligible for the survey, but information on household composition and migration experiences was collected for all contacted households in the sampling universe. In both countries, weights were provided to enable extrapolation to national level. In Moldova probability weights were derived from characteristics of the population contained in the LFS sampling universe, whereas in Georgia, population weights were derived from the population characteristics collected during a listing exercise conducted among all contacted households. The survey eligibility criteria imply that results are relevant for the population of individuals residing in households with children and/or the elderly and not necessarily for the population at large. The data nevertheless allows for very meaningful analysis of the factors that correspond to differing migration propensities between men and women living in similar household contexts. Given the lack of comparable data, it is unclear how different migration

30 Additional information on this project and data collection tools can be found on the project website at: http://mgsog.merit.unu.edu/research/moldova_georgia.php. 
trends would be between individuals with and without dependents in the household; this caveat implies that the results will be discussed as representative only for households with children or elderly individuals-incidentally, those households with which much policy and discourse is the most concerned.

The surveys collected detailed demographic information on all household members as well as information on each person's migration history. In keeping with United Nations conventions, any individual who had lived abroad for three or more months consecutively was considered as a migrant (UN, 1998). Information was collected on the years and destinations of a migrant's first and last departure, the duration and destination of migration episodes between 1999 and 2011, the residency status of current migrants, and characteristics of the migrants' lives abroad. Table 5.1 provides an overview of the survey sample. In both countries significant shares of the adult sample had lived abroad for three or more months at one time-over 22 percent of the weighted Moldovan and 11 percent of the weighted Georgian sample had ever lived abroad. In both countries a smaller proportion of women than men reported ever living abroad. Over ten 10 percent of the total weighted Moldova sample and six percent of the weighted Georgian sample lived abroad at the time of the survey, with men constituting a greater proportion of current migrants than women in both countries.

Table 5.1: Survey Sample by Country

\begin{tabular}{lccccccc}
\hline & \multicolumn{3}{c}{ Moldova } & \multicolumn{3}{c}{ Georgia } \\
& Male & Female & Total & Male & Female & Total \\
\hline Total Survey Sample & 5,806 & 6,459 & 12,265 & 7,334 & 8,906 & 16,240 \\
Total Adult Population Aged 18+ & 4,116 & 4,832 & 8,948 & 5,361 & 7,118 & 12,479 \\
\% of which had ever migrated & 27.4 & 18.7 & 22.4 & 12.9 & 10.1 & 11.3 \\
$\begin{array}{l}\text { \% of which were current } \\
\text { migrants }\end{array}$ & 10.8 & 5.8 & 8.2 & 7.1 & 5.8 & 6.4 \\
\hline
\end{tabular}

Source: CELB-MD/GE (2011/2). Percentages reflect weighted proportions. 


\subsubsection{Methodology \& Variable Definition}

Two analyses were conducted to investigate the research questions. The first predicted the odds ratios of an individual being a current migrant (a person who lived abroad at the time of the survey) rather than a non-migrant given different personal and household characteristics. Return migrants (individuals who had lived abroad for three or more months in the past but did not reside abroad at the time of the survey) were excluded from the analysis, as they represented a unique group from both current- and non-migrants whose past migration propensities could not be appropriately modelled with the available information. The second analysis predicted the relative risk ratios of current migrants migrating to the European Union or "other" region relative to the CIS region. The European Union region included all 28 current member states; the CIS region included the nine current member states and two participating states (Turkmenistan and Ukraine); the "other" region included all other countries, principally Turkey, Israel, and Canada.

Both analyses were restricted to the population aged 18 and over. Proportional population weights were specified in the first analysis to account for oversampling of particular population characteristics inherent to the sampling design. Weights were not specified in the second analysis given the random nature of sampling within the migrant subsample as well as due to small numbers of observations in certain sampling units. The first analysis was conducted three times: once with men and women together and then for men and women separately. Gender-pooled models were used to express the odds of female migration relative to male migration; gender-disaggregated models provided better insight into the differential role of personal and household-level traits on the propensity to migrate for both genders. Gender disaggregated models were not specified in the second form of analysis, as the sample sizes of each gender per destination country were sometimes prohibitively small.

Each analysis controlled for personal and household-level characteristics expected to influence migration propensities. Personal characteristics included an individual's sex; age and age squared, to account for the negative parabolic function between age and migration; the individual's marital status; the years of completed education, split into three groups (10 to 14 years, less than 10 years, and more than 14 years) with the reference category of 10 to 14 years roughly 
corresponding to the years of mandatory education, and; an indicator of an individual's ethnic minority status, to account for differing mobility patterns by ethnicity.

Household-level covariates included the presence of children (aged 17 or younger) and elderly individuals (aged 60 or older) in the household, to control for household structure and the presence of dependents; when the migrant was elderly him/herself, the number of co-resident elderly individuals was reduced by one so that the elderly migrant was not included in the control variable. Other household characteristics included the household's poverty status, determined by whether the household fell into the lowest quintile of a wealth index constructed on the basis of assets and housing conditions ${ }^{31}$, and; the region in which the household was located, to capture differences in migration propensities by geographical locale and proximity to state borders. In Georgia one additional variable was included indicating whether the household was currently considered internally displaced, to control for exposure to conflict and forced mobility in recent years.

The final analytical sample included only those individuals over the age of 18 who had information for each of the indicated control variables and who were not considered return migrants. Based on these exclusion criteria, the final analytical sample included 8,208 adults in Moldova and 11,833 in Georgia. A large number of observations were excluded given the 18+ age criteria; only a relatively small number of observations were excluded due to missing information. In- and out-of-sample observations did not differ significantly from one another on the basis of key variables, suggesting that information was missing at random. Descriptive statistics of the variables included in the analysis can be seen in Table 5.2 .

${ }^{31}$ Refer to Appendix D for additional information on the method used to construct the wealth index. 
Table 5.2: Weighted Means/Percentages of Variables in CELB-MD/GE (2011/2)

Dataset

\begin{tabular}{|c|c|c|c|c|}
\hline \multirow[b]{2}{*}{ Variable } & \multicolumn{2}{|c|}{ Moldova } & \multicolumn{2}{|l|}{ Georgia } \\
\hline & $\begin{array}{c}\text { Percentage/Mean } \\
\text { (SD) }\end{array}$ & $\mathrm{N} / n$ & $\begin{array}{c}\text { Percentage/Mean } \\
\text { (SD) }\end{array}$ & $\mathrm{N} / n$ \\
\hline Migrant Status & & 8,208 & & 11,833 \\
\hline Current Migrant & 8.6 & 878 & 6.6 & 1,934 \\
\hline Non-Migrant & 91.3 & 7,330 & 93.4 & 9,899 \\
\hline Sex & & 8,208 & & 11,833 \\
\hline Male & 44.4 & 3,655 & 42.8 & 5,004 \\
\hline Female & 55.6 & 4,553 & 57.2 & 6,829 \\
\hline Age & $46.5(.31)$ & 8,208 & $47.5(.25)$ & 11,833 \\
\hline Marital Status & & 8,208 & & \\
\hline Married & 66.5 & 5,387 & 66.3 & 7,735 \\
\hline Never Married & 14.6 & 1,284 & 15.2 & 1,868 \\
\hline Widowed & 14.1 & 1,184 & 14.8 & 1,734 \\
\hline Divorced & 4.8 & 353 & 3.7 & 496 \\
\hline Years of Education & & 8,208 & & 11,833 \\
\hline 10-14 Years & 50.6 & 4,141 & 56.4 & 6,909 \\
\hline Over 14 Years & 15.5 & 952 & 30.5 & 3,507 \\
\hline Less Than 10 & 33.9 & 3,115 & 13.1 & 1,417 \\
\hline Years & & & & \\
\hline Ethnic Minority ${ }^{1}$ & 17.1 & 1,336 & 9.9 & 1,112 \\
\hline Resides with Child & 58.9 & 5,074 & 61.8 & 7,427 \\
\hline Resides with & 34 & 2,793 & 47.4 & 5,930 \\
\hline
\end{tabular}


Elderly Person

Region of

Residence

$\begin{array}{lcccc}\text { Capital } & 20.8 & 865 & 25.2 & 2,929 \\ \begin{array}{l}\text { Centre (Georgia: } \\ \text { East) }\end{array} & 29.4 & 2,800 & 17.7 & 2,083 \\ \begin{array}{l}\text { North (Georgia: } \\ \text { West) }\end{array} & 29.8 & & & 5,138 \\ \begin{array}{l}\text { South } \\ \text { Household in }\end{array} & 19.9 & 2,365 & 41 & 1,683 \\ \begin{array}{l}\text { Lowest Quintile of } \\ \text { Wealth Index }\end{array} & 20.5 & 2,178 & 16 & 2,438 \\ \begin{array}{l}\text { Internally } \\ \text { Displaced }\end{array} & -- & 1,724 & 24.1 & \\ \text { Household } & & & & 355 \\ \end{array}$

Notes: Percentages \& means reflect weighted values whereas observation numbers indicate actual numbers in dataset. Standard errors indicated in parentheses. All variables have 8,208 observations (Moldova) or 11,833 observations (Georgia), with $N$ indicating the full sample number \& $n$ indicating the portion of the sample with a given attribute. ${ }^{1}$ Ethnic minorities in Moldova are nonRomanian or Moldova populations (chiefly Russian and Gagauzian) and in Georgia are non-ethnic Georgians (chiefly Armenians and Azeris). 'Internally displaced households occur only in Georgia.

\subsection{RESULTS}

Simple bivariate means comparisons and graphical representations of the mobility patterns of men and women suggest that migration from both Moldova and Georgia is a distinctly gendered process. In both countries, women entered international migration at a slower pace than their male counterparts. Men comprised the majority of migrants from Moldova in most time periods. The greater share of women among migrants who first left in the pre-1990 period likely reflects data collection methods rather than a real trend: information was collected 
only on surviving household members, and as men have lower life expectancies than women, it is likely that fewer male migrants who were old enough to have migrated in the Soviet period were included in the sample. The greatest single share of women among all migrants from Moldova in the post-independence years left in the 2008-2011 time period, when they represented 41 percent of all migrants. Georgian women, in contrast, outpaced their male counterparts as a proportion of new migrants by the 2002-2007 period, during which women accounted for nearly 60 percent of emigrants.

Figure 5.1: Migrants' Year of First Migration, by Gender \& Origin Country

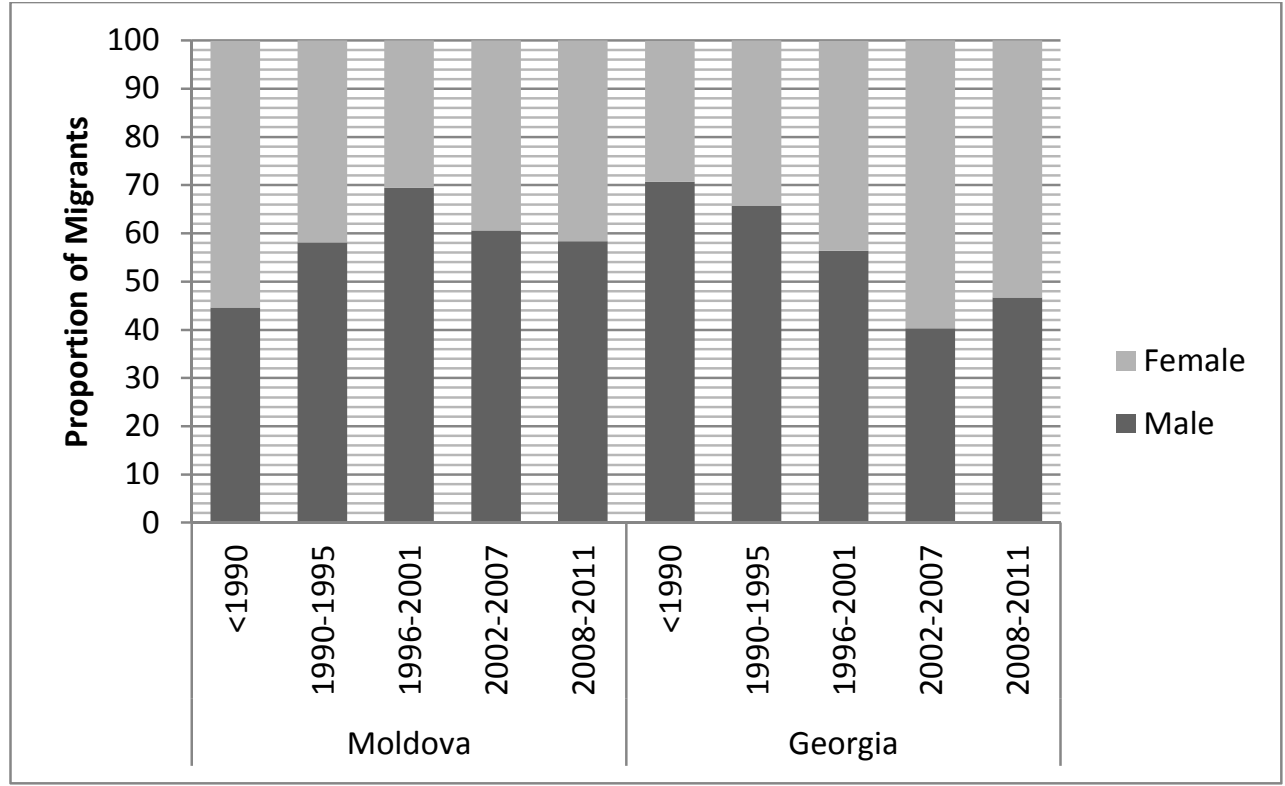

Source: CELB-MD/GE (2011/2). Note: Differences by gender are statistically significant at the 5percent level in both countries.

Male and female migrants not only began their migration projects at different moments but also chose different destinations. Migrants from both countries and of both sexes predominantly migrated to the CIS region (namely Russia) in the early 1990s, a trend that began to change by the mid-1990s. Moldovan men emigrated primarily to the CIS region regardless of time period, whereas Moldovan women began emigrating at higher rates to the EU-28 region in the early 2000s. Georgian men migrated primarily to the CIS region in the early 
transitional years but diversified their countries of destination in the early 2000s, a shift that coincided with the end of the visa-free travel regime for Georgians to Russia (Hofmann \& Buckley, 2013).

Figure 5.2: Destination Region of Georgian $\mathcal{E}$ Moldovan Migrants, by Sex E Year of First Departure

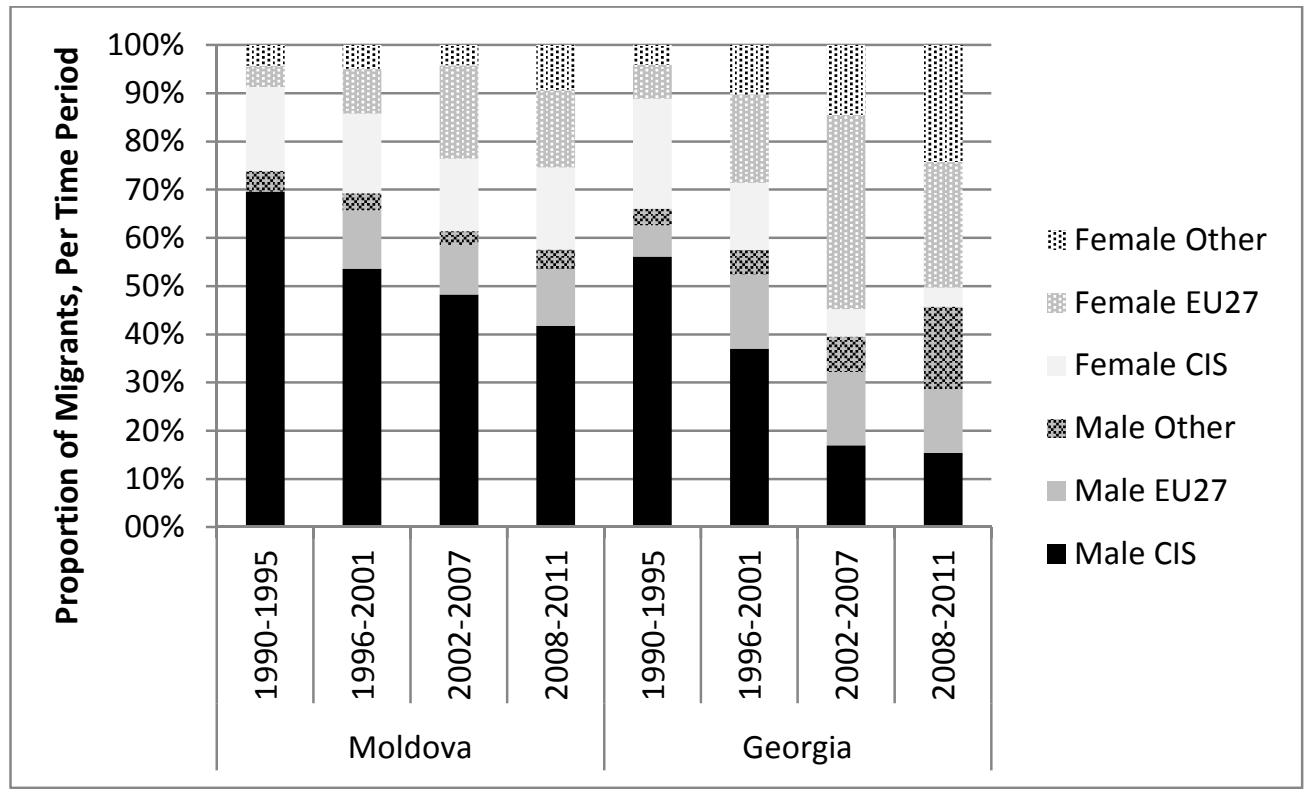

Source: CELB-MD/GE (2011/2). Note: Differences in gender are statistically significant at the 5percent level in both countries.

As would be expected given these flows, the greatest stocks of Moldovan migrants living abroad at the time of the survey resided in the CIS region, and the greatest portion of Georgian migrants resided in the EU-28 region. Men accounted for 75 percent of Moldovan migrants and over three-quarters of Georgian migrants in the CIS, whereas women accounted for over 60 percent of Moldovan and 70 percent of Georgian migrants in the EU region. The majority of migrants from both countries residing in the "Other" region were women. 
Table 5.3: Demographic Traits of Current- and Non-Migrants in Moldova $\mathcal{E}$ Georgia, by Sex

\begin{tabular}{|c|c|c|c|c|c|c|c|c|}
\hline & \multicolumn{4}{|c|}{ Moldova } & \multicolumn{4}{|c|}{ Georgia } \\
\hline & \multicolumn{2}{|c|}{ Male } & \multicolumn{2}{|c|}{ Female } & \multicolumn{2}{|c|}{ Male } & \multicolumn{2}{|c|}{ Female } \\
\hline & $\begin{array}{l}\text { Current } \\
\text { Migrant }\end{array}$ & $\begin{array}{c}\text { Non- } \\
\text { Migrant }\end{array}$ & $\begin{array}{l}\text { Current } \\
\text { Migrant }\end{array}$ & $\begin{array}{c}\text { Non- } \\
\text { Migrant }\end{array}$ & $\begin{array}{l}\text { Current } \\
\text { Migrant }\end{array}$ & $\begin{array}{c}\text { Non- } \\
\text { Migrant }\end{array}$ & $\begin{array}{l}\text { Current } \\
\text { Migrant }\end{array}$ & $\begin{array}{c}\text { Non- } \\
\text { Migrant }\end{array}$ \\
\hline $\begin{array}{l}\text { Average } \\
\text { Age }\end{array}$ & $35.1^{*+}$ & $46.2^{*}$ & $36.9^{*+}$ & $48.5^{*}$ & $40.6^{*+}$ & $46.6^{*}$ & $43.4^{*+}$ & $48.9^{*}$ \\
\hline Average & & & & & & & & \\
\hline $\begin{array}{l}\text { Years of } \\
\text { Education }\end{array}$ & $10.9^{*+}$ & $10.5^{*}$ & $11.4^{*+}$ & $10^{*}$ & $12.8^{*+}$ & $12.2^{*}$ & $13.1^{*+}$ & $12.1^{*}$ \\
\hline $\begin{array}{l}\text { Average } \\
\text { Household } \\
\text { Size }\end{array}$ & $4.6^{*+}$ & $4.1^{*}$ & $4.8^{*+}$ & $3.9^{*}$ & $4.5^{*+}$ & $4.9^{*}$ & $4.7^{*+}$ & $4.6^{*}$ \\
\hline Average & & & & & & & & \\
\hline $\begin{array}{l}\text { No. of } \\
\text { Children }\end{array}$ & $1.1^{*}$ & $1.0^{*}$ & $1.2^{*}$ & $1^{*}$ & $.89^{*}$ & $1.0^{*}$ & $.94^{*}$ & $1^{*}$ \\
\hline Average & & & & & & & & \\
\hline $\begin{array}{l}\text { No. of } \\
\text { Elderly }\end{array}$ & $.19^{*+}$ & $.43^{*}$ & $.27^{*+}$ & $.46^{*}$ & $.61^{*+}$ & $.66^{*}$ & $.52^{*+}$ & $.65^{*}$ \\
\hline Marital Statu & $(\%)$ & & & & & & & \\
\hline Married & $73.1^{+}$ & 71.7 & $62.0^{+}$ & 62.2 & $75.2^{+}$ & 75.8 & $55.7^{*+}$ & $59.4^{*}$ \\
\hline $\begin{array}{l}\text { Never } \\
\text { married }\end{array}$ & $23.2^{*+}$ & $18.4^{*}$ & $16.7^{*+}$ & $10.6^{*}$ & $21.1^{*}$ & $18.3^{*}$ & $18.6^{*}$ & $12.3^{*}$ \\
\hline Widowed & $.43^{*+}$ & $6.6^{*}$ & $5.6^{*+}$ & $21.6^{*}$ & $1.2^{*+}$ & $4.42^{*}$ & $12.7^{*+}$ & $23.3^{*}$ \\
\hline Divorced & $3.2^{+}$ & 3.2 & $15.6^{*+}$ & $5.4^{*}$ & $2.4^{*+}$ & $1.4^{*}$ & $12.8^{*+}$ & $4.8^{*}$ \\
\hline Ethnic & & & & & & & & \\
\hline $\begin{array}{l}\text { Minority } \\
(\%)\end{array}$ & $21.6^{*+}$ & $15.5^{*}$ & $16.8^{+}$ & 17.9 & $8.5^{*+}$ & $9.7^{*}$ & $5.6^{*+}$ & $10.5^{*}$ \\
\hline
\end{tabular}

Source: CELB-MD/GE (2011/2). Note: * $p<0.05$ between current-and non-migrants within gender group; ${ }^{+} p<0.05$ between men and women within current migrant group. 
Additional insight into the relationship between gender and migration is provided by examining the characteristics of migrants. Two telling comparisons can be made: between current migrants and non-migrants within each gender group and between male and female current migrants. Simple bivariate differences between these groups were explored using t-tests (Table 5.3).

Current migrants of both genders from both countries were significantly younger than their non-migrant counterparts, with the greatest age difference apparent between current- and non-migrant Moldovan women. In both countries current migrants were significantly better educated than non-migrants, and current migrant women had accrued more years of education than their male counterparts. In both countries the average household size was significantly larger among current migrants, with the exception of Georgian households containing a male current migrant. In Moldova, current migrants of both genders resided with a slightly higher number of children than did non-migrants, whereas the opposite was true in Georgia. There were no significant differences in the number of coresident children between male and female current migrants in either country. In both countries current migrants resided with a smaller number of elderly individuals than their non-migrant counterparts did. In both countries, a significantly larger proportion of current migrants than non-migrants had never been married or were now divorced or separated. A much larger proportion of women than men were either divorced or widowed. In both countries, ethnic minorities (chiefly Russian or Gagauzian among Moldovans and Azeri or Armenian among Georgians) made up a greater proportion of male than female current migrants. The differences between current- and non-migrants and between men and women suggest that migrants may indeed select into migration based on traits that differ from the general population. The comparisons made here are limited, however, as they do not capture the simultaneous interplay of personal and household characteristics that influence the migration decision. Multivariate probability models are better suited for this purpose.

Two multivariate logit analyses were performed to model how different characteristics shaped the odds of an individual migrating. The first binary logit analysis predicted the odds of men and women living abroad at the time of the survey; full results of this analysis can be seen in Table E.1 in Appendix E. Selected results of this analysis (Table 5.4) supported the suggestion that international migration is strongly gendered. 
Table 5.4: Odds Ratios of Being a Current Migrant, by Gender E Origin Country

\begin{tabular}{|c|c|c|c|c|c|c|}
\hline \multirow[b]{2}{*}{$\begin{array}{l}\text { Reference: Non- } \\
\text { migrant }\end{array}$} & \multicolumn{3}{|c|}{ Moldova } & \multicolumn{3}{|c|}{ Georgia } \\
\hline & $\begin{array}{c}\text { Both } \\
\text { Genders }\end{array}$ & Male & Female & $\begin{array}{c}\text { Both } \\
\text { Genders }\end{array}$ & Male & Female \\
\hline Female & $\begin{array}{l}0.49^{* * *} \\
(0.05)\end{array}$ & & & $\begin{array}{l}0.81 \\
(0.12)\end{array}$ & & \\
\hline Age & $\begin{array}{c}1.28^{* * *} \\
(0.03)\end{array}$ & $\begin{array}{l}1.31^{* * *} \\
(0.05)\end{array}$ & $\begin{array}{c}1.26^{* * *} \\
(0.04)\end{array}$ & $\begin{array}{l}1.40^{* * *} \\
(0.06)\end{array}$ & $\begin{array}{l}1.26^{* * *} \\
(0.07)\end{array}$ & $\begin{array}{c}1.57^{* * *} \\
(0.08)\end{array}$ \\
\hline $\mathrm{Age}^{2}$ & $\begin{array}{l}1.00^{* * *} \\
(0.00)\end{array}$ & $\begin{array}{l}1.00^{* * *} \\
(0.00)\end{array}$ & $\begin{array}{l}1.00^{* * *} \\
(0.00)\end{array}$ & $\begin{array}{l}1.00^{* * *} \\
(0.00)\end{array}$ & $\begin{array}{l}1.00^{* * *} \\
(0.00)\end{array}$ & $\begin{array}{r}0.99^{* * *} \\
(0.00)\end{array}$ \\
\hline $\begin{array}{l}\text { Marital Status (Ref.: } \\
\text { Married) }\end{array}$ & & & & & & \\
\hline Never Married & $\begin{array}{c}1.18 \\
(0.20)\end{array}$ & $\begin{array}{c}0.91 \\
(0.19)\end{array}$ & $\begin{array}{l}1.74^{*} \\
(0.47)\end{array}$ & $\begin{array}{l}1.45^{*} \\
(0.28)\end{array}$ & $\begin{array}{c}0.90 \\
(0.25)\end{array}$ & $\begin{array}{l}2.30^{* * *} \\
(0.57)\end{array}$ \\
\hline Widowed & $\begin{array}{c}1.31 \\
(0.33)\end{array}$ & $\begin{array}{c}0.61 \\
(0.40)\end{array}$ & $\begin{array}{c}1.53 \\
(0.44)\end{array}$ & $\begin{array}{l}1.68^{+} \\
(0.48)\end{array}$ & $\begin{array}{c}1.81 \\
(0.82)\end{array}$ & $\begin{array}{l}1.62 \\
(0.52)\end{array}$ \\
\hline Divorced/Separated & $\begin{array}{l}1.97^{* *} \\
(0.41)\end{array}$ & $\begin{array}{c}0.92 \\
(0.40)\end{array}$ & $\begin{array}{c}3.08^{* * *} \\
(0.70)\end{array}$ & $\begin{array}{c}2.24^{* * *} \\
(0.45)\end{array}$ & $\begin{array}{c}1.30 \\
(0.52)\end{array}$ & $\begin{array}{l}2.84^{* * *} \\
(0.63)\end{array}$ \\
\hline $\begin{array}{l}\text { Years of Education } \\
\text { (Ref.: 10-14) }\end{array}$ & & & & & & \\
\hline Over 14 & $\begin{array}{c}0.86 \\
(0.12)\end{array}$ & $\begin{array}{l}0.64^{*} \\
(0.13)\end{array}$ & $\begin{array}{c}1.15 \\
(0.20)\end{array}$ & $\begin{array}{c}0.93 \\
(0.14)\end{array}$ & $\begin{array}{c}1.03 \\
(0.22)\end{array}$ & $\begin{array}{c}0.86 \\
(0.18)\end{array}$ \\
\hline Less Than 10 & $\begin{array}{l}0.92 \\
(0.09)\end{array}$ & $\begin{array}{c}0.97 \\
(0.13)\end{array}$ & $\begin{array}{c}0.88 \\
(0.14)\end{array}$ & $\begin{array}{l}0.62^{*} \\
(0.13)\end{array}$ & $\begin{array}{c}0.61 \\
(0.19)\end{array}$ & $\begin{array}{c}0.74 \\
(0.21)\end{array}$ \\
\hline Minority Ethnicity & 1.17 & $1.50^{*}$ & 0.83 & 1.23 & 1.32 & 1.13 \\
\hline
\end{tabular}




\begin{tabular}{|c|c|c|c|c|c|c|}
\hline & $(0.15)$ & $(0.26)$ & $(0.18)$ & $(0.31)$ & $(0.24)$ & $(0.60)$ \\
\hline \multirow[t]{2}{*}{ Child in $\mathrm{HH}$} & $0.76^{*}$ & $0.67^{*}$ & 0.80 & $0.45^{* * *}$ & $0.50^{* *}$ & $0.39^{* * *}$ \\
\hline & $(0.10)$ & $(0.13)$ & $(0.13)$ & $(0.09)$ & $(0.13)$ & $(0.11)$ \\
\hline \multirow[t]{2}{*}{ Elderly Person in $\mathrm{HH}$} & 0.94 & $0.67^{*}$ & $1.45^{*}$ & $0.50^{* * *}$ & $0.64^{*}$ & $0.41^{* * *}$ \\
\hline & $(0.12)$ & $(0.12)$ & $(0.22)$ & $(0.07)$ & $(0.12)$ & $(0.08)$ \\
\hline \multirow{3}{*}{$\begin{array}{l}\mathrm{HH} \text { in Lowest Asset } \\
\text { Quintile }\end{array}$} & $0.48^{* * *}$ & $0.53^{* * *}$ & $0.41^{* * *}$ & $0.70^{+}$ & 0.84 & 0.58 \\
\hline & & & & & & \\
\hline & $(0.07)$ & $(0.10)$ & $(0.10)$ & $(0.15)$ & $(0.24)$ & $(0.19)$ \\
\hline \multirow[t]{2}{*}{ IDP Status } & -- & -- & -- & $0.65^{*}$ & 0.67 & $0.58^{+}$ \\
\hline & -- & -- & -- & $(0.13)$ & $(0.18)$ & $(0.17)$ \\
\hline Observations & 8,208 & 3,655 & 4,553 & 11,833 & 5,004 & 6,829 \\
\hline Goodness-of-fit test ${ }^{1}$ & .6777 & .8015 & .2020 & .6181 & .7876 & .9165 \\
\hline \multicolumn{7}{|c|}{$\begin{array}{l}\text { Note: Standard errors reported in parentheses; }{ }^{* * *} p<0.001,{ }^{* *} p<0.01,{ }^{*} p<0.05,{ }^{+} p<0.1 . \text { Regional } \\
\text { residence coefficients omitted for brevity but are available in Appendix E. }{ }^{1} \text { As the } p s e u d o-R^{2} \text { statistic } \\
\text { is not available following weighted estimation, model fit is assessed with the Archer-Lemeshow F- } \\
\text { adjusted mean residual test. }\end{array}$} \\
\hline
\end{tabular}

With never-migrants as the reference category, women in both Moldova and Georgia had lower odds of being international migrants than men. The odds of a Moldovan man living abroad at the time of the survey were twice that of women and significant at the 0.1-percent level. Georgian men also expressed higher odds of being current migrants than their female counterparts, but the difference was not statistically significant.

The results suggest that some factors that influence the migration choice may differ widely for men and women. Some factors, like age, were consistent for both genders. For emigrants from both countries, increased age was associated with greater odds of migrating up to a certain point (approximately 45 for Moldovan men and women, 47 for Georgian men, and 50 for Georgian women), after which the odds sharply declined. Other factors, such as marital status, were 
strongly associated with the migration odds of women but not men. In the genderpooled model, divorced individuals appeared to have higher odds of living abroad than married individuals, but this difference was driven exclusively by women. Gender-split models revealed that the odds of divorced women being current migrants were significantly higher than those of their married counterparts, by three times among Moldovan women and 2.8 times among Georgian women. Georgian women who had never been married also had significantly higher odds of residing abroad than married women, a difference that was not apparent among men. Other individual-level factors were significantly associated with differing migration odds only for men. Years of completed education corresponded to different odds of an individual being a current migrant, but only for Moldovan men, for whom completion of education beyond mandatory schooling corresponded to lower odds of being a current migrant, which may reflect the lowskilled nature of the labour Moldovan men perform abroad. Another factor that proved significant only for Moldovan men was ethnicity: ethnic-minority men (e.g. Gagauzians, Russians, Ukrainians) had odds of living abroad that were nearly 1.5 times higher than those of ethnic Moldovans/Romanians.

Household composition also differentially contributed to the odds of men and women living abroad. With the exception of Moldovan women, individuals who resided in a household with at least one child had lower odds of being current migrants. Georgian women appeared most hindered by the presence of children in the household: within this group, the odds of living abroad were less than half of those of their counterparts not residing with children (a result significant at the one-percent level). Residence with an elderly person corresponded to different migration odds between men and women in both countries. Whereas Moldovan men who resided with an elderly person had significantly lower odds of being a current migrant, women residing with an elderly person had odds of living abroad that were nearly 1.5 times higher than those of their counterparts not residing with an elderly person. Among Georgians, residence with an elderly person corresponded to lower odds of being a current migrant, with women again expressing the lowest odds of living abroad given residence with an older dependent. Some gendered differences in migration odds also appeared by household characteristics. Household wealth implied significant differences in the odds of being a current migrant among Moldovans. Both men and women living in households in the bottom quintile of the asset index had much lower odds of living abroad; for women this was particularly marked, as non-poor women had odds of 
migrating that were more than twice those of their poor counterparts. In Georgia, individuals residing in households that were designated as internally displaced expressed much lower odds of living abroad, a relationship significant at the fivepercent level in the gender-pooled model.

The results of this first analysis suggest that the mobility decisions of men and women may be shaped by different factors-and that female mobility generally lags behind that of men. The lower odds of Moldovan women migrating relative to men demonstrates this well, but an even clearer illustration of this can be made by interpreting results as predicted probabilities. Odds ratios provide a summary score of the constant effect of a variable on the odds of an outcome occurring, whereas predicted probabilities provide a sense of how varying values of predictors affect the probability of a given outcome occurring.

The probabilities of women and men being current migrants were predicted following the gender-pooled estimation represented in Table 5.4, with the age and presence of children in the household variables set at specific values and all other predictors held at their sample means. Probabilities were estimated for individuals with and without children in the household and at five different ages: $24,29,34,42$, and 46 . These ages roughly correspond to different fertility landmarks. According to national statistics, the average age of a woman at the birth of her first child was just over 23 years in both countries in 2010. The ages at which probabilities were estimated thus correspond to the average age at first child birth and then for the ages at which a child would be five, ten, and 18-a selection of ages in early childhood, early adolescence, and late adolescence. The probability was then estimated for the mean age of adults in the sample.

Figure 3 demonstrates that women, particularly those residing with children during prime child-bearing and rearing ages, had much lower probabilities of being current migrants than men. This suggests that women are particularly dissuaded from migrating by family obligations, which is supported by the highly-significant relationship between female marital status and migration odds. Marked differences in migration probabilities can also be seen between the two countries. The difference between the probabilities of men and women being migrants was much greater in Moldova than in Georgia, regardless of residence with a child. In Georgia the differences of probabilities were much greater between individuals with and without resident children. 
Figure 5.3: Predicted Migration Probabilities by Age \& Child Presence

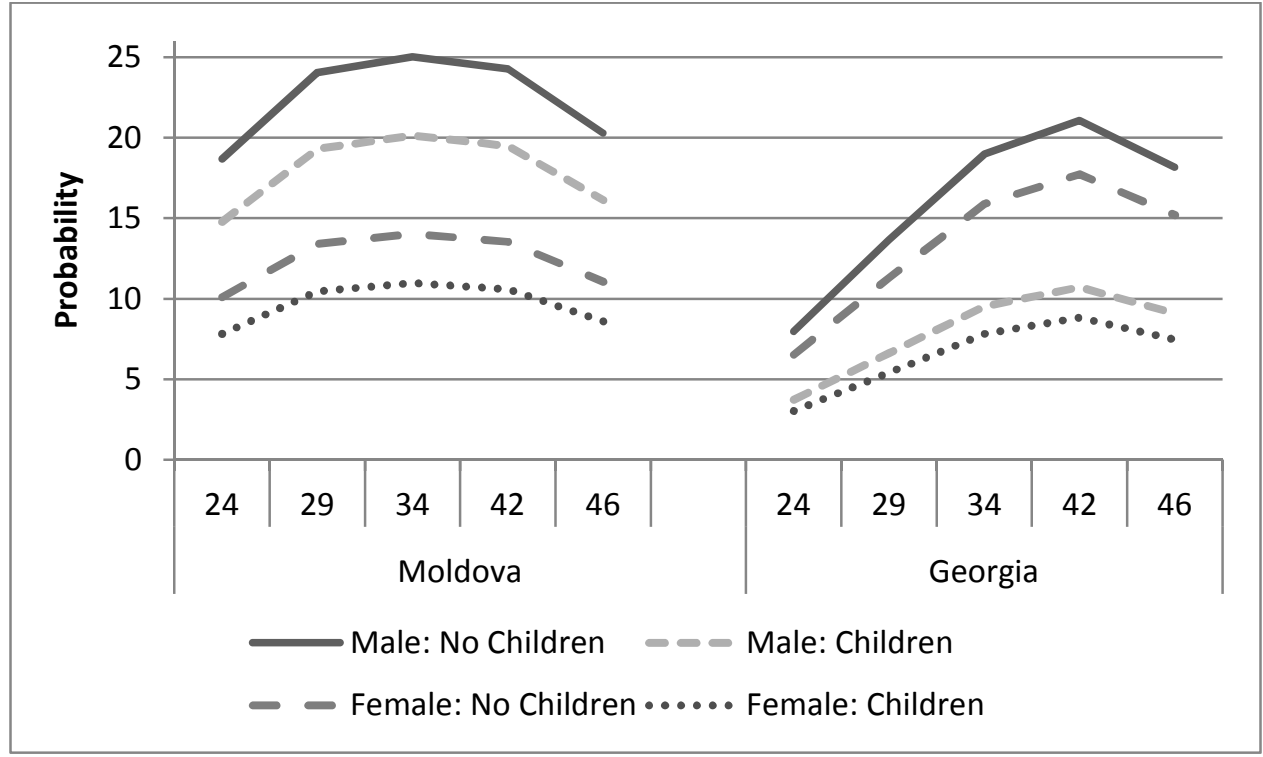

The second analysis, conducted with a multinomial logit model, compared the relative risk of men and women migrating to the EU-28 and "Other" regions relative to the CIS region; the same variables were included in this analysis as in the first, but only the most relevant variables have been selected for discussion, with full model results available in Table E.2 in Appendix E. The results of the multinomial logit analyses (Table 5.5) suggest that women from both countries had much higher relative risks of migrating to both the EU-28 and "Other" regions compared to their male counterparts: Moldovan women had seven times the risk of migrating to the "other" region rather than the CIS region compared to men, and Georgian women had nearly ten times the risk of migrating to the EU-28 region than men.

Some characteristics were more highly associated with migration to specific destination regions than others. Being unmarried or divorced/widowed, for instance, strongly corresponded to higher risks of migration into the EU-28 regions rather than the CIS region among Moldovan migrants. Among Georgian migrants, being divorced/widowed corresponded to increased risks of migrating to the "Other" region. Given the strong domination of women among migrants destined for these regions, these results are likely driven by women. 
Table 5.5: Relative Risk Ratios ${ }^{1}$ of Current Migrants per Destination

\begin{tabular}{|c|c|c|c|c|}
\hline \multirow[b]{2}{*}{ Destination: CIS (ref) } & \multicolumn{2}{|c|}{ Moldova (Both Genders) } & \multicolumn{2}{|c|}{ Georgia (Both Genders) } \\
\hline & $\begin{array}{c}\text { Destination } \\
\text { EU-28 }\end{array}$ & $\begin{array}{l}\text { Destination } \\
\text { Other }\end{array}$ & $\begin{array}{l}\text { Destination } \\
\text { EU-28 }\end{array}$ & $\begin{array}{l}\text { Destination } \\
\text { Other }\end{array}$ \\
\hline Female & $\begin{array}{c}4.57^{* * *} \\
(0.80)\end{array}$ & $\begin{array}{c}7.17^{* * *} \\
(1.81)\end{array}$ & $\begin{array}{c}9.52^{* * *} \\
(1.37)\end{array}$ & $\begin{array}{c}6.17^{* * *} \\
(0.93)\end{array}$ \\
\hline $\begin{array}{l}\text { Marital Status : Married } \\
\text { (ref) }\end{array}$ & & & & \\
\hline Never Married & $\begin{array}{l}1.81^{+} \\
(0.60)\end{array}$ & $\begin{array}{c}1.20 \\
(0.53)\end{array}$ & $\begin{array}{c}1.16 \\
(0.21)\end{array}$ & $\begin{array}{c}0.99 \\
(0.20)\end{array}$ \\
\hline Widowed/Divorced & $\begin{array}{l}2.14^{*} \\
(0.64)\end{array}$ & $\begin{array}{c}1.78 \\
(0.69)\end{array}$ & $\begin{array}{c}1.23 \\
(0.26)\end{array}$ & $\begin{array}{l}1.92^{* *} \\
(0.41)\end{array}$ \\
\hline Children in household & $\begin{array}{l}0.65^{\dagger} \\
(0.17)\end{array}$ & $\begin{array}{c}0.84 \\
(0.29)\end{array}$ & $\begin{array}{c}1.26 \\
(0.20)\end{array}$ & $\begin{array}{l}1.47^{*} \\
(0.24)\end{array}$ \\
\hline Elderly in household & $\begin{array}{c}0.65 \\
(0.18)\end{array}$ & $\begin{array}{c}1.01 \\
(0.33)\end{array}$ & $\begin{array}{l}0.70^{*} \\
(0.11)\end{array}$ & $\begin{array}{l}0.68^{*} \\
(0.11)\end{array}$ \\
\hline Observations & 841 & 841 & 1,890 & 1,890 \\
\hline McFadden's Pseudo $R^{2}$ & 0.191 & 0.191 & 0.150 & 0.150 \\
\hline
\end{tabular}

Note: ${ }^{1}$ Estimated coefficients of multinomial logit models are expressed as relative risk ratios (rather than odds) as the coefficients are always produced relative to a base category in an estimation with more than two outcome categories. Some covariates omitted from display; full results available in Appendix E. Standard errors reported in parentheses; ${ }^{* * *} p<0.001,{ }^{* *} p<0.01,{ }^{*} p<0.05,{ }^{+} p<0.1$.

Household composition also corresponded to differing risks of migrating to a particular region. Residing in a household with children corresponded to marginally lower risks of migrating to the EU-28 region relative to the CIS region among Moldovan migrants and higher risks of migrating to the "Other" region relative to the CIS region among Georgian migrants. These results likely reflect 
how the distance between home and destination, as well as the migration regulations in the destination country, factor into the migration decision. Russia is relatively closer for Moldovan migrants than EU-28 destination countries (such as Italy), whereas for Georgian migrants, the main Russian destinations (Moscow and St. Petersburg) are further away than Turkey. Furthermore, both Moldovans destined for Russia and Georgians destined for Turkey benefit from relatively lax visa and residency requirements in which residency and work permits are not required for individuals who exit the country at least once every 90 days. This is likely to facilitate circular migration and enable migrants to justify international migration without compromising their accessibility to family. Residence with an elderly individual did not correspond to significantly-different risks of migrating to a particular destination among Moldovan migrants, but among Georgian migrants, residing with an elderly person corresponded to lower risks of migrating to a country outside of the CIS region.

\subsection{DISCUSSION \& CONCLUSIONS}

Over the post-Soviet years, both Moldova and Georgia have experienced a "feminisation of migration", but the composition of these feminised flows differs in important ways between the countries. One notable difference is in the scale of the participation of women in international moves. Over the course of the post-Soviet years, Moldovan women consistently comprised a smaller share of new migrants than did men; in Georgia, in contrast, women represented more than half of all new migrants beginning in the early-to-mid 2000s. This descriptive observation is matched by the finding that in Georgia, men and women did not have significantly different odds of being migrants, whereas in Moldova, women had much lower odds than men of migrating.

A second notable difference between Moldova and Georgia is in the intersection between gender and household composition and what this may imply for migration propensities. Among Moldovans, men, rather than women, had lower odds of migrating given the presence of children or the elderly in the household; the odds of a woman migrating were not significantly associated with child co-residence but significantly (and positively) associated to the presence of elderly household members. In Georgia, both men and women had lower odds of 
migrating given the presence of dependents in the household, but the relationship was stronger for women. This difference could suggest that whereas women in Georgia are dissuaded from migrating given perceived and specific obligations to the household (in the form of, for instance, childcare), women in Moldova may be dissuaded from migrating given broader expectations about them as mothers/wives/daughters. This may explain why the odds of Moldovan women migrating are so much lower than those of men despite not being significantly associated with the presence of dependents in the household (a finding visualised in Figure 3).

These differences are likely to reflect the social and political contexts in which migration occurs in each country. Public discussion of the potentiallydisruptive effects of migration for family life is more heated in Moldova, where emigration-particularly that of women-has been addressed in different public fora. In 2008, a national action plan for children left without parental supervision was introduced as part of a larger strategy on the return of labour migrants to Moldova (IOM, 2012). High profile international organisations such as the International Organisation for Migration (IOM), HelpAge International (HAI), and the United Nations Children's Fund (UNICEF) have also conducted studies and projects specifically on the children with migrant parents (see, for instance, UNICEF/CIDDC, 2006; HAI, 2008; UNICEF/CRIC, 2008), which have drawn attention to the potential (and largely negative) repercussions of migration for family solidarity. Such discussions are likely to contribute to public perceptions of migration as a disruptive phenomenon and to contribute to stigmatisation of female migration, particularly given the focus on the negative consequence of mothers' migrations. Perceptions of (female) migration may also differ between Moldova and Georgia due to the reliance in Georgia on female emigration as a livelihood strategy. Following the 2008 Georgia-Russian War, an essential door to foreign employment closed for men, contributing to greater reliance on female migration. In Moldova, no such transition has been required, which may contribute to perceptions that female migration is less necessary and more motivated by personal desires. Family structures and the subsequent roles of women in the household and the family also differ between the countries. In Georgia, multigenerational households are common, and both financial and caring responsibilities are often shared among extended kin (Badurashvili et al., 2008), which may facilitate female migration. Hofmann \& Buckley (2011), for instance, found that the availability of alternative caregivers for children in a household 
(such as grandparents) eased the transition of mothers into international migration. In contrast, nuclear-family households are more common in Moldova and may limit the resources available within the kinship network, implying that that migration of a woman represents a more radical redistribution of roles and tasks.

Moldova and Georgia are valuable to compare for both their differences and similarities. In both countries, current migrant women were on average older than their male counterparts and had more years of education, features that can both be connected to the contexts of female-specific destination countries. Women from both countries had higher odds of migrating to a country outside of the CIS region than did men and represented a greater share of migrant stocks in the EU28 and "Other" region than did men. This likely reflects the expansion of employment opportunities in home- and eldercare markets in countries as varied as Italy, Greece, Turkey, and Israel. A significant share of women in the sample (30 percent of Moldovan and 38 percent of Georgian women) worked for individual household employers as live-in eldercare providers, child minders, or housekeepers (or often, all three). Increased growth in these sectors is likely to increase the employment opportunities for women-particularly those with some education or training and whose own domestic duties, such as childcare, have lessened with their transition to other stages in the life cycle. Men, in contrast, may face diminishing opportunities, particularly given their heavy concentration in sectors such as construction (where more than 68 percent of the Moldovan and 35 percent of the Georgian male sample worked). Changes to receiving-country labour markets as well as shrinking opportunities for legal migration to particular destinations, namely Russia for Georgian men, may promote the allocation of women (and a particular type of women) into particular labour markets. Another striking similarity between Moldova and Georgia is the relationship between migration odds and marital status. In both countries, marital status seldom corresponded to significant differences in the migration odds of men, whereas for women, being married was associated with significantly lower odds of being a migrant (particularly compared to divorced women). This may suggest that lifecycle factors (marriage, child-bearing, and elderly-care, among others) and the gendered expectations they imply shape male and female migration in different ways, a finding that echoes those from other studies in countries such as Mexico (e.g., Kanaiaupuni, 2000; Cerrutti \& Massey, 2001). Taken together, these results illustrate how economic processes and cultural practices can collude to support or constrain feminised migration flows. 
Despite these insights, this analysis faced some limitations. The first is that the results can only be generalised to the population residing in households with children or the elderly as a result of the targeted sampling procedure. This makes it challenging to compare the results to those of other studies that sample from the entire population, but it is notable that the results do broadly align with the results found by Hoffmann and Buckley (2013) in their study of the feminisation of migration from Georgia. Furthermore, it is precisely the population of potential migrants living in households with dependents that many public policies or programme interventions target; the results provide particularly relevant insight into potential migration dynamics within the context of multigenerational families or households.

Reverse causality is a second limitation. The results of the analysis suggest that there is a relationship between female divorce and migration, for instance, but it is unclear if migration precipitates or is precipitated by divorce because information was not collected on the timing of divorce. Evidence from in-depth interviews conducted in both countries suggests that divorce prompts migration by providing an escape from the stigma and shame of divorce and from the tenuous economic situations divorced women face (as found by Hill, 2004), but the survey data provide limited insight into this particular trend. In the future more detailed data on the timing of key life decisions should be collected, and appropriate methods for controlling endogeneity ${ }^{32}$ should be developed.

Despite these limitations, this chapter makes three important contributions to the literature on the feminisation of migration. The first is in highlighting inherent differences in the migration experiences of men and women. The contrast in the results between gender-pooled and gender-split models highlighted the dangers of simply including gender as a control variable rather than specifying gender-separate analyses. Covariates that appeared significant in the genderpooled models were often driven exclusively by one gender, suggesting that the factors that influence (or are influenced by) migration function differently for men and women.

The second contribution is in providing evidence of the size and character of female migration from two countries with growing public interest in the potential social consequences of female mobility. The active discourses

${ }^{32}$ Please refer to section 8.4 for additional discussion of endogeneity. 
surrounding female migration, particularly in Moldova, envisage an exodus of women who have abandoned their households. The results suggest that Moldovan women are not necessarily probable migrants. This is not to say that mothers are not migrating at all, or indeed that their migration has no problematic consequences. What it does suggest, however, is that the choice to become a migrant is likely a nuanced process that is negotiated in specific ways within the households and families in which women are embedded. Rather than problematising female migration in general, policy could more progressively address likely "risk factors" that push women (more so than men) into international migration-including, for instance, with the potential vulnerabilities introduced by divorce.

The final contribution of this paper is in its regional, country-comparative focus. Prior literature on the topic has overwhelmingly focused on countries such as Mexico, with long-established migration routes and networks, or countries like the Philippines, where specific labour migration regimes regulate and promote particular forms of female migration. Moldova and Georgia provide entirely different mobility contexts, particularly as the transition from Soviet republic to independent state enabled unprecedented opportunities for personal mobility. The on-going political and economic transitions in each country have contributed to the development of migration systems that are incomparable to those of many other states. The comparison of the nature and scale of gendered mobility from these two former Soviet states thus not only provides insight into region-specific trends but also provides points of comparison for studies conducted elsewhere, enabling better understanding of what the "feminisation of migration" actually means in a wider global context. 


\section{CHAPTER SIX: 'LEFT BEHIND' BUT NOT LEFT ALONE - PARENTAL MIGRATION \& THE PSYCHOSOCIAL HEALTH OF CHILDREN IN MOLDOVA 33}

\subsection{INTRODUCTION}

In the past decade, female migration from Moldova has rapidly increased, raising concerns about the consequences of migration for families 'left behind'. By 2010 nearly 22 percent of the Moldovan population was estimated to live abroad (World Bank, 2010), with women thought to account for nearly half of all new migrants (Salah, 2008). The increased participation of women in international migration has contributed to a public discourse in which migration is inextricably linked with the family, particularly with the abandonment of children (Flamminio, 2011). Past research, primarily based on small-scale studies and consultancy reports, has focused on negative emotional and social repercussions of migration (UNICEF/CIDDC, 2006; UNICEF/CRIC, 2008) and has sampled children living in extraordinary circumstances of vulnerability (HAI/UNICEF, 2008). This has contributed to a negative and normative discourse on transnational families in Moldova that ignores the inherent complexity of family relations, caregiving regimes, and migration systems. This discourse highlights a need to better understand the dynamics of the relationship between parental migration and child well-being.

Since the end of the 1990s, Moldova has experienced high, sustained emigration that is thought to disproportionately affect certain population groups, such as children and the elderly. Most migrants leave to find work abroad, with men largely destined for low- and medium-skilled (manual) labour markets in Russia and women increasingly migrating for work in the care and home services sector in countries in the European Union, particularly Italy. The majority of migrants are between 18 and 44 (IASCI/CIVIS, 2010)-precisely the ages in which families are started and sustained, resulting in a large number of children being left

33 This chapter is based on: Vanore, M., Mazzucato, V., \& Siegel, M. (2014). "'Left behind' but not left alone: Parental migration and the psychosocial health of children in Moldova". Social Science and Medicine. DOI: 10.1016/j.socscimed.2014.08.040. 
in the care of the other parent, grandparents, siblings, or other caregivers. In 2005, it was estimated that 31 percent of all children aged 0-14 had one or both parents abroad (UNICEF/CRIC, 2008), a trend that has likely persisted.

Despite the size of the population of children with migrant parents, relatively little is known about it. This article empirically measures the influence of parental migration on the psychosocial health of Moldovan children. Using data derived from a large-scale household survey implemented in Moldova in 2011/12, the psychosocial health outcomes of children aged four to 17 with and without migrant parents are compared using multivariate regression methods. The results suggest that parental migration does not correspond to universally negative psychosocial outcomes. Rather, male and female children exhibit different outcomes that vary by the specific form of parental migration. This difference underscores the value of engaging an appropriate control group and analysing male and female children separately. These results contest much of the prior research conducted on children who remain in Moldova following the migration of a parent while suggesting ways forward in elucidating the complex relationship between child psychosocial health and parental migration.

\subsection{BACKGROUND}

A growing body of research within the fields of transnational migration and family and child psychology has focused on the perceived relationship between parental migration and child psychosocial health (Mazzucato \& Schans, 2011). Studies on family and child psychology have investigated the consequences of parental separation on children using largely quantitative approaches, but few have studied migration as a unique form of separation. Transnational family studies, in contrast, have provided qualitative accounts of child psychosocial health in contexts of family migration. Several recent studies, particularly in Asia, have synthesised theoretical frameworks and methodological approaches from both fields in their evaluation of the psychosocial health of children 'left behind' (Graham \& Jordon, 2011; Mazzucato, 2014a).

Family and child psychology studies draw on attachment theory to understand the links between child psychological health and parental absence or presence. An 
attachment is a substantial, enduring, affective bond between individuals. The first type of attachment a child forms is generally to its mother or other habitual caregiver, which is supplemented over time by attachments to other persons (Ainsworth, 1969; Bowlby, 1982). In very young children, attachments tend to be dependency relationships characterised by a drive to maintain physical proximity to a primary caregiver, which transforms into a drive to maintain symbolic proximity via less direct communication, such as through phone calls, as an individual matures. The actual or threatened disruption of attachments can lead a child to experience depression, anxiety, or anger when proximity cannot be maintained. Interruptions in attachment relationships-or the development of unresponsive or unpredictable attachment relationships-shakes the sense of security an individual derives from attachments (Armsden \& Greenberg, 1987). Migration of a caregiver, and the disruption to physical proximity it may bring, may cause significant psychological distress among recipients of care.

Most child and family psychology studies using attachment theory largely focused on the separation of parents from children owing to crisis events such as incarceration, death, or divorce (Mazzucato, 2014a). These studies have found strong negative repercussions of parental loss for children's emotional well-being, particularly in cases in which prolonged uncertainty about the permanence of loss or its cause (ambiguous loss) blocked appropriate coping and stress management, resulting in the deterioration of family life when tasks and roles were not reassigned (Carroll, Olson \& Buckmiller, 2007; Boss, 2004). Despite its conceptual parallels with other forms of ambiguous loss, migration as a specific separation event has seldom been studied. One exception is Nobles (2011), who compared the experiences of children of divorced and migrant fathers in Mexico. Nobles found that despite some similarities between divorce and migration-such as negotiation of the shift in authority within the household, the reconciliation of family and household roles, and coping with a sense of abandonment-the two forms of absence were not equivalent. Migrant fathers were found to communicate more consistently with their children and to invest more equally in their children than did divorced fathers, who tended to privilege specific children in the household (Nobles, 2011). This difference importantly suggests that the results of studies on other forms of loss cannot be extrapolated to situations of parental migration because the underlying mechanisms differ. 
Literature from transnational family studies has focused more on separation through migration; whereas much of the literature has used qualitative methods to study children in transnational family arrangements (Dreby, 2006; Schmalzbauer, 2004; Åkesson, Carling, \& Drotbohm, 2012), this section reviews those studies that have combined a transnational approach with more quantitative techniques given their methodological relevance to the present study. Recent research on children 'left behind' has identified important differences in the contexts of parental migration that influence the emergence of negative outcomes (Mazzucato, 2014a). Smith, Lalonde, and Johnson (2004), for instance, found that children of Caribbean serial migrants often displayed low self-esteem and behavioural problems. Jones, Sharpe, and Sogren (2004) similarly found that children with parents living abroad were twice as likely to experience emotional problems (such as anxiety and depression) as members of their cohorts without migrant parents. In their study of children who had been separated from their migrant parent(s) prior to reunification in the United States, Suárez-Orozco, Ban, and Kim (2011) found that separation and reunification corresponded to a higher incidence of anxiety and depression symptoms among children. These studies all suggest that the development of problematic behaviours is strongly influenced by factors such as the duration of parental absence, the child's age at separation, and the changing of caregivers.

Other studies have found clear differences in child outcomes by who had migrated. In a review of research on children of migrants in the Philippines, Parreñas (2005) noted that many studies found an increased incidence of psychological disturbance, juvenile delinquency, and social problems among the children of migrants, particularly when the mother had migrated. Jordon and Graham (2012), in a comparison of children living in different forms of transnational families in Indonesia, the Philippines, and Vietnam, found that children with mothers living abroad were less likely to report feeling happy than were children living in other household types. In contrast, an earlier analysis of the emotional health of children in transnational families using the same dataset found that Indonesian children with migrant fathers were slightly more likely than children with both parents at home to have an emotional problem, and Thai children with a father abroad were slightly more likely to have a conduct problem (Graham \& Jordan, 2011). Additional research has suggested that it is the combination of who has migrated and who takes on care-giving roles that shapes how children cope with parental migration. Children of migrants cared for by 
grandparents were found to be more likely to experience severe loneliness in China (Jia \& Tien, 2010) and to feel emotional distress and show delinquent or high-risk behaviour in Moldova (Prohnitchi, 2005).

Taken together, these studies provide more richly-textured accounts of the factors that can affect child psychosocial health following parental migration. Importantly, they suggest that parental migration does not automatically imply worse psychosocial outcomes: factors such as the child's age, the child's gender, and characteristics of the migrant and caregiver all affect the consequences parental migration may bear for children. These studies also highlight persistent gaps in the literature. Empirical studies using appropriate analytical methods to assess the consequences of parental migration for children in Eastern Europe are lacking. Studies that have been conducted in this region tend to focus exclusively on children with migrant parents, without comparison to an appropriate control group of children who parents do not live abroad. This limits the degree to which negative psychosocial behaviours can be attributed to parental migration (Mazzucato \& Schans, 2011). An additional shortcoming is that many studies rely on the reporting of feelings rather than on objectively worse outcomes, which problematises behaviours or feelings that are not necessarily indicative of psychosocial abnormalities. These gaps underscore the need to assess the relationship between parental migration and child psychosocial health in Moldova using well-defined, comparable indicators of psychosocial health that facilitate cross-group comparison.

The present study investigates the relationship between parental migration and child psychosocial health outcomes among children between the ages of four and 17 by comparing children with parents who have migrated internationally with children residing with both parents. Based on the above-mentioned studies, several hypotheses are explored: (1) Children with a migrant parent will be more likely than children without migrant parents to achieve abnormal psychosocial outcomes; (2) maternal absence will be associated with stronger, negative psychosocial outcomes than paternal absence; and (3) type of caregiver will mediate the relationship between parental migration and psychosocial health outcomes, with caregiving from a non-parent associated with negative psychosocial outcomes. 


\subsection{METHOD}

\subsubsection{Data}

The analysed data were obtained from the study "Effects of Migration on Children and the Elderly Left Behind in Moldova and Georgia" (CELB-MD). Within this project, a nationally-representative household survey was conducted in Moldova between September 2011 and February 2012 among 3,571 households. Data collection was subject to the ethical standards elaborated in the International Code on Market and Social Research of the International Chamber of Commerce and the European Society for Opinion and Market Research (ESOMAR). The survey spanned all regions of Moldova except the breakaway territory of Transnistria. The sampling frame was provided by the Moldovan National Bureau of Statistics from the Moldovan Labour Force Survey (LFS) conducted in the second quarter of 2011. The LFS is conducted on a quarterly basis and covers the entire population of Moldova with the exception of individuals residing in institutions and those residing in Transnistria (including the city of Tighina).

The CELB-MD survey was implemented among households containing at least one child or elderly individual. The sample included households both with and without migrant members. The survey collected standard demographic information on all household members, information on living standards (including incomes, expenditures, and housing conditions), the migration histories of household members, and the characteristics of the daily lives of the children in the household. The primary respondent was the most-knowledgeable respondent in the household (generally the household head or the spouse of the household head), but specific information on children was collected from the primary caregiver (the individual providing the most care on a frequent basis) of each child in the household. Caregivers were interviewed about each child's health, education, migration plans, time allocation, and emotions and attitudes as well as on their own parenting or caregiving practices. 


\subsubsection{Variable Identification \& Measurement}

Two measures of child psychosocial health were used in the following analysis: the emotional symptoms and conduct problems subscales of the Strengths and Difficulties Questionnaire (SDQ), of which the validated Romanian- and Russian-language translations provided on the SDQ website were implemented. The SDQ is a widely-used behavioural screening instrument developed by Goodman (1997) to measure child and adolescent mental health in clinical practice, epidemiological settings, and developmental research (Goodman \& Scott, 1999). The SDQ comprises 25 questions divided among five subscales: conduct problems, hyperactivity and inattention, emotional symptoms, peer problems, and prosocial behaviour. All subscale scores but the last can be aggregated into a single metric called the total difficulties score. In all subscales but the last, higher scores indicate movement toward problematic behaviours. Scores can be interpreted either continuously or categorically, with scores divisible into "normal", "borderline", or "abnormal" categories.

The emotional symptoms subscale and conduct problems subscale scores were chosen as measures of child psychosocial health as they represent "internalising" and "externalising" problems (Goodman \& Scott, 1999), which generally differ by child gender (Eisenberg et al., 2001). Internalising problem behaviours include anxiety, depression, and psychosomatic reactions, and externalising problem behaviours include the outward expression of negative emotions through aggressive and delinquent behaviours (Eisenberg et al., 2001; Achenbach, Edelbrock, \& Howell, 1987). The emotional symptoms and conduct problems subscales were preferred over the other SDQ subscales in the present data for the internal consistency of their components; a principal components analysis revealed more consistent loadings of the respective subscale items onto single factors than occurred among the items of the other subscales. Larger proportions of the child population scored in the highest ranges of the peer problems and hyperactivity and inattention subscales as well, potentially signalling poor calibration of these scales to the local context. The aggregation of these individual subscales into the total difficulties score could result in a poorlyperforming measure given the Moldovan context, a problem reported in other countries such as Bangladesh where the total difficulties score was found to poorly discriminate between community and clinical samples (Mullick \& Goodman, 2001). 
The emotional symptoms and conduct problems subscales were thus preferred given their better performance.

As dependent variables, the emotional symptoms and conduct problems scores were converted from continuous to categorical values. Normative data are absent for Moldova, thus it is unclear if the score bandings suggested by Goodman (1997) on the basis of child populations in the United Kingdom are appropriate for detecting mental health problems among children in this particular country context. As in prior studies lacking normative data (such as Graham \& Jordan, 2011), scores within the borderline and normal categories were aggregated to reduce possible overestimation of high outcomes. Using this method, scores between zero and four in the emotional subscale and between zero and three on the conduct problems subscale were considered "normal". Scores between five and ten on the emotional symptoms subscale and four to ten on the conduct problems subscale were then considered "abnormal". As the goal of this study is not to determine mental health disorder but rather to compare the outcomes of population subgroups, the normal/abnormal score division is used to signal differences between scores of least concern ("normal") and more concern ("abnormal"), with the "normal/abnormal" designations retained for easier comparison to other studies using the SDQ. Sensitivity analyses using ordered probit models found that the most significant differences between categories occurred at the scores that coincide with the "abnormal" threshold; only marginally-significant differences were apparent at lower thresholds, suggesting that an appropriate categorical threshold was chosen.

Three major predictor variables were constructed relating to parental migration status. The first was a simple binary variable indicating if a child had one or both parents living abroad for at least 12 months consecutively at the time of the survey, and the second was a categorical variable indicating who lived abroad (mother, father, or both parents, with no migrant as the reference category). The third was a categorical variable that identified the unique migrant and caregiver combination (no parent abroad/other caregiver, mother migrant/father caregiver, mother migrant/other caregiver, father migrant/mother caregiver, and both parents abroad/other caregiver, with no parent abroad/parent caregiver as reference category). 
Additional confounders were included in the analysis to control for child-, household-, and caregiver-level characteristics. Child-level covariates included age and age-squared to accommodate the non-linear effect of age on psychosocial health, whether the child had a long-term illness, the caregiver's report of the child's school performance compared with members of his/her cohort, and parity. Household-level covariates included household size, if the household contained a return migrant (an individual who had lived abroad in the past but had since returned to live in the household), and poverty status, a binary variable indicating if the household was in the bottom quintile of a wealth index constructed on the basis of assets and housing quality variables. Caregiver-level covariates related to the child's primary caregiver and included caregiver type (child's parent, grandparent, or someone else), sex, and years of completed education. Other covariates addressed the child-caregiver relationship, including the number of activities the child and caregiver did together at least once a week (such as playing, discussing homework, and doing household chores), a caregiver's use of verbal reprimands such as calling a child "stupid" or "lazy", the caregiver-reported parent-child relationship quality, the proportion of a child's life for which a parent had been absent, and the caregiver's level of reported happiness on a ten-point Likert scale to control for the mental state of the respondent and for potentially inflated perceptions of a child's problematic behaviours (Richters, 1992).

The final sample included 1,979 observations. The sample was restricted to children with complete information on all variables who were between the ages of four and 17, the ages for which Strengths and Difficulties Questionnaire data were available. Children who had a parent absent from the household for a reason other than migration (such as death or divorce) and children with a migrant parent who had been absent for less than one year were also omitted from the final sample. These exclusions were made to isolate the role of migration as a unique form of absence and to limit the influence of short-term changes on psychosocial outcomes. A total of 377 observations were dropped given the exclusion criteria. Bivariate means comparison tests did not find significant differences between missing and non-missing observations in the means of key variables, suggesting that information was missing at random. 


\subsubsection{Statistical Methods}

Binary probit regression models were fitted to examine three research questions: 1) if SDQ scores statistically differed between the cohorts of children with and without parents abroad; 2) if SDQ scores differed between children with a mother abroad, a father abroad, or both parents abroad compared with children living with both parents in Moldova, and 3) if SDQ scores differed between children cared for by different family members (mother, father, grandparent, other) given specific forms of parental migration (mother, father, or both parents) compared to children cared for by a parent living with both parents in Moldova.

The probit regression method was chosen given the binary expression of the dependent variables. The model is indicated as:

$$
\operatorname{Pr}\left(\text { Emo } \text { Cond }_{i}=1 \mid \text { Migi }_{\mathrm{i}}\right)=\Phi\left(\beta x_{i}\right)
$$

Where $\operatorname{Pr}\left(E m o / C_{\text {Cond }}=1 \mid M_{i g_{i}}\right)$ is the probability of child $i$ achieving an abnormal score on the emotional symptoms or conduct problems subscales given the migration status of a parent $\left(M i g_{i}\right), \Phi_{\text {is }}$ the standard normal cumulative distribution function, and $\beta x_{i}$ are the regression coefficients associated with a vector of given covariates. Three different analyses were conducted using the three parental migration variables described above. Within each analysis, three clusters of covariates were added in sequential steps, with the first models containing only the main variables of interest, the second containing confounders related to child and household characteristics, and the third containing confounders related to caregiver/parent characteristics. Each model was split by gender to accommodate fundamental differences between boys and girls. For each model, heteroskedasticity-robust standard errors were estimated and corrected for clustering of observations at household level. Resulting coefficients of all models were transformed into average marginal effects (AME). In calculating AMEs, marginal effects are estimated for each observation on the basis of the actual values of predictors and then averaged over all observations (Hoetker, 2007). 


\subsection{RESULTS}

Table 6.1 provides descriptive statistics of the variables included in the analysis. Within the sample population, 23.8 percent of all children had one or both parents living abroad at the time of the survey. Of those children with a migrant parent, the greatest proportion had a father living abroad.

Table 6.1: Means/Percentages of Variables, CELB-MD(2011/12)

\begin{tabular}{|c|c|c|c|c|}
\hline Variable & $\begin{array}{l}\text { Percentage/ } \\
\text { Mean (SD) }\end{array}$ & Min. & Max. & $\mathrm{N} / n$ \\
\hline Parental Migration Status & 100 & & & 1,979 \\
\hline No Parent Abroad & 76.2 & 0 & 1 & 1,508 \\
\hline Mother Abroad & 8.4 & 0 & 1 & 166 \\
\hline Father Abroad & 11.0 & 0 & 1 & 218 \\
\hline Both Abroad & 4.4 & 0 & 1 & 87 \\
\hline $\begin{array}{l}\text { Parental Migration \& Child Caregiver } \\
\text { Type }\end{array}$ & 100 & & & 1,979 \\
\hline No Parent Abroad/Parent Caregiver & 73.8 & 0 & 1 & 1,462 \\
\hline $\begin{array}{l}\text { No Parent Abroad/Non-Parent } \\
\text { Caregiver }\end{array}$ & 2.3 & 0 & 1 & 46 \\
\hline Mother Abroad/Father Caregiver & 4.3 & 0 & 1 & 86 \\
\hline Mother Abroad/Other Caregiver & 4 & 0 & 1 & 80 \\
\hline Father Abroad/Mother Caregiver & 10.2 & 0 & 1 & 202 \\
\hline Father Abroad/Other Caregiver & 0.8 & 0 & 1 & 16 \\
\hline Both Abroad/Other Caregiver & 4.4 & 0 & 1 & 87 \\
\hline Emotional Symptoms Score & $2.4(1.9)$ & 0 & 10 & 1,979 \\
\hline Conduct Problems Score & $1.4(1.5)$ & 0 & 10 & 1,979 \\
\hline Female & 50.1 & 0 & 1 & 992 \\
\hline Age & $10.8(4.03)$ & 4 & 17 & 1,979 \\
\hline
\end{tabular}




\begin{tabular}{|c|c|c|c|c|}
\hline Age $^{2}$ & $134(87.4)$ & 16 & 289 & 1,979 \\
\hline Has Long-Term Illness & 7.2 & 0 & 1 & 142 \\
\hline Has Good School Performance & 63.7 & 0 & 1 & 1,261 \\
\hline Birth Order (Parity) & & & & 1,979 \\
\hline Eldest Child & 38.4 & 0 & 1 & 761 \\
\hline Only Child & 26.7 & 0 & 1 & 529 \\
\hline Middle Child & 10.4 & 0 & 1 & 207 \\
\hline Youngest Child & 24.4 & 0 & 1 & 482 \\
\hline Household Wealth in Lowest Quintile & 14.6 & 0 & 1 & 289 \\
\hline Household Size & $4.84(1.5)$ & 2 & 13 & 1,979 \\
\hline Household Has Returnee & 24 & 0 & 1 & 475 \\
\hline Respondent Happiness Level & $6.75(2.1)$ & 1 & 10 & 1,979 \\
\hline Caregiver Type & & & & 1,979 \\
\hline Parent Caregiver & 88.4 & 0 & 1 & 1,750 \\
\hline Grandparent Caregiver & 9.8 & 0 & 1 & 195 \\
\hline Other Caregiver & 1.7 & 0 & 1 & 34 \\
\hline Female Caregiver & 90.3 & 0 & 1 & 1,787 \\
\hline Caregiver Years of Education & $11.1(2.7)$ & 0 & 22 & 1,979 \\
\hline Amount of Caregiver-Child Interaction & $2.64(1.8)$ & 0 & 5 & 1,979 \\
\hline Called Names as Punishment & 12.2 & 0 & 1 & 242 \\
\hline $\begin{array}{l}\text { Distant Relationship with } \\
\text { Parent(s)/Caregiver }\end{array}$ & 4.7 & 0 & 1 & 93 \\
\hline $\begin{array}{l}\text { Proportion of Child's Life Father Has } \\
\text { Been Absent }\end{array}$ & $0.10(0.21)$ & 0 & 1 & 1,979 \\
\hline $\begin{array}{l}\text { Proportion of Child's Life Mother Has } \\
\text { Been Absent }\end{array}$ & $0.05(0.15)$ & 0 & 1 & 1,979 \\
\hline
\end{tabular}


Most children (88 percent) were cared for by a parent; among children without a parent abroad, only 2.3 percent were cared for by a non-parent. A similar proportion of children with a mother abroad were cared for by a father as by someone else (namely a grandparent), and among those children with a father abroad, most were cared for by a mother. Given the small number of children with a migrant father who were cared for by someone other than a mother, this group is presented here for descriptive purposes but is excluded from the final analysis.

Table 6.2: SDQ Scores by Child Gender and Parental Migration Status

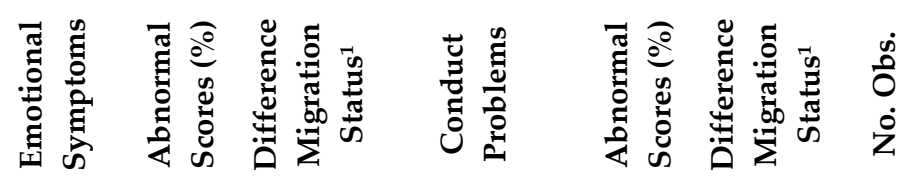

\begin{tabular}{|c|c|c|c|c|c|c|}
\hline \multicolumn{7}{|l|}{ Male Score Averages } \\
\hline No Parent Abroad & $\begin{array}{c}2.23 \\
(1.87)\end{array}$ & 12.1 & $1.55(1.58)$ & 12.1 & & 754 \\
\hline Mother Abroad & $\begin{array}{c}2.34 \\
(1.61)\end{array}$ & 10.8 & $1.77(1.63)$ & 14.5 & & 83 \\
\hline Father Abroad & $\begin{array}{c}2.26 \\
(1.94)\end{array}$ & 13.1 & $2.16(1.91)$ & 23.3 & $* * *$ & 107 \\
\hline Both Abroad & $\begin{array}{c}2.41 \\
(1.82)\end{array}$ & 13.9 & $1.79(1.52)$ & 9.3 & & 43 \\
\hline \multicolumn{7}{|c|}{ Female Score Averages } \\
\hline No Parent Abroad & $\begin{array}{c}2.53 \\
(1.98)\end{array}$ & 16.7 & $1.20(1.32)$ & 7.03 & & 754 \\
\hline Mother Abroad & $\begin{array}{c}2.46 \\
(1.80)\end{array}$ & 15.6 & $1.18(1.77)$ & 10.8 & & 83 \\
\hline Father Abroad & $\begin{array}{c}2.21 \\
(2.07)\end{array}$ & 13.5 & $1.03(1.19)$ & 5.41 & & 111 \\
\hline Both Abroad & $\begin{array}{c}3 \\
(2.03)\end{array}$ & 20.5 & $\begin{array}{c}1.25 \\
(1.41)\end{array}$ & 9.09 & & 44 \\
\hline Difference, Gender & $* *$ & & $* * *$ & & & \\
\hline
\end{tabular}


Among all children in the sample population, the mean score on the emotional symptoms subscale was 2.4, and on the conduct problems subscale, 1.4. Differences in SDQ scores can be observed among children with and without parents abroad, however, as shown in Table 6.2. Boys with a father abroad had the highest conduct problems scores as well as the highest share of abnormal scores on this scale, whereas female children had on average lower conduct problems scores but higher emotional symptoms scores than did their male counterparts. Girls with a father abroad had lower scores on both subscales than girls with neither parent abroad, and the highest share of abnormal scores on the emotional symptoms subscale were among girls with both parents living abroad and on the conduct problems subscale among those with a mother abroad. Despite differences in average scores by gender and parental migration status, all average scores fit within the normal range. These descriptive scoring trends suggest that conduct problems are more prevalent among male children and emotional problems among female children, with statistically-significant score differences by sex. Migration status corresponded to statistically-significant score differences only for boys on the conduct problems scale, however, where the scores of boys with a father living abroad significantly differed from those living with both parents in Moldova.

These bivariate comparisons did not include other factors that may influence psychosocial health outcomes; multivariate analyses were thus conducted to explore the unique relationship between parental migration and child psychosocial health. The first binary probit analysis assessed the relationship between parental migration and child psychosocial health by comparing the outcomes of children with one or both parents residing abroad with the outcomes of those residing with both parents in Moldova. Table 6.3 summarises the regression results for the full models.

The analysis demonstrated that the relationship between parental migration and child SDQ scores differed for male and female children. For male children, having a migrant parent corresponded to a higher probability of an abnormal conduct problems score by nine percentage points, but migration status did not bear a significant influence on the emotional symptoms scale. Parental migration did not correspond to significant differences in either subscale for female children. 


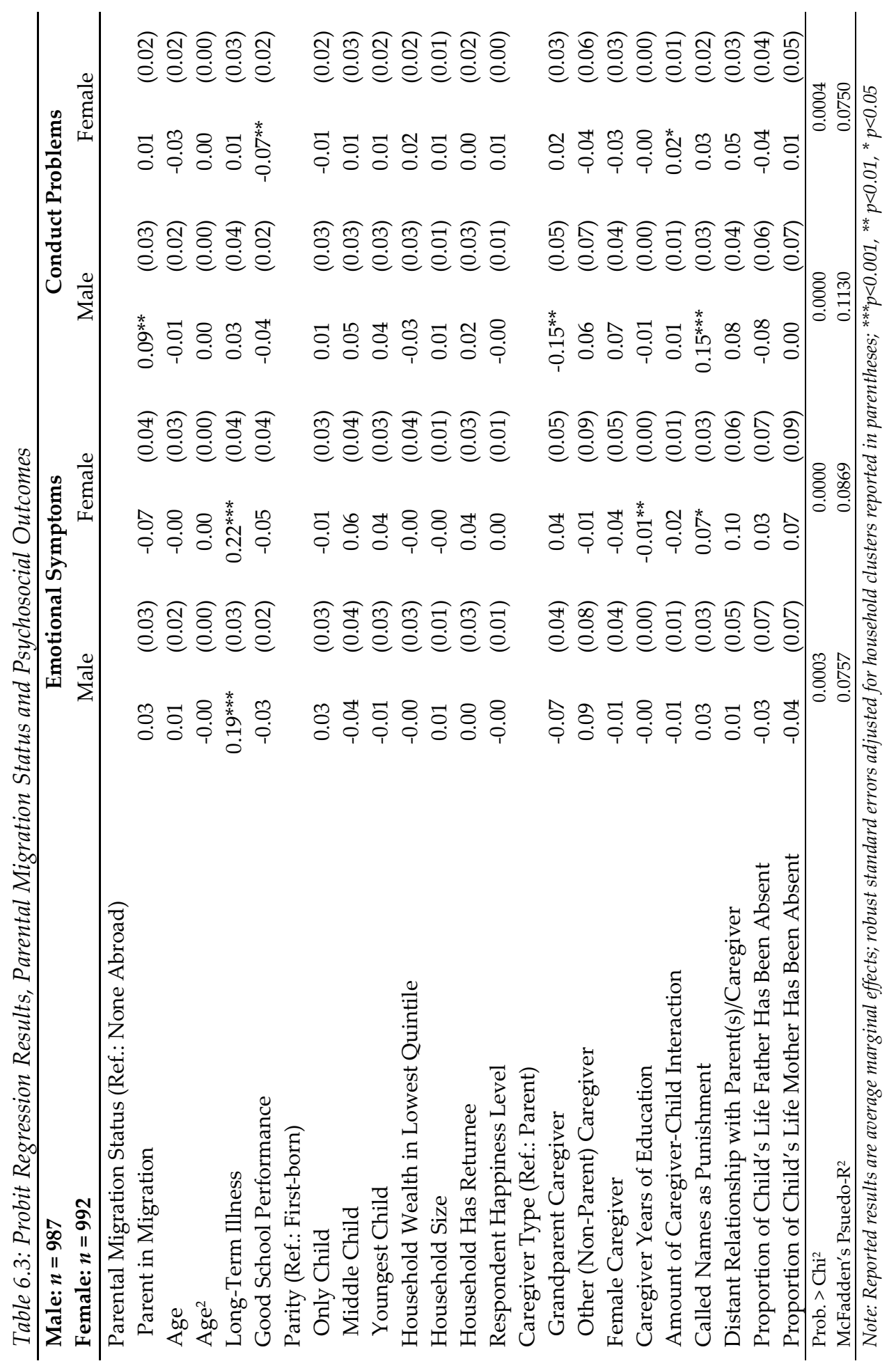




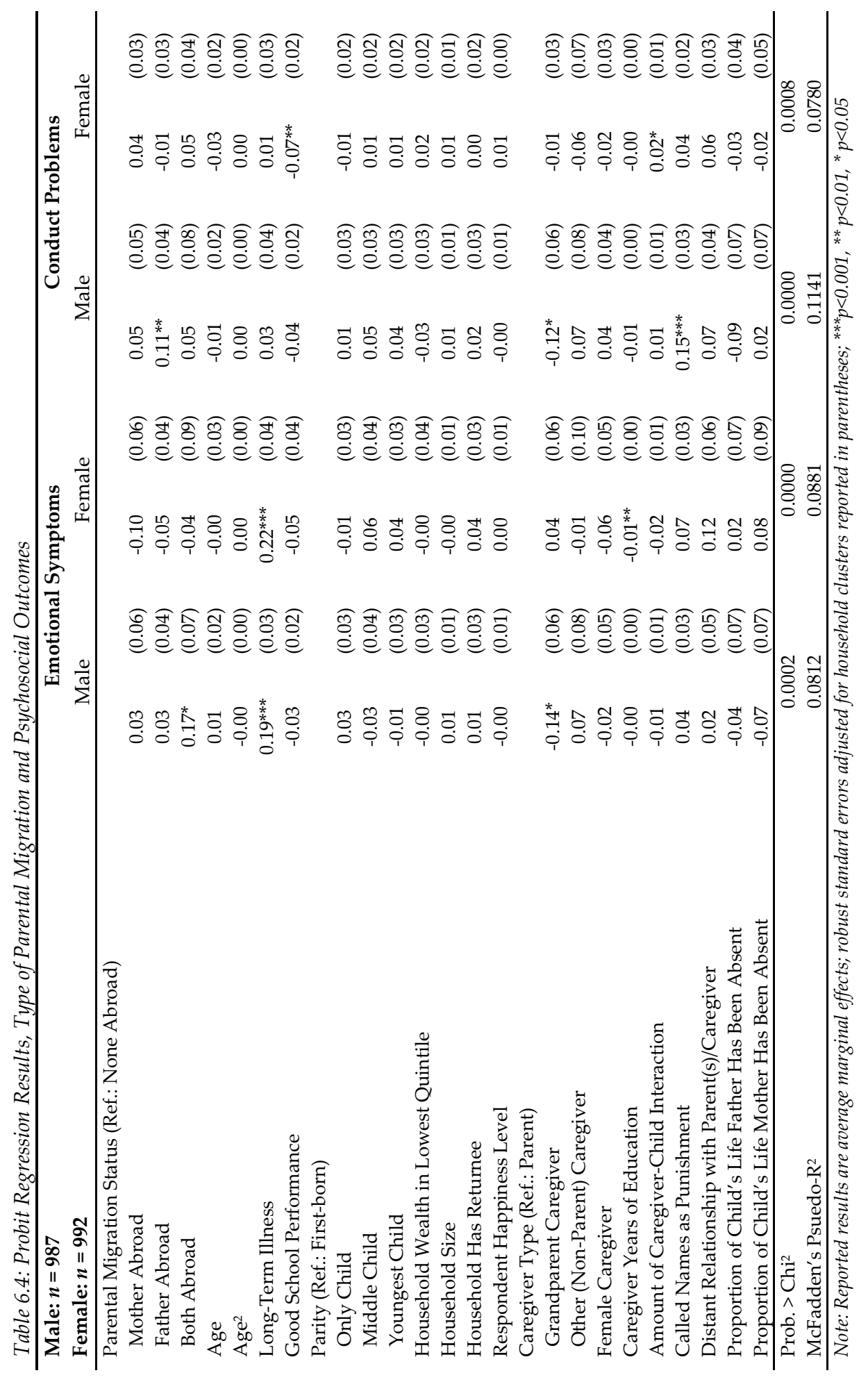




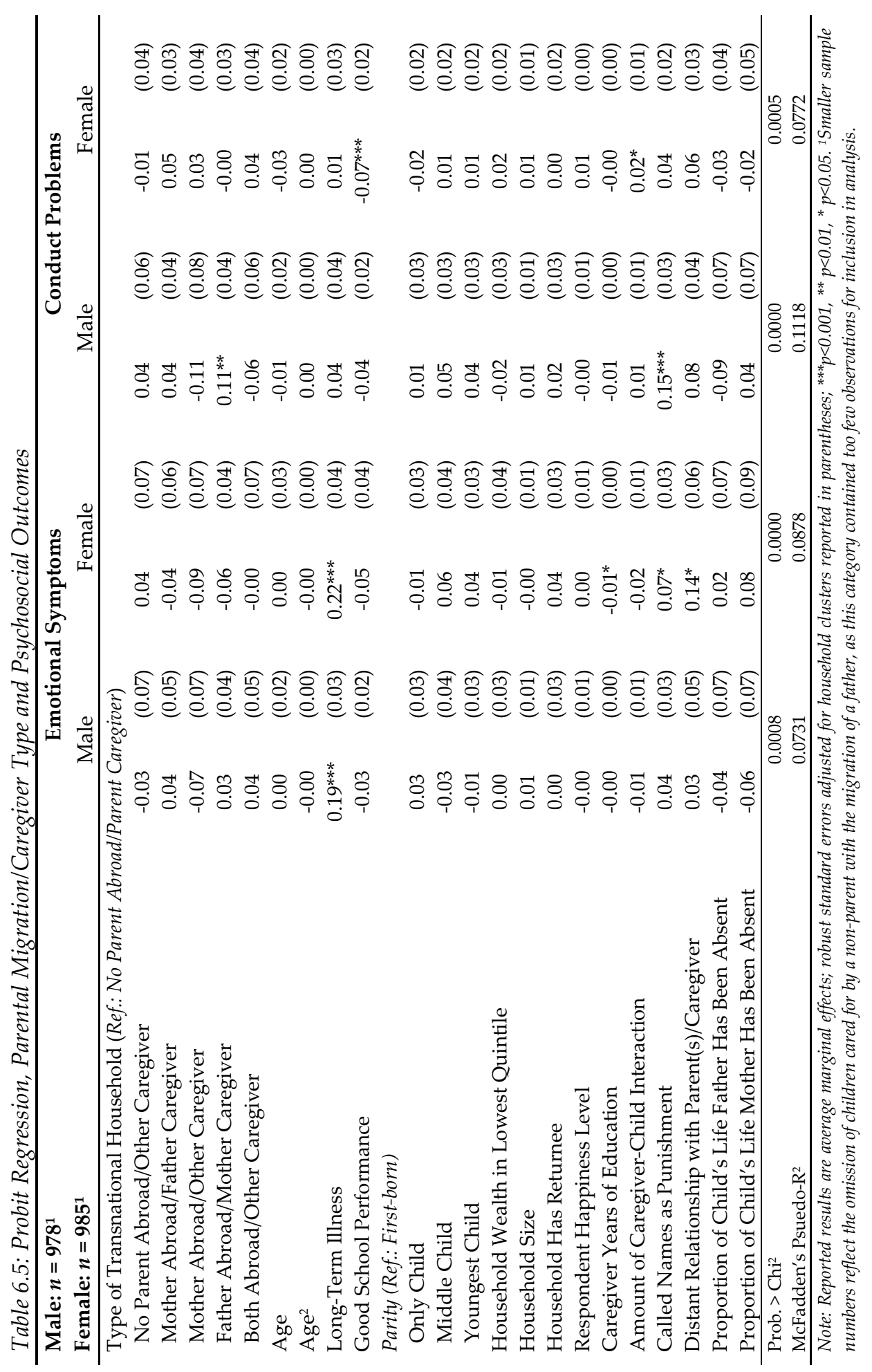


The second analysis disaggregated parental migration into three forms: maternal migration, paternal migration, or migration of both parents. As in the first analysis, children residing with both parents formed the reference category. Table 6.4 demonstrates that who the migrant is has significant bearing on psychosocial outcomes. Male children with both parents living abroad had a 17 percentage-point higher probability of abnormal emotional symptoms scores (significant at the five-percent level). The migration of a father corresponded to a higher probability of an abnormal conduct problems score by 11 percentage points, a result significant at the one-percent level. For female children, no form of parental migration appeared significant.

The third analysis (Table 6.5) compared children without a migrant parent and cared for by a parent with children living under differing caregiving arrangements: those with no parent living abroad and a non-parent caregiver, a mother abroad and a father caregiver, a mother abroad and a non-parent caregiver, a father abroad and a mother caregiver, and both parents abroad and a non-parent caregiver. Among those children cared for by a non-parent, the most common caregiver was a grandmother.

The results of the final analysis indicated that among children with migrant parents, it was not only who had left but who acted as the child's primary caregiver that mattered, but only for boys on the conduct problems subscale. Compared with children without migrant parents who were cared for by a parent, boys with an absent father and a mother caregiver had a higher probability of abnormal conduct problems scores by 11 percentage points, a relationship significant at the one-percent level.

The relationship between SDQ scores and parental migration status should be understood within the context of other confounders. Few covariates proved to be statistically significant throughout all models and for both genders. Age was not a significant confounder for children of either gender on either subscale. Having a long-term illness (such as diabetes or asthma) consistently corresponded to significantly higher probabilities of abnormal emotional symptoms scores for both sexes. The opposite was true for school performance, which demonstrated an inverse relationship to the probability of abnormal conduct problems scores for girls. No household-level covariates were statistically significant. Several caregiver-related covariates were differentially significant for boys and girls. 
Respondent happiness level-used as a proxy for respondent mental healthimproved model fit but did not have a significant impact on coefficients in any model.

As demonstrated in Tables 6.3 and 6.4, being cared for by a grandparent decreased the probability of abnormal emotional symptoms and conduct problems scores among boys, but this relationship lost significance when the specific parental migration and caregiving situation was defined. For girls, increasing years of caregiver education corresponded to lower probabilities of abnormal emotional symptoms scores, whereas greater interaction between girls and their caregivers was associated with slightly higher probabilities of abnormal conduct problems scores. A caregiver's use of verbal punishment techniques (such as calling a child lazy or stupid to show displeasure) significantly hampered the probability of normal emotional symptoms scores for girls and normal conduct problems scores for boys.

\subsection{DISCUSSION}

With the use of quantitative analysis and an appropriate control group, this study found that the link between parental migration and child psychosocial health is mediated by specific factors and varies by child gender and caregiving arrangement. The results suggest that parental migration is not always associated with negative psychosocial health outcomes for children who remain in Moldova following parental migration, which largely counters the study hypotheses.

The first hypothesis that children with a migrant parent would be more likely to achieve abnormal psychosocial outcomes is partially rejected, as parental migration contributed to higher probabilities of abnormal scores only for male children in the conduct problems subscale. Contrary to the second hypothesis, which proposed that maternal absence would correspond to higher probabilities of abnormal psychosocial scores, the association between abnormal scores and parental migration among boys appeared to be driven by the migration of a father in the conduct problems subscale and by the migration of both parents in the emotional symptoms subscale. The final hypothesis, that being cared for by a nonparent would drive abnormal scores, is also rejected. Children with non-parent 
caregivers only expressed a higher probability of abnormal scores in the emotional symptoms subscale, a relationship significant only among boys. In the conduct problems subscale, boys cared for by a mother when a father was a migrant expressed higher probabilities of abnormal scores.

Such results confirm that the relationship between parental migration and child psychosocial health outcomes is not linear and uniform: the gender of the child, gender of the parent, and caregiving arrangement all affected whether and to what extent parental migration corresponded to worse child psychosocial health outcomes. Differences were also clear by domain of psychosocial health: the limited negative role of parental migration on emotional symptoms scores, for instance, suggested that children are not more likely to become anxious or depressed with the migration of a parent, contrary to prior literature on the topic. Past studies conducted in Moldova, despite reaching different conclusions about the repercussions of parental migration for child emotional well-being, may suggest some underlying mechanisms that support particular results.

One study (UNICEF/CIDDC, 2006), for instance, suggests that many of the emotional problems children face are the worst immediately following a parent's migration; because the sample in this analysis included only those children whose parent(s) had been absent for one year or longer, severe, short-term emotional conflicts may have eased over time. Robila (2012), in assessing the educational and psychosocial aspects of parental migration, also suggested that close ties with extended family in Moldova may play a key role in the coping process. The intense support of grandparents for their adult children and grandchildren, both prior to and after migration, is likely to ease the household through the transitions introduced by migration. The current finding that children with parents abroad who were cared for by a non-parent never manifest worse psychosocial outcomes likely reflects this feature of Moldovan families-an important result when considering that nearly the same number of children were cared for by a nonparent as by a father when the mother had migrated.

Gender-specific outcomes merit further exploration. One study (UNICEF/CRIC, 2008) found that many children with migrant parents struggled to find healthy means of emotional expression; boys in particular had the tendency to isolate themselves because of the perception that expressing themselves emotionally made them weak. This may explain the instances when a parent's 
migration corresponded to higher probabilities of abnormal scores. Past research has recognised that boys are more likely to act out in response to emotional conflict than are girls, and in general, conduct problems may be easier for a caregiver to recognise than emotional problems simply because they reflect externalised behaviours rather than internal processes (Jensen et al., 1999).

The finding that parental migration did not correspond to differing psychosocial outcomes for girls also requires examination. Peleah (2007) noted that migration is perceived as a potentially empowering experience for women because it gives them the opportunity to have a greater role in family decision making. Social remittances in the form of values and attitudes may trickle down to the daughters of female migrants, who may be empowered by extension to exert more control over their own lives and decisions. These positive potential changes may be offset by greater household burdens, however, as household tasks normally performed by a migrant may be redistributed among those who remain.

This study faced limitations. One limitation concerns sample size. Despite the relatively large sample of children between the ages of four and 17, the number of children with one or both parents abroad was relatively small; it was thus not possible to conduct an analysis of differences between child gender and migrant/caregiver type including covariates related to parental migration characteristics such as country of destination, frequency of contact, and type of employment abroad. Future analyses should explore these relationships.

Other limitations relate to the use of the SDQ. As noted earlier, normative data that can guide scoring thresholds are absent and therefore the specific applicability of the thresholds for Moldova need to be investigated. Another limitation regarding the use of the SDQ relates to the use of caregiver-reported scores. As noted by Graham and Jordan (2011), not all caregivers may reliably report on children's behaviour. If certain caregiver types systematically under- or over-rate the behaviours of children, and if these caregiver types are disproportionately represented in transnational households, this may bias results. Future research could include a teacher-completed questionnaire and impact assessment to increase reliability.

A final limitation relates to the highly-selective process of migration. Migrants are not randomly selected from the population but have differential characteristics that influence their choice to migrate (self-selection). Some observable factors that 
may influence this self-selection were included, such as parental education level and household wealth, but others, such as child's pre-existing psychosocial health, could not be given the cross-sectional nature of the data. This implies that only correlation and not causation can be inferred. Future studies should include longitudinal data collection.

The current study nevertheless contributes essential evidence to the literature on the 'left behind' and has highlighted the necessity of approaching the topic with a more nuanced lens. In Moldova the topic of migration and family life is unlikely to disappear from public discourse and policy as long as female migration continues at the current pace. The persistence of this topic calls for the construction of a more responsible dialogue about transnational families and their functioning, which can in turn inform better targeting of policy interventions. Children of migrant parents are not automatically more likely to manifest abnormal psychosocial behaviours, but there are certain risk factors that may heighten a child's vulnerability to developing them, such as having a verbally-abusive caregiver, having a caregiver with low levels of human capital, or experiencing long-term physical illness. Parental migration may play a role in enhancing certain vulnerabilities, but it is not a vulnerability in and of itself-an important distinction that has so far been poorly understood. 


\section{CHAPTER SEVEN: ALL IN THE FAMILY - FAMILY MEMBER \\ MIGRATION AND THE PSYCHOSOCIAL HEALTH OF \\ CHILDREN IN GEORGIA ${ }^{34}$}

\subsection{INTRODUCTION}

As the number of female international migrants has increased, so, too, has interest in the potential consequences of migration for families who remain in the country of origin. Children in particular have increasingly drawn the attention of researchers, with a growing number of studies (e.g., Graham \& Jordon, 2011; Heymann et al., 2009; Jia \& Tian, 2010) investigating the consequences of migration for the emotional well-being of immobile children. These studies provide welcome insight into a previously understudied domain yet reveal remaining gaps in knowledge: few studies have been conducted outside of Asia or Latin America, and all focus on the migration of a parent, with limited reference to the experiences of children separated from other kin due to migration. This chapter addresses these limits by investigating the link between child psychosocial health and the migration of normally co-resident family members using data collected in Georgia.

Georgia provides a relevant context to explore the influence of migration on child psychosocial health given its recent history of large-scale emigration and the centrality of the extended family, particularly grandmothers, in child-raising. Around 25 percent of the Georgian population is estimated to live abroad (World Bank, 2010), and women are now thought to account for more than half of all new migrants (Labadze \& Tukhashvili, 2013). Within the migrant population is a growing number of mature women whose migration projects are undertaken to provide financial support for their children and grandchildren (Venturini, 2013). Perhaps not coincidentally, public discourses around migration have subtly shifted over the last decade: the stigmatisation of independent female migrants for "abandoning" their families has gradually given way to acceptance of their role in

34 This chapter is based on an article entitled "Family-member migration \& the psychosocial health of children 'left behind' in Georgia" that is currently under review for journal publication. 
ensuring household survival (Hofmann \& Buckley, 2013). Both types of discourse tie female migration to the health of the family, yet despite the treatment of female migration as essentially a family affair, there is a dearth of literature on the consequences of migration for children with migrant kin who remain in Georgia.

Using the Strengths and Difficulties Questionnaire (SDQ) to measure psychosocial health, sequential quantile regression was used to compare the psychosocial health outcomes of children with different members (a mother, father, grandparent, or other family member) of the normally co-resident family abroad to children without any family members abroad. The results suggest that migration seldom corresponds to worse child psychosocial health as is largely assumed by past research. Migration corresponded only to limited differences in the total difficulties scores of both boys and girls, but the relationship differed depending on the specific person who was absent and for children at different points of the conditional score distribution, with the "healthiest" girls most influenced by (paternal) migration. The results suggest that migration is not as disruptive an event as has been assumed and that maternal migration in particular is limited in its influence on psychosocial health.

\subsection{BACKGROUND}

Much past research on the "effects" of migration for the children who remain in the country of origin assumes that migration is a disruptive event that changes the structure of the family and the resources (both physical and emotional) available to household family members ( $\mathrm{Lu}, 2012)$. The underlying rationale is that migrants are members of larger social units - households or families - that function collectively. Despite this understanding, research on the consequences of migration for children who stay in the country of origin has seldom addressed the role of the extended family in child-raising and care activities, focusing exclusively on the impacts of parental migration. This orientation echoes a larger fixation in child development literature on the mother-child dyad (Falicov, 2007), which is derived largely from the attachment theory.

Within this theory, attachments are understood as persistent, affective bonds formed between a child and a specific attachment figure (Bowlby, 1977). The first 
attachment a child forms is generally to a parent, often a mother. Early attachment bonds may be based on dependency: as an attachment figure meets a child's physiological needs, a child comes to associate the presence and attention of the attachment figure with relief or comfort (Ainsworth, 1969). As an individual matures the level of dependency may change, but the individual will still seek to maintain proximity (both physical and symbolic) to the attachment figure, expressing distress upon separation (Armsden \& Greenberg, 1987). Separation can undermine the security and comfort a child derives from the relationship (Cassidy, 2008), resulting in the development of emotional or psychological disturbances such as anxiety, depression, or anger when the accessibility and responsiveness of an attachment has been undermined (Armsden \& Greenberg, 1987).

Despite the undeniable importance of parent-child attachment in fostering child well-being, child psychosocial health cannot be de-contextualised from the larger family and care environment in which it is formed, which may involve a child developing attachments to other members of the family. In many countries, non-nuclear family living arrangements and caregiving provided by members of the extended family often represent traditional rather than deviant child care environments. In much literature, however, non-nuclear family structures are often assumed to be symptomatic of problems or disruptions to the nuclear family, with family structure treated as "essentially a proxy for related processes that affect children's health and well-being" (Dawson, 1991; pp 574), such as the absence of one parent through divorce and subsequent changes to household resources. The focus on the child-parent dyad within the attachment theory and child development literature in general has inspired criticism, particularly by transnationalism scholars. Suarez-Orozco, Todorova, and Louie (2002), for instance, suggest that the attachment theory strongly reflects Western-centric notions of the importance of the mother-child dyad within a nuclear family. In extended families where a child has multiple caregivers and the opportunity to form enduring attachments with multiple individuals, prevailing norms of family life and its organisation may imply that separation from a parent does not disrupt child psychosocial health as would be expected (Mazzucato \& Schans, 2011). In non-nuclear family structures where children form multiple attachments, disruptions to attachment relationships-to parents as well as other family members-may affect a child's psychosocial well-being, but very little literature addresses this. 
An additional limitation of existing literature, particularly from child development studies, relates to the limited knowledge about how migration as a unique form of absence corresponds to differences in child psychosocial health. Most studies conducted by child psychologists or family sociologists that link caregiver absenteeism to the development of dysfunctional psychosocial behaviours made use of clinical data of children separated from their parents by events such as death, divorce, or abandonment (Mazzucato, 2014a). It is unclear how analogous migration is to other forms of separation, however, particularly as its duration and underlying motivation are likely to differ from those implied by other forms of separation. Carling and Tønnessen (2013), in one of the only studies to compare the well-being outcomes of children in different forms of absentee father households, found marked differences among children who had experienced different forms of separation. Whereas children in Malawi with deceased or divorced fathers appeared to have significantly worse outcomes on most indicators of well-being compared to their peers living with both parents, children with a migrant father attained worse well-being outcomes on only a small number of well-being indicators. This importantly suggests that expectations about child psychosocial health following other forms of loss cannot be easily extrapolated to situations of separation due to migration, requiring more in-depth understanding of the migration-specific context.

\subsubsection{Evidence on the Psychosocial Health of Children with Migrant Kin}

Within the scholarly research on the links between migration and child psychosocial health, two broad strands have emerged: qualitative, small-scale studies that investigate the consequences of transnational family life on the childparent relationship (Mazzucato, 2014a), and large-scale, quantitative studies that quantify and compare specific child psychosocial health outcomes. Studies from both strands have suggested that there are several key differences in the contexts in which migration occurs that can affect if and how children manifest different psychosocial outcomes as the result of migration.

Who has migrated has been found to strongly influence the development of psychosocial health or dysfunction in studies across the world. In the 
Philippines, several qualitative studies conducted in the mid-1990s documented an increased incidence of psychological disturbance, juvenile delinquency, and social problems among the children of migrants, particularly migrant mothers (see Parreñas, 2005, for a review). A recent quantitative study that compared the outcomes of children in transnational families in Indonesia, the Philippines, Thailand, and Vietnam found that children with fathers abroad were slightly more likely than their peers with both parents at home to have emotional problems (in Indonesia) and conduct problems (in Thailand), but the magnitude of those effects were relatively small (Graham \& Jordan, 2011). A comparative study of children living in transnational families in Angola, Ghana, and Nigeria found that children in Angola and Nigeria living in the home country with a father when the mother had migrated internationally had worse emotional well-being outcomes than children living with both parents in the home country. In all three countries, children who experienced a change of caregivers more than once had much worse well-being outcomes, regardless of parental migration status (Mazzucato et al., 2014). This suggests that psychosocial health outcomes are likely to be driven not only by who has migrated but who acts as a caregiver following that migration. Heymann et al. (2009) found in a study of families in high-migration communities in Mexico that children whose primary caregivers migrated were more likely to have emotional problems than children who had experienced the migration of a non-caregiver. Such findings may support the attachment theory and suggest that children with a primary caregiver abroad (often a mother) may manifest worse psychosocial health. They provide limited guidance on what to expect when children live in households with members of the extended family who also participate in the caregiving process, however.

Other studies have found that characteristics of the child, such as gender, may mediate how parental migration affects child psychosocial health. A retrospective study of the children of serial migrants from the Caribbean found that multiple separations and reunifications with parents contributed to low selfesteem and behaviour problems among children, with boys found to be more likely than girls to report deviant behaviours and low self-esteem following reunification (Smith, Lalonde, \& Johnson, 2004). In South-East Asia, Graham and Jordon (2011) found that girls were in general less likely to exhibit conduct problems than boys were and, in some countries, more likely to express emotional problems. In Moldova, a recent quantitative study found that boys with a migrant father were slightly more likely to express conduct problems than boys living with 
both parents, whereas girls did not appear to be affected by any form of parental migration (Vanore, Mazzucato, \& Siegel, 2014). Such findings suggest that the risk parental migration poses to the psychosocial health of children who remain in the origin country may be negotiated differently by boys and girls, challenging generalisations about the "effect" of migration for children as one homogenous group.

Differences in the migration episode and environment in which a child lives have also been linked to differences in the outcomes of children. A study on children separated from migrant parents prior to reunification in the United States found that children separated from their mothers for four or more years reported the greatest amount of psychological distress (Suárez-Orozco, Ban and Kim, 2011). Pottinger (2005), who studied the children of migrants living in inner-city Jamaica, found that parental migration-while not independently correlated to worse outcomes-posed a significant risk factor for children when combined with a child's exposure to violence and poverty. Suárez-Orozco, Todorova, and Louie (2002) similarly suggested that a child's response to a separation would be significantly influenced and compounded by the experience of other traumas such as warfare.

Taken together, these findings support the development of a more nuanced view of the relationship between family migration and child psychosocial health that recognises that neither the population of children with migrant kin nor the migration events they experience are homogenous and easily generalised. As these studies explicitly address only parental migration and not the migration of other family members, it is unclear how children experiencing other forms of migration may fare-highlighting the need to fill this empirical gap by explicitly bringing the extended family into focus.

\subsubsection{Study Context}

Studies on the topic of children with migrant family members in Eastern and Central Europe are relatively rare and have been largely driven by policy or programme interests. In Moldova, several small-scale, qualitative research studies commissioned or conducted by international agencies such as UNICEF and 
HelpAge International explicitly evaluated the situations of children 'left behind' to the end of designing policy interventions. Unsurprisingly given that aim, most found that children with parents abroad were prone to depression and increased conflicts with their peers (HAI/UNICEF, 2008; Prohnitchi, 2005) and feelings of loneliness and longing (UNICEF/CRIC, 2008). Literature on migration and children who stay in Georgia following the migration of kin is conspicuously absent: only one study (to the author's knowledge) has addressed this topic. A qualitative scoping study conducted among six families found that children experienced separation anxiety in the months immediately following parental migration. The expression of this anxiety varied from troubles sleeping to withdrawing from social contact with peers and clinging to caregivers (Svintradze \& Ubiria, 2007).

These studies were all more exploratory in nature and shared methodological choices that limit their generalisability to larger populations. None compared the outcomes of children with and without parents abroad, and most observed small samples of children at only one point in time. Study samples were also often selected because they represented a cross-section of particularly vulnerable children. These limitations highlight persistent gaps in the literature on migration and child emotional health in Eastern Europe, which studies such as this are well positioned to fill given the use of appropriately-detailed data and the availability of a counterfactual group.

Georgia provides a rich context for better understanding the relationship between child psychosocial health and migration given high rates of emigration and gradually-feminised migration flows. Large-scale emigration from Georgia began following independence from the Soviet Union in 1990, which precipitated a protracted economic crisis, political restructuring, and inter-ethnic conflicts over the territories of Abkhazia and South Ossetia that culminated in a civil war lasting from 1991 to 1993 (Fawn, 2012; Tuathail, 2009). Migration was one response to the uncertainties of the immediate post-Soviet transition, and while few estimates are available about the size of yearly emigration flows, by 2010 the stock of emigrants residing abroad was estimated at over one-quarter of the population (World Bank, 2010).

The composition of emigration flows has changed significantly over the post-Soviet period, with women now thought to account for a larger share of firsttime migrants than men (Labadze \& Tukhashvili, 2013). This change reflects both 
shrinking opportunities for migration to the Russian Federation - the largest single destination of Georgian men - as well as expanding migration opportunities to the West, which tend to favour women. Russia's periodic suspension of visas for Georgians in the early 2000s restricted access to the Russian labour market, which disproportionately affected men who worked in low-skilled, physical labour (Hofmann \& Buckley, 2013). The 2008 Georgian-Russian War and Georgia's subsequent withdrawal from the Commonwealth of Independent States further limited opportunities for legal residence and work in the Russian Federation. Simultaneously, increased demand for home-, child-, and eldercare workers increased opportunities for women (young and old alike) to work in countries such as Greece and Italy, as well as beyond Europe in countries such as Israel and the United States (Tchaidze \& Torosyan, 2010; IOM, 2009).

Despite the growing role of women in international migration and sustained rates of emigration in general, very little research has addressed the potential impacts of migration on the family, an important gap given the intimate ties between migration and family life in Georgia. Complex, multigenerational households are common and correspond to traditional practices of marriage mobility and caregiving. Traditionally, a youngest son would stay in the parental home and care for his ageing parents, and women were expected to move to the households of their husbands. Despite changes in traditional attitudes and practices related to co-residence, elderly persons still most often reside with their children's families, resulting in multigenerational households where childcare responsibilities are diffused among members of the extended family (Badurashvili et al, 2008). In many households, grandmothers play an essential role in child care, a practice that may ease the transition of mothers into international migration. Hofmann and Buckley (2011), in their study of female migration and gender norms in Georgia, found that transference of childcare duties to grandmothers allowed migrant women to start their migration projects without feeling as if they were abandoning their children. At the same time, there is an important and underresearched trend of older women engaging in their own migration projects, which is likely to introduce changes in the childcare environment within households. This emphasises the value of assessing how the psychosocial health of children corresponds to different forms of family migration. 


\subsubsection{Hypotheses}

Past research in Georgia, the Eastern European region, and beyond suggest important ways forward in investigating the link between family member migration and child psychosocial health. They highlight remaining gaps in empirical research on the topic and support the use of a comparison group to better understand if and how children with migrant family members differ from their peers who have not experienced family member migration. Based on past research, the following analysis investigates the following hypotheses: 1) Children with a family member abroad will have worse psychosocial health outcomes, but; 2) marked differences will exist based on who has migrated, with maternal migration corresponding to especially negative psychosocial outcomes, and; 3) the migration of other family members, such as grandparents or siblings, will also correspond to worse outcomes, but to a lesser extent than that of parents.

\subsection{METHODS}

\subsubsection{Data \& Sample}

The following analyses use data derived from the study "the Effects of Migration on Children and the Elderly Left Behind in Moldova and Georgia" (CELB-MD/GE). Within this project, a nationally-representative household survey was implemented between March and December 2012 across all regions of Georgia except for the de facto independent regions of Abkhazia and South Ossetia. In lieu of an updated, nationally-representative sampling frame, one was elaborated based on electoral districts. Respondent households were selected in a multi-stage sampling design. Primary sampling units (PSUs) were selected in the first stage, and in the second stage households within each PSU were selected on the basis of stratified random sampling. Purposive oversampling of migrant households then occurred in a third stage following a listing exercise that elicited true migration rates and other population characteristics within a given PSU. Only households 
with one or more members below the age of 18 or over the age of 60 were recruited for completion of the survey.

The survey sampled 4,010 households containing 16,211 individuals. Nearly 60 percent of all households contained one or more children under the age of 18 , resulting in a population of 3,785 children aged zero to 18 . A subsample of children was selected for analysis according to the following criteria: 1) child age between four and 17, the ages for which Strengths and Difficulties Questionnaire data is available; 2 ) complete information on all variables included in econometric models; 3) no parental absence due to separation events such as death or divorce; 4) no more than one migrant in a household, and; 5) family-member migration of only 12 or more months. Children who did not meet the last three exclusion criteria were dropped to avoid potential distortion of results created by other forms of parental separation, from multiple separation events, or from short-term migration episodes. Based on these restrictions, the final analytical sample contained 1,282 children. The casewise deletion of observations with missing values was not considered problematic, as data did not appear to be missing systematically. Bivariate comparison tests found no significant differences in the sample means of key variables between in- and out-of-sample observations.

\subsubsection{Variable Identification \& Measurement}

Child psychosocial health, the dependent variable, was measured with the total difficulties score of the Strengths and Difficulties Questionnaire (SDQ). The SDQ is a behavioural screening instrument that has been widely used to assess child and adolescent mental health across cultures and national contexts (Goodman, 1997; Richter et al., 2011). The questionnaire consists of 25 questions representing five subscales that measure a range of symptoms and positive attributes (Goodman, 1999). These subscales-emotional symptoms, conduct problems, peer problems, hyperactivity, and prosocial behaviours-are based on the concepts underpinning the classifications of childhood psychopathology in the Diagnostic and Statistical Manual of Mental Disorders (DSM) of the American Psychiatric Association and the International Classification of Diseases (ICD) diagnostic tool of the World Health Organisation. The items within each subscale 
correspond to key symptoms domains for diagnosis identified in the DCM-IV and ICD-10 (Goodman \& Scott, 1999). Each subscale is comprised of five individual items with a score of zero to two, with possible aggregate subscale scores ranging from 0 to 10. For each of the subscales (with the exception of the prosocial behaviours subscale, which is reverse coded), higher scores indicate movement to less favourable outcomes (Goodman, 1997).

The version of the SDQ that was implemented in Georgia had been translated by project staff from English to Georgian, back-translated into English to check for potential disparities in wording, and reviewed by an independent child psychologist to ensure equality of meaning and tone between language versions. After implementation, the instrument was revised in conjunction with staff from Youth in Mind, the copyright holders of the SDQ, and minor adjustments were made to wording. The version of the SDQ implemented in the survey thus differs from the final authorised Georgian version downloadable from www.sdqinfo.org, but those differences were minor enough that Youth in Mind gave permission for the data derived from the earlier version of the instrument to be used.

The total difficulties score was used in the following analyses as a proxy for child psychosocial health. As an aggregate measure of all individual subscale scores except for the prosocial behaviours subscale, the total difficulties score provides one convenient metric for understanding a child's potential risk of experiencing poor mental health. Whereas the internal factor structure of the five SDQ subscales can be inconsistent and may not tap into distinct aspects of child mental health in low-risk samples, the total difficulties score avoids this problem altogether by representing potential problems across all domains of mental health. The total difficulties score has been found to be a reliable indicator of child mental disorder in studies across the world, with increasing total difficulties scores found to correspond with increased rates of clinical diagnoses of child mental disorder (Goodman, Lamping, \& Ploubidis, 2010; Richter et al., 2011).

The total difficulties score can be interpreted as either a continuous or categorical value, with scores categorised as "normal", "borderline", or "abnormal" based on score bandings proposed by Goodman on the basis of the distribution of scores among a sample population in the United Kingdom (Goodman, 1999). Lacking normative data for a Georgian child population, it is unclear if the scoring thresholds proposed for categorisation of scores are 
appropriate for the local population; in the following analyses, the total difficulties score is thus used as a continuous integer value ranging from zero to 28 points. As the dependent variable, higher scores (or increases in scores) indicate movement toward less favourable psychosocial health.

Two main predictor variables were created to indicate the migration status of each child's co-resident household family members. The first variable was a binary variable indicating if a child had any family member living abroad at the time of the survey. The second was a categorical variable indicating who the migrant was in relation to the child-a mother, father, grandparent, or other family member.

Additional predictors relating to child-, household-, and caregiver-level characteristics were included in each model. Child-level controls included age and age-squared (to account for differences in behaviour regulation by age), if the child had a long-term illness, and parity. Household covariates included household size, monthly expenditure per capita adult equivalent, and regional location of the household, included to control for a child's exposure to psychosocial stressors such as conflict and political strife. The regional location variable distinguished the Autonomous Republic of Adjara from all other non-autonomous regions (such as Tbilisi, Shida-Kartli, Imereti, Samtskhe-Javaketi, etc).

Caregiver-related controls accounted for characteristics of the individual who provided the most care to the child on the most regular basis. Variables included the respondent's reported level of happiness on a ten-point Likert scale, which accounted for potential overestimation of problematic behaviours in children due to a respondent's own mental state (Richters, 1992); the type of caregiver (parent or non-parent); caregiver gender, and; a caregiver's years of completed education. Two variables accounted for the quality of a child's relationship to his/her caregiver and/or parents: if the caregiver called the child names such as "lazy" or "stupid" as a form of punishment, and if the caregiver reported a distant or very distant relationship between the child and his/her caregiver and/or parents. Finally, the proportion of a child's life that a family member had been absent was included to control for duration of absence; for those children without migrant family members, the proportion was set to zero. 


\subsubsection{Analytical Method}

The sequential quantile regression method was used to model the relationship between migration and child psychosocial health outcomes. For both male and female children, total difficulties scores were heavily concentrated at the lower end of the distribution, resulting in slightly right-skewed data. Given the shape of the distribution, the simultaneous quantile regression method was preferred. Quantile regression describes the central tendency of the data in terms of the median, which better accommodates relatively rare observations at the extremes of a distribution; OLS regression, in contrast, describes the central tendency of the data in terms of the mean, which implies that estimated coefficients are most relevant for the "average" observation. Estimation at the mean disguises the differential influence of independent variables at different points of the distribution, whereas sequential quantile regression advantageously enables analysis of how particular variables influence scores across the conditional score distribution. This method is also particularly well suited for heteroskedastic data such as this, as it does not assume parametric distribution of regression errors (Koenker \& Hallock, 2001; Binder \& Coad, 2010).

Sequential quantile regression analyses were conducted to compare the total difficulties scores of children who had experienced some form of familymember migration (that of a mother, father, grandparent, or other family member) to those of children without any family member living abroad and residing with both parents. In all analyses children without any family member abroad and residing with both parents were the reference category to which comparisons were made. Models within each form of analysis were split by child sex to account for gender differences. The models can be stated formally, as:

$$
\operatorname{TDS}_{i(m / f)}=\gamma+\alpha_{1} \text { MigrationStatus }_{i}+\beta X_{\mathrm{i}}+\varepsilon_{\mathrm{i}}
$$

Where the dependent variable $T D S_{i(m / f)}$ corresponds to the total difficulties score for individual $i$ with distinction by gender $(\mathrm{m} / \mathrm{f}), \alpha_{1}$ MigrationStatus $_{i}$ corresponds to the coefficient estimates of the main predictors (family-member migration status), $\beta X_{i}$ is the vector of coefficient estimates for additional covariates, and $\varepsilon_{i}$ corresponds to the error term. 
Coefficients were estimated for four quantiles of the distribution, representing scores in the $20^{\text {th }}, 40^{\text {th }}, 60^{\text {th }}$, and $80^{\text {th }}$ percentiles. These quantiles were chosen to demonstrate how the relationship between total difficulties scores and various cofounders varied across low, medium, and high scores, which helps profile when and how scores are meaningfully influenced by other independent variables. The analysis was sequentially fit with three clusters of variables (child-, household-, and caregiver-related variables), but only the results of the models containing all covariates are provided here. Standard errors were estimated on the basis of 400 bootstrap replications.

\subsection{RESULTS}

Table 7.1 provides descriptive statistics of the variables included in the analytical models. Nearly 40 percent of children had a normally co-resident family member living abroad at the time of the survey, the largest proportion of whom had a father abroad. Similar numbers of children had a grandparent (generally a grandmother) or other family member (such as a sibling or aunt/uncle) living abroad. 
Table 7.1: Means/Percentages of Variables

\begin{tabular}{|c|c|c|c|c|}
\hline Variable & $\begin{array}{c}\text { Percentage/Mean } \\
\text { (SD) }\end{array}$ & Min. & Max. & $\mathrm{N} / n$ \\
\hline Family Migration Status & & & & 1,282 \\
\hline None Abroad & 60.1 & 0 & 1 & 771 \\
\hline Mother Abroad & 5.6 & 0 & 1 & 72 \\
\hline Father Abroad & 14 & 0 & 1 & 180 \\
\hline Grandparent Abroad & 10.4 & 0 & 1 & 130 \\
\hline Other Family Member Abroad & 10.1 & 0 & 1 & 129 \\
\hline Total Difficulties Score & $8.6(4.8)$ & 0 & 28 & 1,282 \\
\hline Female & 48.7 & 0 & 1 & 624 \\
\hline Child Age & $10.2(3.9)$ & 4 & 17 & 1,282 \\
\hline Child Age ${ }^{2}$ & $119.7(83.7)$ & 16 & 289 & 1,282 \\
\hline Has Long-Term Illness & 4.3 & 0 & 1 & 55 \\
\hline Birth Order (Parity) & & & & 1,282 \\
\hline Only Child & 27.4 & 0 & 1 & 352 \\
\hline Eldest Child & 40.2 & 0 & 1 & 515 \\
\hline Middle Child & 8.5 & 0 & 1 & 109 \\
\hline Youngest Child & 23.9 & 0 & 1 & 306 \\
\hline $\begin{array}{l}\text { Average Monthly Expenditure (Per } \\
\text { Adult Equivalent) in Lari }\end{array}$ & $185.7(170.3)$ & 10.8 & 1206.9 & 1,282 \\
\hline Household Size & $5.1(1.5)$ & 2 & 12 & 1,282 \\
\hline Household Located in Adjara & 11.3 & 0 & 1 & 145 \\
\hline Respondent Happiness Level & $6.8(2.2)$ & 1 & 10 & 1,282 \\
\hline Caregiver Type & & & & 1,282 \\
\hline
\end{tabular}




\begin{tabular}{lcccc}
\hline Parent Caregiver & 94.4 & 0 & 1 & 1,210 \\
Other Caregiver & 5.6 & 0 & 1 & 72 \\
Female Caregiver & 94.5 & 0 & 1 & 1,212 \\
Caregiver Years of Education & $12.9(2.7)$ & & & 1,282 \\
Called Names as Punishment & 27.9 & 0 & 1 & 358 \\
Distant Relationship with & 8.9 & 0 & 1 & 115 \\
Parent(s)/Caregiver & & & & \\
Proportion of Child's Life Migrant & $.21(.33)$ & 0 & 1 & 1,282 \\
Has Been Absent & & & & \\
\hline
\end{tabular}

Note: Standard deviations in parentheses; All variables have N=1,282 total observations, with $\mathrm{n}$ indicating the number of observations with a given attribute.

The average total difficulties score for the whole sample was 8.6 points, but differences in average score can be seen by child gender and by family migration. As Table 7.2 shows, children of both genders with a grandparent abroad expressed the highest total difficulties scores, whereas boys with a father abroad and girls with another family member abroad expressed the lowest. Despite these apparent differences, bivariate means comparison tests found no significant differences in average scores by family-member migration status. The average scores of boys and girls were significantly different, however, with boys expressing average higher scores than girls regardless of family-member migration status.

Bivariate comparisons cannot provide a complete sense of how migration and child psychosocial are related, as the relationship is likely to be mediated or fostered by more complex interactions between migration and other facets of a child's life. Multivariate models were thus fitted to better understand the interplay between child psychosocial health and other features of a child's life. 
Table 7.2: Total Difficulties Scores by Child Gender and Family Migration Status

\begin{tabular}{|c|c|c|c|}
\hline & $\begin{array}{c}\text { Total Difficulties } \\
\text { Score }\end{array}$ & $\begin{array}{c}\text { Difference, } \\
\text { Migration Status }^{1}\end{array}$ & $\begin{array}{c}\text { Observations } \\
(\mathrm{N} / n)\end{array}$ \\
\hline MALE SCORE & $9.22(4.77)$ & -- & 658 \\
\hline \multicolumn{4}{|l|}{ AVERAGES } \\
\hline No Parent Abroad & $9.38(4.98)$ & -- & 387 \\
\hline Mother Abroad & $9.28(4.02)$ & -- & 32 \\
\hline Father Abroad & $8.88(5.15)$ & -- & 98 \\
\hline Grandparent Abroad & $9.57(4.26)$ & -- & 70 \\
\hline Other Abroad & $8.46(3.81)$ & -- & 71 \\
\hline FEMALE SCORE & $8.05(4.78)$ & -- & 624 \\
\hline \multicolumn{4}{|l|}{ AVERAGES } \\
\hline No Parent Abroad & $8.18(4.61)$ & -- & 384 \\
\hline Mother Abroad & $7.42(4.32)$ & -- & 40 \\
\hline Father Abroad & $7.28(5.28)$ & -- & 82 \\
\hline Grandparent Abroad & $9.28(4.88)$ & -- & 60 \\
\hline Other Abroad & $7.51(5.19)$ & -- & 58 \\
\hline Difference, Gender & $* * *$ & -- & \\
\hline
\end{tabular}

Source: CELB-GE 2012; Notes: Standard deviations in parentheses. ${ }^{1}$ Reference category is no family abroa,d but no category of migration was associated with statistical differences in mean score.

${ }^{* * *} p<0.001$ (two-tailed test)

The results of the sequential quantile regression analyses (Tables 7.3 and 7.4) provide a better sense of how migration and child psychosocial heath may be related. In these analyses, the total difficulties scores of children with a mother, father, grandparent, or other family member abroad were compared to those of children without any family members abroad. Reported coefficients indicate the change in the total difficulties score associated with a given variable; positive coefficients indicate increases in the score whereas negative coefficients indicate decreases. Higher scores thus indicate movement toward less favourable outcomes and negative coefficients toward better outcomes. 
For children of both genders, no form of family-member migration corresponded to highly significant differences in total difficulties scores: those results that were statistically significant were only marginally so. For the most-well boys in the sample-those with scores in the lowest $20^{\text {th }}$ percentile-the migration of a father corresponded to a score increase of just over one point, and for the leastwell boys in the sample-those with scores in the upper-most $20^{\text {th }}$ percentile-the migration of a other family member corresponded to a score decrease of over two points. Both of these results were significant only at the 10-percent level. For the most-well girls, whose scores were in the lowest $20^{\text {th }}$ percentile, the migration of a father corresponded to a score decrease of 1.71 points, which was significant at the five-percent level. The limited level of significance and small size of the coefficients associated with different forms of family-member migration suggests that other aspects of a child's life may be more important in mediating psychosocial health.

Two variables in particular stand out for the persistent, highly significant relationship to child psychosocial health outcomes: residence in the Adjara region, and being called names such as "stupid" or "lazy" by a caregiver. Figures 7.1 and 7.2 provide a visual representation of the relationship between these variables, the family-member migration variables, and child total difficulties scores.

These visualisations illustrate the consistent and sometimes substantial score increases associated with living in Adjara and being called names by a caregiver, which are particularly marked compared to the generally downwardsloping relationships between the different migration variables and total difficulties scores. For children of both genders, residing in the Adjara region corresponded to large increases in the total difficulties score, with children in the upper end of the score distribution experiencing the most marked increases. For boys this relationship was strongly significant only in the $60^{\text {th }}$ and $80^{\text {th }}$ percentiles, whereas for girls this relationship was significant across the distribution. As can be seen from figures 7.1 and 7.2, the coefficients associated with residence in Adjara are large: for the least-well children in the sample with scores in the $80^{\text {th }}$ percentile, residence in Adjara corresponded to a score increase of 6.41 points for boys and 4.15 points for girls. The coefficients associated with a child being verbally admonished by a caregiver were also large, ranging from just over two points for children of both genders with scores in the $20^{\text {th }}$ percentile to over three points for children with scores in the $80^{\text {th }}$ percentiles. 


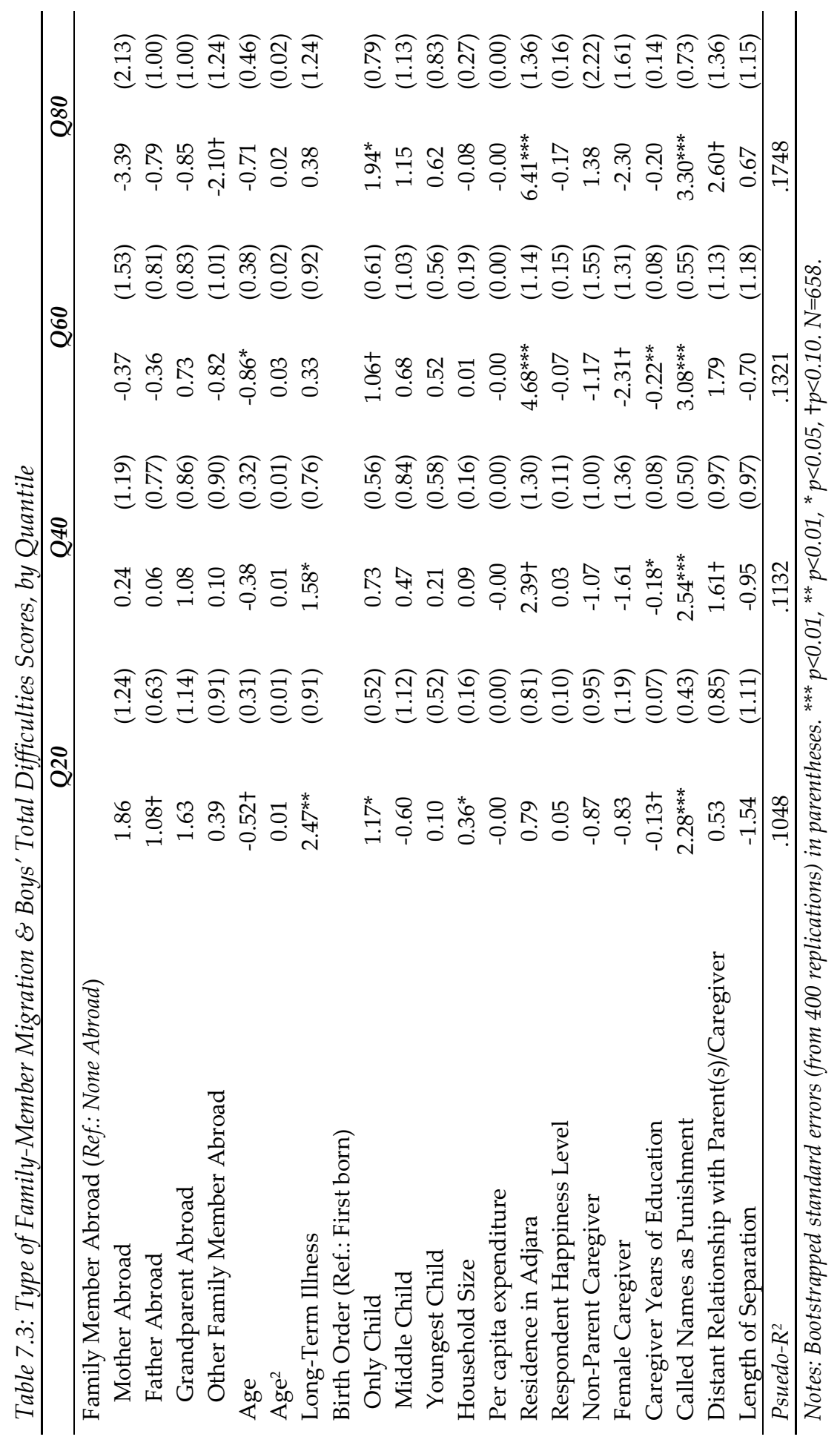




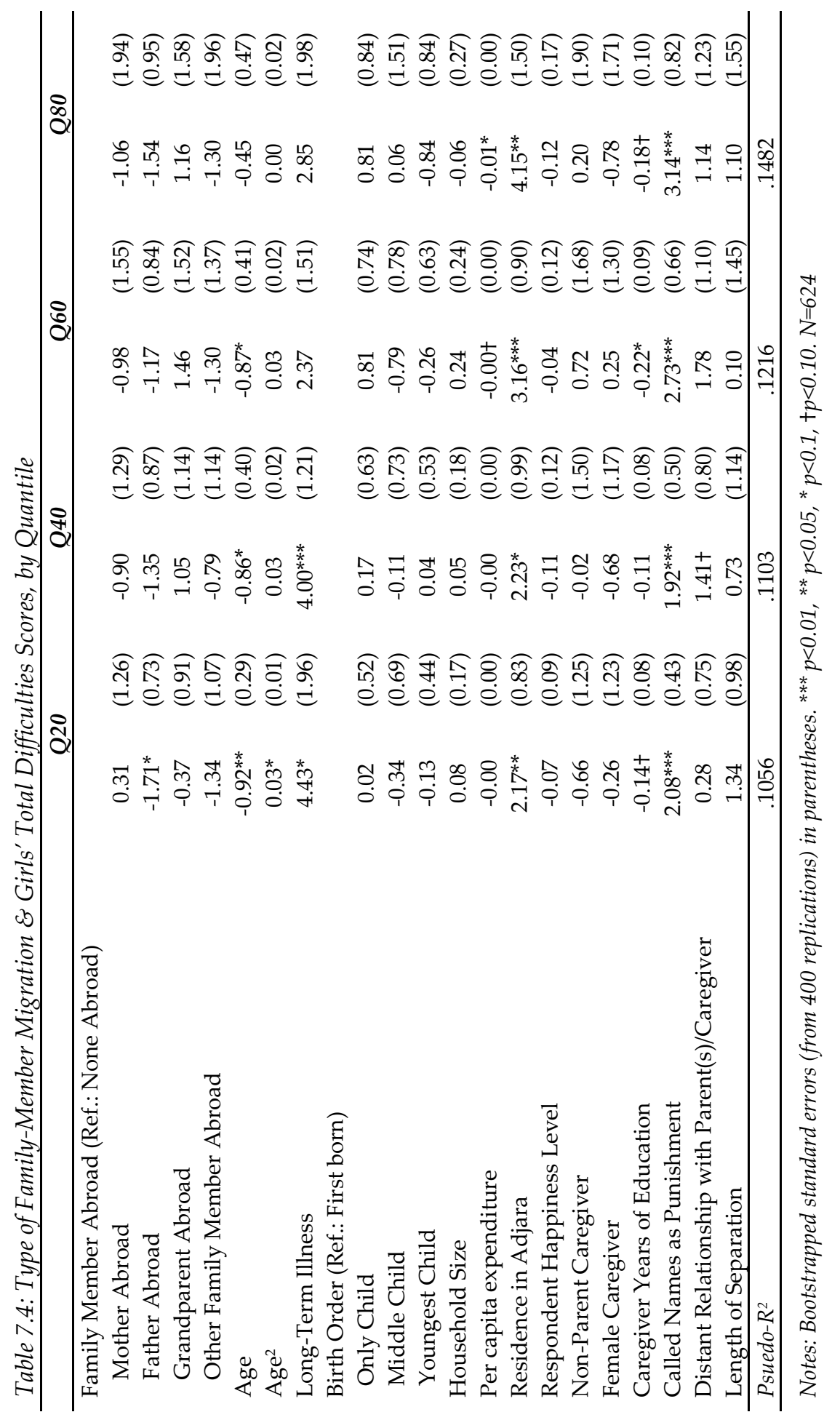




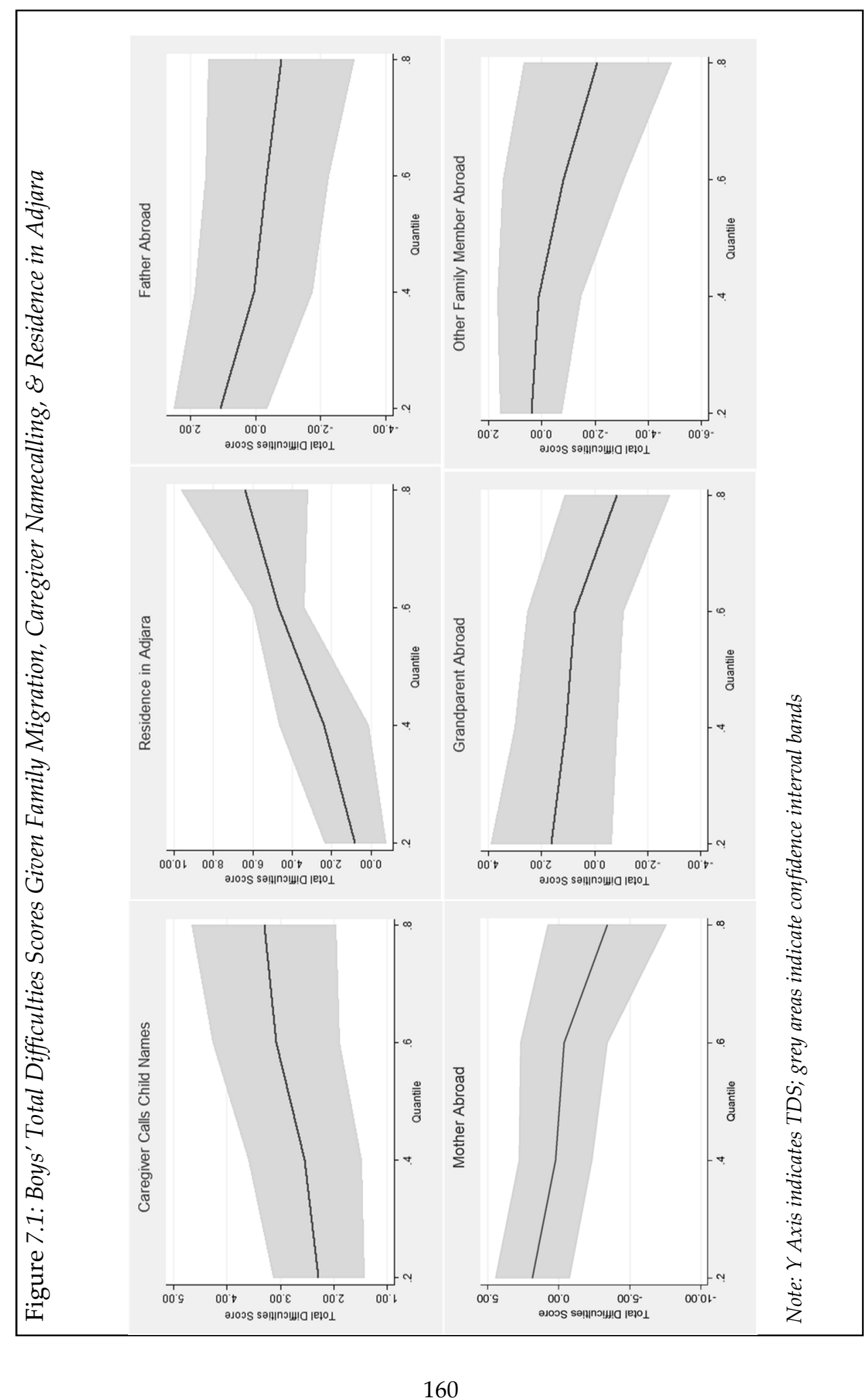




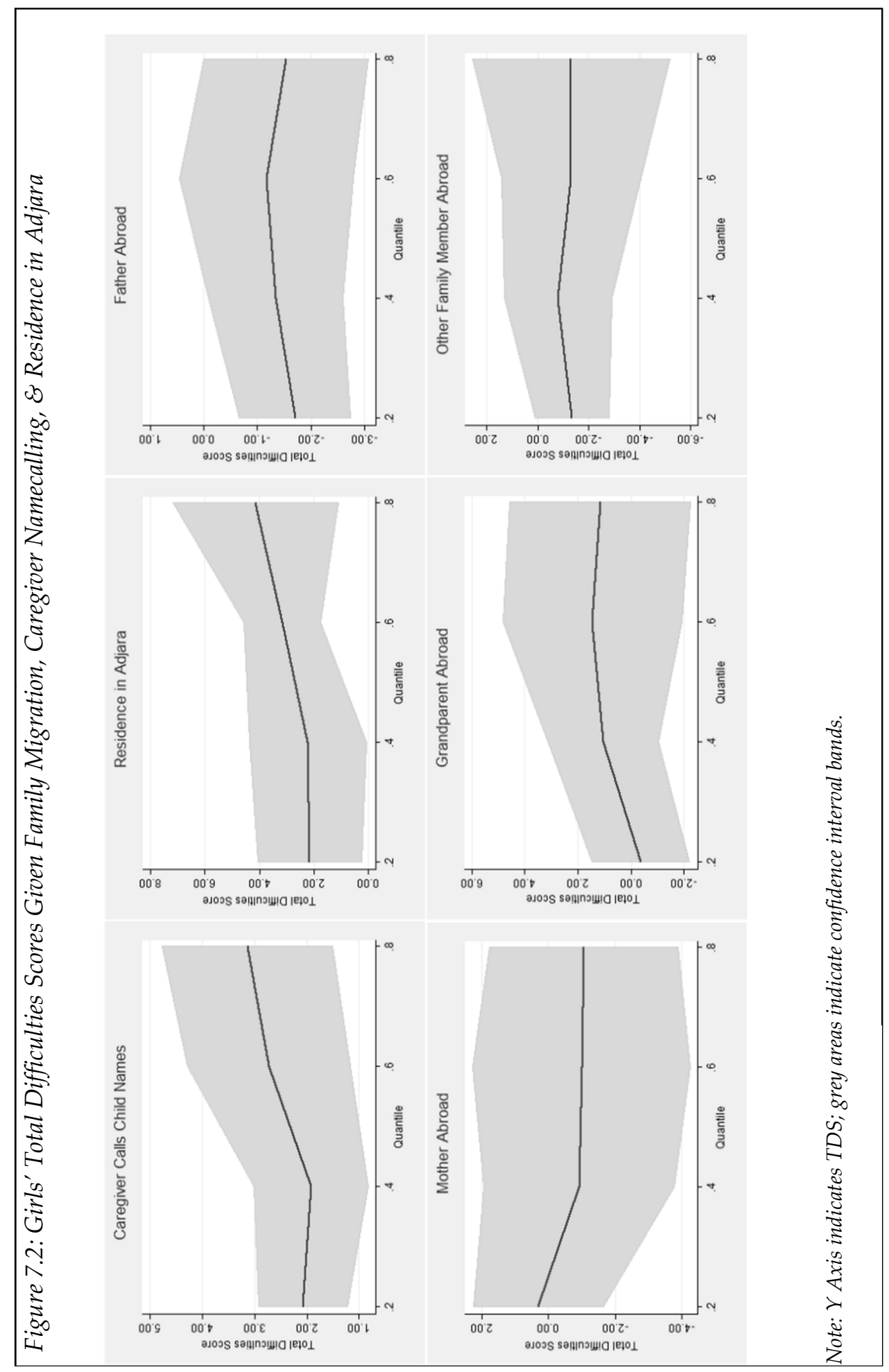




\subsection{DISCUSSION}

The results of the sequential quantile regressions suggest that the relationship between family-member migration and child psychosocial health requires more nuanced discussion. The relationship between migration and child psychosocial health was found to be weak and inconsistent across the conditional score distribution. Only girls with scores in the $20^{\text {th }}$ percentile were found to be significantly influenced by migration, where a father's migration corresponded to a 1.73-point decrease in the total difficulties score.

Such findings lead to rejection of all study hypotheses. The migration of a family member never corresponded to significantly higher total difficulties scores, and the migration of a mother, rather than fuelling particularly bad psychosocial health outcomes, appeared to be insignificant. These results provide three important insights: 1) the relationship between child psychosocial heath and migration is unlikely to be meaningfully understood in averages, necessitating better use of the entire distribution of psychosocial health; 2) psychosocial health and the factors that undermine or support it may differ significantly by child gender, and; 3) the role of migration in influencing child psychosocial health is likely minor compared to other aspects of a child's life such as exposure to conflict and quality of caregiving.

First, the use of quantile regression supports the need to go beyond the "average child" in modelling the relationship between migration and psychosocial health, particularly as it is precisely those children who fall outside the average that appear to be most influenced by migration. A preliminary OLS estimation of the models revealed no significant relationships between migration and total difficulties scores, which would be expected given the finding that only the girls with scores in the lowest end of the distribution appeared to be influenced by any form of migration beyond the ten-percent significance level. Such a finding importantly suggests that children with different 'degrees' of well-being may experience migration in different ways. For instance, it is likely not coincidental that migration appeared significant only for girls with the lowest total difficulties scores, who could be considered at the least risk of having a psychiatric disorder: girls who are already healthy are likely better able to make use of the positive externalities of paternal absence. At the same time, migrant selection is likely to 
play a role in generating these outcomes: potential migrants with psychosocially unwell children may be less likely to go abroad, thus those who do migrate may be expected to have children who are among the healthiest psychosocially.

Second, the differential influence of migration on the total difficulties scores of boys and girls supports the advantages of subpopulation analysis by gender and signals the importance of understanding the intersection between migration and gender. Why do girls appear to be positively influenced by the migration of a father whereas boys appear to be very marginally negatively influenced by it? Perhaps girls benefit more from paternal migration -in the form of remittances, for instance, as well as through less-easily quantified changes such as greater decisionmaking autonomy - whereas boys may experience increased responsibilities given the migration of a father, as they may be expected to assume some of the tasks that their fathers performed prior to migration. That this marginally-negative effect appeared only for the healthiest boys may suggest that a father's presence is most meaningful in boosting psychosocial health once a child has already passed a certain wellness threshold, whereas for those children who are less well, a father's presence or absence makes less of a difference. The link between child psychosocial health and migration is thus likely an inherently gendered one, in two respects: it is not simply child or migrant gender that matters but the interaction between them.

Third, and perhaps more importantly, child psychosocial health appears much less sensitive to the mere presence or absence of a family member than to other aspects of the caregiving environment such as exposure to conflict and use of verbal admonishment by a caregiver. In the Georgian context, the limited role of migration in affecting child psychosocial health likely reflects the consistent quality and availability of childcare given participation of the extended family. Over 60 percent of all children in the sample resided in complex households; a larger proportion of children with a mother abroad-76 percent-resided with the extended family than did any other group of children. Such residency patterns likely reflect the choice of migrants to leave only when their migration would not leave a care deficit for children in the household, as suggested by Hofmann and Buckley $(2011,2013)$. As grandmothers often provide childcare even when their daughters(-in-law) are physically present in the household, the childcare transition experienced with a mother's migration may not be that radical. The lack of statistical significance between maternal migration and psychosocial outcomes is 
thus perhaps unsurprising. The strong, negative relationship between total difficulties scores and characteristics such as residing in the Adjara region and being called names such as "lazy" or "stupid" by a caregiver stands in stark contrast. The marked increase in the scores of both boys and girls associated with these variables across the entire score distribution suggests that quality of caregiving and exposure to psychosocial stressors such as political strife are much more concerning.

The insights generated by the analysis could be enhanced in the future by addressing specific study limitations. One limitation related to lack of information about changes in residency patterns and caregiving arrangements over a child's life. As information was only collected on the present household situation, the premigration household composition and caregiving arrangements are not known. Other studies, such as that of Mazzucato et al. (2014), have suggested that change in caregivers can hamper child psychosocial health, thus it is important to monitor and control for such changes, particularly in the migration context.

Another limitation concerns endogeneity. Migrants are not randomly selected from the population and are likely to have a combination of both observable and unobservable traits that increase their chances of participating in international moves. Individuals residing with children with poor psychosocial health may be less likely to migrate in the first place, thus it is unclear if migration contributes to better child psychosocial health or if better child psychosocial health encourages migration. The collection of panel data and the development of instrumental variables approaches that can control for potential endogeneity would be valuable future strategies for overcoming this constraint.

A final limitation of this study relates to sample size and analytical method. A large portion of children between the ages of four and 18 did not have a complete caregiver-reported SDQ. The missing information appeared to be randomly distributed across the population, but the amount of missing data did reduce the size of the final analytical sample. Small sample numbers in each family migration category precluded analysis of a migrant-only sample, which would have enabled investigation into migrant-specific characteristics that potentially contribute to differing psychosocial outcomes.

Despite these limitations, the findings importantly demonstrate the value of measuring psychosocial health outcomes using standardised indicators of 
psychosocial health and with the use of an appropriate comparison group. The different outcomes observed by quantile of the total difficulties score distribution, by child gender, and by type of family-member migration further suggest that generalising the "effects" of migration on children who remain in Georgia would require ignoring the multitude of factors that contribute to child psychosocial health. They also suggest that the focus on migration as a potential risk factor for child psychosocial health may be misdirected, particularly given the presence of much more significant threats to psychosocial health such as a caregiver's use of verbal punishment techniques. The findings also suggest that the focus on parentchild separation to the exclusion of other types of child-family relations may contribute to poor understanding of how psychosocial health develops in sociocultural contexts where participation of the extended family in childcare is normal. 


\section{CHAPTER EIGHT: CONCLUSION}

This dissertation has examined the relationship between the migration of coresident family members and the psychosocial health of children who remain in Moldova and Georgia, two countries that have experienced rapid and sustained emigration flows over the past 25 years. Analysis of household survey data collected among over 3,500 households in Moldova and over 4,000 households in Georgia has suggested that migration is not as important a factor in the development of psychosocial health as has been suggested by much prior research and discourse. The results challenge many assumptions about how children growing up in transnational families develop and highlight how the context in which migration occurs-including who migrates, who assumes caregiving roles, and how caregivers interact with the children under their care-strongly influences whether and how migration corresponds to differences in child psychosocial health.

This chapter reflects on the findings of this research and addresses how they fit within larger research on the well-being of children in transnational families. Section 8.1 reviews the findings of each chapter, and section 8.2 addresses the research questions posed in the introduction and the hypotheses advanced in Chapter Two. Section 8.3 proposes policy recommendations based on the findings, and the chapter ends with a discussion of research limitations (section 8.4) and future study needs (section 8.5).

\subsection{MAIN FINDINGS}

Following the introduction in Chapter One, Chapter Two explored the theoretical connections between child psychosocial health and migration and canvassed past research on how the migration of a family member, chiefly a parent, can influence child well-being. Over the past 15 years, transnational family scholars, child psychologists, and family sociologists have gradually addressed the experiences of children living in geographically-dispersed families. Transnational 
family studies were among the first to recognise children remaining in the country of origin following the migration of kin as valuable research subjects that merited analysis, with much of the research conducted by scholars in this field addressing how child-parent relationships evolve within transnational families. These largely qualitative explorations assessed child well-being based on children's reported emotional responses to living in transnational families. Such studies were later followed by more quantitative studies by child psychologists and family sociologists, who compared the psychosocial health outcomes of children with and without migrant family members using standardised indicators of health (Mazzucato, 2014a). Across disciplines and analytical methods, most studies on the well-being of children separated from their migrant kin in different countries have emphasised that the relationship between migration and child psychosocial health depends on the context in which migration occurs. Factors found to have particular influence on child well-being outcomes included the gender and role of the absent migrant (Jordan \& Graham, 2012; Mazzucato et al., 2014; Parreñas, 2005), the migration of a caregiver and stability of caregiving arrangements (Mazzucato et al., 2014; Lahaie et al., 2009; Jia \& Tian, 2010), the age and gender of the child (Graham \& Jordan, 2011; Liu, Li, \& Ge, 2009), the level of contact between the migrant and the family remaining in the origin country (Fog-Olwig, 1999; Jia \& Tian, 2010; Smith et al., 2004), and a child's exposure to conflict and poverty (Biao, 2007; Jia \& Tian, 2010; Mazzucato et al., 2014). In synthesising the findings from the qualitative literature generated by transnational family scholars and the more quantitative study findings from sociologists and psychologists, this chapter concluded with several hypotheses about the relationship between the migration of kin and the psychosocial well-being of children in Moldova and Georgia. These hypotheses are addressed in section 8.2 below.

Following the description of data and the methods used for their collection and analysis in Chapter Three, Chapter Four provided background information on Moldova and Georgia with particular focus on how contemporary emigration flows evolved in the post-Soviet period. Different "eras" of migration from both countries were described, revealing that the composition and direction of migration flows from both countries have changed significantly over time. In the immediate post-Soviet years, much emigration from both countries was comprised of the return or repatriation of populations to an ethnic homeland and the migration of whole families fleeing conflict. Beginning in the mid-1990s, more single emigrants seeking work abroad began leaving both countries, the majority 
of whom were young men destined for labour markets in the Commonwealth of Independent States (CIS). Since the early-to-mid 2000s, the composition of emigration flows has changed to include more women destined for a larger number of countries, including Italy, Greece, Israel, and Turkey. This chapter also addressed family organisation and how emigration and family life are connected. Significant differences are apparent between Moldova and Georgia: whereas in Georgia members of the extended family often live together in the same household and share responsibilities such as childcare, nuclear-family households are more common in Moldova, where members of the extended family are less involved in the daily activities of children. Expectations about the roles of men and women are similar in both countries, however, with women expected to perform most domestic tasks (including intensive child-raising activities) and men expected to work and negotiate family needs outside the household. Despite this similarity, female migration in Moldova has been regarded much more negatively than in Georgia, where the migration of women is tolerated as a necessary sacrifice made for family well-being. The similar experiences of post-Soviet transition coupled with differences in family organisation and gendered expectations highlight the value of using Moldova and Georgia as case studies through which migration and child psychosocial health can be explored.

Chapter Five, the first of the analytical chapters, explored the factors that differentially influence the migration propensities of men and women from Moldova and Georgia using data collected in the project "The Effects of Migration on Children and the Elderly Left Behind in Moldova and Georgia". In both countries, women represented a smaller share of new migrants in the earliest years following the post-Soviet transition, and in Moldova, women have yet to outnumber men among migrants leaving in a given time period. In Georgia, the number of women migrating for the first time surpassed men in the early-to-mid2000s. Men from both countries still represented the majority of migrant stocks abroad, but in the EU-28 and "Other" region (including North America, Turkey, and Israel), women from both Moldova and Georgia constituted a greater proportion of migrants. Binary logit regression models revealed that the odds of Moldovan men being international migrants were more than twice those of women, whereas in Georgia, the migration odds of men and women did not significantly differ. Different factors corresponded to significantly different migration odds for men and women, however: marital status, for instance, strongly influenced the migration odds of women from both countries but corresponded to 
only marginally-different odds for men. Divorced women had particularly high odds of being international migrants compared to their currently-married counterparts. Household composition was also found to differentially influence the migration odds of men and women, with potential migrants of both sexes from Georgia and men from Moldova expressing lower odds of migrating given the presence of children or the elderly in the household. The risk of an individual migrating to the EU-28 or "Other" region (relative to the CIS region) were also predicted using multinomial logit models, which revealed that women from both Moldova and Georgia had much risks odds of migrating to a country beyond the CIS region than their male counterparts. The findings suggested that the migration propensities of men and women may be shaped in distinctly gendered ways that differ by country context: whereas in Moldova, women had much lower odds of migrating than their male counterparts, the odds of Georgian women were only significantly less than those of men given the presence of dependents in the household.

Chapter Six assessed the relationship between child psychosocial health and parental migration in Moldova. In this chapter, child psychosocial health was measured using the emotional symptoms and conduct problems subscales of the Strengths and Difficulties Questionnaire (SDQ). The probabilities of a child attaining abnormal emotional symptoms and conduct problems scores were predicted using probit analysis, with the scores of children with one or both parents currently living abroad compared to those of children living with both parents in Moldova. For female children, no form of parental migration corresponded to statistically-significant differences in the probability of abnormal scores on either of the subscales. In contrast, male children with both parents living abroad were more likely than their counterparts living with both parents to have abnormal emotional symptoms scores (by 17 percentage points), and boys cared for by a mother when a father lived abroad were more likely to express abnormal conduct problems scores (by 11 percentage points) than their peers living with both parents. Other factors corresponded to increased probabilities of both male and female children achieving abnormal psychosocial outcomes: being called names such as "lazy" or "stupid" by a caregiver, for instance, increased the probability of girls developing abnormal emotional symptoms scores and boys developing abnormal conduct problems scores. 
Chapter Seven, the final analytical chapter, compared the psychosocial health outcomes of Georgian children with and without members of the normally co-resident family living abroad using the total difficulties score (TDS) of the SDQ, an aggregate measure of psychosocial health comprised of four subscales of the SDQ (the emotional symptoms, conduct problems, peer problems, and hyperactivity and inattention subscales). Sequential quantile regression analyses were conducted to compare the TDSs of children who had experienced some form of family-member migration (that of a mother, father, grandparent, or other family member) to those of children without any family member living abroad who resided with both parents. The sequential quantile regression method allowed for comparisons of scores in the low (20 th percentile), median (40 $0^{\text {th }}$ or $60^{\text {th }}$ percentile), or high $\left(80^{\text {th }}\right.$ percentile) score range. $t$. For both male and female children, the migration of a family member seldom corresponded to significant differences in total difficulties scores. Only female children with scores at the lowest end of the score distribution (within the lowest 20 percent) were significantly influenced by migration, with the migration of a father corresponding to a 1.73-point decrease in the TDS. Other factors, such as living in the Adjara region and being verbally admonished by a caregiver, appeared to much more significantly contribute to score differences.

\subsection{RESEARCH QUESTIONS AND HYPOTHESES}

The four research questions posed in the introduction can now be answered in conjunction with the hypotheses proposed in Chapter Two. The main research question-what is the relationship between the migration of a parent or other member of the co-resident extended family and child psychosocial health?-is best addressed by first answering the three sub-questions. 


\subsubsection{Sub-Question One: The feminisation of migration from Moldova and Georgia}

The first sub-question asked: How has the feminisation of migration from Moldova and Georgia occurred, and how do these gendered migration trends reflect underlying factors that shape the migration propensities of men and women?

As was described above, the feminisation of migration has occurred at a faster pace in Georgia than in Moldova, where the proportion of women among new migrants exceeded that of men beginning in the mid-2000s. In Moldova, the proportion of women among new migrants lagged behind that of men, yet women from both countries did account for the majority of both stocks and flows of migrants in countries outside of the CIS. Women from both countries also expressed higher relative risks than men of emigrating to the EU or non-CIS region, despite the fact that in Moldova, men had higher odds in general of becoming migrants. The factors that shaped these migration trends differed significantly for men and women: whereas marital status had almost no correlation to the migration odds of men, it was highly significant for women in both Moldova and Georgia. In Moldova, men had lower odds of being migrants if they resided with children or elderly individuals; for women, the presence of children was not significant in shaping migration odds, yet co-residence with an elderly individual corresponded to increased migration odds.

Two hypotheses about the feminisation of migration and the gendered selection process were posed in Chapter Two. The first was that in both Moldova and Georgia, female migration-and by extension, maternal migration-will be less common than male migration. This hypothesis must be rejected as stated, as women in Georgia did not have significantly different odds of migrating from men. Pessar (1999) suggests that hierarchies of power based on gender and generation may influence who is seen as a viable migrant; the finding that Georgian women did not have lower odds of migrating than men may reflect processes related to both age and gender. Migrants from Georgia were slightly older than their Moldovan counterparts, and a greater share of female migrants were grandmothers than mothers. In Georgia, expectations about the family roles older women perform are likely to also shape migration propensities, a finding that echoes that of Solari (2010) who found that older women in Ukraine were 
preferred by their families to become international migrants because they could provide economic support for their children and grandchildren while allowing younger women-particularly daughters(-in-law) - to remain at home to care for young children.

The second hypothesis relating to the feminisation of migration was that gendered norms regarding social reproduction will discourage female migration, particularly among women with children or other household dependents. This hypothesis is also rejected: while women in Georgia who resided with household dependents had much lower odds of being migrants than their counterparts without children or elderly household members, women in Moldova expressed a contrary pattern. As is discussed in Chapter Five, the differing outcomes in Moldova and Georgia are likely to reflect gendered norms, but in different ways. Whereas women in Georgia may be discouraged from entering migration given their role as caretakers of household dependents, women in Moldova are discouraged from becoming migrants more broadly, based more on their roles as wives and women than on their roles as mothers or carers of ageing kin.

\subsubsection{Sub-Question Two: Forms of Family-Member Migration}

In narrowing the focus to the potential relationship between migration and child psychosocial health, the second sub-question posed was: What is the relationship between different forms of family-member migration, such as that of a mother, father, grandparent, or other kin, and child psychosocial health?

The analyses in Chapters Six and Seven revealed significant differences in SDQ scores based on who had migrated. In Moldova, boys had higher probabilities of having abnormal emotional symptoms scores given the migration of both parents and of abnormal conduct problems scores given the migration of a father when a mother acted as primary caregiver. In Georgia, only the scores of female children in the lowest end of the score distribution were significantly related to any form of family-member migration, with the migration of a father corresponding to a decrease in total difficulties scores.

Five hypotheses were formulated in Chapter Two relating to differences in child psychosocial outcomes given different types of family-member migration. 
The first three addressed how child psychosocial health would be influenced by different forms of migration, and the last two addressed why the migration of specific individuals would be expected to correspond to worse outcomes. The first three hypotheses will be addressed first. They stated that: 1) the migration of any family member will correspond to worse child psychosocial health outcomes, but; 2) the migration of a mother will correspond to particularly negative outcomes, and; 3) child psychosocial health will also differ by type of caregiver, with children cared for by a non-parent given the migration of a parent at particularly high risk of experiencing poor psychosocial health.

The first hypothesis is rejected, as there is no substantial evidence that the separation of children from their co-resident kin, including parents, corresponds to universally worse psychosocial well-being outcomes. The outcomes of children notably differed by who specifically had migrated, but even when the migration of a particular individual (such as a father) did correspond to significantly different SDQ outcomes, the magnitude of the relationship between migration and score outcome was often marginal. The second hypothesis is likewise rejected: maternal migration did not singularly correspond to worse SDQ score outcomes among children in either Moldova or Georgia. Maternal migration corresponded to worse scores only for male Moldovan children, and only on the emotional symptoms subscale, when maternal migration was experienced jointly with paternal migration. There is no evidence to suggest that this result is driven by caregiver choice, however, as is proposed in the third hypothesis. Being cared for by a nonparent (namely a grandparent or aunt) did not correspond to worse outcomes among children in either country or of either gender. In Moldova, in fact, male children cared for by a grandparent (without distinguishing by parental migration status) expressed lower probabilities of attaining abnormal scores on both the emotional symptoms and conduct problems subscales compared to children cared for by a parent.

These first three hypotheses were formulated based on past literature, and their rejection leads one to question why the findings from this study deviate from those of studies conducted in other places. One key difference is in method. Many of the studies that found negative relationships between family-member migration and child outcomes were based on qualitative accounts in which children or their caregivers described children reacting to parental migration with feelings of abandonment, sadness, loss, or resentment (Dreby, 2007; Moran-Taylor, 2008; 
Parreñas, 2005; Schmalzbauer, 2004). In contrast, this study did not engage feelings or perceptions but instead used indicators of psychosocial health derived from a standardised measurement instrument. How child psychosocial health is defined and operationalised is an important source of difference between studies, even those with similar methodological designs. For instance, Jordan and Graham (2012) found that maternal migration corresponded to lower self-reported happiness among children. Had the psychosocial health of Moldovan and Georgian children been measured in terms of happiness, it, too, may have found a stronger relationship between maternal migration and child outcomes. A further difference in methodological design relates to child sex. In most quantitative studies, male and female children are pooled into one sample, and sex is included as a control variable. In this study, male and female children were studied as separate subpopulations to enable identification of sex-specific trends. The pooling of children of both sexes into one population would have changed the expression of results, and while strong relationships between maternal migration and child psychosocial health would not have emerged, the significant correlations between paternal migration and child outcomes would have disappeared.

Beyond methodology, results would be expected to differ between studies based on country contexts. Upon finding that children living in different forms of transnational households in Indonesia, the Philippines, Thailand, and Vietnam expressed differing outcomes on the same psychological well-being measures, Graham and Jordon (2011) noted that migration may be perceived as advantageous for children in one country and detrimental in another due to cultural contextualisation. The contextualisation process likely reflects the circumstances surrounding migration and the specific norms and behaviours relating to childraising within specific countries. Characteristics of the migration episode, including the duration of migration, the periodicity of physical return, and the destination country of migrants, are likely to contribute to different potential consequences of migration for children. Furthermore, family settings and expectations about child-raising are likely to differ between countries; within this study, family residential arrangements and the participation of members of the extended family in childcare emerged as important sources of difference between Moldova and Georgia.

Differences in results owing to country-specific contexts were envisioned in two additional hypotheses that related to why the predicted outcomes would occur 
given specific characteristics of Moldova and Georgia. The first hypothesis proposed that female migration will correspond to considerably worse outcomes among children in Moldova, where children are less likely to reside with members of the extended family who can provide care. The second hypothesis was that in Georgia, co-residency with the extended family would reduce the potential negative consequences of parental migration, yet the migration of members of the extended family would correspond to negative psychosocial health outcomes given the ability of a child to form multiple attachment relationships.

The first hypothesis is rejected given the relatively benign relationship between maternal migration and child psychosocial health in Moldova, but the second part of the hypothesis - that the absence of members of the extended family as potential providers of care would heighten negative outcomes-merits consideration. In Moldova, why would the absence of a father correspond to worse outcomes among boys? Household composition and the distribution of responsibilities it implies may explain this result. Given the low rates of extended family co-residence in Moldova, mothers provide the most care for children. Past research (for instance, UNICEF/CIDDC, 2006; HAI/UNICEF, 2008; Cheianu-Andrei et al., 2011) has suggested that in Moldova when a mother or both parents migrate, grandmothers, aunts, or other female relatives often become the primary caregivers of the children who remain, signalling a shift in responsibilities to generally non-resident kin. When a father migrates, however, his roles are often assumed by his wife and other household members. In interviews with the families of migrants in Moldova, for instance, all of the women whose husbands had emigrated abroad described assuming their husbands' duties, such as ploughing and sowing the fields, disciplining the children, and becoming the main income earner in the household. Some described engaging their sons in household chores, such as cooking, cleaning, or looking after younger siblings, which the children had not performed before. Girls are often engaged in these activities regardless of who else is in the household, however, thus the migration of a father may increase the responsibilities of boys in the household while bearing only limited consequences for girls.

The second hypothesis can similarly not be completely rejected. A significant share of children in Georgia lived in a household with members of the extended family, and among those children who had a migrant in their family, a large share had experienced the migration of a grandparent, sibling, or other non-parent. 
Given the intense participation of members of the extended family in childcare, particularly grandmothers, it could be expected that the migration of close kin would represent a disruption to an attachment relationship that would correspond to worse psychosocial health outcomes. The finding that no form of familymember migration corresponded to worse child outcomes likely reflects the capacity of the extended family to bridge any potential caregiving gaps introduced by the migration of one specific household member, even a parent. In interviews with the families of migrants in Georgia, respondents noted that the caregiving transition following the migration of a parent was often not abrupt because caregiving responsibilities were dispersed before migration. Grandparents, siblings, aunts/uncles, and even older cousins were discussed as important sources of care in Georgia; some children were cared for more intensively by a grandmother than either parent regardless of parental location. Past studies conducted in countries such as the Philippines (Battistella \& Conaco, 1998), Honduras (Schmalzbauer, 2004), and Mexico (Hondagneu-Sotelo \& Avila, 1997) have also found that the participation of members of the extended family, particularly grandmothers, can promote child well-being during transitional periods by ensuring the availability of care. Within studies of children in transnational families, however, and regardless of discipline, the extended family is generally included only as part of the origin-country care environment; the literature is silent on how the migration of members of the extended kin network can affect child psychosocial health. Given the lack of studies on the separation of children from members of the extended family due to migration, the results of the analyses in Chapter Seven are difficult to interpret within the larger literature, highlighting the need to investigate further how child psychosocial health develops in family and care settings where members of the extended family actively participate in child-raising both prior to and following migration.

\subsubsection{Sub-Question Three: Magnitude of Migration Compared to Other Factors}

The final sub-question concerned the relative importance of migration in the formation of child psychosocial health. It asked: what is the magnitude of the 
relationship between migration and child psychosocial health relative to other factors in a child's life that influence well-being outcomes?

In the analyses conducted in both Moldova and Georgia, migration corresponded to significantly different outcomes in only a small number of models. In both country analyses, other independent variables consistently corresponded to differences in SDQ outcomes, and often with large coefficients, indicating a greater magnitude of influence. In Moldova, for instance, being called names by a caregiver corresponded to higher probabilities of children attaining abnormal scores, for girls on the emotional symptoms subscale and for boys on the conduct problems scale. For boys, the size and significance level of the coefficient associated with being called names was greater than that associated with paternal migration, suggesting that being called names such as "stupid" or "lazy" by a caregiver may be more dangerous for the development of poor psychosocial health outcomes than the presence or absence of a parent. Similar results emerged from the analyses conducted in Georgia, where two factors-residing in Adjara and being called names by a caregiver-consistently corresponded to significantly higher TDS scores for both boys and girls across most of the conditional score distribution.

One hypothesis about the significance of family-member migration relative to other factors was proposed. This hypothesis stated that the migration of a family member is just one of the potential risk factors for the development of poor psychosocial health, with environmental factors such as poverty or exposure to conflict correlated to worse psychosocial health outcomes. This hypothesis is rejected as stated. While indeed migration was not the only factor that corresponded to poor psychosocial health outcomes, poverty was not a consistent predictor of worse outcomes for children in either country. In Moldova, poverty status - indicated by a household belonging to the last quintile in a wealth indexwas not significant in any model. In Georgia, socio-economic status-determined by per capital monthly expenditure per adult equivalent-was significantly correlated to better total difficulties scores, but only for girls with the worst scores (i.e., those in the $80^{\text {th }}$ percentile). Expectations about the role of material poverty in influencing child health outcomes were derived primarily from studies on children in China (Biao, 2007; Jia \& Tian, 2010), where the majority of children separated from their migrant parents are left in rural areas with poor public infrastructure and provision of public goods. Such expectations may not completely carry over to 
other country contexts, including Moldova and Georgia where the nature and scale of poverty may differ. While relative poverty or deprivation may still be expected to affect children in these countries, it seems likely that other factors controlled for in the analyses, such as the human capital levels of caregivers, also act as a proxy for poverty and therefore diminish some of the explanatory power of income or asset deprivation.

Exposure to conflict, or more broadly, conflictual environments, was significantly related to worse child psychosocial outcomes in both countries, however. In Georgia, children residing in the Autonomous Republic of Adjara had significantly worse total difficulties scores across the entire score distribution, a result that likely reflects instability in the region. Until 2004, Adjara was led by an authoritarian ruler (Aslan Abashidze) who refused to follow Georgian central rule after the Rose Revolution in 2003, which brought the reformist president Mikheil Saakashvili to power. An armed conflict between Adjara and Georgia was narrowly averted in 2004, when Abashidze was exiled and a pro-Georgian government came into power. The region was also home to a Russian military base until 2007, which was a constant source of tension between Russia and Georgia. The environment of political instability and potential conflict could play a role in undermining a child's sense of security, but further research would be needed to explore why children in Adjara had such markedly worse outcomes compared to children living in other regions, some of which border recent conflict areas. While not an indicator of physical insecurity and conflict, a child being called derogatory names by a caregiver could also be considered exposure to conflictual environments. The strong correlation between a child being called names and worse SDQ outcomes, which was observed among children of both genders in both countries and across specific SDQ measures, suggests that this form of negative reinforcement is potentially more problematic for the development of poor child psychosocial health than is any form of migration.

While the exact phrasing of this last hypothesis led to its rejection, the core expectation - that factors related to the environment in which children grow and develop can play a significant role in child psychosocial health-has been confirmed within this study, with some parallels with past research. The role of conflict in influencing child health outcomes within transnational family settings has been observed by Mazzucato and colleagues (2014) in Angola, where recent civil conflict was thought to undermine individual- and community-level 
adaptations to transitions such as migration given its corrosive effects on solidarity. Conflictual care environments-or rather the opposite, appropriate monitoring and parenting practices-were also found to be important in the cultivation of child resilience in other studies. Robila (2012), for instance, found in her study of children in migrant families in Moldova that a parent or guardian's use of age-appropriate monitoring and discussion styles helped insulate children from the stresses associated with parental migration. The findings of studies such as Mazzucato et al. (2014) and Robila (2012) suggest that families are unequally equipped to deal with potential challenges: certain behaviours (e.g., calm discussion of issues between parents and children) or contexts (e.g., post-conflict environments) affect the resources children and their families have to build resilience following major transitions such as migration. A similar proposition could be made based on the findings of this study - that children faced by conflict, whether inter-personal or political, have a more limited capacity to develop resilience, but additional research would be needed to investigate the interaction between conflict and transnational family arrangements.

\subsubsection{Conclusions: The Relationship between Migration \& Child Psychosocial Health}

The three sub-questions and eight hypotheses discussed above provide a strong basis for answering the main research question, which is: what is the relationship between the migration of a parent or other member of the co-resident extended family and child psychosocial health?

The answer is that the migration of normally co-resident kin did correspond to some differences in the psychosocial health of children who remained in Moldova or Georgia, but the relationship between migration and psychosocial health outcomes was by no means universal and depended strongly on contextual features, namely: 1) the specific aspect of psychosocial health being measured; 2) the gender of the child, and;3) the gender of the absent migrant.

In the previous chapters, psychosocial health was measured in three ways: as emotional symptoms, conduct problems, and an aggregate measure encompassing multiple dimensions of psychosocial health. The outcomes of the 
analyses differed among these measures, suggesting that the relationship between migration and child psychosocial health depends largely on how the concept of psychosocial health is operationalised. Should the concept be expressed with alternate measures such as hyperactivity and inattention, prosocial behaviours, or self-reported happiness, this study could have drawn different conclusions about the role of migration. It has importantly highlighted, however, that child psychosocial health is complex and unlikely to be appropriately captured by singular indicators; while methods of defining and measuring psychosocial health outcomes should be further refined, this study has contributed some methodological nuance to the body of literature on the 'left behind'. It also suggests one key lesson for future research: that measurement method matters, and caution should be taken not to over-state the relationship between migration and child psychosocial health by not distinguishing among components of psychosocial health.

The gender of the child was also a meaningful factor that shaped overall study outcomes. In all of the analyses, the population was split by gender to accommodate different outcome trends within population sub-groups. Had gender only been included as an independent variable, essential nuance would have been lost, particularly when statistical relationships between male and female subjects and particular variables were of opposite signs. If, for instance, a father's migration corresponded to worse score outcomes among boys and positive outcomes among girls, the "net" relationship between paternal absence and the given outcome could be completely non-significant, which would disguise meaningful sub-population trends. Furthermore, the relationship between a child and a given outcome measure, such as emotional symptoms and conduct problems, may inherently differ by gender (Eisenberg et al., 2001). Sub-population analyses are relatively more common in child psychology and development studies yet are scarce in studies of children in transnational families. As the study of the health and wellbeing outcomes of children separated from migrant kin matures, greater integration between these disciplinary perspectives will likely occur. This study has illustrated the value in doing so, suggesting a second key lesson for future research: that the child population is not homogenous, and results should consequently not be generalised to all children given systematic differences within the population. 
The gender and role of the absent migrant was a final essential factor according to which results differed. As has been discussed at length, not all forms of family-member migration were significantly correlated to the different domains of child psychosocial health, and the relationship depended on the child gender. Such a finding is not new, as much of the literature on child health or well-being outcomes in migration settings has emphasised the importance of who has migrated. This study is a valuable addition to this body of literature, however, given the focus on two specific country contexts within a region that is remarkably under-studied despite the growing volume of transnational families within it. A third key lesson derived from this study is thus that the development of child psychosocial health within transnational family contexts is strongly influenced by interactions between the gender of the child and the gender of the migrant, which are specific to the country- and cultural-contexts in which they are embedded. Furthermore, these interactions pose different consequences for different aspects of child psychosocial health, highlighting the need to measure different components of child psychosocial health.

Given these nuances, the conclusion of this study is that the relationship between the migration of normally-co-resident kin and child psychosocial health is relatively limited, yet the specific nature of the relationship depends on the outcome being measured, the gender of the child, and the gender and role of the absent migrant. These more general conclusions are largely in agreement with those of methodologically-similar studies (e.g., Graham \& Jordan, 2011; Mazzucato et al., 2014) but are nevertheless important additions to the larger literature on children with migrant parents or other kin. The results provide additional geographical points of comparison and suggest methodological nuances for the study of the psychosocial health of children in transnational families, but more importantly, they add to a growing body of evidence that suggests the need for greater care in how the child-migration relationship is implicitly conceptualised.

The term 'left behind' poignantly illustrates how this relationship is often (mis)conceptualised. In its wording the term implies that children are abandoned or deserted by a migrant, which signals an expectation that children will suffer because their needs will not be looked after. The results of this research challenge this assumption, particularly as the relationship between child psychosocial outcomes and migration were generally benign-perhaps because the migration decision was made with its consequences for child well-being kept in mind. This 
research also suggests a more fundamental critique of the term 'left behind', namely that such a normative, categorical label artificially homogenises an internally diverse population. Children in different transnational family configurations - and of different genders living in different country contextscannot be presumed to be impacted by migration in a universal (and universally negative) way.

The findings of this research suggest that the term 'left behind' and the conceptual relationship between migration and child well-being it assumes can be more openly contested in quantitative research. Qualitative transnational family research has been more proactive in addressing the normative dimensions of this term. Such research has suggested that children who are 'left' in the origin country following the migration of a parent are not always excluded from the migration decision and are not powerless in negotiating the post-migration changes that occur within their households and families. On the contrary, children have been found to play an important role in shaping their parents' mobility decisions (Dreby, 2007) and to be crucial players in the "family enterprise that tries to keep the family together at a time of migration" (Asis, 2006; pp 63) by caring for younger siblings or making decisions that help minimise the burdens faced by migrant parents. Such research highlights that children are not just passive recipients of care and the changes brought to it by migration but can be active participants in the migration process, with their own perceptions of migration and their own aspirations related to their experiences as members of a transnational family (Hoang \& Yeoh, 2015). Such findings have been revealed by qualitative accounts provided directly by children themselves or their caregivers, but there is no reason that quantitative assessments that map the potential consequences of migration for child well-being cannot constitute a similar challenge to the assumptions implicitly contained in the 'left behind' terminology.

\subsection{POLICY IMPLICATIONS}

The findings of this research suggest that policy in the country of origin can address the psychosocial well-being of children at different stages of the migration cycle. Within migrants' countries of origin, policy can play a strong role in: 1) facilitating the collection of more systematic data on migration; 2) shaping discourses and public perceptions about migration and the implications of 
migration for the family, and; 3) designing and implementing social service schemes that address childhood vulnerability. In each of these areas, research such as this can improve the quality of policy and its implementation.

\subsubsection{Collection of Migration Data}

This research was conducted amidst negative public discourses about migration, particularly in Moldova, in which migration was unequivocally accepted as a threat to child well-being. The results of this study suggest that migration in general is only marginally correlated to child psychosocial health outcomes, if at all. The lack of a strong association between migration and child psychosocial health outcomes may relate to the nature of migration and the characteristics of specific kinds of migrants. One policy recommendation is therefore to support the more systematic collection of data on migration, specifically on who is emigrating, from what family and household circumstances they embark, and how their destination choices influence their household's postmigration situation.

Throughout this research, comparison has consistently been made between migrants and non-migrants, but sources of diversity within the migrant group could correspond to important differences in the potential consequences of migration for children. Chapter Five suggested as much by demonstrating how certain characteristics (e.g., marital status, education level) were associated with different types of migrants (e.g., men and women, those destined for different regions). Different migrants destined for different locations are likely to have fundamentally different migration experiences that generate different risks and advantages. Important intra-group differences could be unveiled with additional study, which would be beneficial for understanding if the type of migrationrather than the migration itself-plays a role in shaping the post-migration psychosocial health of children. For instance, the results suggest that among Moldovan boys, the migration of a father may pose the greatest challenges; that result may have less to do with the absence of a father as such than with the types of men who become migrants. Many male Moldovan migrants are destined for the Russian Federation; lower levels of educational attainment were associated with 
higher risks of emigrating to the CIS, where many men work in low-skilled functions with limited security and pay. Lower parental social capital and household economic instability have both been recognised as important factors that undermine child psychosocial health (Thomson et al., 1994); might not these characteristics, shared among particular types of migrants, be reasonably expected to correspond to worse child psychosocial outcomes? Policy could play a role in answering such questions by encouraging the more systematic and detailed collection of data on migrant populations. One specific suggestion would be to collect more detailed data on emigrants who are included in the civil registration system. While only a small proportion of emigrants are included in the civil registration system-which generally only includes individuals who register a change of address for six or more months or who are issued a visa for a foreign country ((Makaryan, 2012)-such a method could be a less invasive way to mainstream data collection initiatives into pre-existing information infrastructure.

\subsubsection{Cultivation of Evidence-Based Discourse}

A second area in which origin-country policies could address children with migrant kin is in cultivating more responsible and evidence-based discourses about migration and family life. Discourses that emphasise the potential negative consequences of (parental) migration for children likely contribute to public perceptions that children in transnational families are maladjusted or more likely to behave badly, which may in turn contribute to the stigmatisation of such children. For instance, a study conducted in Moldova noted that: "Numerous members of the community... asserted that the group formed by children with parents abroad often exhibit socially undesirable behaviour, like drug abuse, an exaggerated interest in various forms of entertainment, school abandonment, precocious sexual relationships and delinquent behaviour." (UNICEF/CRIC, 2008: pp 48). The factual basis of these perceptions has not been systematically researched, despite widespread reporting of the potential risk behaviours manifested by children 'left behind'. In collaboration with international organisations, the state could support more systematic collection and analysis of data on children with migrant family members, particularly parents, that could

help shape a more responsible dialogue on migration and family life. In Moldova, 
for instance, UNICEF has included a few questions in the multiple indicator cluster survey (MICS) that determines the location of a child's parents. Questions could be built into future rounds of the MICS that ask specific questions about child risk behaviours, creating the possibility to compare children with and without parents abroad on the basis of specific outcomes. In contrast to past studies that relied on targeted sampling of children 'left behind' and in pre-existing situations of vulnerability, data derived from the MICS would be more representative of the larger group of children with migrant parents and would enable systematic comparison to children without parents abroad. The availability of high-quality data (and its appropriate analysis) plays an essential role in moving the discussion of migration and the family forward, particularly if it is as widely disseminated as the results from the more ad hoc studies conducted in the past.

\subsubsection{Better Targeting of Social Services for Children}

A final policy recommendation to origin-country governments would be to consult research to construct better-targeted social services. Children with migrant parents are often categorically assumed to be worse-off than their peers residing with both parents. In Moldova, for instance, children 'left behind' were specifically addressed in a national action plan for children without parental care, which was originally drafted to last from 2010-2011 as part of a larger strategy the addressed the return of labour migrants. Within this action plan, it was envisioned that all children with a migrant parent should have their situations evaluated so it was clear who was caring for them (Cheianu-Andrei et al., 2011). The migration status of a parent is only one of the many factors that could shape a household's or child's vulnerability to falling below a given standard of well-being, however. The findings from Chapter Six and Chapter Seven suggest that in both Moldova and Georgia, the quality of caregiving is perhaps more meaningful in shaping child well-being outcomes than is the migration status of a parent. In both countries, children who were called names such as "stupid" or "lazy" by a caregiver were more likely to express worse psychosocial outcomes than their peers who were not verbally demeaned. An obvious recommendation based on this finding is to offer social services that address specific caregiver behaviours; this could include trainings or information sessions to caregivers about effective ways of 
communicating with and eliciting change from children without resorting to verbal abuse. Similarly, the finding in Chapter Seven that children residing in the Autonomous Republic of Adjara had worse total difficulties scores than children residing in the other regions suggests that children in Adjara could be targeted for particular forms of social assistance or social services. Additional research would be needed to address why the outcomes of children living in Adjara differed so significantly from those of their peers living elsewhere, and appropriate techniques for addressing those underlying mechanisms could then be developed. If the source of their worse scores relates to exposure to political instability and potential conflict, for instance, counselling could be provided in schools to help children learn techniques for managing anxiety in the face of uncertainty.

\subsection{STUDY LIMITATIONS}

The data and analytical methods employed in this dissertation faced some limitations, which do carry implications for how the results should be understood and used. These limits relate primarily to observation numbers, use of the SDQ as a measure of child psychosocial health, and the use of cross-sectional data.

This dissertation relied primarily on household survey data, which was collected based on random stratified sampling followed, in Georgia, by random purposive sampling. Given this sampling strategy, some characteristics were less prevalent in the resulting data than others; in Georgia, for instance, very few children with both parents living abroad appeared in the data, which would be expected given the low occurrence of dual-couple migration in the general population. While helpful in quantifying the prevalence of specific trends or characteristics, such a sampling strategy often did result in small numbers of observations of key variables, which limited the types of analyses that could be performed. In both Chapter Six and Chapter Seven, for instance, it was not possible to specify models containing only children with migrant family members because of small numbers of children experiencing different forms of family-member migration. Similarly, in both Moldova and Georgia, a relatively small proportion of children had experienced the death or divorce of a parent, which made it impossible to compare psychosocial health outcomes across different forms of 
separation. Small numbers of observations also had implications for model fit. In some analyses, model fit was relatively low, in part because some relevant explanatory variables could not be included in the model due to limited variance in variable expression. For instance, information was collected on child risk behaviours (such as tobacco and alcohol use), but due to extremely limited variation in responses, the information could not be used. Given additional observations, some of these relatively rare outcomes (e.g., expression of risk behaviours, migration, divorce) would be more likely to be captured, but the sample size would need to be significantly larger to encompass these trends well and still result in representative data.

A second limitation of the study relates to the Strengths and Difficulties Questionnaire and the absence of local calibration for Moldova and Georgia. As noted in Chapters Six and Seven, normative SDQ data for children in Moldova and Georgia were missing. Normative data are imperative for understanding what score thresholds are relevant for distinguishing low-, medium-, and high-risk scores within a given cohort of children. The instrument was designed so that the lowest 80 percent of scores would indicate low risk, the next ten percent borderline or middle risk, and the highest ten percent, high risk. The scores that correspond to that population distribution may differ by country, however (Bourdon et al., 2005). The items included within each of the subscales correspond to key symptoms domains for diagnosis identified in the Diagnostic and Statistical Manual of Mental Disorders (DSM) of the American Psychiatric Association and the International Classification of Diseases (ICD) diagnostic tool of the World Health Organisation (Goodman \& Scott, 1999). These tools reflect the standards of the bodies that developed them and as such may not accommodate differences in culturallyacceptable or inadmissible behaviours. For instance, in the Moldovan data, a larger portion of children scored within the upper bounds of the distribution in the peer problems subscale than would be expected given normative data from other countries. Subsequent discussions with sociologists as well as with interview respondents revealed that caregivers often accept that children have contentious relationships with peers, and bullying and minor fights among children (particularly boys) are seen as normal behaviours. This implies that even behaviours classified as abnormal or high-risk using the SDQ score thresholds may not be perceived as problematic within local context, requiring the researcher to reconcile international and national norms in interpretation of SDQ data. This problem can (and has) been addressed by either not using score bandings at all or 
by only using those subscales in which the score bandings derived from UK normative data correspond to expected percentile distributions within the data, but lack of local calibration does imply that the SDQ could be better fitted to the local context.

Another issued faced with the SDQ related to its Georgian-language translation. As described in Chapter Three, in Moldova the SDQ was implemented in Romanian and Russian using translations that were approved by Youth in Mind and posted for public use on their website. In Georgia, no Georgian translation was available when the project started, and project staff in Georgia translated the tool from English to Georgian but did not do so with guidance from Youth in Mind. After implementation, a revised Georgian instrument was created in conjunction with Youth in Mind, and permission was granted by Youth in Mind to use data generated for the previously-unapproved Georgian SDQ translation on the condition that none of the analyses using the Georgian data indicated score ranges or score bandings, as this could signal normative score thresholds. This implied that I could not conduct the same form of analysis in Georgia as in Moldova, which disallows one-to-one comparisons of SDQ outcomes between the two countries. The analyses conducted in Moldova and Georgia also differed because of the type of SDQ subscales used in analysis. As discussed in Chapter Three and hinted at in the previous paragraph, not all subscales could be used in analysis because a greater share of scores fell into the upper score thresholds than would be expected given normative data from other countries. In Moldova this implied that the total difficulties score could not be calculated and used in analysis because it would reflect any potential problems contained in each of the individual subscales. The emotional symptoms and conduct problems subscale scores were used in Moldova because they had an expected distribution pattern whereas in Georgia the total difficulties score could be used (and was preferred as an aggregate measure of psychosocial health).

Two final study limitations relate to the analysis of cross-sectional data, the first of which concerns potential endogeneity. In migration research there are three common sources of endogeneity that can potentially bias regression estimations: self-selection, omitted variables, and reverse causality. Each of these could have been present in this research. As is discussed in Chapter Five, migrants may be unlike other members of the population because they "self-select" into migration based on characteristics that may (e.g., financial status) or may not (e.g., personal 
risk propensity) be observable. Furthermore, some characteristics-such as a child's psychosocial health-may both influence migration and be influenced by it. For example, the weak association found between child psychosocial health outcomes and kin migration in Chapters Six and Seven may reflect the migration selection process: individuals with children who are psychosocially unhealthy before a move even takes place may be less likely to choose to migrate because they anticipate that their migration will bear too high a "cost" for the child and other family members. An individual, particularly a parent, may also be unlikely to choose to migrate unless they are certain that their absence will not create a caregiving gap. These dynamics would be difficult to properly capture in a survey, particularly if they are rooted in the pre-migration situation.

Econometric techniques to address potential endogeneity do exist: propensity score matching and instrumental variable analysis are two potential methods, but neither were considered appropriate for this research. Propensity score matching (PSM) estimates the effects of a "treatment" (in this case, migration) on a given outcome of interest (for example, child psychosocial health) by matching individuals who are part of the "treatment" group to those in the "untreated" group on the basis of observable characteristics that predict the probability of receiving the "treatment" 35 . Within this method, the groups that are compared should differ only on the receipt of the treatment itself rather than on other characteristics that would correlate to the likelihood of the treatment being received. This method relies on the assumption that all relevant pre-treatment differences between treatment and control groups can be captured and that the data contains all relevant characteristics that predict the probability of the treatment being received. These assumptions could certainly not be met with the current data, and the PSM method was therefore considered inappropriate to correct for possible endogeneity in this research. A second method for addressing endogeneity, instrumental variable (IV) estimation, uses an "instrument" to produce consistent regression estimates despite the presence of some source of endogeneity. An appropriate instrument should be correlated to the endogenous independent variable (in this case, migration) but uncorrelated to the dependent variable (for example, child psychosocial health) except through the endogenous regressor. For the regression coefficients produced in an IV estimation to be

${ }^{35}$ Refer to McKenzie, Gibson, and Stillman (2010) for additional discussion of the use of PSM in migration studies. 
consistent, an instrument cannot be "weak"; it should be highly correlated with the endogenous regressor, otherwise the estimation will be biased in the same direction as the non-IV estimation, and confidence intervals will be wrong. Several instrumental variables were tested in the course of this research, including the presence of foreign troops in the community during the Soviet period and the availability of foreign broadcasts during the Soviet period. None of the tested instruments were found to be sufficiently strong to justify their use. Given the potential presence of endogeneity in this research, causation cannot be inferred, and indeed only association or correlation can be established.

A final study limitation is that cross-sectional data does not allow for analysis of changes to a subject over time. The CELB-MD/GE survey collected some information on past events or major life transitions, such as divorce, but the timing of events was generally not recorded. Information was also not collected on important changes a child may have experienced such as transitions in caregiving arrangements, which past research (Mazzucato et al., 2014) has found to be significantly correlated to child psychosocial health. Some detailed retrospective data was collected during interviews with the families of migrants in Moldova and Georgia, but the interview data was limited in that it reflected respondents' opinions and recollections at a particular moment in time, and full life history narratives were not elicited. The lack of longitudinal data presents a unique dilemma to the study of child well-being. Throughout this dissertation, I have referred to child "well-being", which implies a child's state of being at the moment of observation. "Well-being" is different from "well-becoming", that is, how wellness in childhood translates to well-being in adulthood (Ben-Arieh, 2000). The enduring qualities of well-being are uncertain. Are the psychosocial health outcomes measured at one moment in a child's life predictive of larger patterns of well-being? Will a child with "abnormal" psychosocial outcomes become a dysfunctional adult? Lacking observations of a child over time, it would be difficult to assert that child psychosocial "well-being" has any implications for child "well-becoming". Results should therefore not be overstated in terms of why they matter or what they imply for later-life functioning. 


\subsection{FUTURE RESEARCH DIRECTIONS}

In line with the observations made above, there are several clear ways that future research could advance knowledge on the psychosocial health of the children who stay in the country of origin following the migration of a parent or other kin. Four suggestions are proposed: 1) that particular effort be made to understand how transnational families function within and across national boundaries; 2) that migration indicators are mainstreamed into larger data collection initiatives, particularly those that address child well-being, 3) that panel data be collected on children who have experienced parental migration, and; 4) that mixed-method data collection initiatives be developed that address both the pre- and post-migration experiences of children and their families.

Despite the focus of this study and others on transnational families, the transnational element of family interactions is often subverted given the focus on the activities or experiences of particular individuals in one country, generally either in the country of origin or the country of residence. This "methodological nationalism" (Wimmer \& Glick Schiller, 2002; Mazzucato \& Schans, 2011) limits understanding of interactions among members of transnational families and the processes in which they engage. Several past projects suggest methodological innovations that would be beneficial for future research to emulate. The TCRAf-Eu (Transnational Child-Raising Arrangements between Africa and Europe) study provides particularly helpful guidance in this regard given its simultaneous, multisited research design. Within the qualitative part of this study, children, caregivers, and migrants belonging to the same family unit were studied in their different countries of residence, which enabled analysis of how different actors within the transnational family acted within and across geographical spaces (Mazzucato, 2008). Such a truly transnational research design can further understandings of how different processes of life in different geographical and political spaces influence the ability of families to function transnationally, which carries implications for child psychosocial health. By studying family life across the different sites in which it is conducted and by collecting evidence across countries with differing migration and child development contexts, the factors that foster or 
undermine the psychosocial health of children in transnational families may be easier to identify.

A second direction for future research relates to expanding possible sources of data on the children in transnational families. Most research on children in transnational families has relied on data collection instruments designed for the particular population of children with migrant family members; only very few studies (such as that of Carling \& Tønnessen, 2013) made use of data on a more general child population, as few data collection instruments include indicators of migration. Studies on child well-being often rely on sophisticated data collection instruments such as the multiple indicator cluster survey (MICS) of UNICEF, which includes information on a range of child outcomes but often does not indicate where a parent or caregiver is if not in the household or deceased. The inclusion of even simple indicators of migration would yield much more comparative data on children with migrant parents in differing country settings. The MICS instrument, for instance, could be adapted to include migration indicators in particular countries with high rates of migration, which would be an excellent way to mainstream migration indicators into more conventional data collection initiatives. Other surveys, such as the Demographic and Health Survey (DHS), Household Budget Survey (HBS), LFS (Labour Force Survey), and Living Standards Measurement Survey (LSMS) would be ideal to add several questions or short modules about migration into. While not on child well-being specifically, such surveys often collect information on basic well-being indicators of all household members, include large and diverse population groups, and in some countries include panel data for a select sub-sample of the population. With the addition of migration indicators, such data sets could enable unique forms of analysis into the well-being of children in migrant households, particularly given longitudinal data.

A related suggestion for future research would be to adopt longitudinal data collection initiatives that follow individuals over the life course. There is a long-established tradition in child development studies of collecting panel data to better understand how experiences in early childhood influence a range of outcomes in adulthood (see, for instance, Compas, Hinden, \& Gerhardt, 1995). Longitudinal studies of childhood risk and the development of resilient behaviours have included children who have experienced the loss of a parent through death or incarceration; including children who have been separated from one or both 
parents through migration would be a logical next step, and one that would address several of the shortcomings noted earlier. The experiences of children who remain in the origin country following the migration of kin have so far been underresearched in longitudinal studies, in part because indicators of parental (or other kin) migration are absent from most data collection initiatives.

A final direction for future research relates to employing mixed methodological approaches to study the experiences of children and their families throughout the migration cycle-and how those experiences correspond to child psychosocial health outcomes. In line with the recommendation to pursue more longitudinal data collection, future research should address how children and families negotiate different stages of the migration process. Few studies have investigated the involvement of children themselves in the migration decision (Dreby, 2007 is one exception), for instance, despite how important communication and joint problem solving can be in the quality of family relations (Wynne, 1984). There is also a lack of research into how children respond to the absence of a migrant and changes to family composition and roles over time. Some studies (such as that of Suárez-Orozco, Ban, \& Kim, 2011) suggest that the separation of children from one or both parents may have short-term but not long-term consequences. Other studies suggest that reunification with a parent, the consequent changing of caregivers, and re-adaptation of responsibilities within the household can be challenging for both children and their parents/caregivers (Schmalzbauer, 2004; Suárez-Orozco, Todorova, \& Louie, 2002; Dreby, 2007). These studies all highlight how family dynamics and children's responses to them may vary at different stages of migration, from decision making to absence and eventual return. Few studies address how the same individuals navigate each of these stages, however, and fewer still have assessed how different factors related to each stage of the migration process (such as child knowledge of and participation in the migration decision) play into psychosocial health outcomes. These limitations suggest an opportunity for future studies to develop a better understanding of the evolution of the well-being, and well-becoming, of children in transnational families. 


\section{REFERENCES}

Achenbach, T. M., Edelbrock, C., \& Howell, C. T. (1987). “Empirically-based assessment of the behavioral/emotional problems of 2- and 3-year-old children". Journal of Abnormal Child Psychology 15: 629-650. DOI: 10.1007/BF00917246.

Ainsworth, M. D. S. (1969). “Object relations, dependency, and attachment: A theoretical review of the infant-mother relationship." Child Development 40: 9691025.

Åkesson, L., Carling, J., \& Drotblohm, H. (2012). "Mobility, moralities, and motherhood: Navigating the contingencies of Cape Verdean lives." Journal of Ethnic and Migration Studies 38(2): 237-260. DOI: 10.1080/1369183X.2012.646420.

Armsden, G. C. \& Greenberg, M. T. (1987). “The inventory of parent and peer attachment: Individual differences and their relationship to psychological wellbeing in adolescence". Journal of Youth and Adolescence 16: 427-454. DOI: 00472891/87/1000-0427505.00/0.

Arrington, E.G. \& Wilson, M.N. (2000). "A re-examination of risk and resilience during adolescence: Incorporating culture and diversity." Journal of Child and Family Studies 9(2): 221-230.

Asatoorian, E., Baringer L.S.P., Campbell, K.L., Desai, S., Jiang, J., \& Kanthoul, L. (2011). "Gender mainstreaming in education in Georgia: Analysis and recommendations." Report completed in partnership with the Women's Political Resource Centre for the workshop in Development Practise. Columbia University, School of International and Public Affairs: New York.

Asis, M. (2006). "Living with migration." Asian Population Studies 2(1): 45-67. DOI: 10.1080/17441730600700556.

Badurashvili, I. \& Nadareishvili, M. (2012). "Social impact of emigration and ruralurban migration in Central and Eastern Europe: Final country report Georgia." Report prepared within framework of European Commission and GVG project VT/2010/001.

Badurashvili, I., Cheishvili, R., Kapanadze, E., Tsiklauri, S., \& Siribiladze, M. 
(2008). "Gender relations in modern Georgia society". Report on Generations and Gender Survey. Georgian Centre of Population Research: Tbilisi.

Battistella, G. \& Conaco, C.G. (1998). "The impact of labour migration on the children left behind: A study of elementary school children in the Philippines." Sojourn: Journal of Social Issues in Southeast Asia 13(2): 220-241.

Bettio F, Simonazzi, A \& Villa, P. (2006). "Change in care regimes and female migration: the 'care drain' in the Mediterranean." Journal of European Social Policy 16: 271-285. DOI: 10.1177/0958928706065598.

Biao, X. (2007). "How far are the left behind left behind? A preliminary study in rural China." Population, Space and Place 13: 179-191. DOI: 10.1002/psp.437.

Binder, M. \& Coad, A. (2010). “Going beyond average Joe's happiness: Using quantile regression to analyse the full subjective wellbeing distribution." Papers on Economics and Evolution No. 1010.

Blakkisrud, H. \& Kolstø, P. (2012). "Dynamics of de facto statehood: the South Caucasian de facto states between secession and sovereignty." Southeast European and Black Sea Studies 12(2): 281-298.

Boss, P. G. (2004). "Ambiguous loss research, theory, and practise: Reflections after 9/11". Journal of Marriage and Family 66: 551-566. DOI: 10.1111/j.00222445.2004.00037.x

Boss, P.G. \& Greenberg, J. (1984). “Family boundary ambiguity: A new variable in family stress theory." Family Process 23(4): 535-546.

Boss, P.G. (1980). "Normative family stress: Family boundary changes across the life span." Family Relations 29(4): 445-450.

Bourdon, K.H., Goodman, R., Rae, D.S., Simpson, G. \& Koretz, D.S. (2005). “The Strengths and Difficulties Questionnaire: US normative data and psychometric properties." Journal of the American Academy of Child and Adolescent Psychiatry 44(6): 557-564. DOI: 10.1097/01.chi.0000159157.57075.c8

Bowlby, J. (1977). "The making and breaking of affectional bonds: Aetiology and psychopathology in the light of attachment theory." British Journal of Psychiatry 130: 201-210. DOI: 10.1192/bjp.130.3.201. 
Bowlby, J. (1982). "Attachment and loss: Retrospect and prospect". American Journal of Orthopsychiatry: 52(4): 664-678. DOI: 10.1111/j.19390025.1982.tb01456.x.

Boyd M. (1989). "Family and personal networks in international migration: Recent developments and new agendas." International Migration Review 23: 638-670.

Bryceson, D.F. \& Vuorela, U. (2002). The Transnational Family: New European Frontiers and Global Networks. Berg: Oxford.

Cantarji, V., \& Mincu, G. (2013). "Costs and Benefits of Labour Mobility Between the EU and the Eastern Partnership Countries. Country Report: Moldova." Report for project EuropeAid/130215/C/SER/Multi.

Carling, J. \& Tønnessen, M. (2013). “Fathers' whereabouts and children's welfare in Malawi". Development Southern Africa, 30: 724-742. DOI: 10.1080/0376835x.2013.859068.

Carroll, J. S., Olson, C. D., \& Buckmiller, N. (2007). "Family boundary ambiguity: A 30-year review of theory, research, and measurement". Family Relations 56: 210230.

Cassidy, J. (2008). "The nature of the child's ties." In J. Cassidy \& P. R. Shaver (Eds.), Handbook of Attachment: Theory, Research, and Clinical Applications (Second Edition) (pp.3-20). New York: The Guilford Press.

Caucasus Research Resource Centres (CRRC) Georgia (2007). "Migration and return in Georgia: Trends, assessments, and potential". Project reported submitted to the Danish Refugee Council within the project "Toward Durable Reintegration Mechanisms in Georgia."

Cerrutti, M. \& Massey, D.S. (2001). "On the auspices of female migration from Mexico to the United States." Demography 38: 187-200.

Cheianu-Andrei, D., Gramma, R., Milcenco, S., Pritcan, V., Rusnac, V., \& Vaculovschi, D. (2011). "Specific Needs of Children and Elderly Left Behind as a Consequence of Migration." Report prepared within the framework of the International Organisation for Migration project "Supporting the implementation of the migration and development component of the EUMoldova Mobility Partnership" and the State University of Moldova project 
"Support to the National Action Plan on the protection of children left without parental care as a consequence of migration." IOM, Czech Development Agency, UN Population Fund, and CEP USM: Chisinau. ISBN 978-9975-71-1654.

Chumburidze, M. (2013). "Response Paper to the Research Report 'The Effects of Labour Migration on the Demo-Economic Development of Georgia in the PostSoviet Period'". CARIM-East Analytic and Synthetic Note 2013/02. European University Institute, Robert Shuman Centre for Advanced Studies: Florence, Italy.

Compas, B.E., Hinden, B.R., \& Gerhardt, C.A. (1995). "Adolescent development: Pathways and processes of risk and resilience." Annual Review of Psychology 46: 265-293.

Coppieters, B. (2004). "The Georgian-Abkhaz conflict." In Europeanization and Conflict Resolution: Case Studies from the European Periphery, pp 191-232. Academia Press: Ghent, Belgium.

Curran, S.R. \& Saguy, A.C. (2001). "Migration and cultural change: A role for gender and social networks?". Journal of International Women's Studies 2: 54-77.

Curran, S.R., Garip, F., Chung, C.Y., \& Tangchonlatip, K. (2005). “Gendered migrant social capital: Evidence from Thailand." Social Forces 84: 225-255. DOI: 10.1353/sof.2005.0094.

Curran, S.R. \& Rivero-Fuentes, E. (2003). “Engendering migrant networks: the case of Mexican migration". Demography 40: 289-307.

Dawson, D.A. (1991). Family structure and children's health and well-being: Data from the 1988 National Health Interview Survey on Child Health." Journal of Marriage and Family: 53, 573-584.

Diamanti-Karanou , P.(2013). "Migration of Ethnic Greeks from the Former Soviet Union to Greece, 1990-2000: Policy Decisions and Implications." Southeast European and Black Sea Studies 3(1): 25-45. DOI: 10.1080/713999342.

Donato, K.M., Gabaccia, D., Holdaway, J., Manalansan, M., \& Pessar, P.R. (2006). "A glass half full? Gender in migration studies." International Migration Review 40: 3-26. DOI: 10.1111/j.1747-7379.2006.00001.x. 
Dreby, J. (2006). "Honor and virtue: Mexican parenting in the transnational context." Gender \& Society 20 (1), 32-59.

Dreby, J. (2007). "Children and power in Mexican transnational families." Journal of Marriage and Family 69: 1050-1064.

Eisenberg, N., Cumberland, A., Spinrad, T.L., Fabes, R.A., Shepard, S.A., Reiser, M., Murphy, B. C., Losoya, S. H. \& Guthrie, I. K. (2001). “The relations of regulation and emotionality to children's externalizing and internalizing problem behaviour." Child Development, 72(4), 1112-1134. DOI: 10.1111/14678624.00337.

Falicov, C.J. (2002). "Ambiguous loss: Risk and resilience in Latino families." In M. Suárez-Orozco \& M. Paez (eds.), Latinos: Remaking America, pp. 274-288. University of California Press: Berkeley, CA.

Falicov, C.J. (2007). “Working with Transnational Immigrants: Expanding Meanings of Family, Community, and Culture." Family Process 46 (2): 157-171.

Fawn, R. (2012). “Georgia: Revolution and War.” European Security 21(1): 1-4.

Fidrmuc, J. (2003). “Economic Reform, Democracy, and Growth During PostCommunist Transition." European Journal of Political Economy 19: 583-604.

Flamminio, C. (2011). "Left Behind in Moldova." Photo-narrative. Accessed online from http://www.demotix.com/news/1137423/left-behind-moldova\#media1137229 .

Fog-Olwig, K. (1999). "Narratives of the children left behind: Home and identity in globalised Caribbean families." Journal of Ethnic and Migration Studies 25(2): 267284. DOI:10.1080/1369183X.1999.9976685.

Gamburd, M.R. (2000). The Kitchen Spoon's Handle: Transnationalism and Sri Lanka's Migrant Housemaids. Cornell University Press: Ithaca, New York.

Gassmann, F., Berulava, G., \& Tokmazishvili, M. (2013). Economic and Social Vulnerability in Georgia. United Nations Development Programme Georgia: Tbilisi.

GeoStat (2014). National Statistics Office of Georgia, PC-AXIS Database. Available online

at 
http://www.geostat.ge/index.php?action=page\&p_id=1145\&lang=eng>.

Accessed 21 August, 2014.

Glick Schiller, N., Basch, L., \& Szanton-Blanc, C. (1995). "From immigrant to transmigrant: Theorizing transnational migration." Anthropological Quarterly 68(1): 48-63.

Goodman, A., Lamping, D.L., \& Ploubidis, G.B. (2010). “When to use broader internalising and externalising subscales instead of the hypothesised five subscales on the Strength and Difficulties Questionnaire (SDQ): Data from British parents, teachers and children". Journal of Abnormal Child Psychology 38: 1179-1191. DOI 10.1007/s10802-010-9434-x.

Goodman, R. (1997). “The Strengths and Difficulties Questionnaire: A research note". Journal of Child Psychology and Psychiatry, 38(5), 581-586.

Goodman, R., \& Scott, S. (1999). Comparing the strengths and difficulties questionnaire and the child behavior checklist: Is small beautiful?. Journal of Abnormal Child Psychology, 27(1), 17-24. DOI: 10.1023/A:1022658222914.

Görlich, D. \& Trebesch, C. (2008). "Seasonal Migration and Networks-Evidence of Moldova's Labour Exodus." Review of World Economics 144(1): 107-133. DOI: 10.1007/s10290-008-0139-y.

Government of Georgia (2014). "Statement of the Government of Georgia \#262, 31 March 2014".

Graham, E. \& Jordan, L. P. (2011). "Migrant parents and the psychological wellbeing of left-behind children in Southeast Asia". Journal of Marriage and Family 73: 763-787. DOI: 10.1111/j.1741-3737.2011.00844.x.

Grant, G., Falkingham, J. \& Evandrou, M. (2009). “The Impact of Adult Children's Migration on Wellbeing in Later Life: Voices from Moldova." Centre for Research on Aging Discussion Paper no. 0902. University of Southampton.

Grieco, E.M. \& Boyd, M. (2003). “Women and migration: Incorporating gender into international migration theory." Florida State University, College of Social Sciences, Study for Population Studies Working Paper No. WPS 98-139, ISSN 07409095.

Gugushvili, A. (2013). "The Development and the Side Effects of Remittances in the 
CIS Countries and Georgia: the Case of Georgia." CARIM-East Research Report 2013/29. European University Institute.

Haagsman, K. \& Mazzucato, V. (2014). “The quality of parent-child relationships in transnational families: Angolan and Nigerian migrant parents in the Netherlands." Journal of Ethnic and Migration Studies 40(11): 1677-1696. DOI: 10.1080/1369183x.2013.871491.

Harris, J.R. \& Todaro, M.P. (1970). “Migration, unemployment, and development: a two-sector analysis." The American Economic Journal 60: 126-142.

HelpAge International (HAI) and United Nations Children's Fund (UNICEF) (2008). "Grandparents and Grandchildren: Impact of Migration in Moldova." HAI/UNICEF project report of findings and recommendations. HAI Moldova: Chisinau.

Hensel, S. \& Gudim, A. (2004). "Moldova's economic transition: Slow and contradictory", in A. Lewis (Ed.), The EU and Moldova: On a Fault-Line of Europe. Federal Trust: London.

Heymann, J., Flores-Macias, F., Hayes, J.A., Kennedy, M., Lahaie, C., \& Earle, A. (2009). "The impact of migration on the well-being of transnational families: New data from sending communities in Mexico." Community, Work \& Family 12: 91-103. DOI: 10.1080/13668800802155704.

Hill, L. (2004). “Connection between U.S. female migration and family formation and dissolution." Migraciones Internactionales 2: 60-82.

Hoang, L.A. \& Yeoh, B.S.A. (2011). "Breadwinning wives and 'left behind' husbands: Men and masculinities in the Vietnamese transnational family." Gender and Society 25(6): 717- 739. DOI:10.1177/0891243211430636.

Hoang, L.A. \& Yeoh, B.S.A. (2012). "Sustaining families across transnational spaces: Vietnamese migrants parents and their left-behind children." Asian Studies Review, 36(3): 307-325. DOI: 10.1080/10357823.2012.711810

Hoang, L.A. \& Yeoh, B.S.A. (2015). “Children's agency and its contradictions in the context of transnational labour migration from Vietnam." Global Networks 15(2): 180-197.

Hoetker, G. (2007). The use of logit and probit models in strategic management 
research: Critical issues. Strategic Management Journal, 28, 331-343. DOI: 10.1002/smj.582

Hofmann, E.T. \& Buckley, C.J. (2013). “Global Changes and Gendered Responses: the Feminization of Migration from Georgia." International Migration Review 47: 508-538. DOI: 10.1111/imre.12035.

Hofmann, E.T., \& Buckley, C.J. (2011). “Cultural responses to changing gender patterns of migration in Georgia". International Migration 50(5): 77-94. DOI: 10.1111/j.1468-2435.2010.00681.x.

Hondagneu-Sotelo, P. (1992). "Overcoming patriarchal constraints: the reconstruction of gender relations among Mexican immigrant women and men." Gender and Society 6: 393-415.

Hondagneu-Sotelo, P. \& Avila, E. (1997). "'I'm here but I'm there': The meanings of Latina transnational motherhood." Gender and Society 11(5): 548-571.

Human Rights Watch (HRW) (1996). The Ingush-Ossetian Conflict in the Prigorodnyi Region. Human Rights Watch Helsinki. Accessed 11 July, 2013 from < http://www.hrw.org/reports/1996/Russia.htm>.

International Agency for Source Country Information (IASCI) \& Centre of Sociological, Politicological, and Psychological Analysis and Investigation (CIVIS) (2010). "Strengthening the link between migration and development in Moldova." Project report prepared for the World Bank, Migration and Remittance Peer-Assisted Learning Network (MIRPAL).

International Conference on Population and Development (ICPD) Beyond 2014 (ICPD) (2012). Republic of Moldova: Country Implementation Profile.

International Monetary Fund (2003). "Republic of Moldova: Poverty Reduction Strategy Annual Evaluation Report 2005." IMF Country Report No. 06/185. IMF: Washington, D.C.

International Monetary Fund (2006). "Georgia: Poverty Reduction Strategy Paper." IMF Country Report No. 03/265. IMF: Washington, D.C.

International Organisation for Migration (IOM) (2009). "Testing New Channels and Products to Maximise the Development Impact of Remittances for the Rural Poor in Georgia: Tianeti Household Census 2008 \& Tianeti Emigrants to 
Greece 2008 Fieldwork Report". IOM: Georgia.

International Organisation for Migration (IOM) (2012). Extended Migration Profile of the Republic of Moldova. IOM Moldova: Chisinau.

Javakhadze, K. (2006). "Gender Balance and Women in the Board of Trustees Programme in Georgia," in Saurer, E., M. Lanzinger, \& E. Frysak (eds.), Women's Movements: Networks and Debates in Post-Communist Countries in the 19th and 20th Centuries: pp 65-78. Bohlau Verlag GmbH \& Cie: Koln.

Jensen, P. S., Rubio-Stipec, M., Canino, G., Bird, H. R., Dulcan, M. K., SchwabStone, M. E., \& Lahey, B. B. (1999). Parent and child contributions to diagnosis of mental disorder: Are both informants always necessary?. Journal of the American Academy of Child Adolescent Psychiatry, 38(12), 1569-1579.

Jia, Z. \& Tian, W. (2010). "Loneliness of left-behind children: A cross-sectional survey in a sample of rural China." Child: Care, Health and Development 36(6): 812-817. DOI: 10.1111/j.1365-2214.2010.01110.x.

Johnson, E. \& Easterling, B. (2012). "Understanding unique effects of parental incarceration on children: Challenges, progress, and recommendations." Journal of Marriage and Family 74: 342-356. DOI:10.1111/j.1741-3737.2012.00957.x

Jones, A., Sharpe, J., \& Sogren, M. (2004). Children's experiences of separation from parents as a consequence of migration. Caribbean Journal of Social Work, 3(1), 89109. DOI: 10.1037/1099-9809.10.2.107.

Jordan, L.P. \& Graham, E. (2012). "Resilience and wellbeing among children of migrant parents in South-East Asia." Child Development 83(5): 1672-1688.

Kabachnik, P. (2012). "Shaping Abkhazia: Cartographic Anxieties and the Making and Remaking of the Abkhazian Geobody." Journal of Balkan and Near Eastern Studies 14(4): 397-415.

Kabachnik, P., J. Regulska, and B. Mitchneck (2012). "Displacing Blame: Georgian Internally Displaced Person Perspectives of the Georgia-Abkhazia Conflict." Ethnopolitics, formerly Global Review of Ethnopolitics 11(2): 123-140.

Kanaiaupuni, S.M. (2000). "Reframing the migration question: An analysis of men, women, and gender in Mexico." Social Forces 78: 1311-1347. DOI: 
10.1093/sf/78.4/1311.

Koenker, R. \& Hallock, K.F. (2001). "Quantile regression." Journal of Economic Perspectives 15(4), 143-156.

Kolstø, P. \& Malgin, A. (1998). “The Transnistrian Republic: a case of politicized regionalism." Nationalities Papers: The Journal of Nationalism and Ethnicity 26: 103127.

Kuzio, T. (2001). “Transition in Post-Communist States: Triple or Quadruple?" Politics 21(3): 168-177.

Labadze, L. and M. Tukhashvili (2013). "Costs and Benefits of Labour Mobility Between the EU and the Eastern Partnership Countries: Georgia Country Study." Report for project EuropeAid/130215/C/SER/Multi.

Lahaie, C., Hayes, J.A., Markham Piper, T., \& Heymann, J. (2009). “Work and family divided across borders: The impact of parental migration on Mexican children in transnational families." Community, Work, and Family 12(3): 299-312.

Laslett, B., \& Brenner, J. (1989). "Gender and social reproduction: Historical perspectives." Annual Review of Sociology 15: 381-404/.

Lauby, J. \& Stark, O. (1988). "Individual migration as a family strategy: Young women in the Philippines." Population Studies: A Journal of Demography 42(3): 473-486. DOI:10.1080/0032472031000143596.

Lavers, C.A. \& Sonuga-Barke, E.J.S. (1997). Annotation: On the grandmother's role in the adjustment and maladjustment of grandchildren. Journal of Child Psychology and Psychiatry, 38, 747-753.

Liu, Z. \& Ge, X. (2009). “Left too early: the effects of age at separation from parents on Chinese rural children's symptoms of anxiety and depression." American Journal of Public Health 99: 2049-2054.

Lorber, J. (1994). Paradoxes of Gender. Yale University Press: New Haven, Connecticut.

Lu, Y. (2012). Household migration, social support, and psychosocial health: The perspective from migrant-sending areas. Social Science and Medicine, 74, 135-142. DOI: 10.1016/j.socscimed.2011.10.020 
Lundkvist-Houndoumadi, M. (2010). "Treading on the fine line between selfsacrifice and immorality: Narratives of emigrated Georgian women." Transcience 1(2): 50-70.

Lupusor, A., Cenușă, D., \& Romaniuc R. (2013). “Republic of Moldova: State of the Country Report." Report prepared by Expert-Grup with the support of the Friedrich Ebert Stiftung. Chisinau: Moldova.

McKenzie, D., Gibson, J., \& Stillman, S. (2010). "How important is selection? Experimental vs. non-experimental measures of the income gains from migration." Journal of the European Economic Association 8(4): 913-945.

Mahler, S.J. \& Pessar, P.R. (2006). “Gender matters: Ethnographers bring gender from the periphery toward the core of migration studies." International Migration Review 40: 27-63. DOI: 10.1111/j.1747-7379.2006.00002.x .

Makaryan, S. (2012). "Estimation of International Migration in Post-Soviet Republics." International Migration (early view published online before inclusion in an issue). DOI: 10.1111/j.1468-2435.2012.00740.x.

Marchetti, S. \& Venturini, A. (2013). "Mothers and Grandmothers on the Move: Labour Mobility and the Household Strategies of Moldovan and Ukrainian Migrant Women in Italy." International Migration. Early view published online before inclusion in an issue. DOI:10.1111/imig.12131

Marchetti, S. (2013). "Dreaming Circularity? Eastern European Women and Jobs Sharing in Paid Home Care." Journal of Immigrant and Refugee Studies, 11(4): 347363. DOI: 10.1080/15562948.2013.827770.

Marchetti, S., Piazzalunga, D., \& Venturini, A. (2013). Costs and Benefits of Labour Mobility Between the EU and the Eastern Partnership Partner Countries: Italy Country Study. Report prepared within the framework of the project "Costs and Benefits of Labour Mobility Between the EU and the Eastern Partnership Partner Countries" (Grant \# EuropeAid/130215/C/SER/Multi). Turin: Italy.

Massey, D.S. \& Espinosa, K.E. (1997). “What's driving Mexico-U.S. migration? A theoretical, empirical, and policy analysis." American Journal of Sociology 102: 939-999.

Massey, D.S., Arango, J., Hugo, G., Kouaouci, A., Pellegrino, A., \& Taylor J.E. 
(1993). “Theories of international migration: A review and appraisal." Population and Development Review 19: 431-466.

Mazzucato, V. (2008). "Effects of transnational child raising arrangements on lifechances of children, migrant parents and caregivers between Africa and the Netherlands." Research note on the Transnational Child Raising Arrangements programme coordinated by Maastricht University in association with the University of Ghana. Available online at $<\mathrm{http}$ ://fasosresearch.nl/tcra/files/2011/12/TCRA-theoretical-and-conceptualbackground_final.pdf $>$.

Mazzucato, V. (2014a). "Child well-being and transnational families." In A. C. Michalos (Ed.), Encyclopedia of Quality of Life and Well-being Research. Dordrecht: Springer.

Mazzucato, V. (2014b). "Transnational families and the well-being of children and caregivers who stay in origin countries." Social Science $\mathcal{E}$ Medicine. Article in press. DOI: 10.1016/j.socscimed.2014.11.030.

Mazzucato, V. and Schans, V. (2011) "Transnational families and the well-being of children: Conceptual and methodological challenges." Journal of Marriage and Family, 73(4): 704-712.

Mazzucato, V., Cebotari, V., Veale, A., White, A., Grassi, M., Vivet, J. (2014). "International parental migration and the psychological well-being of children in Ghana, Nigeria and Angola." Social Science \& Medicine (forthcoming). DOI: 10.1016/j.socscimed.2014.10.058.

Millennium Challenge Account (MCA) Moldova (2013). "Social and Gender Integration Plan: April 2013." Report compiled for the Government of Moldova.

Mincer, J. (1978). "Family migration decisions." Journal of Political Economy 86: 749773.

Moran-Taylor, M.J. (2008). "When mothers and fathers migrate north: Caretakers, children, and child rearing in Guatemala." Latin American Perspectives 35: 79-95.

Mullick, M.S.I. \& Goodman, R. (2001). "Questionnaire screening for mental health problems in Bangladeshi children: a preliminary study". Social Psychiatry and Psychiatric Epidemiology, 36(2), 94-99. DOI: 10.1007/s001270050295. 
National Bureau of Statistics of the Republic of Moldova (2014). Statistical Databank. Available on the Statistica Moldova website at < http://statbank.statistica.md/pxweb/Database/EN/databasetree.asp $>$. Accessed 21 August, 2014.

National Bureau of Statistics of the Republic of Moldova (NBS) (2011). "Violence Against Women in the Family in the Republic of Moldova (1st Edition)." Publication developed with the support of the United Nations Development Programme, the United Nations Entity for Gender Equality and Empowerment of Women, and the United Nations Population Fund within the join UN project "Strengthening the National Statistical System." Available online at $<$ http://www.statistica.md/public/files/publicatii_electronice/Violenta/Raport_vi olen_fem_eng.pdf>

Nobles, J. (2011). "Parenting from abroad: Migration, non-resident father involvement, and children's education in Mexico." Journal of Marriage and Family, 73, 729-746.

Nogaideli, E. (2012). "Single Mothers-Un-Respectable 'Others' of Georgian Nationalism: Production of Subjectivities Through 'Nesting Respectability'”. Central European University, Department of Gender Studies: Hungary.

Offe, C. (1991). "Capitalism by Democratic Design? Democratic Theory Facing the Triple Transition in East Central Europe." Social Research 58(4): 865-892.

Organisation for Economic Cooperation and Development (OECD) (2008). Black Sea and Central Asia: Promoting Work and Well-Being: An OECD Development Centre Economic Outlook. OECD Publishing: Paris.

Panţîru, M.C., Black, R., and Sabates-Wheeler, R. (2007). “Migration and poverty reduction in Moldova." University of Sussex, Development Research Centre on Migration, Globalisation, and Poverty Working Paper C10.

Papava, V. (2013). "Reforming of the Post-Soviet Georgia's Economy in 1991-2011." GFSIS Center for Applied Economic Studies Research Paper. Georgian Foundation for Strategic International Studies: Tbilisi. Accessed online 26 July, 2013

from: <http://gfsis.org/media/download/library/articles/papava/Papava_Reforming_o f_the_Post-Soviet_Georgia_Economy_in_1991-2011.pdf> 
Parreñas, R. S. (2005). Children of global migration: Transnational families and gendered woes. Stanford, California: Stanford University Press.

Pedraza, S. (1991). "Women and migration: the social consequences of gender." Annual Review of Sociology 17: 303-325.

Peleah, M. (2007). "The impact of migration on gender roles in Moldova." Development and Transition 8: 14-17.

Penger, P. (2009). "Come back or stay? Spend here or there? Return and remittances: the case of Moldova". International Migration 48(5): 142-173. DOI: 10.1111/j.1468-2435.2009.00562.x.

Pessar, P.R. \& Mahler, S.J. (2001). "Gender and transnational migration". Paper presented at conference Transnational Migration: Comparative Perspectives. Princeton University. 30 June-1 July, 2001.

Pessar, P.R. (1999). "Engendering migration studies: the case of new migrants in the United States." American Behavioral Scientist 42: 577-600. DOI: $10.1177 / 00027649921954372$.

Pfeiffer, L., Richter, S., Fletcher, P., \& Taylor, J.E. (2008). “Gender in economic research on international migration and its impacts: a critical review." In Morrison AR, Schiff M, Sjöblom M (eds.), The International Migration of Women: pp 11-50, The World Bank: Washington, DC.

Piper N. 2007. "International migration and gendered axes of stratificationintroduction." In Piper N (ed.), New Perspectives on Gender and Migration: Livelihoods, Rights, and Entitlements: pp 1-34, Routledge: Oxon.

Popescu, N. (2005). "The EU in Moldova: Settling Conflicts in the Neighbourhood." The European Union Institute for Security Studies Occasional Paper No. 60. Paris.

Popescu, N. (2010). "The EU and Civil Society in the Georgian-Abkhaz Conflict." MICROCON Policy Working Paper No. 15. MICROCON: A Micro-Level Analysis of Violent Conflict, Institute of Development Studies, University of Sussex: Brighton.

Pottinger, A.M. (2005). "Children's experience of loss by parental migration in inner-city Jamaica ." American Journal of Orthopsychiatry, 75(4), 485-496. DOI: 
Priel, B. \& Besser, A. (2010). "Bridging the gap between attachment and object relations theories: A study of the transition to motherhood." British Journal of Medical Psychology 74(1): 85-100. DOI: 10.1348/000711201160821.

Prohnitchi, V. (2005)." Poverty of the children of Moldovan migrants." ExpertGrup project report.

Richter, J., Sagatun, A., Heyerdahl, S., Oppedal, B., \& Roysamb, E. (2011). “The strengths and difficulties questionnaire (SDQ) - self report: An analysis of its structure in a multiethnic urban adolescent sample." The Journal of Child Psychology and Psychiatry, 52 (9), 1002-1011. DOI: 10.1111/j.14697610.2011.02372.x.

Richters, J. E. (1992). "Depressed mothers as informants about their children: A critical review of the evidence for distortion." Psychological Bulletin, 112(3), 485499. DOI: 10.1037/0033-2909.112.3.485.

Rieker, P. (2014). “Importance of the European Neighbourhood Policy: A Role for Norway?" Policy Brief 1/2014. Norwegian Institute of International Affairs: Oslo.

Robila, M. (2012). "The impact of migration in children's psychological and academic functioning in the republic of Moldova." International Migration (early article view before inclusion in an issue). DOI: 10.1111/imig.12029.

Roper, D. (2001). "Regionalism in Moldova: the Case of Transnistria and Gagauzia." Regional and Federal Studies 11(3): 101-122.

Rutstein, S.O. \& Johnson, K. (2004). The DHS Wealth Index. DHS Comparative Reports No. 6. ORC Macro: Maryland.

Rutter, M. \& Sandberg, S. (1992). "Psychosocial stressors: Concepts, causes, and effects." European Child and Adolescent Psychiatry 1(1): 3-13.

Salah, M.A. (2008). "The Impacts of Migration on Children in Moldova." United Nations Children's Fund Working Paper. United Nations Children's Fund, Division of Policy and Practise: New York.

Scalabrini Migration Centre (SMC) (2004). "Hearts apart: Migration in the eyes of 
Filipino children." Research report for grant number ECMI-CBCP/AOSMANILA/SMC/OWWA. SMC: Quezon City.

Schmalzbuer, L. (2004). "Searching for wages and mothering from afar: The case of Honduran transnational families." Journal of Marriage and Family 66: 1317-1331.

Sjaastad, L.A. (1962). "The costs and returns of human migration." Journal of Political Economy 70: 80-93.

Smith, A., Lalonde, R.N., \& Johnson, S. (2004). "Serial migration and its implications for the parent child relationship: A retrospective analysis of the experiences of the children of Caribbean immigrants." Cultural Diversity and Ethnic Minority Psychology 10(2): 107-122.

Solari, C. (2010). "Resource drain vs. constitutive circularity: Comparing the gendered effects of post-Soviet migration patterns in Ukraine." Anthropology of East Europe Review 28(1): 215-238.

Stark, O. \& Bloom, D.E. (1985). "The new economics of labor migration". The American Economic Review 75: 173-178.

Stecklov, G., Carletto, C., Azzarri, C., \& Davis, B. (2010). “Gender and migration from Albania." Demography 47: 935-961.

Suárez-Orozco, C., Ban, H. J., \& Kim, H. Y. (2011). “'I felt like my heart was staying behind': Psychological implications of family separations and reunifications for immigrant youth." Journal of Adolescent Research 26: 222-257. DOI: 10.1177/0743558410376830 .

Suárez-Orozco, C., Todorova, I. L. G., \& Louie, J. (2002). “Making up for lost time: The experience of separation and reunification among immigrant families". Family Process 41(4): 625-643. DOI: 10.1111/j.1545-5300.2002.00625.

Sumbadze, N. \& Tarkhan-Mouravi, G. (2003). "Transition to adulthood in Georgia: Dynamics of generational and gender roles in post-totalitarian society." Institute for Policy Studies: Tbilisi.

Svintradze, I. \& Ubiria, G. (2007). "How poverty separates families: Impact of international labour migration on families and children in Georgia." Research report. Eurasia Foundation and Caucasus Research Resource Centre. Accessed 
online October 2013 from < http://www.crrc.ge/research/archive/>

Taylor, J.E. (1999). "The new economics of labour migration and the role of remittances in the migration process." International Migration 37: 63-88.

Tchaidze, R., and K. Torosyan (2010). “'Development on the Move': Measuring and optimising migration's economic and social impacts in Georgia." Project report for the Global Development Network.

Tishkov, V., Zayinchkovskaya, Z., \& Vitkovskaya, G. (2005). "Migration in the countries of the former Soviet Union." Report prepared for the Global Commission on International Migration, Policy Analysis and Research Programme.

Tolstokorova, A.V. (2010). "Where have all the mothers gone? The gendered effect of labour migration and transnationalism on the institution of parenthood in Ukraine." Anthropology of East Europe Review 28(1): 184-214.

Trager, L. (1984). "Family strategies and the migration of women: migrants to Dagupan City, Philippines." International Migration Review 18: 1264-1277.

Tuathail, G.O. (2009). "Russia's Kosovo: A critical geopolitics of the August 2008 War over South Ossetia." Eurasian Geography and Economics 49(6): 670-705.

United Nations Children's Fund (UNICEF) (2010). “How do Georgian children and their families cope with the impact of the financial crisis? Report on the Georgia Welfare Monitoring Survey 2009." UNICEF/York University: Tbilisi.

United Nations Children's Fund (UNICEF) Moldova \& Child Rights Information Center (CRIC) Moldova (2008). "The impact of parental deprivation on the development of children left behind by Moldovan migrants." UNICEF, Division of Policy and Practice Working Paper: New York.

United Nations Children's Fund (UNICEF) Moldova \& CIDDC (2006). "The Situation of Children Left Behind by Migrating Parents." Study Report UNICEF/CIDDC. Child Rights Information Centre with support from UNICEF Moldova: Chisinau.

United Nations Development Programme (UNDP) (2009). Human Development Report 2009: Overcoming Barriers - Human Mobility and Development. United 
Nations Press: Tokyo.

United Nations Development Programme (UNDP) (2014). Human Development Report 2014-Sustaining Human Progress: Reducing Vulnerabilities and Building Resilience. United Nations Development Programme: New York.

United Nations High Commissioner for Refugees (UNHCR) (2008). "Revised Figures Push Number of Georgia Displaced up to 192,000." News bulletin published 12 September, 2008. Available from online archive at < http://www.unhcr.org/48ca8d804.html>.

United Nations (1998). "Recommendation on statistics of international migration: Revision 1." Statistical Papers Series M, no. 58, rev. 1. Department of Economic and Social Affairs, Statistics Division. UN: New York.

United States Agency for International Development (USAID) (2003). "Gender assessment for USAID/Caucuses." Report prepared within USAID Contract\# GEW-I-01-02-00018-00.

Vanore, M., Mazzucato, V., \& Siegel, M. (2014). “'Left behind' but not left alone: Parental migration and the psychosocial health of children in Moldova." Social Science and Medicine. Article in press. DOI: 10.1016/j.socscimed.2014.08.040.

Vladicescu, N., Cantarji, V., \& Jigău, I. (2008). "The impact of migration and remittances on communities, families and children in Moldova." United Nations Children's Fund; Policy, Advocacy and Knowledge Management, Division of Policy and Practise working paper. UNICEF: New York.

Vyas, S. \& Kumaranayake, L. (2006). "Constructing socio-economic status indices: How to use principle components analysis." Health Policy and Planning 21(6): 459-468. DOI: 10.1093/heapol/czl029

Westoff, C. \& Serbanescu, F.I. (2008). "The relationship between contraception and abortion in the Republic of Georgia: Further analysis of the 1999 and 2005 Reproductive Health Surveys." Macro International Inc.: Calverton, MD.

Wheatley, J. (2005). Georgia from National Awakening to Rose Revolution: Delayed Transition in the Former Soviet Union. Ashgate Publishing Limited, Hampshire: United Kingdom.

Wimmer, A. \& Glick Schiller, N. (2002). "Methodological nationalism and beyond: 
Nation-state building, migration and the social sciences." Global Networks 2(4): 301-334.

World Bank (2010). Migration and Remittances Factbook 2011. World Bank: Washington, D.C.

World Bank (2011). "Moldova after the global financial crisis: Promoting competitiveness and shared growth." Report No. 55195-MD. World Bank: Washington, D.C.

World Bank (2015). "Personal remittances, received (\% of GDP)." World Bank Databank. Accessed from <http://data.worldbank.org/indicator/BX.TRF.PWKR.DT.GD.ZS>; April, 2015.

World Economic Forum (2013). Global Gender Gap Report 2013. World Economic Forum: Geneva.

Yeoh, B. \& Lam, T. (2013). "Transnational migration in Southeast Asia and the gender roles of left-behind fathers." Arrow for Change 19(1): 8-9.

Zurabishvili, T. \& Zurabishvili, T. (2010). "The Feminisation of Labor Migration from Georgia: The Case of Tianeti." Laboratorium 1: 73-83. 


\section{APPENDICES}

\section{A. Expert Interview Overview}

\section{Table A.1: Organisation \& Functions of Experts Interviewed}

\begin{tabular}{|c|c|c|}
\hline $\begin{array}{c}\text { Type of } \\
\text { Organisation }\end{array}$ & Organisation Name & Professional Function of Respondent \\
\hline \multicolumn{3}{|l|}{ Moldova } \\
\hline $\begin{array}{l}\text { International } \\
\text { organisation }\end{array}$ & $\begin{array}{l}\text { International Organisation for } \\
\text { Migration (IOM) }\end{array}$ & $\begin{array}{l}\text { 1. Coordinator, Prevention \& } \\
\text { Protection Programme } \\
\text { 2. Chief of mission }\end{array}$ \\
\hline NGO & $\begin{array}{l}\text { Centre for Children and } \\
\text { Young People with Mixed } \\
\text { Severe Disabilities "Danco" }\end{array}$ & Child development psychologist \\
\hline University & Moldova State University & Psychologist \& researcher \\
\hline $\begin{array}{l}\text { International } \\
\text { organisation }\end{array}$ & HelpAge International & Country director \\
\hline $\begin{array}{l}\text { International } \\
\text { organisation }\end{array}$ & $\begin{array}{l}\text { United Nations Children's } \\
\text { Fund (UNICEF) }\end{array}$ & $\begin{array}{l}\text { 1. Coordinator, Monitoring \& } \\
\text { evaluation } \\
\text { 2. Child protection officer }\end{array}$ \\
\hline NGO & Charity Centre for Refugees & Director \\
\hline $\begin{array}{l}\text { Government } \\
\text { organisation }\end{array}$ & $\begin{array}{l}\text { Ministry of Labour, Social } \\
\text { Protection, \& Family }\end{array}$ & Deputy director \\
\hline \multicolumn{3}{|l|}{ Georgia } \\
\hline $\begin{array}{l}\text { International } \\
\text { organisation }\end{array}$ & Save the Children & $\begin{array}{l}\text { Senior programme manager, } \\
\text { Community centres for conflict- } \\
\text { affected communities in Georgia }\end{array}$ \\
\hline $\begin{array}{l}\text { International } \\
\text { organisation }\end{array}$ & $\begin{array}{l}\text { United Nations Children's } \\
\text { Fund (UNICEF) }\end{array}$ & $\begin{array}{l}\text { 1. Country director } \\
\text { 2. Social policy specialist } \\
\text { 3. Chief, Child protection/education }\end{array}$ \\
\hline
\end{tabular}




\begin{tabular}{|c|c|c|}
\hline $\begin{array}{l}\text { Government } \\
\text { organisation }\end{array}$ & $\begin{array}{l}\text { State child care institutions } \\
(2)^{*}\end{array}$ & Directors \\
\hline NGO & Children of Georgia & Director \\
\hline NGO & $\begin{array}{l}\text { Taoba/Coalition Homecare in } \\
\text { Georgia }\end{array}$ & Director \\
\hline NGO & $\begin{array}{l}\text { Katarzizi (elderly outreach } \\
\text { centre) }\end{array}$ & $\begin{array}{ll}\text { 1. } & \text { Director } \\
\text { 2. } & \text { Homeless elderly individuals }\end{array}$ \\
\hline NGO & $\begin{array}{l}\text { Global Initiative for } \\
\text { Psychiatry }\end{array}$ & Programme Director, Child outreach \\
\hline $\begin{array}{l}\text { Government } \\
\text { organisation }\end{array}$ & $\begin{array}{l}\text { Ministry of Labour, Health, } \\
\text { and Social Affairs, State Care } \\
\text { Agency }\end{array}$ & Director, Public affairs \\
\hline $\begin{array}{l}\text { International } \\
\text { organisation }\end{array}$ & EveryChild & Country director \\
\hline $\begin{array}{l}\text { Government } \\
\text { organisation }\end{array}$ & $\begin{array}{l}\text { National Association of Local } \\
\text { Authorities in Georgia }\end{array}$ & Executive director \\
\hline $\begin{array}{l}\text { Private } \\
\text { business }\end{array}$ & Child psychology clinic* & Child psychiatrist \\
\hline University & Tbilisi State University & Associate director of development \\
\hline $\begin{array}{l}\text { Government } \\
\text { organisation }\end{array}$ & $\begin{array}{l}\text { Ministry of Justice, Civil } \\
\text { Service Development Agency }\end{array}$ & $\begin{array}{l}\text { Staff, Secretariat of the State } \\
\text { Commission on Migration Issues }\end{array}$ \\
\hline NGO & $\begin{array}{l}\text { Georgia Centre of Population } \\
\text { Research }\end{array}$ & Director \\
\hline
\end{tabular}

Notes: *Respondents requested that their institutions would not be identified by name, therefore only the type of organisation is noted here 


\section{B. Sample Interview Guide for Caregivers of Children in Migrant Households}

1. Can you tell me a little bit about the children under your care?

a. Do you take care of all of the children in the household?

b. [For non-biological children]: For how long have you been their caregiver?

c. [For non-biological children]" Why did you start caring for them? Why do you think you were chosen as the caregiver?

d. [For non-biological children]: When you first started to care for these children, how did you feel received by them? (What was your relationship like at the beginning?)

e. Has there even been a time when you have not been the caregiver of these children (after coming to care for them)?

2. What are the habitual roles of your household members?

a. Inside the household, what are your duties and responsibilities?

b. [For migrant households]: Have the normal roles of your household members changed since the migration?

3. What are the normal roles of the following people in a Moldovan family/in your family?

a. A father

b. A mother

c. A child

d. A grandparent

$\rightarrow$ What are their responsibilities to each other?

4. Do you find that there are important topics that you and the child/children have very different opinions on? (Ex: Curfews, political party participation, future plans, dating, etc.)

a. If yes, what are they?

b. How do you deal with this difference in opinion? How do you handle it if you and the child have a conflict?

5. How would you characterise your relationship with the child?

6. What kinds of skills do you think are important for the children under your care to possess to succeed in the future?

a. How do you try to contribute to those skills? 
b. Is there a lesson that you try to impart to the children under your care?

7. Have you personally had any migration experience? If yes:

a. When did you leave for the first time and for the last?

b. Where have you lived for the longest amount of time?

c. Do you think living abroad changed you? If so, how?

8. What is your opinion about migration? What are its advantages and disadvantages?

9. I want to ask a few questions about the person in your household who migrated. Can you tell me a little about this person? What is your relationship to the migrant?

a. When did the migrant leave for the first time (when you were living in the same household)?

b. When did the migrant leave for this current migration episode?

c. Who made the decision that this person would migrate this last time (for the current migration episode)?

d. Why did this person decide to leave at the time that they did? Did the migrant have a particular goal in mind when they left?

10. Has this current migration abroad affected you?

a. If so, how?

b. Do you believe that your responsibilities and tasks, in and outside of the household, have changed? If so, how?

c. Since the migrant has gone, are there things that have become easier to do in the household? Are there things that have become more difficult?

i. If yes, can you please give examples?

ii. Why do you think this change has occurred?

iii. Do you and the migrant ever have differences in opinion about key decisions that concern the household? (Ex.: spending of remittances, schooling of children, disciplining of children, etc.)

iv. Since the migrant has left, do you and other people who live here ever have differences in opinion about key decisions that concern the household in general? (i.e., use of remittances, travel plans, other aspects related to migrant) 
v. Do you have particular worries now that the migrant is away?

11. Have conditions at home changed since the migrant left? (Ex: Income, time allocation, safety, housing conditions, etc.)

a. If yes, how?

b. How have you dealt with these changes?

c. Why do you think these changes have occurred?

12. Do you think that being part of a migrant household distinguishes your household from others in your community or in the country in general?

a. Why or why not? How?

b. Do you feel like you are part of an average? Are your experiences common?

c. Do you feel that members of your community (colleagues, neighbours, acquaintances) treat or regard you differently? How? Why?

i. Have you received advice from anyone in your community about the children you care for? (Ex.: educational plans for children of migrants)

ii. Do the children under your care ever have to pay more for basic services? (ex: education or health care). If so, why do you think this happens?

13. I would like to talk a little bit now about how other members of your household have experienced this migration. Do you think the household in general has changed as the result of the migration?

a. If yes, how?

b. Has your relationship with other household members changed?

14. Do you think that the children in your household have been affected by the migration of (name)?

a. How? In what way?

b. Why do you think they have been affected this way?

c. Have any of the children been more or less affected than the others?

d. Do you talk with the children about the migrant? What do you talk about?

e. If one of the children under your care is really down or upset, what do you do to help cheer them up? 
$\rightarrow$ Alternate formulation//Do you think that children in households like yours need something different or more from what children in nonmigrant households need?

f. If yes, what are they, and why do you think that?

g. Do you think such children have certain advantages over other children in their age groups who don't live in households with a migrant? Do you think they face specific disadvantages?

h. Do you think that there are differences between the experiences of children living in a household with a migrant and those that don't? If yes, what are they?

15. In your opinion, how can one help children in migrant households deal with the migration of a household member?

a. Are there particular aspects of a child's life (schooling, emotional health, eating habits, etc.) that change when someone in the household migrates?

b. [In households where both parents have migrated]: Do you feel that you should replace the role of a parent in navigating these changes?

c. [In households where one parent has migrated]: Do you try to compensate for the absence of the other parent? If so, how?

16. [For caregivers who tend to children that are not their own]: Do you think that the children of (migrant) are very different from your own children? Why? How?

a. Do you think they have different needs? Do they expect different things from you?

b. Are you more strict with your own children than with the other children under your care?

c. Do you have different expectations of your own children? In what way?

d. Do your own children and the other children under your care spend a lot of time together? What is their relationship like?

17. Do you and [migrant] coordinate raisin the children? How?

a. Are there certain tasks or roles the migrant takes on in relation to the children?

b. Are there any areas of child raising that you and [migrant] disagree on? 
c. Do you feel helped by the migrant in raising the children?

18. Is there an important thing you think I should know about your experiences with migration or about migration more generally? Is there something I haven't asked that you think I should have?

\section{In-Depth Interview Sample Characteristics}

Table C.1: In-Depth Interview Sample Characteristics

\begin{tabular}{|c|c|c|}
\hline & Moldova & Georgia \\
\hline Total \# Interviews Conducted & 35 & 34 \\
\hline \multicolumn{3}{|l|}{ Field Site Characteristics } \\
\hline Total \# of Visited Field Sites & 17 & 11 \\
\hline Rural & 13 & 5 \\
\hline Semi-Urban & 1 & 1 \\
\hline Urban & 3 & 5 \\
\hline \multicolumn{3}{|l|}{ Regional Distribution of Field Sites } \\
\hline Capital (Chișinău/Tbilisi) & 4 & 1 \\
\hline Centre (Moldova)/Shida-Kartli (Georgia) & 5 & 2 \\
\hline North (Moldova)/ Mtskheta-Mtianeti (Georgia) & 6 & 6 \\
\hline South (Moldova)/Imereti (Georgia) & 3 & 2 \\
\hline \multicolumn{3}{|l|}{ Primary Respondent Characteristics } \\
\hline Total Number of Respondents* & 37 & 35 \\
\hline \multicolumn{3}{|l|}{ Sex } \\
\hline Male & 6 & 2 \\
\hline
\end{tabular}


Female

Age Range (Mean)

Relationship to Migrant

Spouse

Parent(-in-law)

Child

Sibling

Migrant Destination**

CIS

EU-28

Other

Length of Interview (Mean) in Minutes
20-71 (42)

$19-75(43.5)$

18

4

6

11

2

22

12

1

$15-120(71.5) \quad 20-150(48)$

Note: *Some interviews were attended by multiple respondents, thus the number of respondents can differ from the number of interviews; ${ }^{*}$ Several households contained multiple migrants residing in different locations, thus the number of migrants can differ from the number of interviews.

\section{Methodological Note on Creation of the Wealth Index}

In the analyses presented in Chapters Five and Six, a household-level wealth index was created and used as a control variable. The index was constructed on the basis of household assets and housing quality variables in a method similar to that used for the Demographic and Health Survey (DHS) wealth index (Rutstein \& Johnson, 2004) and following the method proposed by Vyas and Kumaranayake (2006). The following steps were taken in constructing this index:

1. Assets were selected for inclusion in the index. The following assets were included: land, house, automobile, motorcycle, bicycle, washing machine, refrigerator, radio, television, personal computer, mobile phone, telephone landline, and internet connection. For each of these assets, a household 
received a score of either 0 (indicating that the household did not have this asset at the time of the survey) or 1 (indicating that the household had at least one unit of a given asset at the time of the survey).

2. Housing quality indicators were defined for the index. The indicators included: if the household had access to electricity, coded as 0 or 1 ; floor type, split into dummy variables by floor material (e.g., clay, polished wood, linoleum or vinyl, ceramic tile, cement, laminate, carpet); type of cooking fuel, split into dummy variables by source of fuel (e.g., electricity, piped gas, bottled gas such as propane, coal, wood); type of drinking water used by the household, split into dummy variables by the source of drinking water (e.g., piped water, well water, spring water, rainwater, water collected from the surface of standing bodies of water like a lake, bottled water), and; the type of sanitation facilities used by a household, split into dummy variables by type of toilet (e.g., toilet inside the house, outhouse, or shared toilet).

3. Principle component analysis (PCA) was run, which essentially reduces the number of variables within the data into a smaller number of correlated components. As the asset and housing quality variables were not standardised prior to the PCA (i.e., not all variable outcomes were expressed in the same units), the PCA was specified to use the correlation matrix. It was specified that only principle components with an eigenvalue greater than one should be retained. The PCA was run for rural and urban areas separately to accommodate regional differences in asset ownership and housing standards.

4. A variable was constructed representing a household's overall socioeconomic score, which was based on the factor scores from the first principle component.

5. Wealth quintiles were then defined based on the distribution of the household population. While individuals within the same household shared assets and housing quality, the quintiles were constructed on the basis of household population distribution since the individual, not the household, is the unit of analysis.

6. Individuals belonging to the lower quintile of the wealth distribution were then identified as "poor".

A wealth index was chosen as a proxy for socio-economic status rather than household income or expenditures because income and consumption data could potentially be more biased due to problems with respondent calculation (i.e., some respondents may not correctly calculate or recall all monthly 
expenses or sources of income) and because income and consumption patterns tend to be sensitive to seasonality, particularly among households that rely on agricultural production. The PCA method was specifically chosen for calculation of a wealth index because it removes the need for the researcher to designate weights or rankings to any given asset. For example, it is unclear if carpet and ceramic tiles should receive different relative rankings that indicate a different wealth ordering; PCA solves this dilemma by calculating correlations among a large number of indicators and suggesting scores based on this information. 


\section{E. Full Models of Analyses Presented in Chapter Five}

Table E.1: Odds Ratios of Being a Current Migrant, by Gender E Origin Country

\begin{tabular}{|c|c|c|c|c|c|c|}
\hline \multirow[b]{2}{*}{$\begin{array}{l}\text { Reference: Non- } \\
\text { migrant }\end{array}$} & \multicolumn{3}{|c|}{ Moldova } & \multicolumn{3}{|c|}{ Georgia } \\
\hline & $\begin{array}{c}\text { Both } \\
\text { Genders }\end{array}$ & Male & Female & $\begin{array}{c}\text { Both } \\
\text { Genders }\end{array}$ & Male & Female \\
\hline \multirow[t]{2}{*}{ Female } & $0.49^{* * *}$ & & & 0.81 & & \\
\hline & $(0.05)$ & & & $(0.12)$ & & \\
\hline \multirow[t]{2}{*}{ Age } & $1.28^{* * *}$ & $1.31^{* * *}$ & $1.26^{* * *}$ & $1.40^{* * *}$ & $1.26^{* * *}$ & $1.57^{* * *}$ \\
\hline & $(0.03)$ & $(0.05)$ & $(0.04)$ & $(0.06)$ & $(0.07)$ & $(0.08)$ \\
\hline \multirow[t]{2}{*}{$\mathrm{Age}^{2}$} & $1.00^{* * *}$ & $1.00^{* * *}$ & $1.00^{* * *}$ & $1.00^{* * *}$ & $1.00^{* * *}$ & $0.99^{* * *}$ \\
\hline & $(0.00)$ & $(0.00)$ & $(0.00)$ & $(0.00)$ & $(0.00)$ & $(0.00)$ \\
\hline \multicolumn{7}{|l|}{ Marital Status (Ref.: } \\
\hline \multicolumn{7}{|l|}{ Married) } \\
\hline \multirow[t]{2}{*}{ Never Married } & 1.18 & 0.91 & $1.74^{*}$ & $1.45^{*}$ & 0.90 & $2.30^{* * *}$ \\
\hline & $(0.20)$ & $(0.19)$ & $(0.47)$ & $(0.28)$ & $(0.25)$ & $(0.57)$ \\
\hline \multirow[t]{2}{*}{ Widowed } & 1.31 & 0.61 & 1.53 & $1.68^{+}$ & 1.81 & 1.62 \\
\hline & $(0.33)$ & $(0.40)$ & $(0.44)$ & $(0.48)$ & $(0.82)$ & $(0.52)$ \\
\hline \multirow[t]{2}{*}{ Divorced/Separated } & $1.97^{* *}$ & 0.92 & $3.08^{* * *}$ & $2.24^{* * *}$ & 1.30 & $2.84^{* * *}$ \\
\hline & $(0.41)$ & $(0.40)$ & $(0.70)$ & $(0.45)$ & $(0.52)$ & $(0.63)$ \\
\hline \multirow{2}{*}{\multicolumn{7}{|c|}{$\begin{array}{l}\text { Years of Education } \\
\text { (Ref.: 10-14) }\end{array}$}} \\
\hline & & & & & & \\
\hline \multirow[t]{2}{*}{ Over 14} & 0.86 & $0.64^{*}$ & 1.15 & 0.93 & 1.03 & 0.86 \\
\hline & $(0.12)$ & $(0.13)$ & $(0.20)$ & $(0.14)$ & $(0.22)$ & $(0.18)$ \\
\hline \multirow[t]{2}{*}{ Less Than 10} & 0.92 & 0.97 & 0.88 & $0.62^{*}$ & 0.61 & 0.74 \\
\hline & $(0.09)$ & $(0.13)$ & $(0.14)$ & $(0.13)$ & $(0.19)$ & $(0.21)$ \\
\hline Minority Ethnicity & 1.17 & $1.50^{*}$ & 0.83 & 1.23 & 1.32 & 1.13 \\
\hline
\end{tabular}




\begin{tabular}{|c|c|c|c|c|c|c|}
\hline & $(0.15)$ & $(0.26)$ & $(0.18)$ & $(0.31)$ & $(0.24)$ & $(0.60)$ \\
\hline \multirow[t]{2}{*}{ Child in $\mathrm{HH}$} & $0.76^{*}$ & $0.67^{*}$ & 0.80 & $0.45^{* * *}$ & $0.50^{* *}$ & $0.39^{* * *}$ \\
\hline & $(0.10)$ & $(0.13)$ & $(0.13)$ & (0.09) & $(0.13)$ & $(0.11)$ \\
\hline \multirow[t]{2}{*}{ Elderly Person in $\mathrm{HH}$} & 0.94 & $0.67^{*}$ & $1.45^{*}$ & $0.50^{* * *}$ & $0.64^{*}$ & $0.41^{* * *}$ \\
\hline & $(0.12)$ & $(0.12)$ & $(0.22)$ & $(0.07)$ & $(0.12)$ & $(0.08)$ \\
\hline \multirow{3}{*}{$\begin{array}{l}\text { HH in Lowest Asset } \\
\text { Quintile }\end{array}$} & $0.48^{* * *}$ & $0.53^{* * *}$ & $0.41^{* * *}$ & $0.70^{+}$ & 0.84 & 0.58 \\
\hline & & & & & & \\
\hline & $(0.07)$ & $(0.10)$ & $(0.10)$ & $(0.15)$ & $(0.24)$ & $(0.19)$ \\
\hline \multicolumn{7}{|l|}{$\begin{array}{l}\text { Region of Residence } \\
\left(\text { Ref.: Chișinău/West }{ }^{1}\right)\end{array}$} \\
\hline \multirow[t]{2}{*}{ Centre/East } & $3.52^{* * *}$ & $2.79^{* * *}$ & $5.08^{* * *}$ & 0.88 & $0.55^{* *}$ & 1.26 \\
\hline & $(0.77)$ & $(0.74)$ & (1.67) & $(0.17)$ & $(0.12)$ & $(0.34)$ \\
\hline \multirow[t]{2}{*}{ North \& Bălți/ Tbilisi } & $3.70^{* * *}$ & $3.76^{* * *}$ & $3.60^{* * *}$ & $0.68^{*}$ & 0.81 & $0.58^{* *}$ \\
\hline & $(0.85)$ & $(1.08)$ & $(1.24)$ & $(0.12)$ & $(0.23)$ & $(0.12)$ \\
\hline \multirow[t]{2}{*}{ South } & $4.74^{* * *}$ & $3.71^{* * *}$ & $6.84^{* * *}$ & $0.38^{* * *}$ & $0.53^{* *}$ & $0.23^{* * *}$ \\
\hline & (1.05) & $(0.99)$ & $(2.38)$ & $(0.07)$ & $(0.12)$ & $(0.08)$ \\
\hline \multirow[t]{2}{*}{ IDP Status } & -- & -- & -- & $0.65^{*}$ & 0.67 & $0.58^{+}$ \\
\hline & -- & -- & -- & $(0.13)$ & $(0.18)$ & $(0.17)$ \\
\hline Observations & 8,208 & 3,655 & 4,553 & 11,833 & 5,004 & 6,829 \\
\hline Goodness-of-fit test ${ }^{2}$ & .6777 & .8015 & .2020 & .6181 & .7876 & .9165 \\
\hline
\end{tabular}

Note: Standard errors reported in parentheses; ${ }^{* *} p<0.001,{ }^{* *} p<0.01,{ }^{*} p<0.05,{ }^{+} p<0.1 .{ }^{1}$ Locations indicated as Moldova/Georgia. Georgian regions are grouped as following: West includes Imereti, Guria, Racha-Lechkumi, Samegrelo, E Adjara; east includes Kakheti, Mtskheta-Mtianeti, E ShidaKartli; south includes Samtskhe-Javaketi E Kvemo-Kartli. ${ }^{2}$ As the pseudo- ${ }^{2}$ statistic is not available following weighted estimation, model fit is assessed with the Archer-Lemeshow F-adjusted mean residual test. 
Table E.2: Relative Risk Ratios of Current Migrants per Destination Country

\begin{tabular}{|c|c|c|c|c|}
\hline \multirow[b]{2}{*}{$\begin{array}{l}\text { Reference: Destination } \\
\text { CIS }\end{array}$} & \multicolumn{2}{|c|}{ Moldova (Both genders) } & \multicolumn{2}{|c|}{ Georgia (Both genders) } \\
\hline & $\begin{array}{c}\text { Destination } \\
\text { EU-28 }\end{array}$ & $\begin{array}{l}\text { Destination } \\
\text { Other }\end{array}$ & $\begin{array}{c}\text { Destination } \\
\text { EU-28 }\end{array}$ & $\begin{array}{l}\text { Destination } \\
\text { Other }\end{array}$ \\
\hline Female & $\begin{array}{l}4.57^{* * *} \\
(0.80)\end{array}$ & $\begin{array}{l}7.17^{* * *} \\
(1.81)\end{array}$ & $\begin{array}{l}9.52^{* * *} \\
(1.37)\end{array}$ & $\begin{array}{l}6.17^{* * *} \\
(0.93)\end{array}$ \\
\hline Age & $\begin{array}{l}0.98 \\
(0.07)\end{array}$ & $\begin{array}{l}1.04 \\
(0.09)\end{array}$ & $\begin{array}{l}1.01 \\
(0.04)\end{array}$ & $\begin{array}{l}0.98 \\
(0.04)\end{array}$ \\
\hline $\mathrm{Age}^{2}$ & $\begin{array}{c}1.00 \\
(0.00)\end{array}$ & $\begin{array}{c}1.00 \\
(0.00)\end{array}$ & $\begin{array}{c}1.00 \\
(0.00)\end{array}$ & $\begin{array}{c}1.00 \\
(0.00)\end{array}$ \\
\hline $\begin{array}{l}\text { Marital Status (Ref.: } \\
\text { Married) }\end{array}$ & & & & \\
\hline Never Married & $\begin{array}{l}1.81+ \\
(0.60)\end{array}$ & $\begin{array}{c}1.20 \\
(0.53)\end{array}$ & $\begin{array}{c}1.16 \\
(0.21)\end{array}$ & $\begin{array}{c}0.99 \\
(0.20)\end{array}$ \\
\hline Widowed/Divorced & $\begin{array}{l}2.14^{*} \\
(0.64)\end{array}$ & $\begin{array}{c}1.78 \\
(0.69)\end{array}$ & $\begin{array}{c}1.23 \\
(0.26)\end{array}$ & $\begin{array}{l}1.92^{* *} \\
(0.41)\end{array}$ \\
\hline $\begin{array}{l}\text { Years of Education (Ref.: } \\
10-14)\end{array}$ & & & & \\
\hline Over 14 & $\begin{array}{l}1.97^{*} \\
(0.58)\end{array}$ & $\begin{array}{l}2.70^{* *} \\
(0.99)\end{array}$ & $\begin{array}{c}1.14 \\
(0.17)\end{array}$ & $\begin{array}{c}0.82 \\
(0.13)\end{array}$ \\
\hline Less Than 10 & $\begin{array}{l}0.64+ \\
(0.15)\end{array}$ & $\begin{array}{l}0.52+ \\
(0.18)\end{array}$ & $\begin{array}{c}1.23 \\
(0.46)\end{array}$ & $\begin{array}{l}2.67^{* *} \\
(0.93)\end{array}$ \\
\hline Minority Ethnicity & $\begin{array}{c}0.20^{* * *} \\
(0.07)\end{array}$ & $\begin{array}{l}1.85+ \\
(0.61)\end{array}$ & $\begin{array}{c}0.11^{* * *} \\
(0.04)\end{array}$ & $\begin{array}{c}0.19^{* * *} \\
(0.05)\end{array}$ \\
\hline Child in $\mathrm{HH}$ & $\begin{array}{l}0.65+ \\
(0.17)\end{array}$ & $\begin{array}{l}0.84 \\
(0.29)\end{array}$ & $\begin{array}{l}1.26 \\
(0.20)\end{array}$ & $\begin{array}{l}1.47^{*} \\
(0.24)\end{array}$ \\
\hline
\end{tabular}




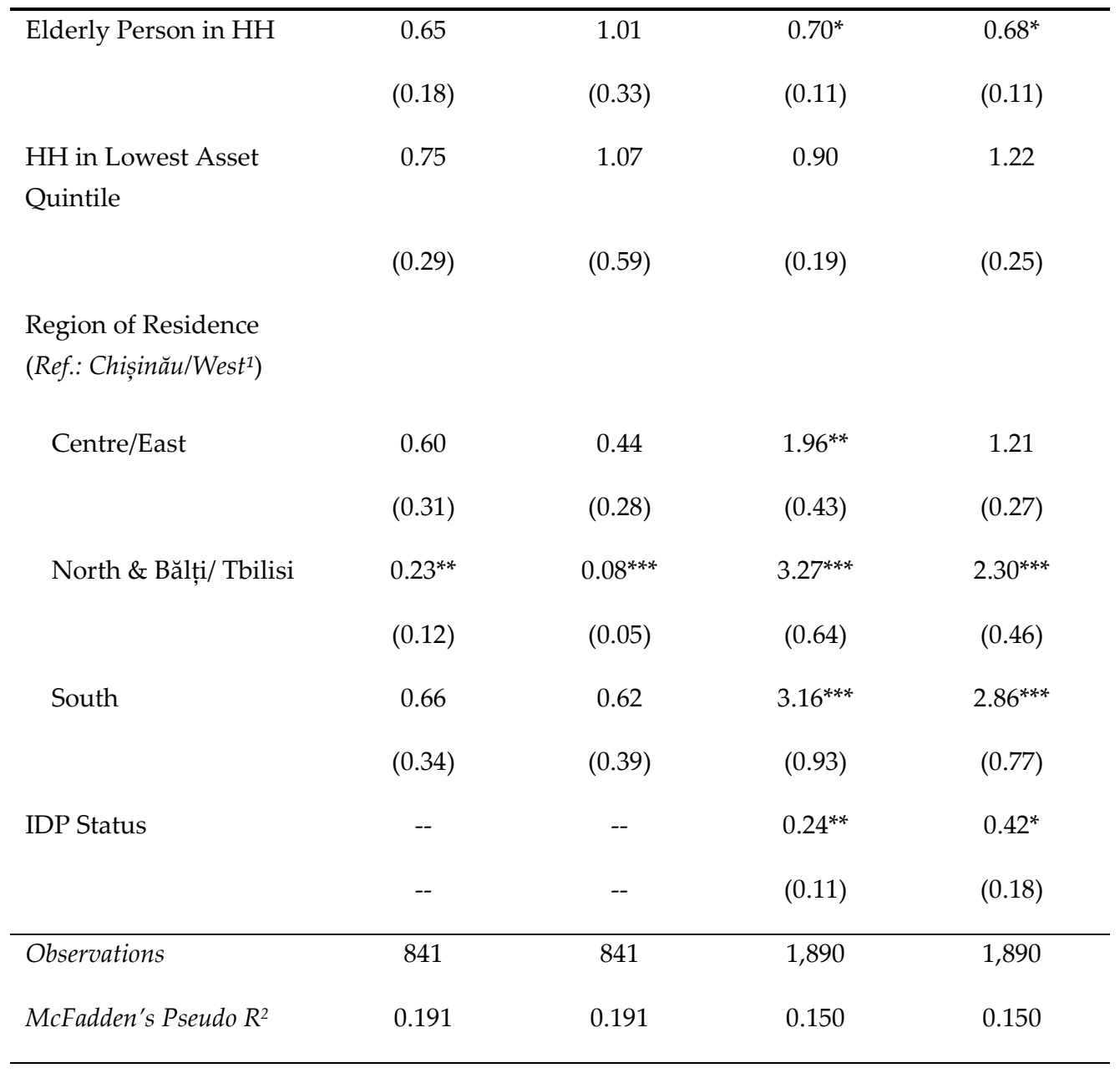

Note: Standard errors reported in parentheses; ${ }^{* * *} p<0.001,{ }^{* *} p<0.01,{ }^{*} p<0.05,{ }^{+} p<0.1 .{ }^{1}$ Locations indicated as Moldowa/Georgia. Georgian regions are grouped as following: West includes Imereti, Guria, Racha-Lechkumi, Samegrelo, \& Adjara; east includes Kakheti, Mtskheta-Mtianeti, \& ShidaKartli; south includes Samtskhe-Javaketi \& Kvemo-Kartli. 


\section{KNOWLEDGE VALORISATION}

The topic of this dissertation-the relationship between the migration of kin and the psychosocial health of the children who remain in the origin countryhas generated intense societal interest in both Moldova and Georgia over the past decade. In both of these countries, migration has become a social and economic dilemma, both for the general population and for the state. Remittances, as one of the most visible "outputs" of migration, represent sizeable financial flows into both countries, accounting for 24.9\% of GDP in Moldova and 12.1\% of GDP in Georgia in 2013 (World Bank, 2015). In Moldova, most of the economic growth that occurred between 2000 and 2010 was "jobless", fuelled by remittances; in 2010 around 40 percent of the Moldovan workforce was estimated to work abroad (World Bank, 2011). Despite such potential economic advantages of migration, however, there has been a social backlash against migration in both countries, largely in response to the migration of women. As more women have entered international migration, contributing to changing roles and relationships within families, migration has increasingly been associated with the breakdown of family relationships, growing child delinquency, and deteriorating child mental health (Prohnitchi, 2005; Salah, 2008; Cheianu-Andrei et al., 2011). In both policy and public discourses, children 'left behind' by migrant kin, chiefly parents, are assumed to suffer from that absence, yet little research has explored the phenomenon of children in transnational families systematically. This dissertation is relevant exactly because it addresses the question of whether the migration of a parent or other close kin is actually a source of vulnerability that undermines child well-being.

Given the strong focus in discourse on the deleterious effects of migration for child emotional health, as well as the close ties between psychosocial health and other aspects of well-being such as physical health or educational performance, this dissertation specifically explored if children with migrant family members had different psychosocial health outcomes than children who had not experienced the migration of kin. The findings suggest that migration may be only marginally associated with the psychosocial health of children 'left behind', as the migration of kin was not found to strongly predict psychosocial dysfunction of children in either country. No form of family-member migration (that of a mother, father, grandparent, or other family member such as a sibling) was significantly associated with worse child psychosocial outcomes in Georgia. In Moldova, no 
form of parental migration corresponded to worse psychosocial outcomes among girls. Among boys, however, a father's migration was associated with worse conduct problems scores, and the migration of both parents was associated with marginally worse emotional symptoms outcomes. These results undermine the assertion made in discourse that migration has consistently negative consequences for the children who experience it, as important differences existed between children in the two study countries, between boys and girls, and between children who had experienced different forms of family-member migration.

This research has clear social relevance because it highlights the gap between discourse and the lived experiences of the children and families such discourse encompasses. The framing of children in transnational families as "left behind" can (inadvertently) stigmatise migrants and their families. This is especially evident in Moldova, where children with migrant parents are regularly discussed as victims of migration by the media, international and nongovernmental organisations, and policies at both national and local level. The emphasis on the suffering of children following migration-or, conversely, on the economic benefits children with migrant parents enjoy through the receipt of remittances - can make children feel ashamed of their parents' choices and can lead to unequal treatment in society (Salah, 2008; HAI/UNICEF, 2008). Salah (2008), for instance, noted that children with migrant parents may not be informed about social assistance programmes or may be denied access to them because they are assumed to benefit from remittances and therefore to belong to richer households (Salah, 2008). Other studies (e.g., UNICEF/CRIC, 2008) found that some teachers may favour the children of migrants or punish them unduly on the basis of the children's perceived financial status. Such attitudes or experiences may not be prevalent, but they do highlight how generalisations of an internally-diverse population (such as children with migrant kin) can impair the functioning of public services or policies.

The results of this dissertation therefore also have relevance for policy, primarily by highlighting that policies that address complex issues such as migration and its potential consequences for children need to be appropriately tailored to the populations they intend to address. The evidence does not suggest that family-member migration is universally bad for child well-being, but it does suggest important inequalities in experiences among different groups of children. Child psychosocial health outcomes differed markedly not only by child sex but also by who specifically had migrated, suggesting that there are distinctly gendered ways in which children negotiate the changes brought about by 
migration. This research emphasises that not all forms of family-member migration carry the same opportunities and risks for the children who experience them. This is an important finding for policy or programme interventions, the effectiveness of which could be enhanced by designs that more conscientiously engage the needs of specific sub-population groups (e.g., boys with fathers abroad).

In investigating the relationship between family-member migration and child psychosocial health, this research also uncovered characteristics beyond migration that appeared to undermine child psychosocial health. Being called names such as lazy or stupid by a caregiver, or living in a region that had experienced political turmoil were consistently associated with worse psychosocial health outcomes. These characteristics were much stronger in predicting psychosocial dysfunction than family-member migration status, for children of both genders. Policy makers or programme planners who design interventions for organisations such as UNICEF could use such results to design better-targeted social services for at-risk children. Such social services could include classes on proactive child-raising that emphasise how to positively elicit behaviour change from children (without resorting to verbal abuse) or the provision of counselling services to children in the regions that have experienced particularly intense political instability. The findings that not all children were equally exposed to characteristics or factors that could act as potential psychosocial stressors suggests that any policy targeted at the child population should consider which children are at most risk and under what conditions those risks appear. To better target the vulnerable child population, however, additional data on child well-being and sources of inequality in well-being would likely need to be collected.

As this dissertation has addressed a topic that is relevant both to academia and to policy, parts of it have been strategically disseminated to different audiences. Several academic publications have resulted from this work; two articles have been accepted in international peer-reviewed journals, and another two articles are under review as of this writing. Results have also been disseminated to policy makers and child protection practitioners in Moldova and Georgia as part of the larger project to which this dissertation belongs. The work for this dissertation was completed within a European Commission-funded project called "The Effects of Migration on Children and the Elderly Left Behind in Moldova and Georgia", which explored the potential consequences of migration for different dimensions of well-being among children and elderly individuals who experienced the migration of family members. Throughout this project, stakeholders from government and non-government agencies were asked for their 
input through bilateral meetings, periodic technical working groups (TWGs), workshops, and conferences in both Moldova and Georgia. These events engaged government agencies, NGOs, and international organisations (IOs) in the research and output dissemination process, which helped ensure that many of the project outputs-such as policy briefs and multidimensional well-being indices-would be useful to policy makers and practitioners working in the field. In Moldova, the TWGs and conferences included representatives from international organisations like HelpAge International, the International Organisation for Migration (IOM), and UNICEF as well as representatives from the Ministry of Labour, Social Protection, and Family, the Ministry of Health, and the Ministry of Education. In Georgia, local NGOs involved in child and elderly protection services attended project workshops and conferences, as did representatives from IOs such as UNDP, IOM, and UNICEF and from government agencies such as the Ministry of Justice, the Ministry of Internal Affairs, the Ministry of Health, and the State Commission on Migration Issues. The conferences and consultative meetings provided a useful platform for the dissemination of research results, including some of the results of this dissertation. The project officially ended in June 2013, but one of the project's legacies has been continued dialogue with the government of Georgia. Upon the request of the Ministry of Health and the Ministry of Education, the research team at the Maastricht Graduate School of Governance will be developing policy briefs describing the health and education outcomes of children in migrant households in Georgia.

The dissemination of results of this research will also continue in other, less direct forms. Over the course of my $\mathrm{PhD}$, I have also become a teacher in the Migration Management Diploma Programme, a three-month course for migration management practitioners from mostly developing countries that is offered at Maastricht University, Maastricht Graduate School of Governance/UNU-MERIT. Within this programme, participants are encouraged to consider how prior research can contribute to evidence-based policy relating to migration and its potential developmental impacts. As a teacher in the course on mainstreaming migration into development policy planning, I am able to use the knowledge I have gained on the potential micro-level impacts of migration for the families and communities that remain in the origin country to better instruct students on potential policy mechanisms that can address these populations. 


\begin{abstract}
About the Author
Michaella Vanore was born in 1986 in Colorado in the United States of America. She completed her Bachelor's degree (2008) in political science in the United States before moving to the Netherlands to pursue a Master of Science degree in public policy and human development (2009) from Maastricht University, Maastricht Graduate School of Governance (MGSoG). In the Master programme she was introduced to the complexities of human mobility and its development dimensions, a topic that would lead her to work on a number of migration-related projects and teaching activities at MGSoG. In December 2010, Michaella joined the project "The Effects of Migration on Children and the Elderly Left Behind in Moldova and Georgia", within which this dissertation was completed. Since that time, her work at MGSoG has allowed her to explore and teach on a diversity of topics, including the consequences of migration for members of transnational families in the origin country, remittance systems and trends, mainstreaming migration into development planning, and diaspora engagement, among others.
\end{abstract}




\section{MGSoG Dissertation Series}

Sonja Fransen

The Economic and Social Effects of Remittances and Return Migration in ConflictAffected Areas: The Case of Burundi

MGSoG Dissertation Series, nr 56 (2015)

Ibrahim Khalil Conteh

The Impact of Floods on Primary School Education in Zambia

MGSoG Dissertation Series, nr 55 (2015)

Richard Bluhm

Growth Dynamics and Development

Essays in Applied Econometrics and Political Economy

MGSoG Dissertation Series, nr 54 (2015)

Nevena P. Zhelyazkova

Work-Family Reconciliation and Use of Parental Leave in Luxembourg

Empirical Analysis of Administrative Records

MGSoG Dissertation Series, nr 53 (2015)

Sachin Kumar Badkas

Metachoice and Metadata

Innovating with Environmental Policy Analysis in Europe

MGSoG Dissertation Series, nr 52 (2014)

Irina S. Burlacu

An Evaluation of Tax-Benefit Systems Impact on the Welfare of Frontier Workers The Case of Luxembourg and Belgium

MGSoG Dissertation Series, nr 51 (2014) 
Özge Bilgili

Simultaneity in Transnational Migration Research:

Links Between Migrants' Host and Home Country Orientation

MGSoG Dissertation Series, nr 50 (2014)

Yulia Privalova Krieger

Reshaping the Big Agenda: Transnational Politics and Domestic Resistance

Financial crisis and social protection reform in Bosnia and Herzegovina

MGSoG Dissertation Series, nr 49 (2014)

Marieke van Houte

Moving Back or Moving Forward?

Return migration after conflict

MGSoG Dissertation Series, nr 48 (2014)

Oxana Slobozhan

Global Governance in the Management of Natural Resources

The Case of the Extractive Industries Transparency Initiative (EITI)

MGSoG Dissertation Series, nr 47 (2014)

Luis Bernardo Mejia Guinand

The Changing Role of the Central Planning Offices in Latin America:

A Comparative Historical Analysis Perspective (1950-2013)

MGSoG Dissertation Series, nr 46 (2014)

Cheng Boon Ong

Ethnic Segregation in Housing, Schools and Neighbourhoods in the Netherlands

MGSoG Dissertation Series, nr 45 (2014) 


\author{
Luciana V. Cingolani \\ Bureaucracies for Development: Oxymoron or Reality? \\ Studies on State Capacity in Challenging Governance Contexts \\ MGSoG Dissertation Series, nr 44 (2014) \\ Carlos Cadena Gaitán \\ Green Politics in Latin American Cities - Sustainable Transport Agendas \\ MGSoG Dissertation Series, nr 43 (2014) \\ Katie Kuschminder \\ Female Return Migration and Reintegration Strategies in Ethiopia \\ MGSoG Dissertation Series, nr 42 (2014) \\ Metka Hercog \\ Highly-Skilled Migration and New Destination Countries \\ MGSoG Dissertation Series, nr 41 (2014) \\ Margaret Agaba Rugadya \\ Can Remittances Influence the Tenure and Quality of Housing in Uganda? \\ MGSoG Dissertation Series, nr 40 (2014) \\ Ilire Agimi \\ New Governance Under Limited Statehood \\ The Case of Local Government Reform in Kosovo \\ MGSoG Dissertation Series, nr 39 (2014) \\ Kristine Farla \\ Empirical Studies on Institutions, Policies and Economic Development \\ MGSoG Dissertation Series, nr 38 (2013)
}


Marina Petrovic

Social Assistance and Activation in the Pursuit of Happiness:

Shedding New Light on Old Policy Solutions to Social Exclusion

MGSoG Dissertation Series, nr 37 (2013)

Laura Torvinen

Assessing Governance Assessments; The Case of Mozambique

Governance Assessments in the Context of Aid Effectiveness Discourse

MGSoG Dissertation Series, nr 36 (2013)

Biniam Egu Bedasso

Institutional Change in the Long Shadow of Elites

Essays on Institutions, Human Capital and Ethnicity in Developing Countries

MGSoG Dissertation Series, nr 35 (2013)

Sepideh Yousefzadeh Faal Deghati

Childhoods Embargoed

Constructing and Reconstructing Multidimensional Child Poverty in Iran 1984-

2009

MGSoG Dissertation Series, nr 34 (2013)

Robert Bauchmüller

Investing in Early Childhood Care and Education:

The Impact of Quality on Inequality

MGSoG Dissertation Series, nr 33 (2013)

Martin Rehm

Unified Yet Separated

Empirical Study on the Impact of Hierarchical Positions within Communities of Learning

MGSoG Dissertation Series, nr 32 (2013) 
Dorcas Mbuvi

Utility Reforms and Performance of the Urban Water Sector in Africa

MGSoG Dissertation Series, nr 31 (2012)

Lina Salanauskaite

Distributional Impacts of Public Policies:

Essays in Ex-Ante and Ex-Post Evaluation

MGSoG Dissertation Series, nr 30 (2012)

Esther Schüring

To Condition or not - is that the Question?

An Analysis of the Effectiveness of Ex-Ante and Ex-Post Conditionality in Social

Cash Transfer Programs

MGSoG Dissertation Series, nr 29 (2012)

Joe Abah

Strong Organisations in Weak States

Atypical Public Sector Performance in Dysfunctional Environments

MGSoG Dissertation Series, nr 28 (2012)

Zina Samih Nimeh

Social Citizenship Rights: Inequality and Exclusion

MGSoG Dissertation Series, nr 27 (2012)

Lenka Eisenhamerová

Legitimacy of 'Humanitarian Military Intervention'

MGSoG Dissertation Series, nr 26 (2011) 


\section{Sonila Tomini}

Informal Payments for Health Care Services in Albania

MGSoG Dissertation Series, nr 25 (2011)

\section{Jinjing Li}

Dynamic Microsimulation in Public Policy Evaluation

MGSoG Dissertation Series, nr 24 (2011)

\section{Aziz Atamanov}

Rural Nonfarm Employment and International Migration as Alternatives to

Agricultural Employment:

The Case of Kyrgyzstan

MGSoG Dissertation Series, nr 23 (2011)

Frieda Vandeninden

Poverty Alleviation: Aid and Social Pensions

MGSoG Dissertation Series, nr 22 (2011)

Juliana Nyasha Tirivayi

The Welfare Effects of Integrating AIDS Treatment with Food Transfers:

Evidence from Zambia

MGSoG Dissertation Series, nr 21 (2011)

\section{Agnieska Ewa Sowa}

Who's Left Behind? Social Dimensions of Health Transition and Utilization of

Medical Care in Poland

MGSoG Dissertation Series, nr 20 (2011)

\section{Emmanaouil Sfakianakis}

The Role of Private Actors in the Provision of Public Goods with Applications to Infrastructure and Financial Stability MGSoG Dissertation Series, nr 19 (2011) 


\section{Siu Hing Lo}

White Collars Green Sleeves: An Interonganizational Comparison of Determinants of Energy-Related Behaviors among Office Workers

MGSoG Dissertation Series, nr 18 (2011)

Treena $\mathrm{Wu}$

Constraints to Human Capital Investment in Developing Countries: Using the Asian Financial Crisis in Indonesia as a Natural Experiment

MGSoG Dissertation Series, nr 17 (2011)

\section{Henry Espinoza Peña}

Impact Evaluation of a Job-Training Programme for Disadvantaged Youths: The Case of Projoven

MGSoG Dissertation Series, nr 16 (2011)

Florian Tomini

Between Family and Friends: Understanding the Interdependency of Private

Transfers

MGSoG Dissertation Series, nr 15 (2010)

\section{Michał Polalowski}

The Institutional Transformation of Social Policy in East Central Europe: Poland and Hungary in comparative and historical perspective

MGSoG Dissertation Series, nr 14 (2010)

\section{Maha Ahmed}

Defining, Measuring and Addressing Vulnerability: The Case of Post Conflict Environments

MGSoG Dissertation Series, nr 13 (2010) 


\section{Pascal Beckers}

Local Space and Economic Success: The role of spatial segregation of migrants in the Netherlands

MGSoG Dissertation Series, nr 12 (2010)

\section{Victor Cebotari}

Conplicting Demands in Ethnically Diverse Societies: Ethnopolitical Contention and Identity Values in Europe

MGSoG Dissertation Series, nr 11 (2010)

Dennis Gyllensporre

Competing and Complementary Perspectives on the EU as a Crisis Management Actor:

An Examination of the Common Security and Defence Policy through the Lenses of Idealism and Realism

MGSoG Dissertation Series, nr 10 (2010)

Judit Vall Castello

Business Cycle and Policy Effects on Labour Market Transitions of Older and Disabled Workers in Spain

MGSoG Dissertation Series, nr. 9 (2010)

Keetie Roelen

False Positives or Hidden Dimensions: the definition and measurement of child poverty

MGSoG Dissertation Series, nr. 8 (2010)

Denisa Maria Sologon

Earning Dynamics in Europe

MGSoG Dissertation Series, nr. 7 (2010) 


\author{
Melissa Siegel \\ Money and Mobility: Migration and Remittances \\ MGSoG Dissertation Series, nr. 6 (2010) \\ Jessica S. Hagen-Zanker \\ Modest Expectations: Causes and effects of migration on migrant households in \\ source countries
}

MGSoG Dissertation Series, nr. 5 (2010)

Mirtha R. Muniz Castillo

Human Development and Autonomy in Project Aid: Experiences from four

bilateral projects in Nicaragua and El Salvador

MGSoG Dissertation Series, nr. 4 (2009)

Christiane Arndt

Governance Indicators

MGSoG Dissertation Series, nr. 3 (2009)

Britta Augsburg

Microfinance - Greater Good or Lesser Evil?

MGSoG Dissertation Series, nr. 2 (2009)

Geranda Notten

Measuring and Managing Poverty Risks

MGSoG Dissertation Series, nr. 1 (2008) 